\title{
Recursos semióticos en la enseñanza de las matemáticas
}

\author{
Dr. José Gabriel Sánchez Ruiz \\ Dr. Eduardo Alejandro Escotto Córdova \\ COMPILADORES
}




\section{Recursos semióticos en la enseñanza de las matemáticas}

COMPILADORES

Dr. José Gabriel Sánchez Ruiz

Dr. Eduardo Alejandro Escotto Córdova 
Universidad Nacional Autónoma de México

Facultad de Estudios Superiores Zaragoza

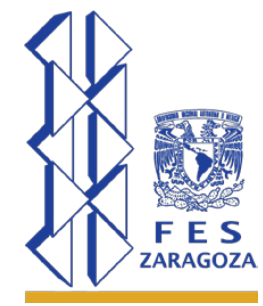

Datos para catalogación bibliográfica

Compiladores: José Gabriel Sánchez Ruiz y Eduardo Alejandro Escotto Córdova.

Recursos semióticos en la enseñanza de las matemáticas.

UNAM, FES Zaragoza, enero de 2018.

Peso: $5.6 \mathrm{MB}$

Diseño de portada: Raziel Leaños Castillo

Formación de interiores: Claudia Ahumada Ballesteros

ISBN: 978-607-02-9977-3

Financiado por el proyecto PAPIME-UNAM 302915

\section{DERECHOS RESERVADOS}

Queda prohibida la reproducción o transmisión total o parcial del texto o las ilustraciones de la presente obra bajo cualesquiera formas, electrónicas o mecánicas, incluyendo fotocopiado, almacenamiento en algún sistema de recuperación de información, dispositivo de memoria digital o grabado sin el consentimiento previo y por escrito del editor.

\section{Recursos semióticos en la enseñanza de las matemáticas.}

D.R. @ Universidad Nacional Autónoma de México

Av. Universidad \# 3000, Col. Universidad Nacional Autónoma de México, C.U., Delegación Coyoacán, C.P. 04510, México, D.F.

\section{Facultad de Estudios Superiores Zaragoza}

Av. Guelatao \# 66, Col. Ejército de Oriente,

Delegación Iztapalapa, C.P. 09230, México, D.F. 


\section{RELACIÓN ALFABÉTICA DE AUTORES}

\section{Dra. Ana María Baltazar Ramos}

Profesora de tiempo completo en el área Educativa de la Facultad de Estudios Superiores Zaragoza, Universidad Nacional Autónoma de México, colaboradora del proyecto de investigación "El uso didáctico del lenguaje natural en la enseñanza del lenguaje formal de la estadística en la FES Zaragoza” PAPIME-UNAM 302915.

aniuxbaltazar@gmail.com

\section{Dr. Ricardo Arnoldo Cantoral Uriza}

Investigador titular Categoría 3D del Departamento de Matemática Educativa del Centro de Investigación y de Estudios Avanzados del Instituto Politécnico Nacional. Investigador del Sistema Nacional Nivel III Miembro de Academia Mexicana de Ciencias Director de la Revista Latinoamericana de Investigación en Matemática Educativa.

\section{Lic. Guadalupe M. Corona Rafael}

Facultad de Estudios Superiores Zaragoza, Universidad Nacional Autónoma de México, colaboradora del proyecto de investigación "El uso didáctico del lenguaje natural en la enseñanza del lenguaje formal de la estadística en la FES Zaragoza" PAPIME-UNAM 302915.

Guadalupe.unam.cr@gmial.com

\section{Dr. Eduardo Alejandro Escotto Córdova}

Profesor titular A de la Carrera de Psicología de la Facultad de Estudios Superiores Zaragoza, Universidad Nacional Autónoma de México. Responsable del proyecto de investigación "El uso didáctico del lenguaje natural en la enseñanza del lenguaje formal de la estadística en la FES Zaragoza” PAPIME-UNAM 302915.

aescotto@unam.mx

\section{Dra. Rosa María Farfán Márquez}

Investigador titular Categoría 3C del Departamento de Matemática Educativa del Centro de Investigación y de Estudios Avanzados del Instituto Politécnico Nacional. Investigador del Sistema Nacional Nivel II.

\section{Lic. Yarel González-Alatorre}

Facultad de Estudios Superiores Zaragoza, Universidad Nacional Autónoma de México, colaboradora del proyecto de investigación "El uso didáctico del lenguaje natural en la enseñanza del lenguaje formal de la estadística en la FES Zaragoza" PAPIME-UNAM 302915.

y-arel.ze@hotmail.com 


\section{Lic. Valeria González Calixto}

Facultad de Estudios Superiores Zaragoza, Universidad Nacional Autónoma de México, colaboradora del proyecto de investigación "El uso didáctico del lenguaje natural en la enseñanza del lenguaje formal de la estadística en la FES Zaragoza" PAPIME-UNAM 302915.

calixtovalery@gmail.com

\section{Lic. Sofía Berenice Olmos-Sánchez}

Facultad de Estudios Superiores Zaragoza, Universidad Nacional Autónoma de México, colaboradora del proyecto de investigación "El uso didáctico del lenguaje natural en la enseñanza del lenguaje formal de la estadística en la FES Zaragoza” PAPIME-UNAM 302915.

Sofia-60@hotmail.com

\section{Dra. Luz Graciela Orozco Vaca}

Departamento de Matemática Educativo, Centro de Investigación y de Estudios Avanzados del Instituto Politécnico Nacional (CINVESTAV-IPN).

\section{Dr. Ricardo Quintero Zazueta}

Investigador titular del Departamento de Matemática Educativa del Centro de Investigación y de Estudios Avanzados del Instituto Politécnico Nacional. Pionero en la investigación sobre el empleo de las microcomputadoras en la enseñanza de las matemáticas.

\section{Mtro. José Sánchez Barrera}

Profesor de Tiempo completo de la Carrera de Psicología de la Facultad de Estudios Superiores Zaragoza, Universidad Nacional Autónoma de México. Corresponsable del proyecto de investigación "Factores subjetivos, institucionales y culturales que influyen en la representación política sustantiva de las minorías indígenas en México"; PAPIIT IN305015.

jsb111201@yahoo.com.mx

\section{Dr. José Gabriel Sánchez Ruiz}

Profesor de tiempo completo de la Carrera de Psicología de la Facultad de Estudios Superiores Zaragoza, Universidad Nacional Autónoma de México, Co-responsable del proyecto de investigación "El uso didáctico del lenguaje natural en la enseñanza del lenguaje formal de la estadística en la FES Zaragoza” PAPIME-UNAM 302915. josegsr@unam.mx 


\section{ÍNDICE}

Introducción

1 Alternancias semióticas en el aprendizaje de la estadística

9

2 Análisis bibliométrico sobre la investigación en recursos

2 semióticos en la enseñanza-aprendizaje de las matemáticas

3 Matemáticas, lenguaje y cognición

4. El uso de recursos semióticos como estrategia pedagógica en la enseñanza de la estadística

5 La escritura como herramienta en la resolución de problemas de geometría

6 El papel de la representación en la formación del lenguaje gráfico 


\section{INTRODUCCIÓN}

as matemáticas son un sistema de signos y significados unívocos que tienen su propia sintaxis (la forma en que se ordenan y combinan sus signos); como sistema de signos es un campo que también investiga la semiótica, es decir, la disciplina que estudia los diversos sistemas de signos y sus significados. La enseñanza de la matemática en cualquiera de sus ramas, no solo utiliza el sistema de signos que le es propio (al que llamamos recursos semióticos formales), sino que todo profesor utiliza, además, diversos recursos semióticos no formales, comenzando por otro sistema de signos, la lengua o idioma, hablada o escrita, generalmente para comunicar con sus recursos lingüísticos las propiedades, relaciones y reglas de los recursos semióticos formales. También utiliza una variedad de indicios y signos como: (a) los involucrados en el llamado lenguaje no verbal (kinesis o sea, movimientos corporales; proxemia o sea, manejo de la distancia y el espacio; miradas; prosodia o manejo de la voz; gesticulaciones, generalmente asociadas a la expresión facial de las emociones; emblemas, entendidos como signos hechos con las manos altamente estereotipados y propios de una cultura, como cerrar la mano y elevar el pulgar al pedir aventón; y movimientos de dedos, manos y brazos que acompañan al discurso verbal que apuntalan o ilustran los significados de las palabras, como cuando se forma una curva con el brazo al momento de decir "una curva"); (b) dibujos, esquemas, gráficas, objetos, colores, imágenes, videos, etcétera.

En la enseñanza de los recursos semióticos formales se utilizan siempre los recursos semióticos no formales. La proporción, uso y destreza que un profesor muestra para utilizar los no formales en la enseñanza de los formales es un componente básico de lo que se llama pedagogía de las matemáticas. Este texto es uno de los productos académicos generado bajo el amparo del proyecto financiado (PAPIME-UNAM PE-302915) titulado "El uso didáctico del lenguaje natural en la enseñanza del lenguaje formal de la estadística en la Facultad de Estudios Superiores Zaragoza". El libro tiene por objetivo compilar diversos textos de especialistas relacionados con la semiosis, el lenguaje hablado y escrito, la cognición, la solución de problemas, y las matemáticas. Está compuesto por seis capítulos. En el primer capítulo se definen conceptos como lenguaje, lengua, habla, semiosis, signo y símbolo; se reflexiona sobre las lenguas formales y naturales; y se analiza el papel de la lengua natural y otros recursos semióticos en el aprendizaje de las matemáticas. En el segundo capítulo se hace una revisión biliométrica de la relación de recursos semióticos y matemáticas en 22 documentos publicados en revistas especializadas de educación matemática entre 2006 y 2016. En el capítulo tercero se analiza la relación entre la cognición, el lenguaje y las matemáticas; también de definen el lenguaje, la lengua o idioma, el signo, el símbolo y la cognición; se comentan las categorías gramaticales de todos los idiomas (sustantivos, verbos, adjetivos, etc.) y se ejemplifica con varios de ellos; se analiza la relación entre la gramática y la cognición; y finalmente la relación entre lenguaje y la matemática y la lógica ejemplificándose con varias lenguas. El cuarto capítulo analiza el uso de los recursos semióticos como estrategia pedagógica en la enseñanza de la estadística reportada en la literatura especializada. El capítulo quinto analiza el papel de la escritura como herramienta en la resolución de problemas geométricos, es un artículo empírico. Se plantea a la escritura como una forma de pensamiento, se analiza el papel de la metacognición y la relación lenguaje, pensamiento y matemáticas. El capítulo sexto aborda la propuesta didáctica de la socioepistemología, basada en la construcción social del conocimiento en los escenarios culturales, históricos e institucionales y en los procesos mentales del estudiante y su intuición, aterrizando en una propuesta para la 
construcción de un lenguaje gráfico en operaciones gráficas, resolución gráfica de desigualdades y construcción de funciones.

Este texto será de utilidad para todos aquellos que estén interesados en las ventajas de la alternancia de códigos semióticos en la enseñanza de las matemáticas, es decir, en el conocimiento e implicaciones de utilizar unos recursos semióticos para enseñar otros recursos semióticos, en este caso, temas de matemáticas: estadística y geometría. Concienciar las potencialidades del lenguaje cotidiano, la comunicación no verbal y del uso de dibujos, esquemas, gráficas, objetos, colores, videos, etcétera, en enseñanza de los recursos formales de las matemáticas mejorará las destrezas pedagógicas de todo profesor.

Los compiladores

FES Zaragoza, UNAM, octubre del 2017 


\title{
CAPITULO 1 \\ Alternancias semióticas en el aprendizaje de la estadística
}

\author{
Eduardo Alejandro Escotto Córdova \\ José Gabriel Sánchez Ruiz \\ Ana María Baltazar Ramos
}

\section{Lenguaje, lengua, habla, semiosis, signo y símbolo}

EI I aprendizaje de la estadística requiere el conocimiento de los recursos formales que utiliza la matemática: los signos, las operaciones, las fórmulas, los números etcétera, es decir, el llamado lenguaje matemático, que más propiamente hablando debe llamarse la lengua matemática. Lenguaje y lengua no son lo mismo. Toda lengua es lenguaje, pero no todo lenguaje es una lengua.

Como medio de comunicación, el lenguaje es la capacidad de significar (creación, modificación y uso de signos y significados) abstrayendo los rasgos esenciales de las cosas, sus relaciones, procesos y estados mediante signos fónicos, gestuales, gráficos, imágenes, objetos etc. Los signos y sus significados son históricos y socialmente construidos, pero la capacidad de significar es biológica, propia de la especie humana, y depende de la integridad del cerebro humano. Todos los seres humanos (Homo sapiens) en cualquier época histórica han tenido la capacidad neurobiológica de crear, modificar y utilizar signos en la comunicación con sus congéneres. Los productos de esta capacidad neurobiológica, los signos y sus significados, son, sin embargo, históricos; dependen de la interacción comunicativa entre dos o más personas, de los consensos de cada grupo social, del contexto en que se usan y de la época histórica en que se crean. Cuando un conjunto de signos se organiza en un sistema de contrastes vinculado a la comunicación (unos signos frente a otros marcan significados diferentes) se produce una lengua. Por ejemplo, el sistema de signos fonológicos implica que ciertos sonidos que no tienen significado por sí mismo, como por ejemplo [s] en el español, marcan significado en el contexto de otros sonidos cas as.

La lengua o idioma es un sistema de signos social e históricamente construido, suele tener propiedades lingüísticas tales como sintaxis, morfología, semántica, fonología y pragmática. Las lenguas (idiomas) suelen ser naturalmente sonoras, es decir, sistemas de sonidos contrastados para expresar significados en el proceso comunicativo, pero también pueden ser no fónicas, como los sistemas de señas de los sordos, o la escritura. En el primer caso, las lenguas sonoras se expresan mediante el habla y no requieren esfuerzo de enseñanza para su adquisición; en el segundo, se requiere una instrucción específica para aprender el sistema de signos de señas o de grafismos. El momento evolutivo en el cual el habla se convirtió en la forma más natural de significar está ligado a la aparición del Homo sapiens, un contemporáneo de éste, el homínido Neandertal, se comunicaba con signos, pero no está claro si lo hacía mediante el habla como la hacía el Homo sapiens. Lo anterior, por supuesto, es una inferencia 
a partir del hecho de que enterraban a sus muertos, lo que suele estar asociado a una representación simbólica de la muerte. A partir del momento en que aparece el lenguaje hablado, las formas de comunicarse con sonidos estuvieron ligadas a los grupos sociales, y la separación, dispersión, aislamiento de estos condicionó la aparición de distintas lenguas. Toda lengua es un lenguaje, pero no al revés. La capacidad de significar, el lenguaje, se puede dar con dibujos, como en el caso de los emoticones, pero éstos no tienen, hasta ahora, una morfosintaxis ni propiedades fonológicas socialmente admitidas; en tales casos decimos que hay lenguaje, pero no lengua. Los bebés de 8 meses se comunican con algunos signos como decir adiós con las manos, pero no hablan todavía, decimos entonces que están desarrollando el lenguaje, pero no el habla, y mucho menos, la lengua materna con sus propiedades gramaticales. Tanto el lenguaje como las lenguas son parte de la semiosis.

La creación social de signos es el proceso de la semiosis, presupone al menos a dos personas para que los signos signifiquen algo para alguien en un contexto comunicativo. Un signo es algo que es usado por alguien para que esté en lugar de algo para alguien; es arbitrario en el sentido de que puede ser intercambiado por otro signo a voluntad; es social e histórico en el sentido de que se gesta en el intercambio entre personas en un momento histórico y social concreto; el signo representa a lo que sustituye, es decir, al referente, y a esto le llamamos significado, que es codificado socialmente en los diccionarios. Los signos tienen, además del significado, un sentido, es decir, se usan en contextos específicos de comunicación; la oración "se comió una torta", en el contexto de que solo había dos y los demás no habían comido, tiene un sentido diferente (comunica abuso y desconsideración) que si se pronunciara en el contexto de que el niño todavía no había comido (comunica que por fin se alimentó): en ambos casos, el significado de diccionario es el mismo, pero su sentido es diferente. En términos semióticos, y para fines matemáticos, el signo y el símbolo son, para nosotros, equivalentes: todo símbolo es un signo $(+, x,=, \Sigma)$ La forma de muchos símbolos suele ser gráfica (figuras o dibujos):

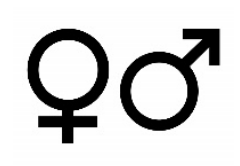

Pero la noción de símbolo no se reduce a ello, si así fuera no tendría sentido expresiones del tipo "fulano de tal es símbolo de la juventud". En términos comunicativos, los símbolos difieren de los signos no en la forma en que se representan, sino en la génesis del sentido que tienen: el contexto que genera el sentido de los signos suele ser el de la interacción entre dos o más personas, y se reproduce y generaliza entre dos o más personas, aunque esta reproducción "en corto" alcance a toda una población. El sentido de los símbolos se genera en el curso de intensas movilizaciones populares de todo tipo. Así, por ejemplo, la palabra "cruz" es un signo del objeto cruz, o el dibujo $\widehat{c}$ es un signo de un objeto cruz, pero en el contexto de la intensidad religiosa de los movimientos cristianos, la palabra, el objeto o el dibujo se tornan símbolos del cristianismo: tienen un sentido comunicativo y emocional gestado en la movilización popular y su justificación ideológica. La misma palabra o signo fónico "cruz" puede referir a otra configuración diferente como la cruz gamada, existente en muchas culturas desde hace cientos de años, pero en el contexto de la Segunda Guerra Mundial se convirtió en el símbolo del nazismo hasta nuestros días: tiene un sentido comunicativo y emocional gestado en la movilización popular y su justificación ideológica de uno u otro bando. La palabra "Gandhi" es un signo que refiere a una persona (el nombre del hindú Mohandas Karamchand Gandhi, llamado Mahatma Gandhi), pero ese signo fónico, o la persona, como símbolos, representan a la intensa movilización, ideología y lucha pacifista no solo de la India, sino de todos los pueblos. El color del arcoíris en cualquier objeto o rostro humano ha devenido en símbolo de la homosexualidad y la diversidad sexual gracias a las movilizaciones sociales. 
Para evitar la confusión de sentidos al usar la palabra "símbolo" en la enseñanza de las matemáticas, nosotros preferimos utilizar la palabra "signo matemático", aunque al referirnos a las publicaciones de otros autores, si ellos usan la palabra símbolo, respetaremos su nominación.

El lenguaje (la capacidad de significar) suele confundirse con la lengua (un sistema específico e histórico de signos), y en particular con el habla. Ésta es la capacidad fonoarticuladora de signos fónicos, es decir, de sonidos con significados propios de cada lengua hablada. Mientras que el lenguaje depende de la integridad neurobiológica de los individuos, el habla depende de ésta y de la integridad de ciertas partes del cuerpo: el aparato fonador, es decir, el involucrado en el manejo del aire para producir sonidos (labios, lengua, dientes, paladares, laringe, faringe, diafragma, pulmones, estómago). La aparición evolutiva de la capacidad de hablar en el Homo sapiens impulsó la creación sociohistórica de las lenguas habladas, es decir, de los sistemas de signos propios de cada grupo social; cuando los grupos humanos que las ejercían se trasladaron a regiones relativamente aisladas, su habla tuvo un desarrollo fonético y de significados propio, y con ello se posibilitó la creación de sistemas de signos fónicos distintos: las lenguas. Ontogenéticamente, la comunicación del bebé deviene en intención comunicativa y uso de signos gestuales (inicios de la capacidad de significar, es decir, del lenguaje), previos al habla, la que comienza a desarrollarse cercana al primer año de vida; el desarrollo del habla del bebé lo llevará al dominio de la lengua que utilizan sus familiares. El lenguaje se expresa en forma natural en las lenguas habladas, y como resultado de una instrucción especializada, en las lenguas de señas y las lenguas formales.

\section{Las lenguas formales y naturales}

La lengua matemática es una lengua formal (LF); consiste en un sistema de signos social e históricamente construido. Tiene su propia sintaxis (reglas para la combinación de sus signos) y su semántica (el significado de sus signos), e incluso, para algunos autores, su pragmática (Ávila, Ibarra y Grijalva, 2010); se diferencia de las lenguas naturales (LNs) en primer lugar, en que éstas no requieren ninguna instrucción para su dominio, mientras que las matemáticas sí; en segundo lugar, en que los signos y significados de las lenguas naturales tienen una gran variabilidad, permiten la polisemia (diversos significados para el mismo signo), y el contexto comunicativo determina los significados y sentidos. La lengua matemática suele tener signos estables, significados unívocos, sintaxis rígida y el contexto comunicativo no determina los significados, aunque si pudiera determinar los sentidos de sus signos. La lengua matemática se aprende en las escuelas y el proceso de su aprendizaje suele ser tortuoso para la mayoría de los estudiantes, sobre todo, cuando solo se basa en un solo tipo de recursos semióticos, los formales. La lengua natural se aprende en los primeros años de vida sin instrucción específica, solo bajo el contacto comunicativo con otros interlocutores con los que interactúa y habla el niño. Tanto las lenguas naturales como las formales (matemáticas, lógica, lenguajes computacionales, química) son sistemas de signos históricamente determinados, y, por tanto, son campo de estudio de la semiótica, la disciplina que estudia los signos (Beuchot, 2004). Todas las lenguas formales requieren para su comunicación de las lenguas naturales. Las matemáticas, en particular, suelen ser enseñadas utilizando diversos recursos semióticos que se alternan durante el proceso de enseñanza-aprendizaje, estos recursos pueden dividirse en formales y no formales.

Se entiende por recursos semióticos formales a toda expresión escrita o hablada matemática consistente en letras, números, signos para realizar operaciones, algoritmos, fórmulas, reglas de combinación de los símbolos propias de la lengua matemática. Frente a los recursos semióticos formales hablamos de recursos semióticos no formales: 
la lengua natural con sus múltiples recursos (metáforas, analogías, metonimias, etc.), los gestos, los dibujos, los diagramas, las gráficas, los colores, las imágenes estáticas (fotos) o dinámicas (videos) y los objetos utilizados como signos durante el proceso de la enseñanza-aprendizaje. El recurso no formal más utilizado es la lengua natural (LN).

La LN es el idioma que un hablante normal adquiere durante su desarrollo en un contexto histórico-social determinado, es predominantemente oral (puede ser de señas en el caso de los sordos) hasta que la escolaridad desarrolla la forma escrita. La lengua oral no requiere ser enseñada, sólo se aprende en la comunicación hablada con otros. Toda lengua hablada es, por definición, lenguaje. En la lengua natural, los signos orales que utiliza una lengua, las palabras (léxico), suelen ser polisémicas y dependientes del contexto y uso comunicativo (pragmática), de ahí que lo que comunican pueda tener múltiples interpretaciones del sentido. Esta misma característica se transmite a la escritura de la lengua. La LN representa mediante el léxico, la morfosintaxis, la semántica y la pragmática, a la realidad objetiva y subjetiva: sus estados, relaciones y procesos. Y esto lo puede hacer en ausencia sensorial de esa realidad, es decir, una propiedad central de todo lenguaje-lengua es que permite al sujeto operar con un mundo ausente sensorialmente: se puede ver un vaso o se puede decir "vaso" en ausencia del objeto vaso. La lengua natural es el recurso semiótico más utilizado en la enseñanza de recursos semióticos formales o lenguas formales.

La lengua formal (LF) es un sistema de signos y significados no natural, es decir, no se aprende por el solo contacto con otras personas; necesariamente se tiene que enseñar a los usuarios. Los significados de sus signos no son polisémicos y no dependen del contexto de uso entre los usuarios; los significados de los signos formales no dependen de una pragmática del lenguaje formal en el sentido que lo hace la lengua natural, por ejemplo: en el contexto de mucho calor en un cuarto con ventanas cerradas, preguntar ¿hace calor?, puede significar abran las ventanas, pero en el mismo contexto de calor, decir $\mathrm{X}+2$ significa lo mismo que cuando hace frío. En el sistema de signos matemáticos no ocurre que la intención comunicativa de un usuario cambie la semántica de los signos dentro del mismo sistema, ello solo podría ocurrir en un juego verbal en el que los signos matemáticos signifiquen, para los usuarios, otra cosa más allá de lo que significan dentro del sistema de reglas matemático. Las lenguas formales (LF) tienen su propio léxico y sintaxis, son un sistema semiótico con derecho propio (Puig, 1994) que sólo cambia por convenciones entre el grupo de usuarios o situaciones de crisis propias de la disciplina particular (Beyer, 2001), y, sobre todo, el léxico y la sintaxis formal no corresponden ni traducen a la sintaxis del lenguaje natural, es decir, hablado en la vida cotidiana. La LF, por su naturaleza abstracta ( $2 X+B)$, representa los entes formales, sus relaciones y procesos alejados del mundo real específico, lo que, a su vez, le permite ser aplicadas a múltiples fenómenos objetivos (dos manzanas más una pera, dos cabras más un león, dos átomos de hidrógeno más uno de oxígeno, etc.). La forma fonética de las LF corresponde a cada lengua natural, pero el léxico y la sintaxis son los mismos independientemente de la lengua que se hable. Esta es la razón histórica de porqué las LF han sido propuestas como un camino para una lengua universal (Eco, 1994). Las lenguas formales como las matemáticas son un sistema de signos que hay que reconocer como tales (Sastre, Boubée, Cempio, 2013). Las autoras proponen que más que hablar de matemáticas como signos individuales, hay que hablar del sistema de signos, esto es, las matemáticas. (p.82).

Los signos matemáticos han evolucionado y según Florian Cajori (en Sastre, Boubée y Cempio, 2013) hay al menos tres etapas de su desarrollo: la primera llamada "álgebra Retórica". No utilizaban abreviaturas, ni símbolos especiales; se usaban palabras para realizar los cálculos (época paleobabilónica); la etapa llamada "Álgebra sincopada" en la cual se utilizaban abreviaturas simbólicas (siglo III- siglo XVII); y la tercera etapa llamada "Álgebra 
simbólica" a partir de XV. A partir de entonces se desarrollaron los signos propiamente dichos, así hacia 1557 se comenzó a utilizar el signo igual =; hacia 1631 se comenzó a utilizar los signos de menor, mayor, incluido, pertenece (<>c, $€$ ); en el siglo XIV se comenzó a utilizar el signo + y -; hacia 1631 se utilizó el signo de multiplicar X, pero el punto como símbolo lo utilizó Thomas Harriot (1560-1621) y lo popularizó Leibniz (1646-1716); en el siglo XIII Fibonacci utilizaba la barra diagonal / para la división y Johann Heinrich Rahn (1622-1676) creó el signo con la barra horizontal; hacia 1636 se comenzó a utilizar el signo de exponente como se usa actualmente; el signo de raíz lo introdujo el matemático Christoph Rudolff (1500-1545) en 1525; Descartes introdujo los signos x, y, z como variables o incógnitas; Joohn Wallis utilizó en 1655 el signo de infinito. (Sastre, Boubée y Cempio, 2013).

Pese a estas diferencias, la lengua natural es indispensable para la enseñanza de la lengua formal. La LN es la herramienta comunicativa primaria para la enseñanza de las LF, específicamente de las matemáticas. Sin embargo, muchos profesores solo utilizan la LN para dar cuenta del léxico formal ("equis al cuadrado": X2) y sintaxis del LF ("equis al cuadrado menos ye": X2-Y) evitando utilizar otros recursos de la LN para introducir a la LF. La conversión semiótica de la LN a la LF, o a la inversa, es un aspecto importante en la enseñanza de las LF. El uso de la LN puede, sin embargo, ser un apoyo fundamental para el dominio de la LF por sus propiedades inherentes (uso de metáforas; léxico que refiere a cosas, estados y procesos que ayudan a su representación mental en ausencia de éstos; léxico cuantitativo y relacional como muchos, pocos, mayor que, menor que, más, menos, etcétera) incluso, las propiedades lingüísticas de la enseñanza de las matemáticas pueden mejorar la narrativa de ella misma (Barwell, 2005). Una propiedad de la lengua natural es la de operar con un mundo sensorialmente ausente. Esta propiedad del LN (operar con un mundo ausente) es uno de los factores que ayudan al dominio mental de los procesos del pensamiento mediante la interiorización del lenguaje y los procesos intelectuales (Vygotski, 1934/1993; Galperin, 1969/1998; 1957b/1998; 1957c/1998). La lengua formal (LF) opera también con un mundo sensorialmente ausente, pero con niveles de abstracción mayores que la lengua natural.

\section{El papel de la lengua natural en el aprendizaje de las matemáticas}

El papel de la lengua natural en distintas disciplinas que utilizan lenguas formales es destacado como fundamental por varios autores (Méndez y Moreiro, 1999). Su importancia como recurso pedagógico para la enseñanza de las matemáticas ha sido utilizada por diversos investigadores, por ejemplo, Hernando (2009) quien sostiene que una idea matemática puede ser representada de alguna forma por el uso del lenguaje hablado, de símbolos escritos, de dibujos u objetos físicos, y distingue que una cosa es saber el procedimiento para realizar tal operación y otra es comprenderla. Hernando (2009) investigó el discurso en el aula durante la enseñanza del concepto función con el fin de evaluar su influencia en las respuestas de los estudiantes de primer semestre de ingeniería. En su "experimento didáctico", analiza cuatro representaciones semióticas o lenguajes de los objetos matemáticos: el álgebra, la aritmética, el lenguaje geométrico y el lenguaje verbal o natural "centro de atención de su experimento didáctico"; la investigación se propuso que los estudiantes representaran el concepto de función en un determinado lenguaje. El autor fundamenta la necesidad de que el estudiante de matemáticas sea capaz de trasladar los conceptos de una representación semiótica a otra, y hace de esta destreza el objeto de su investigación. Sostiene que una idea matemática puede ser representada de alguna forma del tipo de lenguaje hablado, de símbolos escritos, de dibujos u objetos físicos, y distingue que una cosa es saber el procedimiento para realizar tal operación y otra es comprenderla. Exponer un concepto matemático en el lenguaje natural es uno de los objetivos que se propuso su investigación. Utilizó dos grupos, el grupo A atendió una exposición en el aula en la que el profesor utilizó 
una plantilla que tenía los cuatro lenguajes, después se les pidió que, utilizando la misma plantilla del profesor, representaran en los cuatro lenguajes otra función cuadrática. Los sujetos del grupo B recibieron las mismas instrucciones, pero por escrito. El criterio de comprensión del objeto matemático fue que pudiera expresarlo, al menos, en dos tipos de "lenguaje" (se refiere a lenguas). El análisis que el autor hace de la relación entre el lenguaje natural y el matemático lo lleva a sostener que un objeto matemático es equivalente al sustantivo de una oración que puede ser sujeto u objeto directo o indirecto; al operador matemático (suma, resta, división, raíz, multiplicación, función, etc.) lo equipara al verbo; y el grado de precisión de los cálculos (la cantidad de decimales, el instrumento utilizado, el margen de error en la medida o cálculo, el método de solución) lo equipara al adverbio o complemento circunstancial. Con ello argumenta que las definiciones rigurosas en matemáticas no van acompañadas de su definición verbal, e incluso las definiciones algebraicas no suelen ser acompañadas del lenguaje geométrico. En ambos casos los conceptos algebraicos pueden ser oscuros a un estudiante primerizo. Las conclusiones a las que llega el autor es que el lenguaje natural o verbal es un instrumento pedagógico fundamental para la enseñanza matemática, pero no puede ser el único, toda vez que los cálculos matemáticos no son posibles en el lenguaje natural. A su vez, sostiene que la preferencia por el lenguaje algebraico de muchos profesores es pedagógicamente inadecuada para la enseñanza de las matemáticas.

La relación entre el lenguaje natural con el aprendizaje de nociones matemáticas en un primer momento y, posteriormente, de conceptos formales de matemáticas, comienza en los primeros años de vida, y se va consolidando con la educación formal de los primeros años y con el desarrollo del lenguaje hablado. Ya que las capacidades matemáticas van desarrollándose paralelamente con la lengua natural, el influjo de ésta en el aprendizaje matemático es inevitable, toda vez que el lenguaje (la capacidad de significar) es el soporte del pensamiento. Con el uso de la lengua natural se generan representaciones diversas, muchas de ellas orientadas a la comprensión y adquisición de algunas habilidades matemáticas.

Existen pocos estudios que revelan la relación de la lengua natural en el desarrollo matemático, varios de ellos se han implementado particularmente en niños. Por ejemplo, al analizar específicamente la relación entre el desarrollo de la lengua y el conocimiento numérico en los niños preescolares, Viera (2009) reflexiona que la noción que tiene el niño a esa edad (como uno sin pensamiento lógico-racional) lleva a que la práctica educativa se centre en colorear y delinear números y figuras geométricas, cuando se podrían utilizar nociones que el niño tiene expresadas en su lengua natural como cuántos son, qué duración tiene, qué frecuencia, qué parecido/diferencia. Estos instrumentos conceptuales dados ya en la lengua natural acercan al niño al conocimiento matemático, y una enseñanza así tendría el propósito de hacerlos más capaces de "pensar lo que hablan y hablar lo que piensan", sobre todo que en su vida cotidiana el niño dialoga con otros sobre los objetos y sus relaciones, y que su aprehensión se da mediante el lenguaje hablado.

Carey (2004) sugiere que los niños aprenden los conceptos numéricos a partir de un bagaje verbal natural que ya utilizan cotidianamente, tal como cuántos, muchos, mayor, menor, algunos, menos, más etc., por lo que el "lenguaje natural" es un recurso permanente del aprendizaje numérico. Spaepen, Coppola, Spelke, Carey, y Goldin-Meadow, (2011) investigaron las habilidades numéricas de niños nicaragüenses sordos que no tenían acceso a un tipo de "modelo de lenguaje utilizable", incluso el de señas (utilizaban signos hogareños, propios de la comunicación espontánea con su familia), y encontraron deficiencias importantes en las representaciones numéricas mayores de tres, sugiriendo que la carencia de la lengua convencional juega un papel esencial en este tipo de representaciones, toda vez que las representaciones de números mayores requiere del "lenguaje”. 
Por su parte, Manghi (2010) reflexiona sobre los recursos semióticos (escritura, habla, gestos, gráficos, mapas, imágenes, etc.) utilizados como apoyos multimodales comunicativos en los cursos de matemáticas, proponiéndose investigar el papel del habla y los gestos deícticos en la enseñanza de las matemáticas. Utilizando la Lingüística Sistémica Funcional como modelo teórico, se plantea la existencia de múltiples formas de comunicar y significar utilizadas socialmente. Ello ha llevado a la noción de alfabetizaciones múltiples, cuyo eje es ir más allá de la lengua escrita como recurso semiótico del aprendizaje. Sin embargo, en el caso de las matemáticas, los recursos más utilizados son: interacción cara a cara, cuaderno, guía, exámenes, enfocándose en el simbolismo matemático y su escritura. En estas condiciones, la conversión de un código semiótico a otro es una necesidad de la enseñanza matemática. Con este modelo de análisis, el autor realizó una investigación cualitativa con dos profesores que enseñaban matemáticas, sus resultados indican que los recursos más utilizados fueron la interacción cara a cara, el habla, los gestos deícticos y el simbolismo matemático, todo ello mediado por la utilización del pizarrón. Su conclusión fue que estos recursos semióticos tienen implicaciones pedagógicas en la enseñanza de las matemáticas

Otra óptica para analizar la importancia la lengua natural en el razonamiento matemático la da Pedrosa (2008), quien analiza el uso de la lengua natural en la representación del pensamiento numérico confrontando dos posturas sobre el papel del lenguaje y el pensamiento: el universalismo (propone que la diferencia de lenguas no supone diferencias del pensamiento), versus el relativismo (propone que la diferencia de lenguas implica diferencia de pensamientos). El relativismo lingüístico es la postura clásica de Edward Sapir (hacia 1929) y su alumno Benjamin Lee Whorf, (en los años 50), ambos lingüistas, que sostenían que las propiedades gramaticales y léxicas de la lengua o idioma utilizadas por cada pueblo, le daba a éste formas diferentes de concebir e interpretar la realidad. Uno de esos aspectos tiene que ver con los cálculos numéricos, es decir, si la presencia o ausencia del léxico correspondiente facilita o no dicho cálculo. Pedrosa comenta las investigaciones realizadas por otros investigadores con tareas de operaciones numéricas en dos pueblos amazónicos cuyo vocabulario numérico es escaso, los Piraha y los Mundurukú cuya característica verbal es que sus lenguas respectivas carecen de palabras para números de cierta cantidad: los Piraha no tienen palabras para cantidades mayores de dos; los Mundurukú para más de cinco. Los resultados indicaban que el rendimiento de las operaciones caía drásticamente cuando se superaba la cantidad que cada lengua puede nombrar. En general, ambos pueblos usaban los números como aproximaciones, es decir, cuando referían tres o cinco implicaban que eran eso o más que eso. Aunque estos datos generan controversia, sugieren el papel de la lengua en la representación numérica.

La lengua natural en su modalidad narrativa también ha sido investigada como una herramienta para la enseñanza de las matemáticas. Blanco, Caballero y Blanco (2010) analizan el papel de la lengua natural a través del cuento de matemáticas como recurso didáctico para la enseñanza de las matemáticas en secundaria. Los cuentos de matemáticas pueden tener personajes matemáticos (una ecuación o una figura geométrica) o simplemente tramas en las que el desenlace conlleva operaciones matemáticas. Con estos recursos estimulan la competencia lingüística y la competencia matemática como una unidad para el aprendizaje de ésta última. Los ejercicios prácticos que los autores proponen conllevan la lectura de cuentos matemáticos, así como la elaboración de narrativas con contenido matemático. En ambos casos, el uso del lenguaje natural como recurso didáctico en la enseñanza de las matemáticas es fundamental.

Por otro lado, algunos hechos clínicos sugieren la importancia de la lengua natural en el aprendizaje matemático: la dislexia (dificultades para el aprendizaje de la lectoescritura) suele ir acompañada de discalculia, lo que implica que zonas cerebrales adyacentes (giro angular y supramarginal del hemisferio izquierdo) al procesamiento fonológico de la lengua natural involucradas en al trastorno de la lectoescritura también puede afectar al procesamiento numérico 
y matemático (Goswami, 2004). El uso de signos fónicos y numéricos pudiera compartir estructuras cerebrales comunes, lo que sirve como indicio para analizar la estrecha relación entre el habla natural y la comprensión de las matemáticas.

Las matemáticas son una lengua formal que se autoexplica, es decir, expresa teoremas y también los demuestra (Rojano, 1994). Pese a que el lenguaje matemático, particularmente el álgebra, es una lengua de signos autocontenido cuyo desarrollo significó alejarse de la lengua natural y de la geometría, el aprendizaje de esa lengua formal requiere de la lengua natural en algún grado y extensión. La lengua natural es un recurso que ya tienen todos los estudiantes y profesores de matemáticas, su utilidad para hacer conversiones a otro código semiótico como el de las matemáticas, no siempre es clara en el aula escolar, generalmente se utiliza para introducir ejemplos que inmediatamente se narran en lenguaje formal. La tasa de conversión semiótica (TCS) de una lengua a otra, y viceversa, (indica la frecuencia con que se cambia de una lengua a otra) puede ser una variable importante en el proceso enseñanza aprendizaje de las matemáticas. El uso extensivo de la LN puede ser utilizado para interiorizar los procesos objetivos representados por la LF de las matemáticas (Escotto, Sánchez y Baltazar, 2014).

\section{Alternancias semióticas}

Una serie de investigaciones han sido encaminadas para analizar el uso de diversas alternancias de código semiótico (lengua natural, recursos computacionales, objetos, gráficas, esquemas, etc.) en distintos temas matemáticos.

Álvarez (2012) propone un análisis semiótico integral incorporando aspectos visuales, no solo verbales, a los recursos semióticos utilizados en la enseñanza, particularmente en línea, textos digitales y multimedia. Sostiene que las mediaciones en la triada estudiante-docente-contenidos se han ampliado con mediaciones semióticas diversas. La interfaz con el computador no es neutral ni ingenua en términos semióticos. Las hipermediaciones "pueden ser entendidas como aquellas que apuntan a la confluencia de lenguajes, reconfiguración de géneros y la aparición de nuevos sistemas semióticos caracterizados por la interactividad y las estructuras reticulares" (p. 225), implican nuevos recursos semióticos a partir de la hipertextualidad y la convergencia de medios. Concluye que el uso de sonidos, imágenes y lenguaje en la red, junto con los hipervínculos, fortalecen la hipertextualidad.

El uso de diversos medios semióticos para fortalecer la enseñanza de las matemáticas apunta a la construcción social del conocimiento. Representantes explícitos de esta postura son Aparicio y Cantoral (2006) para quienes la construcción social del conocimiento es el eje de la postura teórica socioepistemológica, y su importancia para la enseñanza de las matemáticas. Los autores aplican sus propuestas a un tema específico de matemáticas: continuidad puntual. Proponen un enfoque sistémico que incluya la comunicación, la búsqueda de consensos, la construcción de lenguajes o el diseño de herramientas. Se proponen explicar cómo las formas discursivas y la gestualidad de los estudiantes les permiten acceder a las nociones matemáticas estudiadas "continuidad puntual de una función real de variable real". El discurso matemático escolar parece estar desligado de la cultura y de las emociones de quienes lo aprenden, sin embargo, la construcción del conocimiento no está desligada de aspectos epistemológicos, prácticas socioculturales y del pensamiento, "La socioepistemología plantea el examen del conocimiento matemático, social histórico y culturalmente situado, problematizándolo a la luz de las circunstancias de su construcción y difusión". (p. 9). Los autores concluyen que "En la práctica, el discurso académico desconoce las bondades del discurso cotidiano" (p. 12) en donde la gestualidad y reflexividad juegan un papel importante. 
Adam Vile (1999) sigue en la lógica de los factores socioculturales para el aprendizaje de las matemáticas. Sostiene que las matemáticas son un sistema de signos complejo y que el contexto sociocultural del aprendizaje de las matemáticas es esencial como mediador de este proceso. La construcción del significado matemático es social por su naturaleza. La red de experiencias personales ayuda a construir el significado. Se propone una guía para la interpretación semiótica del medio y el texto (p. 94):

1. ¿Cuáles son los significantes importantes y qué los hace significativos (qué significan)?

¿Cuál es el sistema dentro del cual esos signos cobran sentido?

¿Qué connotaciones parecen estar involucradas?

2. ¿Cuál es la estructura sintagmática del texto?

¿Cómo se relaciona una unidad del texto con otra?

¿Son esos rasgos de fórmulas los que forman el texto?

\section{Análisis paradigmático}

¿Qué clases de paradigmas (medio, género, tema) son pertenecientes al texto total?

¿Cómo podría haber sido el texto si hubiera formado parte de un género diferente?

¿Qué paradigmas están notablemente ausentes?

¿Qué pares opuestos parecen estar involucrados (ejemplo: naturaleza/cultura)?

¿Es esto una oposición central en el texto?

¿Cuál es la importancia psicológica, social y política tienen esas oposiciones?

4. ¿Qué códigos semióticos son usados?

¿Cuáles convenciones son las más obvias en el texto?

¿Cuáles códigos son específicos del género del texto (escribir, actuar, hablar)?

¿Cuáles códigos son compartidos con otros géneros?

¿Qué supuestos culturales son llamados a cuenta?

¿Cuál parece ser la lectura preferida?

¿Hasta qué punto esto refleja o se aparta de los valores culturales dominantes?

¿Qué lecturas alternativas parecen posibles?

5. Intertextualidad

¿Alude a otros textos?

¿Alude o compara con otros textos dentro del género?

¿Cómo se compara con los tratamientos de temas similares dentro de otros géneros?

¿Qué otras contribuciones han hecho los semióticos que se pueden aplicar al texto?

¿Qué minimiza o ignora un análisis puramente estructural del texto? 
La utilidad de otros recursos semióticos en la enseñanza de la lengua formal de las matemáticas tiene que ver con que el lenguaje matemático, al tener sus propios signos, facilita o dificulta la discursividad matemática, es decir, los signos potencializan o dificultan la significación que con ellos se pretende dar en la medida en que se despliegan en el "discurso". Los diversos recursos semióticos nos deben permitir transitar de una lengua coloquial a una lengua matemática. El uso de diversos recursos semióticos tiene ese propósito en la enseñanza de la matemática, estos recursos son variados, pero todos están al alcance de cualquier profesor, un ejemplo de ellos es el uso de diagramas en la narrativa.

Para Ariza (2012) los relatos pueden expresarse como diagramas de árboles jerárquicos, de síntesis, boolena, kleineana. Desde una perspectiva diagramática, un relato se visualiza como un conglomerado susceptible de ser modulado y con conexiones relacionales; cuando el relato se hace relacional, se construye el objeto al momento de narrarlo. Los sucesos narrados se localizan dentro del entorno diagramático que a su vez presupone la existencia de eventos relacionados entre sí, lo que les da existencia dentro del relato diagramático. Esta secuencia permite expresarse en un árbol de "presuposición" que dotado de contigüidad sintagmática compuesta de figuras. El diagrama tiene ordenación jerárquica y puede ser visualizado como un cuasitexto. Las relaciones entre eventos se tornan figurativas con sentido semántico. Este ejemplo de alternancia semiótica (de la escritura al diagrama) ilustra la diversidad de medios semióticos que pudieren utilizarse en la enseñanza de las matemáticas.

La diversidad de recursos semióticos no se agota en el habla cotidiana, para Arzarello (2006), las aproximaciones semióticas que restringen los signos a la escritura y el habla, presentan limitaciones para dar cuenta de otros recursos semióticos que se expresan en el salón de clases, tales como gestos, gráficas, miradas, dibujos, etc. Los cambios de recursos semióticos también incluyen los problemas que construyen contextos de enseñanza, el uso de esos recursos en contextos diferentes puede cambiar la profundidad con que se comprenden los significados matemáticos, esto ha dado pie a que se habla de pragmática en la enseñanza de las matemáticas.

Ávila, Ibarra y Grijalva (2010) analizaron el contexto de enseñanza de los objetos matemáticos y su influencia en el aprendizaje de los significados de los objetos matemáticos dentro del aula. Suele entenderse por matemáticas en contexto, que su aprendizaje se basa en situaciones problemáticas en la aplicación de las matemáticas. Sin embargo, para los autores la noción de contexto es más amplia, entienden por contexto no solo las situaciones problemáticas, sino el lenguaje que se usa en la manera de representarlas, los argumentos utilizados y las circunstancias bajo las cuales se estudia, lo que implica al sujeto que conoce y su sistema conceptual. Ubican su propuesta en una concepción pragmática del significado al concebir "a los objetos matemáticos como herramientas conceptuales que surgen y se desarrollan a través de su uso...” (p. 339). Entienden a la matemática como una actividad de solución de problemas, con un lenguaje simbólico y un sistema conceptual lógicamente organizado, lo que les permite arribar a la concepción pragmática de los objetos matemáticos. Es este uso en contexto de problemas, de conflictos cognitivos, lo que permite desarrollar el significado de los objetos matemáticos. Las actividades ostensibles o interiorizadas que el sujeto realiza para solucionar los problemas enriquecen el significado de los objetos matemáticos. Los recursos semióticos utilizados en el aula siempre interactúan con los recursos que utiliza la lengua natural, lo que de suyo obliga a utilizar diferentes aproximaciones metodológicas para su estudio.

Beiza (2015) investigó la semiótica en la comprensión del lenguaje matemático utilizando metodología cualitativa (método etnográfico, observación participante, entrevistas semiestructuradas, notas de campo, grabaciones) y un enfoque de semiótica sociocultural. Uno de sus propósitos fue la relación entre el lenguaje natural y el lenguaje matemático, lo que implica la conversión de ciertos recursos semióticos como los signos fonéticos y escritos de 
la lengua natural, y los recursos semióticos formales de la lengua matemática, la que utiliza al menos cuatro tipos de símbolos o signos: ideogramas, pictogramas (íconos geométricos), signos de puntuación, por ejemplo, a: b), signos alfabéticos ( $a, b, c$, etc.). Sus resultados muestran que el poco dominio de los signos matemáticos de los estudiantes está asociado a problemas de la enseñanza de esos signos apoyándose en la lengua natural:

"Por ende, estos estudiantes tienen complicaciones en la superación de objetivos, su lenguaje coloquial choca contra una pared cuando lo que aplican no es válido al llegar al liceo mientras ellos defienden que si lo es, empiezan a tener contradicciones de lo que han aprendido y saben a lo que están descubriendo como diferente en todo el sentido de la palabra, la experiencia de estas vivencias es como comenzar de nuevo, desde cero...” (Beiza, 2015, p. 141)

El intercambio semiótico en la enseñanza de las matemáticas (pasar de un tipo de signo a otro, generalmente con el propósito de usar un tipo de signo para esclarecer otro), incluye no solo los signos fónicos de la lengua natural, los gestos, sino ante todo representaciones visuales: dibujos, gráficas, esquemas, colores, etc. El papel de los signos visuales en la enseñanza de las matemáticas debe valorarse como recurso didáctico, sobre todo, por la importancia de los signos visuales y espaciales para la comunicación de los significados matemáticos. Caivano (2005) analiza la importancia de los signos visuales en el proceso de la comunicación visual y de la cognición, su aproximación retoma la propuesta semiótica de Charles Sanders Pierce (1860-1908) que habla de representamen (el signo), de objeto e interpretante: "El representamen es el signo sustituyente, el objeto es la cosa sustituida y el interpretante [no el intérprete] la idea que transmite acerca de la cosa" (Caivano, 2005, p. 115). La alternancia de distintas representaciones sígnicas la ilustra con la parábola, ésta puede representarse diciendo con palabras "curva plana cuyos puntos equidistan del foco y de la directriz", o puede hacerse un trazo gráfico-visual de ella, o puede representarse por un objeto que al ser lanzado describe una parábola, o representarse con su fórmula: $y=x 2$. Estas diferentes representaciones semióticas expresan distintos aspectos de la noción matemática de parábola y pueden ser utilizados en una secuencia didáctica que vaya de la representación objetual, a la visual a la representación formal $y=x 2$, a la verbal (definición). En general, pasaríamos de la representación visual a la formal, utilizando las propiedades de los signos visuales. A decir de Caivano, los signos visuales implican al menos tres nociones básicas: luz, espacio y tiempo que implican color, cesía (percepción de las diferentes formas de distribución de la luz en el espacio), textura, forma y movimiento. Todos estos aspectos pueden ser utilizados como recursos semióticos en la enseñanza matemática, sobre todo con la disponibilidad tecnológica de las computadoras y programas disponibles en el mercado.

Caligaris, Rodríguez y Laugero (2015) sugieren que para la comprensión de objetos matemáticos es necesario transitar de unas representaciones semióticas a otras según el tratamiento que se le dé a los objetos, esto se facilita con el uso de computadoras las cuales ellas utilizaron para la enseñanza de las "transformaciones lineales", sobre todo por la facilidad para la representación visual de los conceptos matemáticos. Asumen que en el pensamiento matemático se dan dos operaciones cognitivas: el tratamiento y la conversión. El tratamiento de una representación consiste en su transformación dentro de los límites de la misma representación semiótica (transformaciones algebraicas utilizando álgebra), y la conversión consiste en un cambio de código semiótico o "registro". El aprendizaje de un concepto matemático puede expresarse en el momento en que un alumno es capaz de transitar de una representación semiótica a otra.

"cada sistema de representación permite ver una faceta diferente del objeto a estudiar y pone de manifiesto algunas de sus propiedades relevantes. Esto quiere decir que toda representación es 
cognitivamente parcial en referencia a lo que ella representa y que si cada sistema de representación ofrece una consideración parcial para un concepto, el cruce de representaciones relativas a ese concepto mejora la comprensión sobre el mismo". (Caligaris, et al., 2015, p. 2)

El uso de los signos visuales utilizando computadoras es un recurso accesible a la mayoría de las escuelas en que se enseña algún tópico de matemática, pero el recurso más directo es la lengua natural, sobre todo en su función dialógica en el aula (Diéz-Palomar, García, Molina, Rué, 2010). Estos autores utilizan el llamado "aprendizaje dialógico" como herramienta didáctica para la enseñanza de las matemáticas. Este tipo de aprendizaje asume que el diálogo y las interacciones son generadores de aprendizaje en el aula en la medida en que mediante él se construyen socialmente los significados. El diálogo no solo es el de alumno profesor, sino también entre pares de estudiantes o en el ámbito de sus relaciones sociales.

En el aprendizaje dialógico se toman en cuenta y se respetan las diferencias del alumnado, poniendo el énfasis en las interacciones que pueden potenciar el aprendizaje y en la transformación del contexto, tanto escolar como el entorno, para conseguir una educación igualitaria (Diéz-Palomar et al., 2010, p. 76)

El diálogo dentro del aula permite justificar los argumentos, aclarar los significados y precisar los conceptos. El conocimiento es resultado de ese proceso dialógico. La experiencia de estos autores utilizando el diálogo en la enseñanza del cálculo (las operaciones para calcular en el nivel de primaria) es ilustrativa. Formando grupos pequeños en el aula, los niños dialogan sobre las nociones aritméticas que se enseñan, el resultado es una constante negociación intersubjetiva de los significados matemáticos. Los autores reportan que el aprendizaje conseguido es más acelerado e intenso, y la participación de todos los estudiantes es notoria. La disparidad entre niños (unos avanzan más que otros) es atendida por la misma dinámica del grupo interactivo, ya que los más avanzados dialogan con los menos avanzados y ayudan a su aprendizaje. Esta experiencia muestra que el uso de la lengua natural con su natural manifestación, el diálogo, es un poderoso instrumento didáctico en la enseñanza de las matemáticas desde los niveles más básicos de la escuela. La enseñanza de las matemáticas necesita de la interacción dialógica para el mejor aprendizaje de los diversos recursos semióticos posibles en la representación matemática; aprender a utilizar distintas formas de representación de los objetos matemáticos es uno de los objetos del proceso de aprendizaje.

Duval (2006) analiza el pensamiento matemático en relación al lenguaje y otros sistemas de representación semiótica en el contexto de las dificultades de aprendizaje de las matemáticas. Sostiene que la transformación de representaciones semióticas está implicada en el pensamiento matemático, éste requiere una coordinación interna construida entre los diversos sistemas de representación que se elijan para representar el mismo objeto matemático. Propone dos clases de transformaciones: la conversión y el tratamiento. La conversión implica pasar de un sistema de representación a otro, por ejemplo, de un problema explicitado verbalmente a su conversión en ecuaciones. El tratamiento es la secuencia de transformaciones. La conversión de un código semiótico a otro está implicada en la geometría en la cual una representación verbal puede convertirse en representación visual la cual se convierte a su vez en otra representación semiótica, las ecuaciones. Un problema importante en el aprendizaje de las matemáticas es la dificultad del alumno para pasar de un código semiótico (una figura geométrica de un triángulo) a otro (su formulación como teorema) en el tratamiento de un mismo objeto matemático. Una de las implicaciones del planteamiento de Duval es que cada profesor puede utilizar diferentes recursos semióticos para el tratamiento de un mismo objeto matemático, este proceso puede ser conscientemente o inconscientemente utilizado. De hecho, en los cursos de una rama de las matemáticas, la estadística, los profesores utilizan diferentes 
recursos semióticos (lengua natural, ejemplos cotidianos, figuras, gráficas, colores, etc.), pero no siempre son conscientes de ello.

Según Fernández y Cuadrado (2008), los profesores no son conscientes de los recursos comunicacionales que utilizan en el aula, de los significados que adquieren y las interpretaciones de sus alumnos., lo que les impide utilizar recursos verbales, no verbales y prosódicos para la creación. Buena parte de los estudios son sobre la comunicación verbal, pero se ha relegado la comunicación no verbal en el aula para la creación de un clima emocionalmente positivo en el aula. El objetivo de su investigación fue el nivel de conciencia y conocimiento de los docentes sobre su comportamiento comunicativo. Utilizaron metodología cualitativa con estudios de casos; seis sujetos que imparten lengua y literatura, y tres técnicas: observación videograbada, entrevista, cuestionario. Su investigación se centró en las estrategias comunicativas del discurso: meta-representaciones, preguntas, repetición de aportaciones de alumnos, etcétera, logrando elevar la conciencia de los profesores.

Corona, Escotto, Sánchez y Baltazar (2016), y Velázquez, Escotto, Sánchez, y Baltazar (2016), investigaron el tipo de recursos semióticos utilizados por profesores de estadística y su relación con el rendimiento académicos de los estudiantes. Los autores dividieron los recursos semióticos en dos tipos: formales (fórmulas, letras, números, símbolos, operaciones, etcétera) y no formales (lengua natural, ejemplos cotidianos y relacionados con la materia de estudio -psicología-, colores, gráficas, esquemas, etcétera). Ambos recursos están presentes en toda clase de estadística, pero su proporción y uso varía de profesor a profesor. Mediante metodología cualitativa (grupos de discusión, observación participante) se pudo averiguar que los profesores con menor rendimiento académico de sus grupos utilizaban dominantemente los recursos formales y en menor proporción los no formales; mientras que los profesores con mayor rendimiento académico y reputados por los alumnos como más didácticos, utilizaban dominantemente recursos semióticos no formales para introducir a los recursos formales utilizados en estadística. Los recursos semióticos no formales están a disposición de cualquier profesor, pero no siempre son utilizados conscientemente como recurso didáctico para introducir a los recursos formales. Ello sugiere la necesidad de sistematizar los recursos no formales y hacer consciente a los profesores de su utilidad como recurso didáctico en la enseñanza de la estadística, y en general, de cualquier tema matemático.

La lengua natural hablada, el idioma, es el principal recurso semiótico con que cuenta un profesor de estadística y, en general, de cualquier lengua formal. No solo sus propiedades léxico-semánticas son útiles, sino ante todo sus propiedades psicológicas. Una propiedad psicológica del lenguaje, y por tanto de todas las lenguas, es la de operar con un mundo sensorialmente ausente. Es decir, con las palabras podemos evocar objetos, procesos, relaciones, estados que no están presentes en el campo sensorial. Esta capacidad de representarnos el mundo mediante los significados de los signos es el fundamento de la función simbólica en los niños. La palabra, al sustituir al referente, lo evoca cognitivamente, abstractamente. Cuando esto ocurre, el niño comienza a relacionarse con el mundo en forma sensorial y abstracta: lo percibe y lo concibe. Los primeros juegos infantiles en los que la niña mece un trapo como si fuera un bebé muestran la emergencia de la función simbólica en ella, es decir, la capacidad de representar a un ente utilizando un sustituto (el trapo por el bebé), y su capacidad de operar con un mundo ausente sensorialmente (no está el bebé). Otra propiedad de las lenguas es que durante el desarrollo infantil se transita de nombrar el mundo objetivo a la creación ontológica mediante la lengua, es decir, el niño pequeño, en una etapa del desarrollo de la lengua nombra lo que existe, y en otra etapa, cree que lo que nombra existe (el coco, el fantasma, etc.), a esta etapa la llamamos (Escotto, 2014) creación ontológica del lenguaje. Las matemáticas crean mundos abstractos con el desarrollo de su sistema de signos, algunos de los cuales son difíciles de percibir (las dimensiones). En el proceso de la enseñanza de las lenguas formales los profesores y alumnos usan esas dos 
propiedades de las lenguas: la capacidad verbal de operar con mundos ausentes, de evocarlos y de representarlos mediante palabras, y la creación ontológica mediante la lengua matemática. Estas propiedades de las lenguas son el recurso más a la mano para utilizarse en la alternancia semiótica durante la enseñanza de las matemáticas, o en particular de la estadística. Pueden, y deben, ser usadas hasta agotar sus posibilidades aun en ausencia de otros signos (objetos, figuras, gráficas, etc.). Se puede decir, por ejemplo, que la ropa que está de moda es la más frecuentemente usada en una época determinada, y que es lo mismo en la moda estadística: es la mayor frecuencia en una distribución de datos. En este ejemplo no se ha utilizado ningún recurso formal para introducir el concepto estadístico de la "moda". La lengua hablada tiene, además, un sin número de palabras que refieren nociones numéricas, de relación, de cantidad que pueden ser utilizadas antes de alternar el código semiótico a nociones formales (fórmulas, signos especializados de matemáticas, operaciones, etc.).

Este vocabulario de nociones de cantidad y numéricas, más la propiedad de referirnos a mundos sensorialmente ausentes posibilita otra propiedad igualmente poderosa de las lenguas naturales: la metáfora y la metonimia. La metáfora es una comparación abreviada y elíptica (suele omitir el verbo) basada en la relación de semejanza entre significados o referentes. La capacidad metafórica de las lenguas naturales permite pasar cotidianamente de una representación semiótica a otra, decir por ejemplo que un árbol y su sombra proyectada sobre el piso forman los lados de un triángulo. La metonimia es la figura retórica con la que se designa una cosa con el nombre de otra ya sea por su contigüidad espacial, temporal o lógica. Estos dos recursos retóricos (metáfora y metonimia) son de gran frecuencia en la lengua hablada que sirven como herramienta para alternar códigos semióticos en la enseñanza de las matemáticas.

\section{Referencias}

IIII Álvarez, G. (2012). Hacia una propuesta de análisis semiótico integral de ambientes virtual de aprendizaje. ONOMÁZEN 25(1):219-239.

IIII Aparicio, E., y Cantoral, R. (2006). Aspectos discursivos y gestuales asociados a la noción de continuidad puntual. Relme 9, (1):7-30.

IIII Ariza, M. (2012). Pensamiento diagramático y narratividad: una articulación semiótico-matemática. Forma y función, 25 (1): 147-167.

IIII Arzarello, F. (2006). Semiosis as a multimodal process. Relime, número especial, pp. 267-299.

IIII Ávila G., R.; Ibarra O., S. E.; y Grijalva M., A. (2010). El contexto y el significado de los objetos matemáticos. Revista Latinoamericana de Investigación en Matemática Educativa, vol. 13, núm. 4, 2010, pp. 337-354.

IIII Beiza, J. E. (2015). Semiótica en la comprensión del lenguaje matemático. Tesis de Maestría. Venezuela, Universidad de Carabobo, Facultad de Ciencias de la Educación.

IIII Barwell, R. (2005). Language in the Mathematics Classroom, Language and Education, Vol. 19, No. 2, 97-102

IIII Beuchot, M. (2004). La semiótica. México, Fondo de Cultura Económica.

IIII Beyer, W. (2001). Algunos aspectos epistemológicos de la matemática: ¿Es la matemática un lenguaje? Educere, Año 4, No. 14, 236-240. 
IIII Blanco, B., Caballero, A., Blanco, L. J. (2010). Matemática y lenguaje a partir de la lectura de cuentos. Aula de Innovación Educativa, 189, 86-96.

IIII Caivano, J. L. (2005). Semiótica, cognición y comunicación visual: los signos básicos que constituyen lo visible. Tópicos del Seminario, 13, 113-135.

IIII Caligaris, M., Rodríguez, G. y Laugero, L. (2015). El papel de los registros semióticos en el aprendizaje de las transformaciones lineales. https://www.researchgate.net/publication/237394236_El_papel_de_los_registros_ semioticos_en_el_aprendiz_aje_de_las_transformaciones_lineales

IIII Carey, S. (2004). Bootstrapping and the origins of concepts. Daedalus, 133, 59-68.

IIII Corona, R. G., Escotto, C. E. A., Sánchez, R., J. G., Baltazar, R. A. M. (2016). Los recursos semióticos del profesor de estadística asociados al rendimiento académico delos estudiantes. Revista Electrónica de Psicología de la FES Zaragoza-UNAM, 6 (11), 15-33.

IIII Diéz-Palomar, J., García, W. P., Molina, R. S., y Rué, R. L. (2010). Aprendizaje dialógico en las matemáticas y en las ciencias. Revista Interuniversitaria de Formación del Profesorado, 67 (24,1), 75-88.

IIII Duval, R. (2006). Un tema crucial en la educación matemática: la habilidad para cambiar el registro de representación. La Gaceta de la RSME, 9.1, 143-168

IIII Eco, H. (1994). La búsqueda de la lengua perfecta. Barcelona, Editorial Crítica. (Trad. Italiano: María Pons).

IIII Escotto, C. E. A., Sánchez R., J. G. Baltazar R. A. Ma. (2014). El método de Galperin de la formación de las imágenes mentales y su importancia para la enseñanza de las matemáticas. En Eduardo Alejandro Escotto Córdova y José Gabriel Sánchez Ruiz. Estrategias de Intervención-Rehabilitación en Dificultades en el Aprendizaje de las Matemáticas. (Pp. 1-19). Universidad Nacional Autónoma de México, Facultad de Estudios Superiores Zaragoza. (Proyecto PAPIME PE-3031111).

IIII Escotto, C. E. A. (2013). El lenguaje. En Israel Grande-García y Jesús Silva Bautista. Psicología. Historia, teoría y procesos básicos. (Pp.175-194). México, Manual Moderno.

IIII Galperin, P. Ya (1969/1998) Acerca de la investigación del desarrollo intelectual del niño. En Luis Quintanar Rojas (Comp.) (1995) La formación de las funciones psicológicas durante el desarrollo del niño.( Pp. 67-84) México, Universidad Autónoma de Tlaxcala.

IIII Galperin, P. Ya (1959a/1998) Tipos de orientación y tipos de formación de las acciones y de los conceptos. En: Luis Quintanar Rojas (Comp.) (1995) La formación de las funciones psicológicas durante el desarrollo del niño. (Pp. 41-56.). México, Universidad Autónoma de Tlaxcala.

IIII Galperin, P. Ya (1957b/1998) Sobre la formación de imágenes sensoriales y de los conceptos. En: Luis Quintanar Rojas (Comp.) (1995) La formación de las funciones psicológicas durante el desarrollo del niño. (Pp. 27- 39). México, Universidad Autónoma de Tlaxcala.

IIII Galperin, P. Ya (1957c/1998) Acerca del lenguaje interno. En: Luis Quintanar Rojas (Comp.) (1995) La formación de las funciones psicológicas durante el desarrollo del niño. (Pp. 57-65). México, Universidad Autónoma de Tlaxcala,.

IIII Goswami, U. (2004). Neuroscience and education. British Journal of Educational Psychology, 74, 1-14.

IIII Hernando, D. (2009). El lenguaje verbal como instrumento matemático. Educación y Educadores. 12 (3), 13-31. 
IIII Manghi H. D. (2010). Recursos semióticos del profesor de matemática: funciones complementarias del habla y los gestos para la alfabetización científica escolar. Estudios Pedagógicos XXXVI, № 2: 99-115.

IIII Méndez R. E. Ma. \& Moreiro G. J. A. (1999). Lenguaje natural e Indización automatizada. Ciencias de la Información, vol. $30,3,11-24$.

IIII Pedrosa, R. (2008). Palabras y números: El pensamiento matemático y su relación con el lenguaje. Ciencia Cognitiva: Revista Electrónica de Divulgación, 2: 3, 72-74.

IIII Puig, L. (1994). Semiótica y matemáticas. Valencia, España, Eutopías.

IIII Rojano, T. (1994). La matemática escolar como lenguaje. Nuevas perspectivas de investigación y enseñanza. Enseñanza de las Ciencias, 12 (1), 45-56.

IIII Spaepen, E., Coppola, M., Spelke, E., Carey, S., Goldin-Meadow, S. (2011). Number without a language model. Proceedings of the National Academy of Sciences, 108 (8), 3163-3168.

IIII Velázquez M. J.A., Escotto, C. E. A., Sánchez, R. J. G., Baltazar, R. A. M. (2016). Análisis de recursos semióticos para el proceso de enseñanza-aprendizaje en clases de estadística. Revista Electrónica de Psicología de la FES Zaragoza-UNAM, 6 (11), 34-57.

IIII Viera S. A. (2009). El desarrollo del lenguaje y la actividad matemática, dos elementos básicos en la práctica educativa en la etapa infantil. Participación Educativa, 12, 77-86.

IIII Vygotski S. L. (1934/1993). Pensamiento y Lenguaje. En Amalia Álvarez y Pablo del Río. Problemas de Psicología General. (Pp.11-348). Obras Escogidas, T. II. Madrid. Visor. (Trad. José María 


\section{CAPITULO 2}

Análisis bibliométrico sobre la investigación en recursos semióticos en la enseñanza-aprendizaje de las matemáticas

José Gabriel Sánchez Ruiz

Eduardo Alejandro Escotto Córdova

Sofía Berenice Olmos-Sánchez

Yarel González-Alatorre

- I objetivo de este trabajo es mostrar los resultados obtenidos de un análisis bibliométrico sobre el tema de

- recursos semióticos (que puede tener como sinónimos los siguientes: lenguaje natural-lenguaje formal; lenguaje formal-lenguaje no formal; lenguaje matemático-lenguaje no matemático; entre otros). El estudio abarcó el periodo de 2006-2016.

La semiótica es la teoría cuyo tema de interés son los signos y que, además, se encarga de estudiar, entre otros aspectos, su presencia, uso y configuración en la sociedad. E. Verón, al revalorizar los trabajos de Charles Pierce, importante filósofo estadounidense considerado el fundador de la semiótica moderna, sugiere el concepto de semiótica social para referirse a la significatividad social que pueden asumir algunos fenómenos, y aunque este término podría incluir a todos los contextos sociales, Christie (2002, citado en Manghi, 2013) propone una noción, la lingüística educacional, que al hacer alusión a las maneras de crear significado específicamente en los ámbitos pedagógicos, educativos y didácticos. De acuerdo a esta lingüística es factible plantear que al interior de la escuela existen numerosas maneras de crear significado, por lo tanto, no es suficiente para que los estudiantes aprendan a conocer un solo tipo de comunicación, sino que deben dominar muchos de ellos. Podría decirse que, partiendo de los planteamientos de Christie, Unsworth (2011, citado en Manghi, 2013) al desarrollar investigación acerca de cómo se crea significado, específicamente en contextos educativos, propone el término de semiótica educacional. Con él define, como señala Manghi (2013), "a la disciplina que se enfoca en las formas de crear significado en los contextos educativos..." (p. 37).

La investigación en el tema revela que precisamente durante la etapa escolar los estudiantes amplían su repertorio de herramientas semióticas, asimismo, que específicamente al iniciar la Educación Media ellos requieren comunicarse para aprender con base en diversos discursos. Esta pluralidad de discursos se justifica por la particular forma de los profesores de representar y comunicar el contenido de cada asignatura escolar. Recuérdese que en México, en este nivel escolar, las asignaturas son impartidas en su mayor parte por profesores formados en el área a la que corresponde la asignatura.

Manghi es aún más preciso en la terminología usada para describir este proceso de adquisición de múltiples herramientas semióticas. Al respecto dice que "el aprendizaje de esta diversidad de formas de representar y 
comunicar se ha denominado "alfabetizaciones múltiples" (multiliteracies)... y redefine la alfabetización como práctica social. Este concepto abarca el aprendizaje semiótico o multimodal de los significados que han sido convencionalizados a través de múltiples recursos semióticos: esquemas, gráficos, fotos, dibujos, fórmulas, etc." (Manghi, 2013, p. 37).

Para Veel (1997) alfabetizarse requiere aprender prácticas semióticas, como: hablar, escribir, hacer esquemas, manejar fórmulas, manipular objetos e interpretar diagramas y mapas. Se debe destacar que el concepto de alfabetización se vuelve aún más interesante al hablar de alfabetización múltiple ya que en el contexto escolar se traduce en la idea de que en cada asignatura, o materia escolar, el alumno requiere aprender prácticas semióticas especiales, que son las que impone cada asignatura, por lo que cada profesor especialista en una asignatura precisa conseguir formas determinadas de crear significado en sus alumnos haciendo que estos se acerquen a una configuración semiótica determinada. Aunque a veces tal uso de recursos múltiples comprenda moverse entre el discurso específico de la disciplina y el discurso cotidiano. El trabajo de Córdova, Melo, Bacigalupo y Manghi (2016), sobre un análisis del discurso de las actividades típicas en un aula de enseñanza de ciencias naturales, aporta evidencia sobre este planteamiento. Ellos mencionan que en las clases escolares de ciencias gran parte de los significados se construyen a partir de la interacción oral, mediante representaciones lingüísticas y visuales, sin embargo, los profesores se mueven entre el discurso científico y el discurso cotidiano. Asimismo, enfatizan en el valor de estos movimientos porque permiten que los alumnos razonen y perciban el mundo desde la perspectiva de la disciplina.

Consecuencia del afán de conocer las características de los recursos semióticos utilizados por los profesores en el proceso educativo en general, es decir, sin precisarlo para un nivel escolar o una asignatura académica, se han realizado diversos estudios. Entre ellos destacan, juzgados como trabajos pioneros por Manghi, los de Márquez y Prat (2005) quienes analizan la actuación del profesor al tender puentes para vincular las distintas actividades que realiza en el salón de clases con el propósito de lograr que el alumno, en la medida de sus posibilidades, construya el conocimiento. Los autores concluyen que las situaciones de enseñanza-aprendizaje son mucho más complejas, variadas y dinámicas y que disponen de más recursos que la simple lectura y que el conocimiento científico, sobre lo que trata el trabajo, también se construye cuando se habla, se discute en el aula, cuando se trabaja, se observa, se experimenta, etc., y le dan énfasis al lenguaje visual y a los gestos.

También sobresalen las investigaciones que indican que en el discurso del docente se integra texto, dibujos y palabras (Pozzer-Ardenghi y Roth, 2005) y las de Unsworth (2006, citado en Manghi, 2013) que abordan los textos escolares desde la multimodalidad.

En particular, en estudios realizados en aspectos concernientes a la enseñanza de las matemáticas concretamente o alguna de sus ramas, como la aritmética, la estadística, la geometría, entre otras, se aprecia una interesante diversidad de situaciones respecto a la manera de proceder en el discurso del profesor y los recursos que lo caracterizan. Por ejemplo, Ortiz de Haro, Batanero y Serrano (2001), respecto a la educación en estadística, mencionan que actualmente la enseñanza de la estadística ha alcanzado gran importancia, lo cual es evidente al analizar distintos planes de estudio vigentes, siendo el eje de la enseñanza la adquisición de un lenguaje preciso sobre el azar y la probabilidad. Sin embargo, aunque el objetivo es el aprendizaje de un vocabulario o terminología precisa y especializada de la probabilidad, es decir lo que podría denominarse un lenguaje formal o lenguaje matemático, el inicio en la enseñanza del alumno en esta no es frecuentemente con expresiones formales para 
referirse a eventos aleatorios. Como indican dichos autores, el primer acercamiento es en un lenguaje ordinario, que alude a conceptos fundamentales de la probabilidad como azar y aleatorio, con términos como accidental, fortuito, eventual, suerte y "chiripa".

Destacamos que en el trabajo de Ortiz de Haro, Batanero y Serrano (2001) se analiza el tipo de lenguaje empleado en libros de texto, que constituyen un recurso y o material al que puede recurrir el profesor para facilitar el aprendizaje de las matemáticas.

En cuanto a los antecedentes de trabajos enfocados a reflexionar acerca del uso de los recursos semióticos naturales, cotidianos, no formales o, como lo designa Pimm (1989), lenguaje corriente, principalmente lingüísticos, como recursos didácticos para la enseñanza de las matemáticas podríamos citar los de Orton (1990), Pimm (1989) y Rotherry (1980, citado en Ortiz de Haro, Batanero y Serrano (2001). Pimm menciona que el lenguaje cotidiano con un sentido matemático, así como las metáforas con palabras cotidianas son muy importantes en, y para, la construcción del conocimiento matemático.

En el ámbito del tipo de lenguaje presente en la enseñanza de las matemáticas, Rotherry (1980) señala que se pueden distinguir tres situaciones: primera, el uso de palabras específicas, de uso técnico o propias de las matemáticas que no constituyen parte del lenguaje cotidiano; segunda, términos que aparecen tanto en las matemáticas como en el lenguaje ordinario, pero no siempre con el mismo significado; y tercera, términos con un significado muy similar en las matemáticas y en la vida cotidiana.

Las situaciones descritas por Rotherry son explicables si se considera lo que han expuesto algunos autores, como Muñoz (2010) al analizar la incorporación del lenguaje matemático al lenguaje cotidiano. Él dice que una lengua viva incorpora continuamente palabras usuales de muy diversas situaciones humanas, lo cual puede observarse al analizar el vocabulario español cotidiano que está plagado de palabras típicas de determinadas actividades, por ejemplo, dice el autor, las del mundo deportivo. Otro ejemplo puede ser el vínculo que se establece, por medio del lenguaje, entre dos actividades humanas al parecer totalmente disímiles: el de la milicia y el deporte, con frases como la siguiente para describir el estilo de juego de un deportista en un encuentro deportivo "su influencia en ataque y defensa resultó completamente abrumadora". Una muestra más, aunque de otro tipo de relación es la que se puede observar entre el campo de la publicidad con las matemáticas, como cuando se anuncia una venta en promoción: "rebajas al 3²", "pague la mitad..." o "venta especial, 18 meses $+25 \%$ de descuento...". Aunque a veces, remitiéndonos a un caso citado por Muñoz, la referencia matemática curiosamente es totalmente contraria a su fundamento matemático. Si bien, se sabe que un ángulo agudo siempre es más cerrado que uno obtuso, paradójicamente al aplicarlo a una persona para describir su inteligencia se usa en el sentido opuesto: la de mente aguda siempre es más inteligencia que la de mente obtusa.

Centrándonos en el contexto de la enseñanza de las matemáticas, la relación entre el lenguaje formal de las matemáticas y el lenguaje natural se inscribe en el intercambio de códigos semióticos. Con más detalle, en el proceso de la enseñanza el lenguaje formal y el natural se intercambian y refuerzan constantemente, aunque no siempre en la proporción adecuada.

Zapata (2011) plantea que el lenguaje natural hablado y escrito es el principal medio para transmitir ideas de contenidos matemáticos y por el cual los estudiantes construyen su conocimiento. 
En la búsqueda de facilitar el aprendizaje de las matemáticas se recurre a muchos recursos y didácticas compartidos en la enseñanza de cualquier temática que abarca las matemáticas y otras disciplinas. Un aspecto fundamental que se pondera es el uso del lenguaje cotidiano y, en términos generales, el uso de múltiples recursos semióticos que están a disposición de los profesores que enseñan lenguajes matemáticos diversos. Las experiencias documentadas son variadas: se ha estudiado el uso del cuento, relatos, textos literarios en la enseñanza de las matemáticas en el nivel secundario (Blanco, Caballero y Blanco, 2010). En otros casos, como en el de la enseñanza del concepto de función en estudiantes de ingeniería, se ha destacado el lenguaje verbal como instrumento de transferencia hacia los lenguajes geométrico, algebraico y aritmético (Hernando-Díaz, 2009).

Es indiscutible que la enseñanza-aprendizaje es un proceso que involucra tanto a docentes como a estudiantes. Es deseable que en este proceso los docentes sean facilitadores, por esto entendemos que el profesor esté más interesado en que los alumnos aprendan y no tanto en enseñar, así el éxito del proceso depende de las contribuciones del docente pero, también, de las de los alumnos.

Según Manghi (2012), en las últimas décadas, las definiciones del aprendizaje y la enseñanza han privilegiado, sobre otros, ciertos recursos para significar. En ello, el interés en el uso del lenguaje, en especial la lectura y la escritura, han ocupado un rol protagónico en los estudios sobre cómo aprendemos y cómo enseñamos. Sin embargo, ella dice, en la labor de comunicación, sea de manera oral o escrita, entran en juego múltiples recursos para significar. De este modo, en una interacción cara a cara, se habla, pero al mismo tiempo nos expresamos mediante prosodia, gestos, expresiones faciales, entre otros. En su análisis, Manghi (2012) menciona que lo mismo ocurre en la comunicación escrita, al escribir se usa este tipo de lengua, la escrita, pero no solo se dispone de letras en un continuo de izquierda a derecha, de arriba a abajo en una hoja de papel, sino que frecuentemente se recurre a otros recursos como dibujos, esquemas o, incluso, al uso de otros negrillas, subrayados, color, etc. para significar. La presencia o ausencia de estos recursos depende donde se sitúe el interés sobre la comunicación para aprender.

Tal como se refirió antes, la semiótica educacional asume que existen muchas maneras de crear significado al interior de la escuela. En el proceso de enseñanza aprendizaje esto implica que el estudiante necesita adquirir y estructurar un repertorio amplio y diverso de herramientas comunicativas y lingüísticas, empleando un término más amplio diríamos que de herramientas semióticas.

En la información antes expuesta se ha pretendido esbozar el papel de las distintas formas que puede adoptar el contenido del discurso del profesor para ampliar y contextualizar los conocimientos del alumno en una disciplina particular, ya sea en el marco de la alfabetización múltiple o multimodalidad o en el de la combinación de recursos semióticos formales, que algunos autores (Córdova et al, 2016; entre otros) denominarían discurso académico o discurso vertical, con recursos semióticos naturales o recursos del discurso cotidiano.

Antes de proseguir nos parece importante precisar un poco los términos usados por Córdova et al (2016) en su tipología de los recursos semióticos, dado que no aparecen en la literatura frecuentemente como las palabras recursos semióticos no formales y recursos semióticos formales: “...Los conceptos cotidianos y sus formas de comunicarlos corresponden a un discurso horizontal, accesible a todos, que tiende a ser un discurso oral, local, dependiente y específico del contexto, tácito y de múltiples significados...(El) discurso vertical o académico ... corresponde a uno de tipo especializado, coherente, oficial, independiente del contexto, explícito y jerárquicamente 
organizado" (p. 337). En suma, el discurso horizontal corresponde a lo que llamamos recursos naturales, mientras que el discurso vertical o académico concierne a los recursos naturales.

Con base en lo anterior juzgamos interesante conocer el interés que ha generado el tema en la comunidad científica, en particular entre la de los especialistas en educación matemática quienes están interesados en el estudio de la problemática de la enseñanza y el aprendizaje de las matemáticas.

Como mencionan Torralbo, Fernández, Rico, Maz y Gutiérrez (2003), la educación matemática es aún un campo de investigación joven, sin embargo, es fuente de muchos estudios. Asimismo, consideran que la investigación en educación matemática tiene dos propósitos: el primero, encaminado a comprender la naturaleza del pensamiento matemático, la enseñanza y el aprendizaje (Shoenfeld, 2000, citado en Torralbo et al, 2003). El segundo, interesado en usar tales comprensiones para mejorar la enseñanza de las matemáticas. Según Rico y Sierra (2000, citado en Torralbo et al, 2003) ambos objetivos se encuadrarían en la perspectiva de la educación matemática como un conjunto de actividades implicadas en la construcción, representación, transmisión y valoración del conocimiento matemático.

Explorar el estado de la investigación sobre un tema, así como sus resultados, en un periodo determinado permite conocer los patrones de productividad investigadora sobre este y constituye un indicador pertinente del interés que hay dentro de una disciplina por el tema. En este tipo de trabajo, al revisar y analizar las estrategias metodológicas empleadas es posible identificar los métodos de investigación y las tendencias que caracterizan los trabajos de investigación.

De trabajos de esta naturaleza se encarga la cienciometría. Esta forma parte de la sociología de la ciencia. Con cierta especificidad, los temas que interesan a la cienciometría incluyen el crecimiento cuantitativo de la ciencia, el desarrollo de disciplinas específicas y de sus subdisciplinas, la relación entre ciencia y tecnología, la obsolescencia de los paradigmas científicos, la estructura de comunicación entre los científicos, la productividad y creatividad de los investigadores, las relaciones entre el desarrollo científico y el crecimiento económico, entre otros de este tipo.

Entre los aspectos cuantitativos que trata la cienciometría está el estudio de las publicaciones, del que se encarga concretamente la bibliometría. Existe una distinción entre bibliometría e informetría, la segunda se encarga de cuestiones cuantitativas de la información en cualquier modalidad. La bibliometría se concentra en la revisión de libros, revistas, artículos y autores, principalmente.

Según Licea de Arenas y Santillán-Rivero (2002) la bibliometría ha sido utilizada durante décadas para medir la actividad y repercusión científica. Estos autores dicen que: "La cuantificación de las publicaciones es el elemento básico de la mayor parte de los estudios bibliométricos,..." (p. 3).

Al revisar en la literatura trabajos realizados en esta línea, y en el contexto de la educación matemática, solo se encontró el de Torralbo et al (2003) donde se examinaron algunas características de la producción de tesis doctorales en educación matemática en las universidades españolas durante 1976-1998.

De este modo, el objetivo de este trabajo consiste en mostrar los resultados de realizar un análisis bibliométrico de la presencia de investigaciones en el tema de recursos semióticos en la enseñanza-aprendizaje de las matemáticas. 
Como lo hemos mencionado, un trabajo con estas características permitirá conocer los rasgos y la evolución, en términos de continuidad y discontinuidad, de los estudios desarrollados en dicho tema. Se quiere dejar claridad principalmente en dos situaciones: primera, que no es un trabajo exhaustivo, ya que la visión que muestra está limitada a la consulta de algunas de las publicaciones que se consideran relevantes en el campo de la educación matemática, o matemática educativa y, segunda, que la revisión comprende un periodo reciente específico.

El trabajo se estructuró siguiendo los lineamientos de Ariza y Quevedo-Blasco (2013), quienes también realizaron un estudio bibliométrico.

\section{Método}

\section{Unidad de análisis}

Se analizaron 22 documentos publicados en distintas revistas, como ya se indicó, especializadas en educación matemática. Estos pueden clasificarse en la categoría de artículos o reportes de investigación.

\section{Materiales}

Las revistas consultadas fueron:

- Revista Latinoamericana de Investigación en Matemática Educativa.

- Revista Educación Matemática.

- ZDM (Zentralblatt für Didaktik der Mathematik) International Journal on Mathematics Education.

- Educational Studies in Mathematics.

Aunque las dos primeras tienen un título en español publican artículos en otros idiomas. La primera de ellas en inglés, portugués y francés. Ambas revistas son representativas del quehacer científico de los educadores matemáticos, se editan en México y buscan la comunicación y la vinculación entre investigadores nacionales e internacionales. Con respecto a la revista ZDM, está catalogada como una de las revistas más antiguas sobre investigación en educación matemática. Periódicamente, en uno de los números publicados al año aparecen solo y estrictamente artículos que fueron solicitados por invitación. Tanto ZDM como la revista Educational Studies in Mathematics son editadas por la Editorial Springer que localizada en Berlín, Alemania. Un rasgo sobresaliente de Educational Studies es que fue fundada por uno de los educadores matemáticos más destacados, Hans Freudenthal.

En todos los casos son revistas científicas en que los trabajos remitidos para su posible publicación son sometidos a una rigurosa revisión por pares dentro del campo de la educación matemática.

Con respecto a la periodicidad de su publicación se puede mencionar lo siguiente:

- La Revista Latinoamericana de Investigación en Matemática Educativa edita habitualmente tres números por año, sin embargo, algunos años ha publicado números extra o números especiales. 
- La Revista Educación Matemática publica tres números al año.

- De la revista ZDM aparecen seis números en un año, siendo bimestral su publicación.

- Educational Studies in Mathematics publica tres números por año.

Finalmente, al retomar el planteamiento de Licea de Arenas y Santillán-Rivero (2002), en cuanto a que la cuantificación de publicaciones no está libre de sesgos, siendo uno de ellos el que no reflejan la calidad de los documentos, se escogieron estas revistas por el prestigio que tienen respecto a esta cualidad. Obviamente, estas no son las únicas revistas que gozan de reputación académica, pero escapaba a nuestras posibilidades tratar de abarcar más revistas. Reconocemos que pudieron ser otras, pero también recalcamos que estas tienen buena proyección hacia el exterior de su país y que su estatus las hace muy respetables entre la comunidad de los educadores matemáticos.

\section{Diseño y procedimiento}

Este trabajo es un estudio descriptivo que se basa en la observación y el análisis de publicaciones. Se seleccionaron los materiales indicados en el apartado anterior correspondientes al periodo de junio del 2006 a junio del 2016. Únicamente se consideraron reportes de investigación. Algunos de los indicadores usados, para orientar el análisis de las publicaciones, fueron el año de publicación, idioma, metodología utilizada, tipo de muestra, temática en la que se contextualizó la investigación, y la autoría y la filiación institucional de estos.

Para identificar los artículos con los que se trabajó, primero se realizó una búsqueda electrónica de artículos referentes a recursos semióticos o discurso del docente y matemáticas. No se recurrió sistemáticamente a ninguna base de datos sobre el tema, más bien a los índices de cada una de las cuatro revistas nombradas antes. Se acordó que la revisión de las revistas no la realizaría nunca uno solo de los autores, por separado dos de ellos realizaron la búsqueda de los artículos.

\section{Resultados}

En la Figura 1 se observa que en los primeros años del periodo analizado se concentra la productividad en el tema y que, a partir del 2014, al menos en estas revistas, el interés es nulo. Queremos mencionar que, no obstante, esta situación, en la revista Educación Matemática en el número 1 del año 2017 está publicado un artículo relacionado con el tema. Los autores son Carmen Samper y Plazas Tania, el trabajo tiene el título Tipos de mensajes del profesor durante la producción de una demostración en geometría.

En la Figura 2 se presenta el porcentaje de publicaciones, tomando en cuenta todas las consideradas en el estudio, por revista. En esta figura aparece abreviado el nombre de las revistas de la siguiente manera:

- Revista Latinoamericana de Investigación en Matemática Educativa (RELIME).

- Revista Educación Matemática (EM).

- ZDM, International Journal on Mathematics Education (ZDM).

- Educational Studies in Mathematics (ESM). 


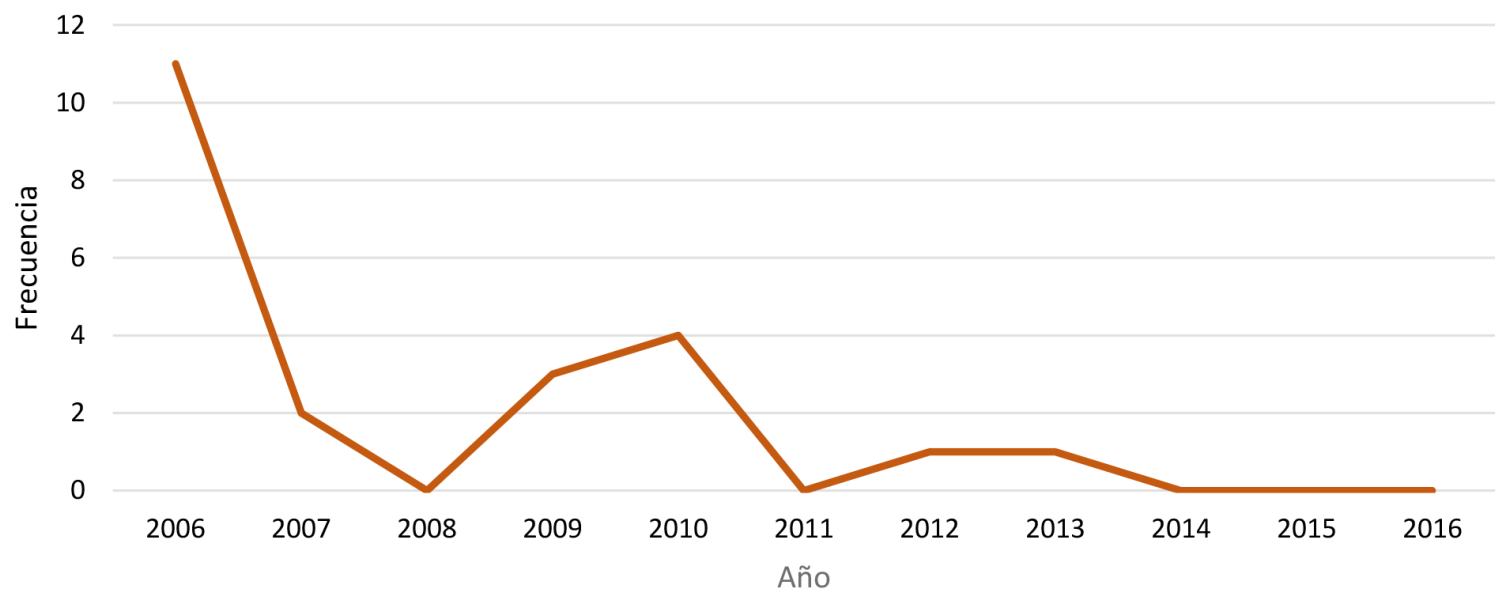

FIGURA 1. Evolución del número de artículos en todas las revistas, por año.

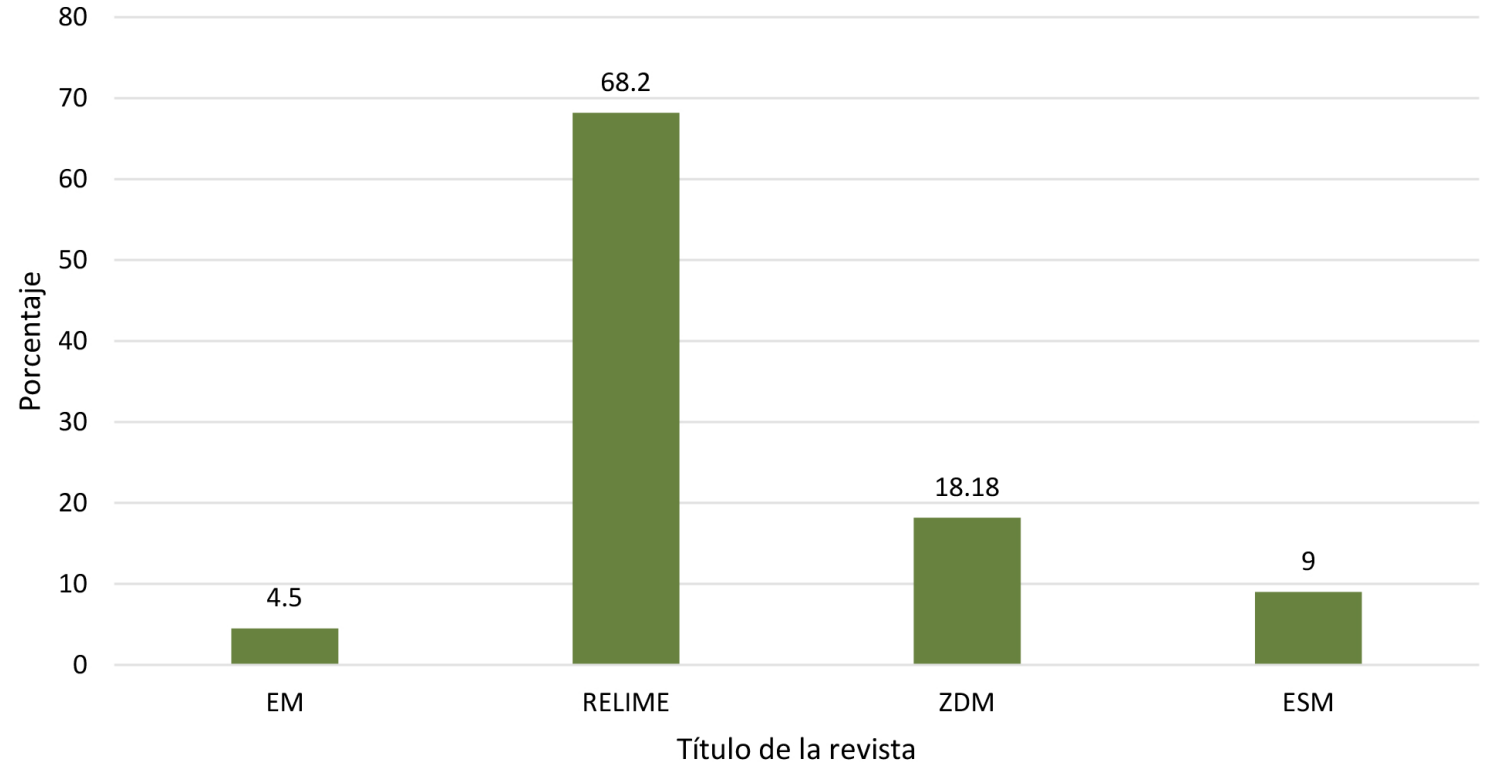

FIGURA 2. Porcentaje de publicaciones en cada revista en el lapso examinado.

En la Revista Latinoamericana de Investigación en Matemática Educativa se concentra el mayor número de trabajos publicados; no obstante, es interesante que en todas se han publicado estudios sobre el tema.

Otro indicador de este estudio bibliométrico fue el idioma en que se publicó el artículo revisado. En la Figura 3 se muestran los resultados obtenidos. Se observa que más de la mitad de los trabajos realizados fueron publicados en español.

Al analizar de los trabajos publicados encontrados en función de la filiación institucional de los autores se consideró más conveniente presentar los resultados obtenidos de acuerdo al país en el que se sitúa la institución educativa en que laboran los autores, en la Figura 4 se presentan los resultados obtenidos. 


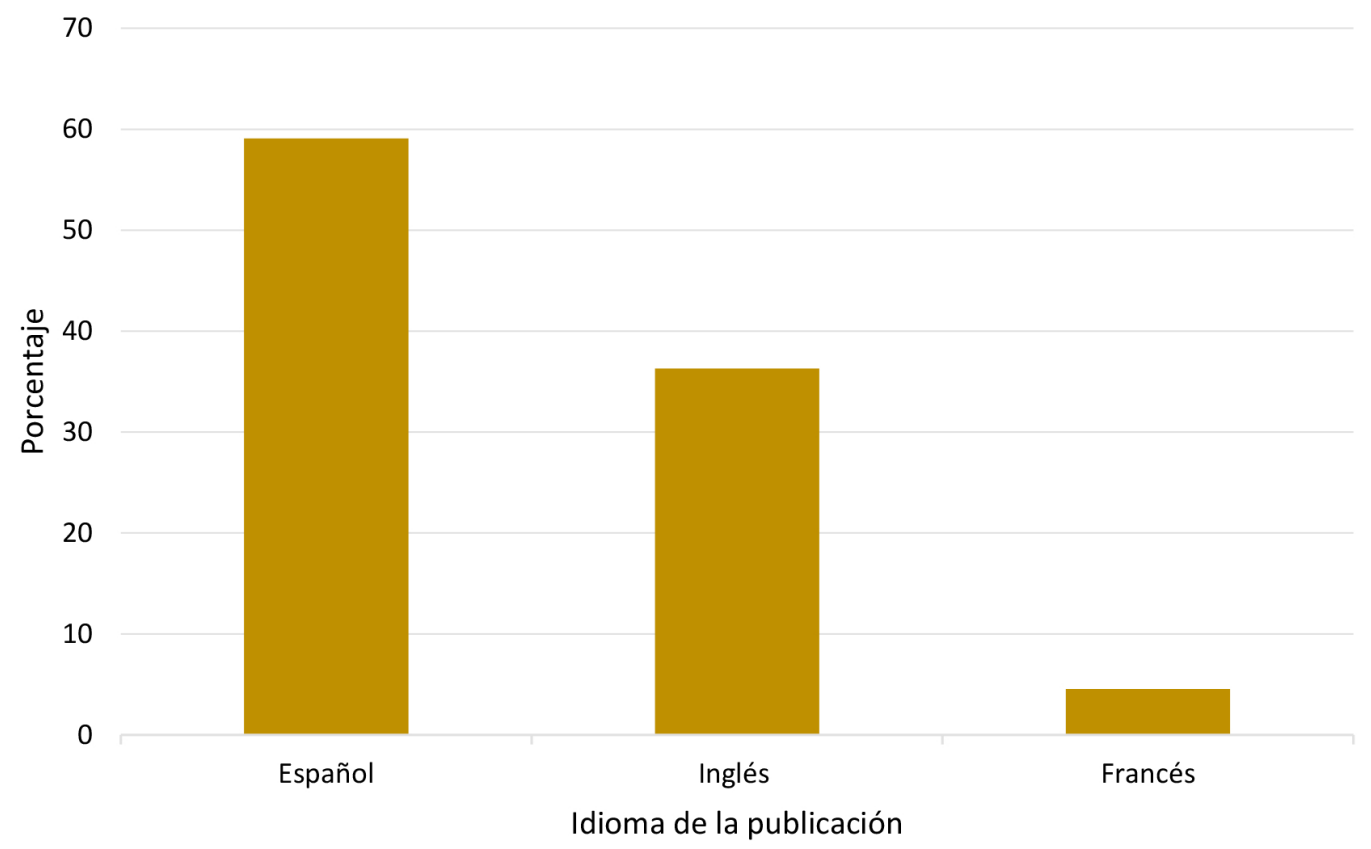

FIGURA 3. Distribución porcentual de las publicaciones por idioma.

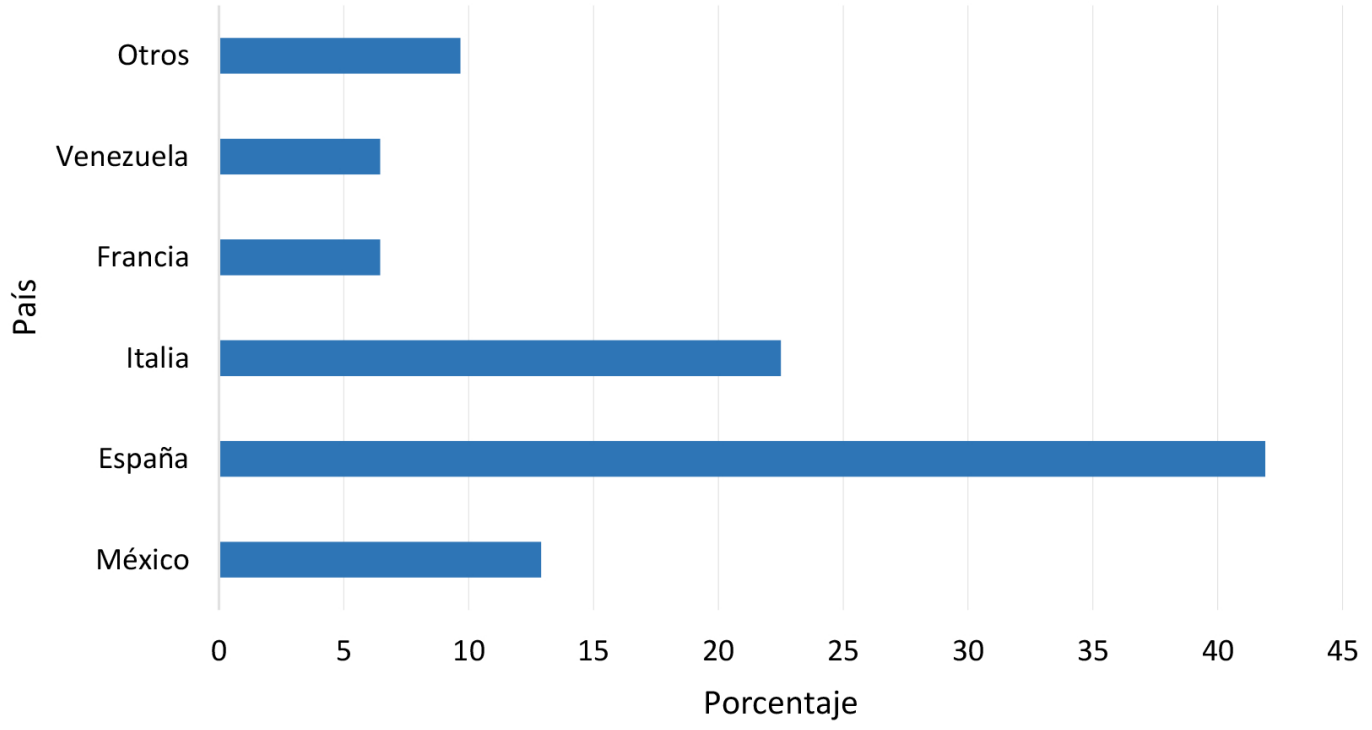

FIGURA 4. Distribución porcentual de publicaciones por el país de la adscripción institucional de los autores.

En la Figura 4 puede apreciarse que los educadores matemáticos españoles son los más productivos en el tema, en el periodo escogido para este trabajo, alcanzando casi el $50 \%$ de todos los trabajos revisados. En este caso se contabilizó el país de la institución donde laboraban los autores al momento de publicar su trabajo. Dado que en varias ocasiones se encontraron artículos con más de un autor, cada uno perteneciente a una institución diferente, se cuantificaron todos los países que podían figurar en el trabajo publicado. En la Figura 4, aparece una categoría denominada otros países, en ella estaban comprendidos Noruega, Sudáfrica y EUA. 
Se consideró también como criterio de análisis la metodología empleada en el estudio. Las categorías fueron método cualitativo, cuantitativo y mixto. En la Figura 5 aparecen los resultados obtenidos.

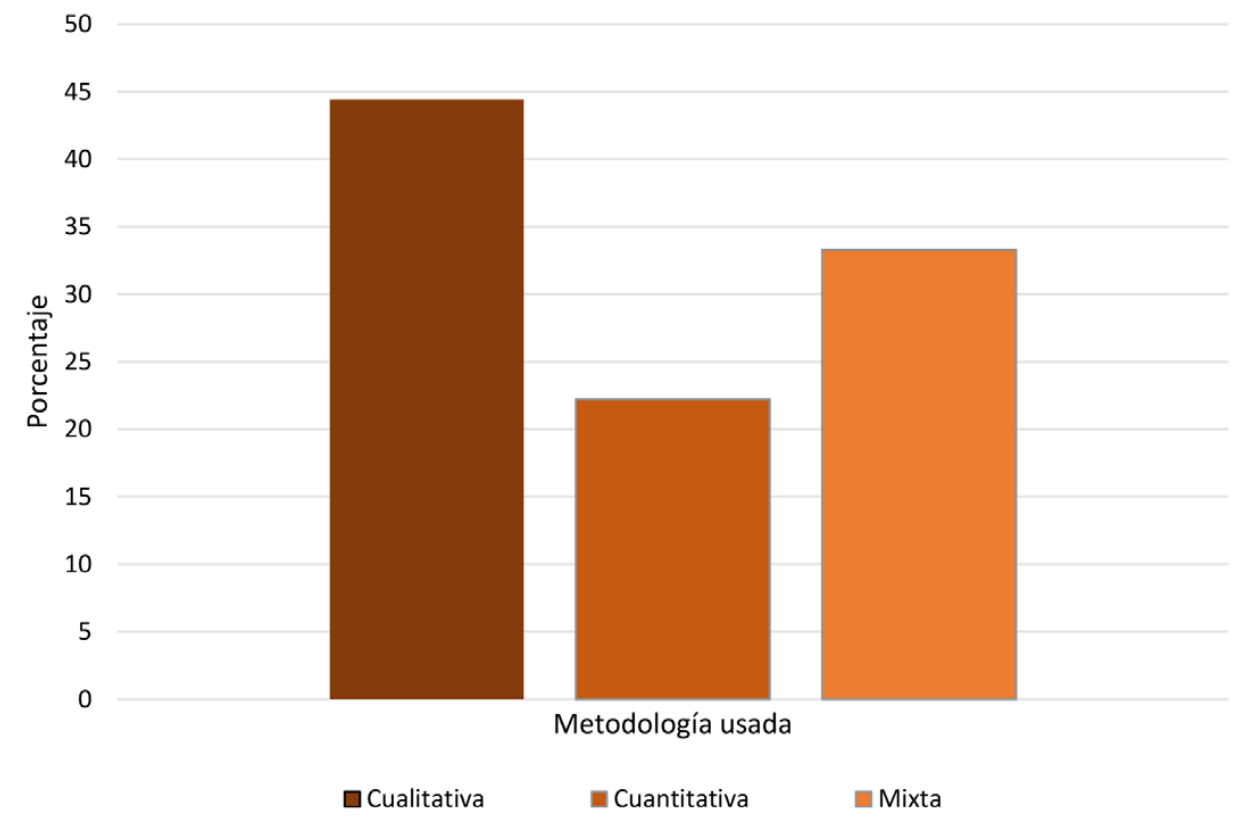

FIGURA 5. Distribución porcentual de trabajos realizados, según la metodología empleada.

En la Figura 6 se presentan los resultados al analizar los artículos por tipo de estudio: empírico o teórico.

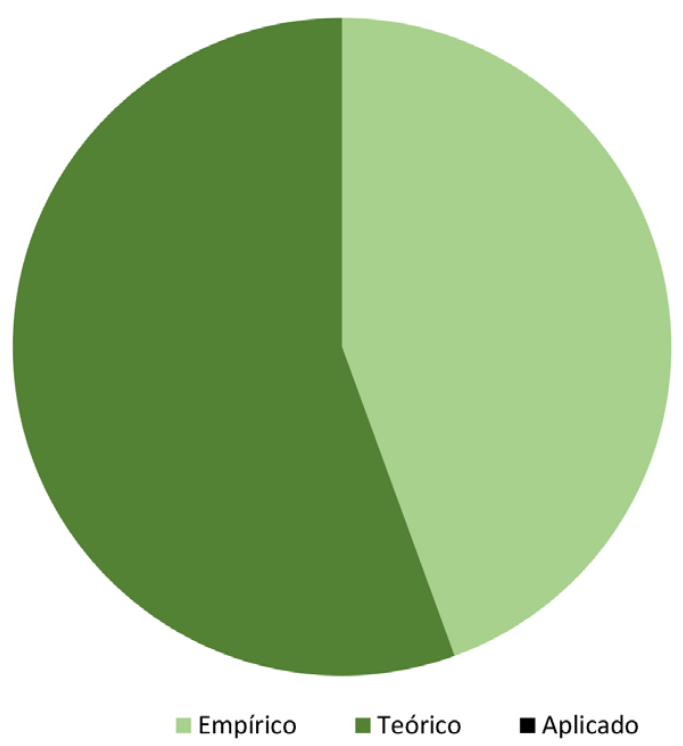

FIGURA 6. Distribución en porcentajes de los artículos analizados por tipo de trabajo.

La Figura 7 permite observar que es casi equitativa la frecuencia con la que se realizaron trabajos empíricos y teóricos. Lo que se encontró no indica que existe una brecha importante entre los trabajos teóricos o empíricos que se realizaron sobre los recursos semióticos en la enseñanza de las matemáticas. 
Cuando fue posible se examinó el nivel escolar de la población participante referida en los artículos revisados, recuérdese que un número considerable de estos estudios eran de naturaleza teórica. Predominó la población de nivel superior y luego del nivel básico.

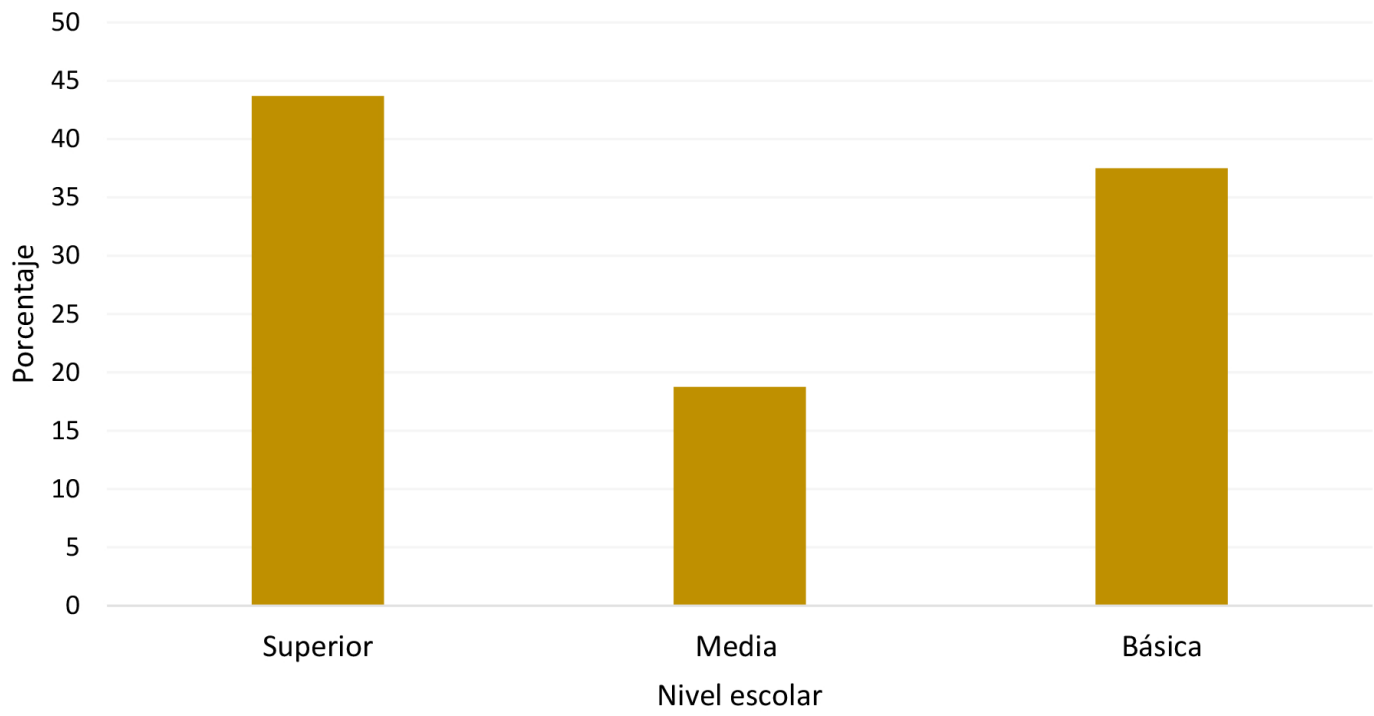

FIGURA 7. Distribución porcentual del nivel escolar de los participantes en los estudios analizados.

Por último, se indagó en la temática de matemáticas en la que se desarrollaron los estudios revisados. En la Tabla 1 se presentan los resultados obtenidos. Predomina el tema que hemos denominado Matemáticas en general ya que no se precisa un tema, simplemente se menciona matemáticas. Es interesante que se encontraron diversos temas, entre ellos geometría, estadística y aritmética.

TABLA 1. Porcentaje de temas matemáticos en que se sitúan las investigaciones revisadas.

\begin{tabular}{|c|l|c|}
\multicolumn{2}{|c|}{ TEMA } & PORCENTAJE \\
\hline 1 & Cálculo & 25 \\
\hline 2 & Matemáticas en general & 50 \\
\hline 3 & Aritmética & 5 \\
\hline 4 & Estadística & 5 \\
\hline 5 & Álgebra & 10 \\
\hline 6 & Geometría & 5 \\
\hline
\end{tabular}




\section{Discusión}

Se esperaba una situación muy diferente en cuanto a un mayor interés y atención actual, por parte de los especialistas en la enseñanza y el aprendizaje de las matemáticas, en el tema de los recursos semióticos. Los resultados observados en cierto modo son desalentadores tomando en cuenta la importancia de las herramientas semióticas para la enseñanza de las matemáticas como lo evidencian algunos de los estudios realizados en este contexto. Se observa también que en los años más recientes la investigación no se ha enfocado a seguir profundizando en el tema. Sin embargo, es posible que algunos estudios se estén reportando en otras revistas que no son las que escogimos para este trabajo. Este planteamiento, cuyo trasfondo es que el tema sigue vivo, lo hacemos con base en lo que mencionamos en otro apartado de este documento, respecto a que en el 2017 se publicó un artículo sobre el tipo de mensajes que envía el profesor de matemáticas a los alumnos a través de su discurso en el salón de clases. Nos parece interesante destacar que los investigadores matemáticos mexicanos también tuvieron presencia en la temática, si bien el grupo predominante lo conformó la comunidad española, seguida de la italiana. Como se dijo antes, este tipo de estudios son importantes porque aportan información que nos permite caracterizar y perfilar la evolución y la situación actual de una comunidad científica respecto a los temas que son objeto de su interés. Por ejemplo, pudimos constatar que los educadores matemáticos españoles fueron los más productivos en el estudio de los recursos semióticos y que podría considerarse que, por lo menos, durante varios años fueron líderes en el tema.

Dado el interés de los autores de este escrito en el tema se considera factible, en otro momento, ampliar el trabajo tratando de incorporar otras revistas para su análisis. Pero, esto también podría hacerse con otros temas de investigación, como los factores emocionales y afectivos en la enseñanza y el aprendizaje de las matemáticas o en áreas nuevas de estudio.

\section{Referencias}

IIII Ariza, T. y Quevedo-Blasco, R. (2013). Análisis bibliométrico de la Revista de Investigación Educativa (20002012). Revista de Investigación Educativa, 31 (1), 31-52.

IIII Blanco, B. Caballero, A., Blanco, L. J. (2010). Matemática y lenguaje a partir de la lectura de cuentos. Aula de Innovación Educativa, 189, 86-96.

IIII Córdova, J. J. P., Melo, G., Bacigalupo, F. y Manghi, D. (2016). Olas de significado en la interacción profesoralumno: análisis de dos clases de Ciencias Naturales de un 6to de Primaria. Ciência \& Educação (Bauru), 22 (2), 335-350.

IIII Hernando-Díaz, H. (2009). El lenguaje verbal como instrumento matemático. Educeduc, 12, 3, 13-31.

IIII Licea de Arenas, J. y Santillán-Rivero, E. G. (2002). Bibliometría ¿para qué? Biblioteca Universitaria, 5 (1), 3-10.

IIII Manghi, H. D. (2012). La perspectiva multimodal sobre la comunicación. Desafíos y aportes para la enseñanza en el aula. Revista Electrónica. Diálogos Educativos. 11 (22), 4-15.

IIII Manghi, H.D. (2013). Representación y comunicación del conocimiento en Educación Media: análisis multimodal del discurso de materiales utilizados para la enseñanza escolar de la historia y la biología. Onomázein, 27 
(junio): 35-52.

IIII Manghi, H. D. (s.f.). La mediación del profesor especialista para la alfabetización semiótica en el aula de matemática. En E. I. Moyano (Coordinadora). Aprender ciencias y humanidades: una cuestión de lectura y escritura. Aportes para la construcción de un programa de inclusión social a través de la educación lingüística (en prensa). Consultado en:https://brochagorda.files.wordpress.com/2008/07/5-dmanghi-mediacic3b3nemic3b3 tica-en-el-aula-de-matemc3a1tica-en-prensa.pdf

IIII Márquez, C. y Prat i Pla, À. (2005). Leer en ciencias. Enseñanza de las Ciencias, 23 (3), 431- 440.

IIII Ortiz de Haro, J. J., Batanero, B. C. y Serrano, L. (2001). El lenguaje probabilístico en los libros de texto. Suma, $38,5-13$

IIII Orton, A. (1990): Didáctica de las matemáticas, MEC y Morata, Madrid.

IIII Pimm, D. (1987): Speaking Mathematically, Routledge and Kegan Paul, New York.

IIII Pozzer-Ardenghi, L. y Wolf-Michael, R. (2005). Photographs in lectures: Gestures as meaning-making resources. Linguistics and Education, 15, 275-293.

IIII Torralbo, M., Fernández, C. A., Rico, L., Maz, A. y Gutiérrez, M. del P. (2003). Tesis doctorales españolas en educación matemática. Enseñanza de las Ciencias, 21 (2), 295-305.

IIII Veel, R. (1997). Learning how to mean- scientifically speaking: apprenticeship into scientific discourse in the secondary school. In: F. Christie y J. Martin (Eds.). Genre and institutions: social processes in the workplace and school. London: Painter, Pp. 160-194.

IIII Zapata, C. L. (2011). ¿Cómo contribuir a la alfabetización estadística? Revista Virtual Universidad Católica del Norte, 33, (mayo-agosto de 2011). 


\section{CAPÍTULO 3 \\ Matemática, lenguaje y cognición}

José Sánchez Barrera

L

I lenguaje es una función del cerebro, que se expresa por medio de movimientos espaciales como en las abejas

o ademanes, como en los humanos sordomudos y algunos primates de laboratorio, o con sonidos, como los humanos y algunos primates en ambiente natural. La complejidad del lenguaje depende de la complejidad del sistema nervioso; así que se observa las formas más complejas del lenguaje en el Homo sapiens sapiens, y a partir de éste, en progresión descendente de la escala filogenética, la complejidad correspondiente hasta los niveles en que ya no hay lenguaje, aunque sí se mantenga un intercambio de información hormonal o simplemente química.

El lenguaje es un sistema de comunicación, cuya complejidad está en correspondencia con el sistema nervioso; como aquél es una función (como los latidos del corazón, la respiración, la locomoción, y otros), cuando el individuo nace, si es completamente sano, nace con ella. $Y$ no hay que caer en confusiones, no hay genes de las funciones; hay genes de las estructuras, y éstas llevan a cabo funciones. No hay un gen del lenguaje, y no es que el lenguaje sea heredado, que sea innato; si es función, ésta existe, si existen las estructuras correspondientes. Pero aprovechemos los ejemplos arriba citados, no se hereda los latidos del corazón, se hereda el corazón y éste late, se hereda un conjunto de estructuras anatómicas que reciben el nombre de sistema respiratorio, y ocurre la respiración; los genes determinan todas estas estructuras y ellas llevan a cabo sus funciones.

El lenguaje es una función del sistema nervioso que se realiza en el idioma, es decir, que socialmente se presenta en forma de idioma. Las funciones no se aprenden, son inherentes a la estructura correspondiente; pero sí se puede aprender a optimizar la función. Se puede aprender a respirar mejor; la biorretroalimentación (en inglés: biofeedback) permite entrenar a sujetos para que controlen su frecuencia cardiaca; y tal optimización se logra con varias de las funciones del organismo. Los idiomas son optimización pragmática del lenguaje. Es decir, el Homo sapiens apareció en la tierra con la función del lenguaje, como con todas las demás funciones; y cuando se encontraron dos individuos de esta especie y permanecieron juntos apareció el idioma, que es la manifestación pragmática del lenguaje.

Un idioma, para el caso del Homo sapiens, es un sistema de comunicación sígnico. Un signo se define como cualquier entidad que por asociación sustituye a otra cualquiera entidad. Por eso, un conjunto de sonidos, como la expresión 'silla' es el signo de un mueble en que nos sentamos; y el mueble puede ser el signo del conjunto de sonidos 'silla'. Esta circunstancia -y el hecho de que haya miles de formas diferentes de decir silla atinente a los miles de idiomas que existen en la tierra- señala la característica de arbitrariedad del signo. Y es que cada palabra o afijo de cualquier idioma es, en primera instancia, signo de cualquier rasgo de la gramática de aquél. Tales rasgos son las raíces o desinencias verbales, que señalan persona, número, tiempos y modos; las desinencias que marcan el caso en los nombres comunes, en los idiomas que -como el ruso- tienen declinación nominal en singular y plural; las preposiciones, etcétera. 
Todos los idiomas tienen términos para nombrar cosas (se llaman sustantivos); términos para nombrar procesos (se llaman verbos); términos para calificar a los sustantivos (se llaman adjetivos); términos para calificar a los verbos y los adjetivos (se llaman adverbios); términos para unir a todos los anteriores y construir una frase bien formada, según las reglas gramaticales de cada idioma (se llaman funtivos). Pues bien, los rasgos de que se habla en el párrafo anterior son los sustantivos, los verbos, los adjetivos, los adverbios y los funtivos; los idiomas, entonces, son conjuntos de signos de estas cinco clases de constituyentes lingüísticos. Una última aclaración, posiblemente necesaria, acerca de este tópico, mientras que los primeros cuatro conjuntos de constituyentes lingüísticos tienen un carácter fundamentalmente positivo, el último -el de los funtivos- puede ser positivo como en el caso de las preposiciones y las desinencias de la conjugación y declinación nominal; pero también puede ser solamente relacional, sin ninguna marca fónica.

Hasta aquí queda claro lo que es un idioma, pero hace falta agregar otra característica, la cual consiste en que los idiomas están constituidos de variantes regionales a las que llamamos dialectos. En México -cuando menos- esta palabra no es manejada correctamente; si pedimos a cualquier persona en las calles o universidades de la Ciudad de México, sin tomar en cuenta su nivel académico, que nos dé un ejemplo de 'dialecto', la respuesta común es la de citar alguna lengua mexicana como zapoteco, mixteco, nahuatl, otomí. Y aún escuché a un animador de televisión calificar de dialectos las lenguas de África. A los mismos individuos de las calles o universidades de México, si les pedimos nos digan ejemplos de idiomas, la respuesta común son lenguas europeas como el italiano, alemán, francés. Pero dejemos esa condición traumática para nosotros que se origina en los programas deficientes de la Secretaría de Educación Pública del gobierno de México (en adelante, SEP) y remachemos el dato técnico: los dialectos son variantes regionales de los idiomas, de tal manera que un idioma está compuesto por sus variantes regionales (dialectos); y en ese sentido el idioma es un constructo, no existe de manera real, lo que existe son los dialectos. Y es que todo mundo cuando habla, habla en algún dialecto, jno hay de otra!, porque tiene que -irremisiblemente- hablar en alguna variante regional. Sólo eso existe: variantes regionales (dialectos). Y TODOS los idiomas están constituidos por dialectos. Enseguida, un diagrama del idioma y los dialectos:

\begin{tabular}{|c|c|c|c|}
\hline$a$ & $b$ & $c$ & $d$ \\
\hline$e$ & $f$ & $g$ & $h$ \\
\hline$i$ & $j$ & $k$ & l \\
\hline$m$ & $n$ & $\tilde{n}$ & $o$ \\
\hline
\end{tabular}

El idioma está aquí representado por el rectángulo, que se compone de 'o' dialectos y todos tienen el mismo derecho de considerarse el idioma.

Son necesarias algunas palabras de política lingüística. No obstante, el dato de la ilustración de que todos los dialectos tienen el mismo derecho de considerarse el idioma, en el México actual, los profesores de la SEP enseñan a los niños de los pueblos que hablar su variante regional es hablar mal, y hablar bien es usar el dialecto del altiplano central de México, es decir aquél en que están escritos los periódicos, los discursos del presidente. Si alguien dice: “¿Ontá Pedru?”. Y otra contesta: “Quiaque se jué”. A ambos se les corrige, y se les informa que deben decir, respectivamente: “¿Dónde está Pedro?” Y "Hace mucho que se fue”. Y se les recomienda que hablen bien, que no hablen como gente de rancho. Este punto nos lleva al criterio de corrección y más allá. Nos lleva a un punto en que se trasciende las regiones, pero que es análogo en una situación global: la idea -naturalmente errónea y racista- de que existen lenguas inferiores y lenguas superiores; o primitivas y evolucionadas. 
Efectivamente, hay estudiosos que creen que existen lenguas superiores y lenguas primitivas. Guillermo de Humboldt plantea en su "Escritos sobre el lenguaje” (Humboldt, W. von. 1991): “.... Las excelencias y defectos de una lengua .... (Humboldt, 1991, p. 68)"; "Y cuando alguien que ha obtenido su formación en otras lenguas estudia una lengua cualquiera menos perfecta y la domina, ese alguien puede producir mediante ella un efecto que en sí y por sí a ella le resulta ajeno .... (Humboldt, 1991, p. 69)". Se echa de ver que para Humboldt sí hay lenguas superiores y lenguas inferiores y que -por citar a un congénere del hermano del explorador llamado Alejandro- el europeo que logre expresiones primorosas en alguna lengua americana, logra tal cosa porque es europeo, no porque la lengua permita tales primores. Otro ejemplo de este punto de vista: “.... la lengua de algunos pueblos que están en un nivel bajo de desarrollo cultural es difícil de entender sin el significado de la situación en la que se pronuncian las palabras dadas. Así es imposible entender de qué habla esta gente en la oscuridad, cuando no se pueden ver la situación ni los gestos, porque solamente del conocimiento de la situación y de la entonación toma la palabra su significado determinado. Hechos análogos en cierta medida tienen lugar en situaciones difíciles cuando al lenguaje debe agregarse el gesto, que hace la comunicación más comprensible" (A. R. Luria, 1984, p. 31). El entrecomillado es extraído de una de las obras de un gran pensador soviético ${ }^{1}$, exitoso en el campo de las neurociencias, fundador de la neuropsicología, y totalmente humano. No podía ser más que un personaje de su tiempo; así que creía que había lenguas superiores y lenguas primitivas. Pero no puedo dejar pasar esta cita bibliográfica así nada más, sin declarar que Alexander Románovich Luria es uno de mis maestros de siempre, aunque sea sólo a través de la lectura de sus libros, con todo y sus defectos en la apreciación de las culturas. Como sea, esta confusión se origina en la idea de que existen culturas primitivas y culturas desarrolladas; y que aquéllas hablan lenguas primitivas y éstas, lenguas desarrolladas. Esta confusión tiene lo suyo de racista, pues lleva a creer que existen culturas mejores que otras; una creencia de ese tipo no nos conviene, y a ella no me afilio. Pero sí me uno a la corriente de pensamiento que sostiene que las culturas son perfectas en el ámbito histórico y espacial en que ocurren.

Respecto de los idiomas, éstos son coexistentes y coefectivos con las culturas de que forman parte. Los idiomas son perfectos en el ámbito cultural en que actúan y cambian a la par que la cultura con la cual coexisten. Pero si los sacamos de su ámbito cultural dejan de ser perfectos; y por tanto, tienen muchas fallas. Eso le pasó al castellano cuando los europeos recién llegados a (la posteriormente llamada) América quisieron hablar de las cosas que veían, y le llamaron "pera de las Indias" al ahuakał (aguacate, en castellano moderno; y nótese que la 't' sustituye a la 'tl', y la ' $k$ ' a la 'c' del alfabeto de la SEP, según el Sistema de Escritura Un Fonema Un Signo); "chumbera" al nohpalkuahuit (nopal) e "higo chumbo" a la tuna ${ }^{2}$ o tenocti, por ejemplo (donde la 'c' vale por 'ch'). Pero no sólo los cambios de lugar ponen en apuros a las lenguas, también los cambios de época: el castellano tuvo que inventar las palabras "semáforo", "cromosoma”, "teléfono", "teléfono celular", "célula”, "psicología”, "biología”, "mecatrónica"; asimilar "software", "hardware", "chatear", "accesar" (aunque ya existieran quincalla, cotorrear y acceder, respectivamente), "cursor", un término correctamente latino, que -sin importar su origen, junto con los anteriores cuatro- nos llegan del inglés porque el castellano actual es profundamente anglofílico.

No. No existen lenguas superiores y lenguas inferiores, ni culturas superiores y culturas inferiores; solamente existen lenguas y culturas, a secas. Y no hay que confundir poder bélico con calidad cultural o lingüística -introduzco esta idea porque resulta que los países que poseen más armas son aquéllos de los cuales se dice que hablan idiomas-; las armas no hacen excelsas a las culturas, sólo las hacen agresivas o cínicas, como la yanqui de nuestros días.

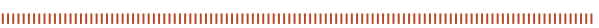

1 La alusión es correcta: me refiero sí a la época en que aún existía la URSS.

2 La palabra 'tuna' es préstamo taíno. 
Veamos, por ahora el último ejemplo acerca de este tópico. En el periódico español "El mundo"3 apareció el 7 de mayo de 2007 un artículo de Íñigo García en el que se refiere que el pueblo pirahã del Amazonas, que vive en la ribera del río Maici habla el idioma más simple y extraño de alrededor de 6000 hablados actualmente en el mundo. El idioma de los pirahã no tiene números, pronombres, colores, tiempos verbales ni oraciones subordinadas, y cuenta con sólo ocho consonantes y tres vocales. El autor nunca dice que ésta sea una lengua primitiva y falta confirmar los datos que el explorador presenta, teniendo en mente que existen muchas estrategias para expresar esas categorías; pero para A. S. Diamond (1974, p. 70), éste sí sería un excelente ejemplo de primitivismo en el lenguaje. Dice este autor que "el andamanés ${ }^{4}$ [tiene] frases breves, coloquiales e imperfectas [debido a] la ausencia de conjunciones y de subordinación entre una oración y otra" (Diamond, p. 71). Y para él "el yahgan es quizá el más primitivo de todos los pueblos" (Diamond, p. 126). Faltaban décadas para que fueran conocidos los pirahã, de quienes hay que esperar más datos porque lo presentado por García en su artículo de El Mundo, no está libre de sospechas. Pero aun confirmándose tales datos, si el idioma permite a ese pueblo mantenerse unido en comunicación, entonces el pirahã es una lengua bien desarrollada. Además, hace falta un estudio comparativo, pues lenguas que no están en duda como el chino no tiene desinencias para marcar los tiempos verbales ni tiene verbos irregulares y el nahuatl tiene solamente trece consonantes. Faltan pues estudios materialistas y no prejuiciados acerca de lenguas como el pirahã.

Un punto importante que se debe comentar aquí es el de la diversidad lingüística. Es decir, ¿Y de dónde surgieron tantos idiomas? En el entendido que el idioma es la realización del lenguaje; es decir, el lenguaje es una función que sólo puede expresarse en el idioma que es aprendido; y existen, en nuestro planeta, cuando menos 6000 formas de hacerse perceptible esa función. He aquí una respuesta de necesidad: Todas las gentes de la tierra pertenecen a una sola especie (Homo sapiens sapiens), que se originó sólo una vez, en África; y a partir de allí pobló todo el planeta. A esta condición la podemos llamar 'el principio de sólo una vez' y a partir de él plantear que todos los idiomas del mundo surgieron por derivación de una lengua prístina; que al separarse las poblaciones fueron configurándose formas grupales de expresión, mismas que con el tiempo y la distancia adquirieron rasgos tan particulares que llegaron a ser ininteligibles de población a población. Y las lenguas que así aparecieron dieron lugar a familias lingüísticas, éstas cambiaron y dieron origen a otras familias, y aquéllas a otras y las otras a otras; y quedó la diversidad que ahora existe en el mundo. Pero todas las lenguas, cada vez que aparecieron ya fueron desde su primer momento completas, correctas y perfectas; no aparecieron inmaduras y se fueron desarrollando, no son las lenguas como cría de humano, que nace, madura y perece. La alegoría de la sociedad humana tampoco se aplica. No hay lenguas primitivas y lenguas superiores, todas son perfectas en el tiempo y lugar de su uso. Si a una lengua le cambiamos cualquiera de los dos, parecería defectuosa en su nuevo ambiente. Y un pensador etnocéntrico o racista diría que esa lengua es primitiva, sea la que fuere de todas las actuales lenguas del mundo.

Otro punto interesante es si sólo el Homo sapiens sapiens tiene lenguaje, y en todo caso, ¿cuál es el rasgo distintivo del lenguaje humano? En efecto, si aceptamos que existe una escala filogenética, de la cual el nivel más alto lo ocupa nuestra especie, entonces los animales de los niveles más bajos comparten nuestros rasgos en la complejidad que el nivel que ocupan les permite. Ello significa que, en escala descendente, puesto que el cerebro es retrospectivamente complejo, las posibilidades cognoscitivas de las especies infrahumanas son atinentemente retrospectivas en complejidad. Así podemos observar formas de comunicación gradualmente menos complejas conforme descendemos en la escala filogenética, hasta que, en hablando de lenguaje, éste desaparezca por completo y sólo queden formas bioquímicas de intercambio de información.

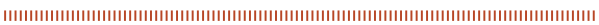

3 Página electrónica: www.elmundo.es/2007/05/07/ciencia

4 Lengua hablada en las islas Andamán, situadas entre el Golfo de Bengala y el Mar de Andamán, en el océano Índico. 
Para aclarar estos conceptos es preciso primero hablar de los constituyentes mínimos del lenguaje, aunque para algunos sean lugar común; y es que será más sencilla la comunicación si estandarizamos el conocimiento. Estos constituyentes mínimos son los fonemas y los morfemas. El fonema es la unidad del lenguaje porque son los sonidos de que se construye las palabras, pero éste es una abstracción, realmente el fonema nunca ocurre. Lo que en verdad ocurre es el fone, el cual se simboliza, técnicamente hablando, encerrándolo en paréntesis angulares, por ejemplo [b]; y los fonemas son encerrados por dos líneas diagonales, por ejemplo /b/. Aquí se echa de ver que los fones y fonemas corresponden a las letras con que se escribe los idiomas; y como siempre que se habla de estos elementos se hace referencia al fonema, así lo habré de hacer aquí en adelante, a menos que se requiera de alguna especificación particular. Así que, para ya no darle más vueltas al asunto, hay que decir que el fonema es la unidad mínima, sin significado, del lenguaje; y, como éstos son representados por las letras, los sistemas alfabéticos dan alguna idea de la cantidad de fonemas que tienen los idiomas. Sólo una idea, porque los sistemas de escritura tienen gran cantidad de excepciones y redundancias -incluso la escritura china y la maya, que no son alfabéticas-; también hay que mencionar aquí el caso de la escritura coreana, que parece que solamente tiene una excepción, y mi sistema de escritura un fonema un signo (S1f-1s), diseñado para mi curso de nahuatl (Sánchez B., J. en prensa), que -definitivamente sólo tiene una excepción-. Más adelante volveré al tema de la escritura.

Quedan muchas cosas por decir acerca de los fonemas, pero aquí ya sólo quiero señalar dos, a saber: existen fones de variación libre y de distribución complementaria. Cuando una persona habla y repite la misma palabra en diferentes circunstancias, por ejemplo, 'bueno', el fonema /b/ puede en cada caso sonar ligeramente diferente; el sonido de cada ejemplo producido es el fone [b]. Pero, para la persona que escucha, esas diferencias no son importantes, en realidad él está escuchando el mismo fonema; estos fones son llamados de variación libre. Hay fones que no tienen variación libre, su pronunciación es obligada por el contexto fonético, y se llaman de distribución complementaria; permítaseme citar un ejemplo del inglés. Los sonidos K en las palabras 'key' y 'ski', son diferentes uno del otro; el primero es un sonido aspirado (que se produce con un soplo que se puede sentir en el dorso de la mano), mientras que el segundo normalmente no se aspira; a éstas dos variedades del fonema se les llama alófonos de /k/ (Bourne, Lyle E., et al., 1976, p. 377).

Otra estructura necesaria de conocer para comprender el lenguaje es el morfema, que es la unidad mínima con significado. Aclaremos, y ésta es una repetición pertinente, el fonema es la unidad mínima del lenguaje, pero que no tiene significado; el morfema es la unidad mínima del lenguaje con significado. De éstos últimos existen dos tipos: los morfemas libres y los morfemas enlace. Al conjunto de los primeros corresponde la palabra 'silla', que toda ella es un morfema; al conjunto de los segundos corresponde la palabra 'sillas', que está compuesta de dos morfemas; \{silla\}, que se refiere a un mueble donde la gente -comúnmente hablando- se sienta y \{s\} que señala que se trata de más de un mueble de ese tipo. Un ejemplo más: la palabra 'gatitos' se compone de cuatro morfemas. Veamos, \{gat-\}, que hace alusión a un cierto animal; \{-it-\}, que indica que el animal es pequeño; $\{-0-\}$, que indica que es macho; $\{-\mathrm{s}\}$, que indica que son más de uno.

Volvamos ahora a la pregunta planteada arriba sobre ¿cuál es el rasgo distintivo del lenguaje humano?

La doble articulación es el rasgo distintivo del lenguaje humano; éste es un concepto propuesto por A. Martinet (cf Ducrot y Todorov, 1980, p. 69). La primera articulación queda constituida por la sintaxis, o sea, la manera como se combinan los morfemas para formar frases; la segunda articulación tiene qué ver con la morfología y se realiza a través de la fonología, es decir, la manera como se combinan los fonemas para formar morfemas. 
No importe de qué estén formados los fonemas y los morfemas. Estas unidades -en especies de éste o de cualquier otro planeta-, que pueden estar constituidas por olores, sabores, colores o campos eléctricos o cromodinámicos, si existen, entonces la especie que las posea tiene doble articulación y un lenguaje tan complejo como el del Homo sapiens. El hombre tiene dos formas materiales de lenguaje: por sonidos y por movimientos; éste último que es el caso del lenguaje de los sordomudos, donde la unidad mínima sin significado se llama cinema y la unidad mínima con significado, cinomorfema (Birdwhistell, 1952). En ningún otro animal -por lo pronto de este planeta- existe la doble articulación; lo que ocurre en los gorilas y chimpancés es una suerte de palabras holofrásticas; incluso en el caso de Sarah, el chimpancé hembra del estudio de Premack, A. J. \& Premack, D. (1972), las figuras geométricas que representaron en ese estudio a las palabras eran figuras totales: una figura para 'dar', una para 'chocolate', una para 'Sarah', etcétera. No había doble articulación.

Veamos, aunque sea, algunos conceptos acerca de escritura porque ésta es la manera de representación como producto permanente del lenguaje y la cognición. Existen varios tipos de sistemas de escritura, pero todos se reducen básicamente a tres categorías, a saber: logográfica, silábica, alfabética. Un logograma es un signo escrito que representa un morfema, aunque en ocasiones (pero de escasa frecuencia) puede representar a una palabra completa; los sistemas logográficos consisten de una mezcla de logogramas y signos fonéticos. Ejemplos extranjeros de este tipo de escritura son la sumeria, la egipcia y la china. Los signos de ésta última están, normalmente, formados por dos partes; una de las cuales es el radical, que sirve para agrupar temáticamente el logograma, la otra sirve para indicar ya el significado, ya el sonido o ambos. En los caracteres: 扰 (răo) acosar, causar problemas; 折 (shé) romper, reventar; 擂 (lèi) golpear un tambor, el componente de la izquierda 'f' es el radical, que se deriva de 手 (shǒu) mano. El componente de la derecha, en el primer caso '龙' (lóng) y en el tercero “雷' (léi) significan, respectivamente, 'dragón' y 'trueno', considerados de manera independiente; pero, ¿acaso no se nota la comunidad de significado entre 'causar problemas' y 'dragón', por un lado, y entre 'golpear un tambor' y 'trueno', por el otro? Otro conjunto de logogramas está agrupado por el radical 'i', a saber, 话 (hùa) palabra, 语 (yǔ) idioma, 诗 (shī) poesía, entre muchas más palabras; y existen 214 radicales, lo cual significa que existen 214 conjuntos de signos logográficos en que queda clasificada toda la escritura china, que consiste de unos 50000 signos, de los cuales el dominio de 5000 permite realizar las lecturas necesarias de los estudios universitarios, pero con el conocimiento de unos 2000 se está en posibilidad de leer el periódico 5 .

Los otros dos sistemas de escritura son más fáciles de describir, pues el silábico usa signos que representan sílabas como el katakana japonés y el cheroqui de Sequoyah; y el alfabético es el sistema con el cual está escrita esta página. Veamos ilustraciones de los dos ejemplos silábicos:

El katakana 6 .

\begin{tabular}{|c|c|c|c|c|c|c|c|c|c|c|c|}
\hline & & $\mathrm{K}$ & $\mathrm{S}$ & $\mathrm{T}$ & $\mathrm{N}$ & $\mathrm{H}$ & $\mathrm{M}$ & $\mathrm{Y}$ & $\mathrm{R}$ & $\mathrm{W}$ & $\mathrm{N}$ \\
\hline $\mathrm{A}$ & ア & カ & サ & タ & ナ & ハ & マ & ヤ & ラ & ワ & ン1 \\
\hline I & イ & キ & ッ2 & チ3 & ニ & ヒ & ミ & キ & リ & & \\
\hline $\mathrm{U}$ & ウ & ク & ス & ッ & ヌ & フ & ム & ユ & ル & & \\
\hline $\mathrm{E}$ & エ & ケ & セ & テ & ネ & ヘ & メ & & レ & & \\
\hline $\mathrm{O}$ & オ & コ & ソ & ト & ノ & ホ & モ & ヨ & ロ & フ4 & \\
\hline
\end{tabular}

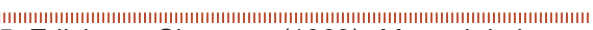

5 Ediciones Shangwu (1963), Manual de lengua china moderna, pp. 21-28.

6 Akira Aoki (1988), Vamos a estudiar japonés, p. 11. 
La tabla es clara, se ve que, si se quiere escribir un sonido vocálico solo, se usa cualquier signo de la segunda columna; y para las sílabas, se busca el cruce correspondiente entre consonante y vocal de nuestro sistema de escritura. Por ejemplo, para escribir 'no', busco el sitio donde se cruzan la columna 'n' y el renglón 'o', donde se encuentra el signo: ‘ノ’, que se lee 'no'. Otros ejemplos: メキッコ (mekishiko) México, ポルトガル (porutogaru) Portugal, ロッァ (roshia) Rusia. En los ejemplos aparecen signos con marcas particulares (ポ, ガ); no hay que sorprenderse por ello, pues en el mismo sitio en que aparecen se anota su pronunciación.

El japonés usa otros dos sistemas de escritura, al mismo tiempo: el hiragana y los logogramas chinos; pero para ejemplo, con lo revisado hasta aquí, basta.

El cheroqui de Sequoyah.

\begin{tabular}{|c|c|c|c|c|c|c|c|c|}
\hline $\mathrm{D}_{\mathrm{a}}$ & & $\mathbf{R}_{e}$ & & $\mathbf{T}_{\mathrm{i}}$ & & $\sigma_{0}$ & $0_{u}$ & $\mathbf{i}_{\mathrm{v}}$ \\
\hline $\mathbf{s}_{\mathrm{ga}}$ & $\partial_{\mathrm{ka}}$ & $\mathbf{r}_{\mathrm{ge}}$ & & $\mathbf{y}_{\mathrm{gi}}$ & & $\mathbf{A}_{\mathrm{go}}$ & $\mathbf{J}_{\mathrm{gu}}$ & $\mathbf{E}_{\mathrm{gv}}$ \\
\hline$\Phi_{\text {ha }}$ & & $\mathbf{P}_{\text {he }}$ & & $\boldsymbol{\theta}_{\mathrm{hi}}$ & & $\mathbf{F}$ ho & $\mathbf{\Gamma}_{\mathrm{hu}}$ & $\theta_{\mathrm{hv}}$ \\
\hline $\mathbf{W}_{\mathrm{la}}$ & & $\boldsymbol{\delta}_{\mathrm{le}}$ & & $\mathbf{P}_{\mathrm{li}}$ & & $\mathbf{G}_{10}$ & $\mathbf{M}_{\mathrm{lu}}$ & $\mathbf{9}_{\mathrm{IV}}$ \\
\hline$\sigma_{\mathrm{ma}}$ & & $\mathbf{a}_{\mathrm{me}}$ & & $\mathbf{H}_{\mathrm{mi}}$ & & $\mathbf{5}_{\mathrm{mo}}$ & $\mathbf{y}_{\mathrm{mu}}$ & \\
\hline $\boldsymbol{\theta}_{\mathrm{na}}$ & $\mathbf{U}_{\text {hna }}$ & $\boldsymbol{\Lambda}_{\mathrm{ne}}$ & & $\mathbf{h}_{\mathrm{ni}}$ & & $\mathbf{Z}_{\mathrm{no}}$ & $\mathbf{q}_{\mathrm{nu}}$ & $\mathbf{O}_{n v}$ \\
\hline $\mathbf{T}_{\text {qua }}$ & & $\omega_{\text {que }}$ & & $\gamma_{\text {qui }}$ & & $w_{\text {quo }}$ & $\iota_{\text {quu }}$ & $\boldsymbol{E}_{\text {quv }}$ \\
\hline $\mathbf{H}_{\mathrm{sa}}$ & $0 \boldsymbol{D}_{\mathrm{s}}$ & $\mathbf{1}_{\mathrm{se}}$ & & $\mathbf{b}_{\mathrm{si}}$ & & $\boldsymbol{\Psi}_{\mathrm{so}}$ & 8 su & $\mathbf{R}_{\mathrm{sv}}$ \\
\hline $\mathbf{I}_{\mathrm{da}}$ & $\mathbf{W}_{\mathrm{ta}}$ & $\mathbf{S}_{\mathrm{de}}$ & $\mathbf{G}_{\text {te }}$ & $\mathbf{I}_{\mathrm{di}}$ & $\mathbf{J}_{\mathrm{ti}}$ & $\mathbf{V}_{\text {do }}$ & $\mathbf{S}_{\mathrm{du}}$ & $\sigma^{p}{ }_{d v}$ \\
\hline$\delta_{\text {dla }}$ & $\boldsymbol{L}_{\text {tla }}$ & $\mathbf{L}_{\text {tle }}$ & & $\mathbf{C}_{\text {tli }}$ & & $\boldsymbol{J}_{\text {tlo }}$ & $\boldsymbol{\gamma}_{\text {tlu }}$ & $\mathbf{P}_{\text {tlv }}$ \\
\hline $\mathbf{G}_{\text {tsa }}$ & & $\mathbf{V}_{\text {tse }}$ & & $\mathbf{I} \mathrm{tsi}$ & & $\mathbf{K}_{\text {tso }}$ & $\mathrm{d}_{\mathrm{tsu}}$ & $\mathbf{C}_{\text {tsv }}$ \\
\hline $\mathbf{C}_{\text {wa }}$ & & $\mathscr{Q}_{\text {we }}$ & & $\boldsymbol{O}_{\mathrm{wi}}$ & & $\mathfrak{O}_{\text {wo }}$ & $\vartheta_{\mathrm{wu}}$ & $6_{w v}$ \\
\hline $\boldsymbol{\omega}_{\text {ya }}$ & & $\boldsymbol{\beta}_{\mathrm{ye}}$ & & $\boldsymbol{\delta}_{\mathrm{yi}}$ & & $\mathbf{f}_{\text {yo }}$ & $\mathbf{G}_{\mathrm{yu}}$ & $\mathbf{B}_{\mathrm{yv}}$ \\
\hline
\end{tabular}

Este sistema de escritura fue inventado hacia 1820 por el indio cheroqui Sequoyah, conocido también como George Guess. El cuadro, inspirado en la escritura románica, es muy claro; los signos representan todas las sílabas posibles del idioma, así que, para escribir una palabra, simplemente se seleccionan los signos correspondientes a las sílabas de que esté formada ésta y se colocan uno detrás de otro en la misma línea, de manera horizontal.

Queda claro que no hace falta ejemplificar el sistema alfabético, pues cada renglón de este trabajo es un buen ejemplo de él.

La escritura en México tiene una antigüedad de miles de años. Es seguro que todos los pueblos que gozaron de alguna porción de civilización conocieron la escritura logográfica, pero es común citar a los que sobresalieron en 
aquellos tiempos, es decir, a los nahuas, los zapotecas, los mixtecos y los mayas; siendo éstos últimos aquéllos cuya escritura alcanzó los mayores logros, pues con la escritura maya se puede escribir lo mismo, en cualesquiera de las lenguas mayas, que se escribe en árabe, latín, chino o griego. Para el caso de Mesoamérica, los signos de la escritura se llaman glifos y los sistemas se llaman 'escritura glífica'. Ejemplos de tales sistemas son:

है

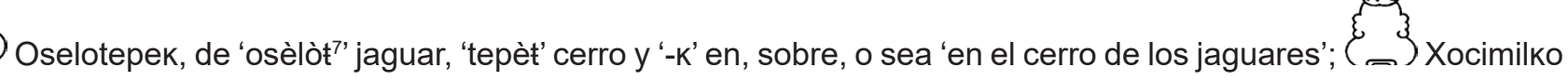

de 'xòcit' flor, 'milli' sembradío y '-ко' en, sobre, de donde 'en el sembradío de flores'; كalli' casa; tahtoà

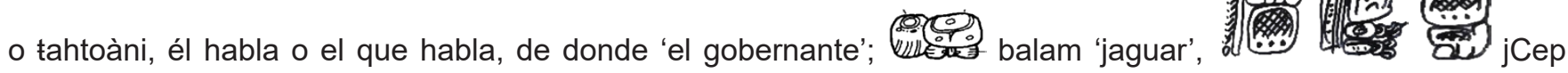
Santis Pakh 'José Sánchez Barrera' dos ejemplos en nahuatl y dos en maya, respectivamente; donde se nota el carácter silábico de éste último sistema de escritura. En la tercera sección revisaremos el sistema numérico, que también forma parte de la escritura.

En esta sección ya sólo quiero comentar una curiosidad histórica, pero de preeminente significado. F. Engels, en "El origen de la familia, la propiedad privada y el estado", siguiendo a Morgan divide el desarrollo de la sociedad en tres etapas: salvajismo, barbarie, civilización; y cada una de éstas tres en estadio inferior, medio y superior. A partir de este criterio considera que los pueblos de América, en las fechas de la invasión española, se encontraban en el estadio medio de la barbarie (1968, p. 22), de la cual salieron gracias a los españoles. Y el requisito para él fundamental del paso a la civilización es la invención de la escritura (Engels, F. 1968, p. 23). Bueno, arriba ya mostré modelos de escritura existentes en Mesoamérica cientos de años antes de la invasión española; y también hay que decir que, de éstos, el más completo es el sistema maya con el que se puede escribir una página como ésta, una prueba de ello es mi nombre, en ortografía maya (cf p. 12).

¿Cuál es la implicación aquí para una teoría de la historia? Que los pueblos en Mesoamérica no se encontraban en la barbarie, sino en una civilización diferente a la cristiana que los invasores no tuvieron capacidad para comprender, pero que, en realidad, ni siquiera intentaron porque esa invasión tuvo como objetivo primordial el robo descarado a mano armada de los bienes de los pueblos de América. Cosa que cumplieron a cabalidad; y los pobladores una vez derrotados fueron tratados como reses. El modelo de desarrollo de la sociedad que Engels preconiza en su "El origen de la familia, la propiedad privada y el Estado" tiene una visión parcial, no podría ser de otra manera: es eurocéntrico.

Antes de pasar a otra sección, hay que aclarar un punto, que en realidad es una llamada de atención al lector ingenuo, con las debidas disculpas del caso. En la época que le tocó vivir a Engels no se sabía que los mayas hubieran desarrollado una escritura cabal con la que se pudiera escribir un texto como éste que aquí estoy presentando; a él le tocó interpretar el mundo con los datos que en su tiempo existían (perogrullada necesaria), e hizo mucho. $Y$ no conocer la escritura maya -que en ese tiempo nadie la conocía- no le quita méritos a su pensamiento de filósofo social.

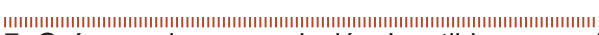

7 Guía para la pronunciación. Las tildes, que sólo aparecen en la lista del vocabulario, sobre las vocales de las palabras nahuas indican que tal vocal se pronuncia con una duración mayor que la no tildada. La ce (c), del nahuatl y el tzotzil se pronuncia como la che (ch) del castellano; la equis (x) como 'sh' del inglés; la ' $ł$ ' es algo parecida a 'tl'; la doble ele del nahuatl se pronuncia como dos eles juntas; la 'kh' es glotalizada. 
Cognición es un término genérico para referirse a los procesos simbólicos, es decir, los que se llevan a cabo mediante el lenguaje tales como pensamiento, memoria, percepción, solución de problemas, etcétera; éstos también se pueden llamar procesos cognoscitivos. $Y$ éstos a su vez existen en dos modalidades, a saber: conscientes y automáticos. De los primeros, como su nombre lo indica, el sujeto tiene conocimiento y los controla voluntariamente; los segundos no son voluntarios y tienen lugar cuando deben suceder en la actividad del individuo, independientemente del control consciente de éste. En algunos casos, como en el hablar, la decisión de echar a andar el proceso es consciente, pero su desarrollo es automático, nadie va pensando -al hablar- si la palabra siguiente está bien enlazada con la anterior. Como en los procesos simbólicos el lenguaje tiene un papel preponderante, enseguida revisaremos como se expresan lingüísticamente aquéllos; tal cosa significa que en esta sección se repetirá alguna parte de los conceptos revisados en la anterior, pero ello redundará en una visión más profunda de tales tópicos.

Conocer es saber. Se sabe algo o se sabe que se sabe. Y siendo el caso que, al menos un autor (Vygotsky, 1996, p. 58), plantea que hay situaciones extremas de pensamiento sin lenguaje -en la fase prelingüística del desarrollo del pensamiento-, se hace preciso destacar que la cognición se realiza, de manera regular, mediante el concurso de aquél. Pero el lenguaje, en calidad de segundo sistema de señales (Le Ny, J. F., 1971, p. 160) es antes que nada signo o símbolo. No hablo aquí de categorías gramaticales: éstas que acabo de mencionar son categorías semióticas. Y de este razonamiento parto para llamar simbólicos a los procesos que tienen qué ver, o versan, de alguna manera, sobre la cognición; de los cuales el pensamiento y el lenguaje son dos ejemplos preeminentes, siendo el segundo la parte audible del primero. Revisémoslos de manera conjunta.

Todo proceso cognoscitivo es, en un sentido u otro, proceso lingüístico, debido a que el lenguaje es la parte pública de la mente. Veamos primero una definición de los términos de los cuales nos habremos de ocupar aquí. Por pensamiento podemos entender, de acuerdo con Bourne et alia (1976, p. 17): "Pensamiento es un proceso complejo con múltiples facetas; esencialmente interno [....] que implica representaciones simbólicas, eventos y objetos no presentes en la realidad inmediata, pero iniciado por algún evento externo"; y apoyándonos en Ruhlen, M. (1994, p. 31), podemos entender el lenguaje como: “.... a rule-governed system, definable in terms of a grammar which separates grammatical from ungrammatical sentences, assigning a pronunciation and a meaning to each gramatical sentence"8. De estas dos definiciones conviene resaltar el carácter sistémico del lenguaje por el hecho de que la cognición se realiza a través de éste, razón por la cual podemos también suponer un carácter sistémico para aquélla. En cuanto al pensamiento, toda vez que éste implica procesamiento de información de alguna manera (y no existe ninguna razón para creer que éste sea, necesariamente, el procesamiento de información simple de las computadoras), pero que es inseparable del lenguaje podemos - por esa razón- con confianza atribuirle también un carácter sistémico.

Se piensa con conceptos y se habla con signos y símbolos. Ahora bien, aunque arriba ya se definió el concepto de signo, recordémoslo aquí de nuevo, veamos algunos ejemplos y pasemos al concepto de símbolo. Un signo, ya vimos que se puede definir como, cualquier entidad que, por asociación, puede sustituir a otra cualquiera entidad; su característica sobresaliente es que es arbitrario. Por ejemplo, el conjunto gráfico 'nakasti' puede sustituir al conjunto fónico [nakásLi]; y éste, a la figura '马’', que, a su vez, sustituye a la parte humana correspondiente; lo asignando una pronunciación y un significado a las oraciones gramaticalmente correctas" [Traducción mía]. 


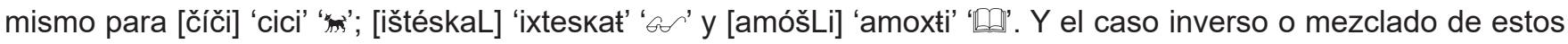
ejemplos también es válido, pues [číči] puede ser sustituido por 'cici' o por 's', dependiendo de las circunstancias o intereses del hablante. Igual para los demás ejemplos. Y, desde luego, aquí no estamos comenzando de cero en el uso de estos signos porque estoy dando por supuesta ya una sustitución, pues he estado usando los signos

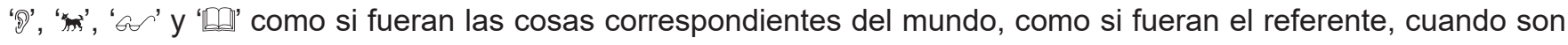
también una representación como cualquiera otra de aquéllas. Como esta convención es necesaria en el texto para discurrir sobre estos temas, me seguiré ateniendo a ella en la esperanza de que cumpla una función esclarecedora. Sigamos, pues, haciendo como si ' $G \alpha$ ', por ejemplo, no fuera una representación de unos lentes, sino fueran los lentes mismos. Pero un punto importante todavía por mencionar es que esas cosas del mundo, como las representadas por ' $G \sigma$ ', '乌', etc. también pueden ser signo de las cuatro figuras diez renglones arriba mostradas. Por último, en esta sección, y sólo por no dejarlo de lado, quiero explicitar el hecho de que la relación entre las entidades puede no ser de uno a uno; por ejemplo, el uso del conjunto fónico [palóma] para $y^{\natural} \checkmark$.

Un detalle importante sobre el signo es que éste es una entidad que, independientemente de los problemas teóricos que su definición suscita, cumple dos requisitos básicos, a saber: "1) puede hacerse sensible y 2) para un grupo definido de usuarios señala una ausencia en sí misma" (Ducrot, O y Todorov, Tz., 1980, p. 122). La expresión "puede hacerse sensible" se fundamenta en el hecho de que existan signos no conocidos por los individuos externos a la comunidad lingüística sujeta a estudio en algún momento particular. En esos casos no es sensible, pero pude hacerse sensible cuando es estudiado y comprendido. Un ejemplo espectacular de este punto es el caso de la escritura maya, que llegó a hacerse sensible sólo después de que Viktor Knorosov estableciera las bases para su desciframiento (Coe, Michael D., 1995, pp. 157-180). Saussure (1979, p. 129) llama significante a la parte del signo que puede hacerse sensible; significado a la parte ausente, y significación a la relación que surge entre ambas. Y de mi parte agrego que no existen significantes sin significado, tales cosas serían simplemente objetos, sonidos al ser carentes de la relación de significación; y como tampoco existen significados sin significante queda claro que la relación entre ambos es de índole necesaria. La relación de significación es necesaria porque no pueden existir significantes sin significado, y viceversa. Pero antes de establecerse esta relación, aquello que habrá de ser significante de algún significado no tiene -y las onomatopeyas también son convencionales- ninguna relación con éste: el conjunto gráfico swahili kisu no evoca ninguna idea relacionada con cortar, aunque su significado sea "cuchillo". En la mente del lector no versado en la lengua de Tanzania kisu no provocaba ningún significado antes del renglón anterior, es decir, kisu no era signo de nada. No era signo; punto. Ahora existe una relación de significación entre un significante (kisu) y un significado (cuchillo); y tal relación es necesaria en el sentido de esta imposibilidad de que existan significados sin significante. Esta característica es muy útil a la hora de hablar de lenguaje, porque un conjunto fónico que no tiene significado no es palabra, aunque exista como manifestación electromagnética en el ambiente.

El símbolo goza casi de las mismas características que el signo; su diferencia con éste es que aquél es motivado, y la motivación se establece mediante los procesos de asociación por parecido y contigüidad. La palabra "fuego" significa 'fuego', pero simboliza 'pasión' en una relación no necesaria entre el simbolizante (fuego) y el simbolizado (pasión). No necesaria porque en este caso sí pueden existir de manera independiente el simbolizante y el símbolo. Ello es así porque, en lo atinente al signo -como ya se dijo en el párrafo anterior-, entre el significante y el significado no existe ninguna relación de inicio, ambos son de naturaleza diferente. Pero en el símbolo sí existe una cierta homogeneidad entre simbolizante y simbolizado: no sucede (no es posible que suceda) que alguien diga "el hielo de mi pasión", porque la pasión se entiende como fuego, como llama, como calor. Pero 'calor', 'llama', 
'fuego' y 'pasión' tienen, de por sí, sus propios valores semánticos, la asociación que aquí comento surge de la cercanía (en espacio o tiempo) o semejanza entre estos términos, lo que da el carácter de motivada a la relación de simbolización.

Existe otro concepto que es generalmente asociado con signo y símbolo, incluso en los libros de semiótica, pero es de un carácter diferente, se trata del concepto de síntoma. A éste también lo considero necesario de mencionar con el fin de hacer consciente su presencia, pero no me es imprescindible, por lo pronto, para el esquema que estoy aquí pergeñando. El signo implica una relación arbitraria con un referente; el símbolo, una relación motivada, también con un referente. Pero el síntoma no plantea ninguna relación, sino una inclusión, pues aquél es, en realidad, una parte del referente. El humo no tiene una relación ni arbitraria ni motivada con la combustión; aquél es parte de ésta, como la temperatura es la parte sensible de la infección en los animales. Se ve, pues, que la diferencia básica entre estas tres categorías (signo, símbolo y síntoma) es que los dos primeros combinan entidades, pero el último tiene una manera de ser diferente porque éste no combina nada; es tan sólo una parte de una cierta entidad. El humo es al fuego como la hoja al árbol. Y si digo que el síntoma no es imprescindible en este ensayo es porque la comunicación se lleva a cabo mediante signos y símbolos, y quizá básicamente con los primeros.

Por otro lado, sin intentar una tipificación de los signos, sí conviene poner en claro que el signo lingüístico tiene como característica sobresaliente el hecho de que sea sistémico. Es decir, tiene una cierta articulación, que consiste de la forma en que se conectan los signos entre sí en la frase. Ello es el resultado de la aplicación de las reglas de combinación de las palabras, que forman el conjunto que se conoce como gramática, y que se imbrica a la visión de mundo de los hablantes.

En tratando del signo lingüístico uno no puede evitar el pensar en lo que son las palabras y los conceptos y la relación existente entre ambos. Además, si hemos de discurrir sobre el papel de la gramática en la vida del hombre o cualquier animal que tenga lenguaje, sí se hace necesario lidiar con estos dos términos. Y con esa intención, comienzo la tarea de definirlos resaltando el hecho de que uno pertenece al orden de lo objetivo ${ }^{9}$ (la palabra); y el otro, al de lo subjetivo (el concepto). Ambos forman parte de un continuum inquebrantable. El tratamiento inicial de cada uno de estos dos extremos por separado es conveniente porque su definición no está exenta de dificultades técnicas, que nos pueden complicar la tarea si no somos conscientes de ellas. Así que antes de revisar una definición general de 'palabra', veamos cómo se entiende ésta en el seno de la lengua castellana, en donde dice Manuel Ortuño Martínez, que se trata de un:

"Elemento lingüístico, formado por uno o varios morfemas, dotado de acento, capaz de formar por sí solo un enunciado, perfectamente delimitable desde el punto de vista fónico y cuya transcripción gráfica en castellano no admite la menor indeterminación: constituye una unidad limitada por espacios vacíos" (1999, p. 137).

Se echa de ver, por los detalles de esta definición, que la categoría de palabra tiene muchos vericuetos técnicos y no es, por lo tanto, fácil de asir. Como quiera que sea, aquí queda bien delimitada, como tarea inicial, la 'palabra' de la lengua oriunda de Castilla; pero como yo estoy discurriendo sobre el lenguaje no sobre las lenguas, aplicaré mejor la definición operacional de 'palabra' como las entradas del diccionario, sin dejar de advertir a quien esto leyere el hecho de que la unidad de pensamiento no es la palabra, sino la frase. Pasemos a otra cosa.

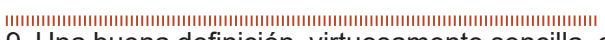

9 Una buena definición, virtuosamente sencilla, de estos términos es aquélla en la que se entiende -matices aparte- lo subjetivo como privado y lo objetivo como público. 
El diccionario de la Real Academia de la Lengua Española proporciona varias acepciones para concepto, pero a mí sólo dos de ellas me parecen útiles para mi cometido. Helas aquí: "concepto, ta (del latín conceptus) 2. m. Idea que concibe o forma el entendimiento. 3. Pensamiento expresado en palabras" (Real Academia Española, 2001, p. 414). Bourne et alia definen el concepto como "cualquier regularidad de eventos u objetos, reales o imaginarios, que se pueda describir" (Bourne jr, L. E. et alia, 1976, p. 221); y un viejo libro de la autoría de Roberto Alatorre Padilla lo define como "la representación de un objeto en el plano del pensamiento, sin afirmar o negar" (1980, p. 140). Este autor presenta también varias clasificaciones de conceptos, pero eso ya no viene al caso. No vale la pena consultar más fuentes; todas van a destacar el hecho de que el aspecto fundamental del concepto es que éste es una generalización que se forma en la mente del individuo pensante ${ }^{10}$ en función de los rasgos preeminentes del objeto. Por ello, el concepto pertenece al orden de lo cognoscitivo; el concepto es idea. Aunque por el hecho de que existan los términos 'concepto' y 'palabra', y por las dificultades de la definición de la segunda, se puedan enunciar ambos términos por separado, en la realidad humana son inseparables. No existen palabras sin sentido, como en el pionero estudio de Ebbinghaus: ¡si no tiene sentido no es palabra! Estoy seguro que se podrá entender mejor esta relación entre concepto y palabra con el expediente que, para entendernos mejor, a partir de ahora llamaré el principio del hombre invisible. En el relato de H. G. Wells el hombre invisible sólo puede ser visto cuando se pone la ropa, pero en sentido estricto nunca se puede ver el hombre invisible, lo que se ve es la ropa que adquiere una cierta tensión, volumen, acción. La ropa, cuando no se la ha puesto el hombre invisible no tiene tensión, volumen ni nada; está por allí, botada o alzada en el ropero, puede estar planchada o arrugada, pero no tiene volumen ni actividad. Así son las palabras y los conceptos. Es decir, que para mejor entender hay que entender la palabra como un conjunto compuesto de un elemento fónico y un elemento cognoscitivo. El elemento fónico sin el cognoscitivo es como la ropa del hombre invisible. En este caso, es un ruido cualquiera; es un sonido sin ningún valor o sentido. El elemento cognoscitivo sin el fónico es idea que no se ve o no se escucha; es como el hombre invisible sin ropa. Ahora viene al caso la aclaración de que, si bien siempre que hablamos de lenguaje ejemplificamos con la forma fónica de éste, ello se debe a que es la más común en nuestro ambiente. Pero todo lo dicho hasta ahora y lo que se diga en adelante, también se aplica al lenguaje de señas de los sordomudos, y a cualquier otro lenguaje que cumpla el requisito de la doble articulación ${ }^{11}$ de Martinet, sin importar la característica material de éste. Es decir, el lenguaje se puede formar de sonidos, señas, colores o sabores, lo que importa es que la materia de que esté hecho se organice en dos articulaciones (morfema y fonema) y en dos niveles (significado y significante).

Volviendo al punto, resulta pues que las díadas palabra-concepto y lenguaje-pensamiento son un todo en sí mismas, donde la parte audible o visible es síntoma de la otra parte. En este caso se trata de la realización de un correlato necesario entre la parte objetiva y la parte subjetiva de un mismo acontecimiento.

\section{Cognición y Gramática}

Los procesos cognoscitivos no pueden sino expresarse a través de las gramáticas de las lenguas, por eso es imprescindible pasar revista a la díada gramática y cognición. Primero recordemos el meollo de cualquier idioma.

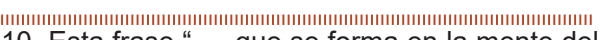

10 Esta frase “.... que se forma en la mente del individuo pensante” se ha vuelto problemática por el uso que del concepto 'mente' hacen los pensadores metafísicos; pero, por lo pronto, podemos entender la mente como proceso cognoscitivo, o entender la mente como la cognición misma no como cosa o sitio de ningún tipo, y con ello dejar de lado la visión cristiana de la mente como análogo de alma. Hace falta mucho trabajo para poner en su lugar toda esta terminología antigua.

11 Repasemos: a) Primera articulación. Las frases resultan de la articulación de los morfemas. B) Segunda articulación. Los morfemas resultan de la articulación de los fonemas. 
Ya vimos que todas las lenguas de este planeta están formadas, en última instancia, por cinco categorías gramaticales primigenias, a saber: 1) términos para nombrar cosas; 2) términos para nombrar procesos; 3) términos para calificar cosas: 4) términos para calificar procesos; 5 ) términos para relacionar a todos los anteriores entre sí. Los primeros se llaman sustantivos, los segundos, verbos; los que siguen, adjetivos; los otros, adverbios; y los últimos, funtivos. Podrían reducirse a tres: la uno y la dos constituirían la de nombrar; la tres y la cuatro, la de calificar; y la cinco, la de relacionar. Pero conviene conservar las cinco categorías porque ello facilita el análisis de la lengua y el pensamiento. Nombrar, calificar y relacionar son las funciones básicas de cualquier idioma. Más adelante nos será muy útil este dato; por lo pronto, revisemos con algún detalle estas cinco categorías e identifiquemos los rasgos que las caracterizan, al menos aquéllos que son útiles para mi análisis. Si a las palabras del castellano les quitamos desinencias y afijos y dejamos los puros radicales, que en la gramática tradicional francesa se llaman semantemas y los alemanes llaman Bedeutungslaute, nos quedan separadas las cinco categorías de marras. Los semantemas o radicales forman las primeras cuatro categorías, quedando los funtivos representados por desinencias y afijos en algunas lenguas, y por éstos y relaciones sintácticas o espaciales, en el texto escrito, en otras lenguas. Desde luego, esas relaciones espaciales vienen de las originales relaciones temporales del habla. Pero también son funtivos 'haber', 'estar', 'ser', 'hoy', 'nunca', 'aquí, 'y', 'pero', 'mas', preposiciones y conjunciones, los pronombres, etc. Como ya antes dije, son funtivos todos los términos que sirven para relacionar a las categorías numeradas del 1 al 4 (cf. Hockett, 1976, p. 267).

Veamos los siguientes ejemplos: a) Prœdam militibus donat; b) Militibus prœdam donat; c) Donat prœdam militibus. Cualquiera de las tres formas tiene el mismo significado Regala el botín a los soldados porque las características de la lengua latina permiten esos cambios, las relaciones entre los elementos de la frase se rigen por la declinación del nombre, y el cambio de lugar no afecta al valor de las desinencias de la palabra. Pero en a) 我爱你 (wǒàinǐ); b) 你爱我 (ňàiwǒ); c) 爱你我 (àinǐwǒ), no da el mismo resultado, porque, de acuerdo a las características del chino, el orden también es funtivo. Así que a significa te amo; b, me amas, y c no tiene sentido. En este ejemplo, el resultado es diferente que en el anterior, porque aquí el valor de los términos depende del lugar que ocupan en la frase no de las desinencias, como es el caso en latín.

Resumiendo, hay idiomas en los que cada una de estas categorías tiene una estructura particular, como en castellano que los verbos terminan en desinencias que indican persona, número, tiempo y modo. Los nombres tienen singular, plural y algunos de los seis géneros, etc. Pero también hay idiomas, como el chino, que usa mucho del orden para marcar las relaciones. Desde luego, no son éstas dos las únicas posibilidades, existe una gama de ellas en las familias lingüísticas conocidas.

La forma de las cinco categorías y la manera de relacionarse las primeras cuatro dan como resultado los idiomas del mundo, que dicen los estudiosos ser como 6000, organizados en alrededor de 26 grandes familias. De hecho, para cumplir mi objetivo bastaría que existieran sólo dos idiomas, lo que permitiría un contraste, que por mínimo que fuera, sería suficiente.

La comparación es necesaria porque los idiomas son como ciudades: todas están compuestas de calles, plazas, jardines, parques, edificios de gobierno y religiosos. Conocer una ciudad significa saber hacia dónde van las calles, dónde están las plazas, etc.; conocer un idioma significa saber cómo se conectan las estructuras, qué partícula interactúa con qué raíz, etc. La forma de las ciudades refleja la historia del pueblo que las habita y determina las interacciones de los individuos en ellas; en la calle uno sólo puede moverse en la dirección que esté orientada ésta, aunque tenga la opción de cambiar de calle. De igual manera, la estructura de las lenguas determina la visión de 
mundo del que habla y troquela su cognición. La lengua categoriza y da orden a los objetos del mundo. Veamos algunos ejemplos sencillos, en relación al nombre común o sustantivo.

El castellano tiene seis géneros, a saber, epiceno, ambiguo, común, masculino, femenino y neutro. Son de género epiceno los nombres de animales en los que una misma terminación y artículo designa al macho y a la hembra, por ejemplo la tortuga. El género ambiguo se aplica a sustantivos que pueden llevar atributos masculinos o femeninos indistintamente, por ejemplo, el calor, la calor. El común es el ambiguo de los sustantivos de personas, por ejemplo, el testigo, la testigo. El masculino se refiere al sexo de los machos o nombres que llevan el artículo 'el'. El femenino se refiere al sexo de las hembras o nombres que lleven el artículo 'la'. Pertenecen al género neutro los sustantivos que llevan el artículo 'lo'. El nombre de los verbos es masculino, pero el verbo no indica el género del nombre.

Debido al discurso político y al feminismo de nuestros días, cuando se habla de género parece que éste se originara en el sexo del animal del cual se hable, pero la definición técnica sólo indica que los "géneros son clases de sustantivos que se reflejan en el comportamiento de palabras asociadas, [cuya] clasificación debe ser exhaustiva y admitir muy pocas intersecciones [....], cada sustantivo debe pertenecer a una de las clases y muy pocos pueden pertenecer a más de una" (Hockett, 1976, p. 235). En castellano el género se establece de acuerdo a la concordancia con el artículo determinativo, que en los animales es marcador de sexo. Pero el swahili12 no usa artículo determinativo y el género se establece a partir de la manera como se percibe que es el objeto. El nombre de cosas inanimadas se marca con el prefijo 'ki-', en singular, que cambia a 'vi-', en plural (kitabu, libro; vitabu, libros). Los siguientes son otros marcadores genéricos, pero no anoto todos, que son ocho. Además, siguiendo a Perrott (1978) no los llamo géneros, sino clases, ya que esto no contradice la definición:

\begin{tabular}{|c|c|c|c|c|}
\hline clase & singular & Plural & ejemplo & traducción \\
\hline planta & $\mathrm{m}-$ & $\mathrm{mi}-$ & $\mathrm{mti} / \mathrm{miti}$ & árbol / árboles \\
\hline persona & $\mathrm{m}-$ & wa- & $\mathrm{mtu} /$ watu & hombre / hombres \\
\hline miscelánea & - & $\mathrm{ma}-$ & jambo/mambo & cosa / cosas \\
\hline
\end{tabular}

Las etiquetas de la columna 'clase' no son exactas según la perspectiva del castellano. En general tienen más amplitud categorial de lo aquí anotado, pero justamente esta aparente imprecisión es el rasgo explicativo que me interesa ${ }^{13}$. Los prefijos organizan en clases al nombre común, y el swahili considera, por ejemplo, los nombres siguientes como pertenecientes a una misma clase: 'mwaka', año; 'mwili', cuerpo; 'muhindi', caña de maíz; 'muwa', caña de azúcar; 'moto', fuego; 'mundu', daga (aparte de los ya mencionados). Se ve que la mejor manera de nombrar las clases no es a partir de etiquetas en castellano, sino de los prefijos swahili, que clasifican al sustantivo de acuerdo a criterios no claros para el fuereño: 'Shauri', 'shamba', 'jibu', 'yai', 'ua' -plan, sembradío, respuesta, huevo, flor, respectivamente- pertenecen a la clase que aquí llamo 'miscelánea'. ¿Qué tienen de común? Para el occidental quizá nada, pero hay que buscar la respuesta en la perspectiva de mundo del pueblo swahili.

Otros idiomas como el tzotzil14 utilizan clasificadores al numerar clases; '-phej'15 sirve para contar cosas redondas, casas, flores, etc. ('vakphej na', seis casas); '-voh', para contar personas ('canvoh zeb', cuatro muchachas), etc. Es

12 Lengua bantú del oriente de África, actualmente lengua oficial de la República de Tanzania. cf. D. V. Perrott (1978).

13 Por ejemplo, en la clase 'planta' o sea la de los prefijos 'm- mi-' también se incluye 'mji / miji', pueblo; 'mkono / mikono', brazo, mano; etcétera. 14 Lengua maya de los Altos de Chiapas (cf. Haviland, 1981).

15 La hache $(\mathrm{h})$ detrás de la consonante indica que ésta es glotalizada, y detrás de cualquier vocal representa al cierre glotal o saltillo /?/. La ce (c) se lee como /č/, la zeta (z) como /申/ y la be (b) final como $/$ ? $\mathrm{m} /$. 
decir, la raíz para cuatro y seis son 'can-' y 'vak-', respectivamente, de modo que también podemos decir 'vakvoh zeb' (seis muchachas) o 'canphej na' (cuatro casas).

Tradicionalmente, pues, la palabra gramática se usa para referirse a una colección de reglas de combinación de elementos de formación de frases, en las que se incluye ortografía, conjugaciones y significados, etc. La actitud medieval de algunos estudiosos en este campo y en psicología, cuando se introducen al lenguaje, no permite apreciar correctamente la enorme diversidad de maneras de organizar los datos de la experiencia cognoscitiva del Homo sapiens. La responsabilidad de estas fallas recae en buena parte en la tradición grecolatina que confunde hasta a los más enterados, como le sucede a Carlos Robles Uribe, que siendo gran conocedor del tzeltal, cree que el uso de clasificadores por parte de ésta y todas las lenguas mayas ${ }^{16}$ se debe a "la índole tan concreta del tzeltal" (Robles Uribe, 1962, p. 72). Esto significa que no entiende que esas lenguas clasifican el mundo de otra manera que las lenguas indoeuropeas. Estoy completamente de acuerdo con Andrés Bello cuando dice que esos gramáticos proceden como un naturalista que dividiese a los animales en cuadrúpedos, pájaros, caballos, perros, águilas y palomas (Hjelmslev, 1976, p. 21).

Permítaseme agregar los siguientes comentarios para cerrar esta sección. La gramática, en tanto esquema categorial, es el conjunto simbólico que configura los procesos cognoscitivos del hombre, que señala las relaciones de éste con el mundo; pero no del hombre frente al mundo, sino del hombre en el mundo, ¿cómo podría ser de otra manera? No comienza pues el niño, aprendiendo sonidos aislados y luego va aprendiendo la gramática que le permite adquirir un lenguaje, sino que primero aprehende sus relaciones, su manera de estar en el mundo, y luego va reconociendo los fonemas a su alrededor que, según lo indica el principio del hombre invisible, visten a la gramática.

Precisando el contenido del párrafo anterior. Desde el momento del nacimiento, el niño comienza a aprehender relaciones espaciales y temporales, que le definen su lugar en el mundo; adquiere las estructuras simbólicas inherentes al concepto de persona, de vida, de muerte; las maneras de ser y comportarse, según la tradición de su pueblo. A esas estructuras les podemos dar aquí en nombre de $G^{c}$, cuya aparición es requisito indispensable para que se forme la gramática propiamente dicha. El concepto de $G^{C}$ da un sentido ampliado a $G^{E}$ (que consiste en las reglas de combinación de los elementos del lenguaje), de donde resulta que $G^{C}$ y $G^{E}$ en conjunto representan no sólo el orden de las palabras, sino el orden del mundo, del cual, la segunda, es un modelo fónico o gráfico, en dependencia de si se platica o escribe la comunicación en cuestión. A partir del momento de nacer, la cría de Homo sapiens, pues, comienza a adquirir la gramática (en calidad de $\mathrm{G}^{\mathrm{C}}$ ); y luego, en los primeros años de vida, aprende a nombrar las relaciones que constituyen la gramática (en calidad de $\mathrm{G}^{\mathrm{E}}$ ); pero, cuando se aprende una segunda lengua, el proceso es inverso, porque los cursos de idiomas como $L^{2}$ privilegian el aprendizaje de $\mathrm{G}^{\mathrm{E}}$; y $\mathrm{G}^{\mathrm{C}}$ se adquiere después de años de estudio de la cultura del pueblo que habla ese idioma.

La Matemática y la lógica son en el fondo la misma disciplina; la primera calcula con números, la segunda calcula con letras. La terminología con la que se explica los conceptos de que están constituidas es de un alto nivel de especialización; o quizá sea mejor decir: de una gran calidad hermética, porque a fin de cuentas se trata, como en todas las especializaciones, sólo de una jerga particular más. Y manejar con precisión los conceptos, 
sin importar que tan esotéricos sean éstos, es un requisito imprescindible porque todo problema científico es en primera instancia un problema de significado. Veamos el concepto de jerga con algún detalle.

Caló, germanía, jerga, jerigonza, argot; son todos sinónimos en un sentido. Una definición general -de cualquiera de los cinco términos citados en el renglón de arriba- puede ser: "Sistema privado de comunicación entre individuos de un mismo grupo". Tal grupo puede ser la pandilla del barrio, o los miembros de alguna profesión como la de abogados, médicos, físicos o psicólogos.

Para ilustrar este tópico me serviré de una nota publicada por Tomás Mojarro en el Uno más uno del domingo 25 de mayo de 1980: "Cierto párroco de arrabal conocedor del caló hamponil, se percató en el púlpito que unos tipos robaban los cepos de las limosnas. Para evitar el escándalo les habló en caló; total, los feligreses creerían que estaba hablando en latín. He aquí lo que dijo el curita: ¡Os jurnio afanes furris poniéndole con fe el tibor, enbaisando las buchacas a los batos, a las biturras y sonando las morenas! Trinquen varilmente y piren dejando una hebra de la baraña para mi menda en la otrofa morenáis. Licad al Gran Doráis con un chutazo en el catecismo y otrofo en la vera de su mendurria, hostigado por la jara del romano entre un vati de afanes, todano por vosocláis... Aguzadeis afanes fu, la jara se aplacera en la burda del tibor echardo los oclayos a sus mendolatos, San José el pintor y de retinto, si la jara os apaña. San Javier amuraba a los afanes... Amen. Traducción resumida del mensaje: Los veo, imprudentes ladrones, robando en la iglesia, bolseando a los fieles y abriendo los cepos de las limosnas. Roben y váyanse, dejando mi parte en el cepo. Vean al señor, con una herida en la cara y otra en su divino costado, sufriendo castigo de los guardias romanos, entre un par de ladrones, todo por ustedes. Váyanse, que si los aprehenden, los matan".

Se echa de ver, con el párrafo anterior, que el caló como forma grupal de hablar tiene un alto nivel de especialización -quizá así se formó las lenguas romances, a partir del latín-, quien no conoce las palabras, realmente no entiende nada.

Los cinco términos que inician este texto son sinónimos en un sentido, pero algunos de ellos también tienen valor lingüístico particular, como es el caso del término 'caló', que aparte del significado arriba indicado también se usa para nombrar al idioma que hablan los gitanos españoles; o 'argot', palabra de origen francés y que se refiere a la forma de hablar entre personas de un mismo oficio. Y dice la XXII edición del Diccionario de la Lengua Española de la Real Academia Española que 'germanía' es “jerga o manera de hablar de ladrones y rufianes”.

En resumen, los cinco términos susodichos son sinónimos en algún sentido y a eso aquí me atengo; pero para no cansar al lector sólo usaré la palabra 'calo' para referirme a este tipo particular de habla, que tiene un fuerte arraigo popular y cuando es altamente especializado es definitivamente hermético, no para profanos.

Sin embargo, también hay que decir que toda jerga especializada es hermética; los siguientes ejemplos ilustran este aserto:

1. "La mente humana está organizada en módulos con especificidad de dominio";

2. "Número imaginario es la raíz de toda ecuación de la forma $x^{2}+1$ ";

3. "La cromodinámica cuántica maneja tres cargas que llevan por nombre: rojo, azul y amarillo, respectivamente". 
La primera frase pertenece a la jerga de los neuropsicólogos; la segunda, a la de los matemáticos; la tercera pertenece a la física cuántica. Se ve que estos ejemplos requieren de información especializada para entenderlos; o sea, solamente los que pertenecen al gremio saben de qué se trata. Y ése es el punto. En México, el caló se entiende como el habla de las colonias populares de la ciudad de México, y por extensión de los grupos de delincuentes de los barrios bajos; ;como si no hubiera delincuentes en los barrios altos!

Aunque sea machacón, se llama caló al habla de los "proles" -como dice la hija de Peña Nieto-; pero si bien, en las colonias de gente pobre se origina esta manera de hablar, los medios de comunicación la generalizan y se vuelve común, y finalmente se usa en los salones elegantes y en las universidades. Algunos ejemplos de este tipo son los siguientes: chido, dos tres, ¿qué onda? -que son más o menos tradicionales-, junto a la expresión moderna generalizada de "güe", que viene de "güey", y ésta de "buey", que es un toro castrado. Pero ni duda cabe que el caló más exitoso es el de Buenos Aires, que recibe el nombre de "lunfardo"; comenzó como jerga del bajo mundo y se elevó, de la mano del tango, a los niveles más altos de la intelectualidad porteña, argentina y universal. Para recordar, vayan estos versos de "Mano a mano", de Celedonio Flores: Se dio el juego de remanye/ cuando vos, pobre percanta,/ gambeteabas la pobreza/ en las casas de pensión./ Hoy sos toda una bacana,/ la vida te ríe y canta,/ los morlacos del otario/ los tirás a la marchanta/ como juega el gato maula/ con el mísero ratón. Enseguida, el vocabulario porteño: remanye, conocer bien; vos, tú; percanta, mujer joven, liberal; gambetear, esquivar; sos, eres; bacana, mujer pudiente, estupenda, sobrada; morlacos, billetes de banco; otario, badulaque, necio, menso; tirar a la marchanta, derrochar, malgastar; maula, despreciable, cobarde.

Ahora hablemos en jerga matemática; ya quedó claro que ésta es un caló especializado. También aquí encontramos nombres o sustantivos, verbos, adverbios y adjetivos.

Los sustantivos son las variables, que normalmente se representa con $x, y$ o $n$. Donde $x$ puede ser peso, velocidad, número de respuestas o cualquiera otra variable, $y$ digamos, altura y $n$ el número de observaciones o de sujetos. Lo que comúnmente se llama operadores en matemáticas son los verbos, por ejemplo: $\sqrt{ }, \Sigma$. El primero nos indica que debemos realizar una raíz cuadrada, el segundo que hay que hacer una suma. Por ejemplo: $\sum\left(x_{1}, x_{2}, x_{3}, x_{4}\right.$, $x_{5}$ ), donde se indica que hay que sumar todas las cantidades desde $x_{1}$ hasta $x_{5}$. También son verbos, los siguientes muy comunes:,$+ \div, \times,-$.

Los adjetivos ya quedaron mostrados en el ejemplo de la sumatoria porque son los subíndices, como en $x_{1}, x_{2}$, $x_{3}$, etc. También podemos encontrar la expresión $X i$, donde $i$ puede tomar el valor que queramos. Los adverbios modifican a los verbos, entonces en la figura:

$$
\sum_{i=1}^{N} X_{i}
$$

los signos colocados arriba y abajo del símbolo de suma $(\Sigma)$ son adverbios, e indican que $i$ tomará sucesivamente los valores $1,2,3,4,5, \ldots$ hasta $N$. ¿Y cómo leemos todo el conjunto? De la siguiente manera: Se suma todas las cantidades de $\mathrm{X}$, empezando en $i=1$, que es $\mathrm{X}_{1}$ para llegar a $i=N$, que es $\mathrm{X}_{\mathrm{N}}$ (Haber, A. \& Runyon, R. 1990, pp. 10).

La matemática se puede dividir en tres partes principales, a saber: a) geometría y topología; b) teoría de números y álgebra; c) análisis. La geometría se ocupa de diversos tipos de espacio y configuraciones; la topología de las 
deformaciones espaciales continuas; el álgebra de las propiedades de las operaciones básicas de sumar, restar, multiplicar y dividir; y la teoría de números se ocupa de las propiedades aditivas y multiplicativas de los números enteros en general. El análisis trata del infinito matemático en sus aspectos más variados; o sea, lo infinitamente grande, lo infinitamente pequeño, la proximidad infinita, lo infinitamente divisible, etc. Sus conceptos básicos son: el concepto de sucesión infinita, el de serie, el concepto de función $y=f(x)$, el de continuidad de una función, el de derivada de una función $y^{\prime}=d f / d x$, y el de integral de una función (Bochner, S., 1991, p. 255).

Otra categorización de la matemática establece que ésta tiene cuatro estructuras madres, a saber: aritmética, álgebra, topología y cálculo. Pero no se trata de pasar revista a todas o muchas de las conceptualizaciones de la matemática; basta con éstas dos.

Veamos otros términos, en calidad de ejemplo, de la jerga matemática, para ello nos habremos de servir de Valiente Barderas, Santiago (1988, p. 176).

Número real (número que pertenece al conjunto de los números racionales y los números irracionales);

Número natural (número que sirve para contar y que es elemento del conjunto: $N=\{0,1,2,3, \ldots\}$ );

Número primo (número natural mayor que uno que sólo admite dos divisores, el mismo número y la unidad: 2, 3, $5,7, \ldots)$;

Campo hiperreal (un sistema numérico en el cual, aparte de los números ordinarios que estamos acostumbrados a manejar, se incluyen (sic) números infinitamente grandes e infinitamente pequeños (Ímaz J., C. \& Moreno A., L., 2010, p. 67)).

Todo lo hasta aquí dicho se lleva a cabo con algún sistema numérico; por eso, es necesario revisar ese concepto con alguna amplitud. El sistema numérico popular que el mundo entero usa en la actualidad es el de base 10, llamado sistema decimal; y también existe el sistema binario, llamado así porque es de base 2, que junto con el sexagesimal de base 60 , es usado en el software de los sistemas computacionales. Todos los idiomas originarios de México que se habla actualmente son vigesimales, o sea, de base 20.

Decir que un sistema numérico es de base $X$, es decir que se comienza a contar de 1 en 1 hasta llegar a la base; a partir de allí se puede seguir contando de uno en uno o de tanto en tanto, según la base hasta llegar al siguiente orden, lo cual ocurre cuando agotamos todos los dígitos (guarismos, cifras) y debemos agregar otro cero. ¡Ah, cero! Antes de continuar debemos aclarar este concepto.

Valiente B., S. (1988, p. 74) considera al cero un dígito y lo coloca en la lista de los símbolos del sistema de numeración decimal, a saber: 0, 1, 2, 3, 4, 5, 6, 7, 8, 9. Pero él mismo, en otro lugar del mismo diccionario, define número como "símbolo o conjunto de símbolos que representa una cantidad (Valiente B., S., 1988, p. 173)". Y bien, el cero no representa ninguna cantidad, por ello se define en teoría de conjuntos como $N(\varnothing)$. Se echa de ver que en matemática teórica hay dificultades sobre el cero. Aquí no es el lugar -y este no es el momento- para entrar en el territorio de esas dificultades; sigamos adelante. Todos los sistemas numéricos que usan el cero se comportan de la misma manera; así que en lo que sigue vamos a revisar un sistema numérico actual de México; allí quedará explicado el concepto de cero y su función, así como de los otros signos numéricos. 
La numeración nahuatl, como todas las de Mesoamérica, es de base veinte; de allí el calificativo de vigesimal. Aunque para algunos lectores parezca innecesario, repitamos: el sistema numérico que usamos en castellano es de base diez (Repetto, C. H., 1967, pp. 32-49); por ello se llama decimal; y los signos numéricos se llaman dígitos porque se dice que representan los dedos de las manos, a saber: 1, 2, 3, 4, 5, 6, 7, 8, 9, 0. A los dígitos también se les Ilama cifras o guarismos; y un número puede tener una $(2,4,9$, etc.) o dos o más cifras (22, 222, etc.). Estos signos se llaman arábigos porque se derivan de los correspondientes árabes que son los siguientes: $1, r, r, \varepsilon$, $\bullet,\urcorner, \vee, \wedge, ~ १, ~ • ;$ pero, en realidad, tales signos no son árabes, sino indios: los árabes los aprendieron en La India y los llevaron a sus dominios, incluido el sur de la actual España; y de allí a toda Europa. Los signos numéricos originales árabes y los modernos europeos se parecen, de alguna manera, en la forma; pero lo verdaderamente importante es que son idénticos en la función, debido al uso del cero. Los sistemas numéricos que tienen 'cero' $\left(0,{ }^{\circ}, \mathrm{D}\right)$ son sistemas posicionales; significa que aumentan de tanto en tanto, en dependencia de la base. Los de base diez aumentan de diez en diez; los de base veinte, de veinte en veinte y tienen veinte dígitos, término que conservaremos para el caso del sistema vigesimal, pues también hay gente que cree que estas cifras resultan de la consideración de los dedos de pies y manos.

El sistema binario, o sea de base dos, tiene dos dígitos y aumenta de dos en dos. Ya vimos los signos correspondientes al sistema decimal; los del binario son: 1 y 0 . Si tuviéramos un sistema de base siete, éstos serían sus dígitos: 1, 2, $3,4,5,6$, 0; en el de base cuatro serían 1, 2, 3, 0. En el sistema binario la base se escribe 10, en el de base siete 10, y en el sistema de base cuatro 10. En todos los sistemas la base se escribe igual porque el uno indica que se alcanzó el primer orden -el de la base-, y el cero, que no hay dígitos; pero los dígitos que sigan sustituirán al cero hasta llegar al siguiente valor (20), que en el sistema de base siete es catorce, en el de base 4 es 8 , en el de base 3,6 . Y así hasta llegar al siguiente orden (100), que en el sistema de base veinte es cuatrocientos porque resulta de multiplicar veinte por veinte. ¿Cuáles son los dígitos del sistema vigesimal de México? Helos aquí:

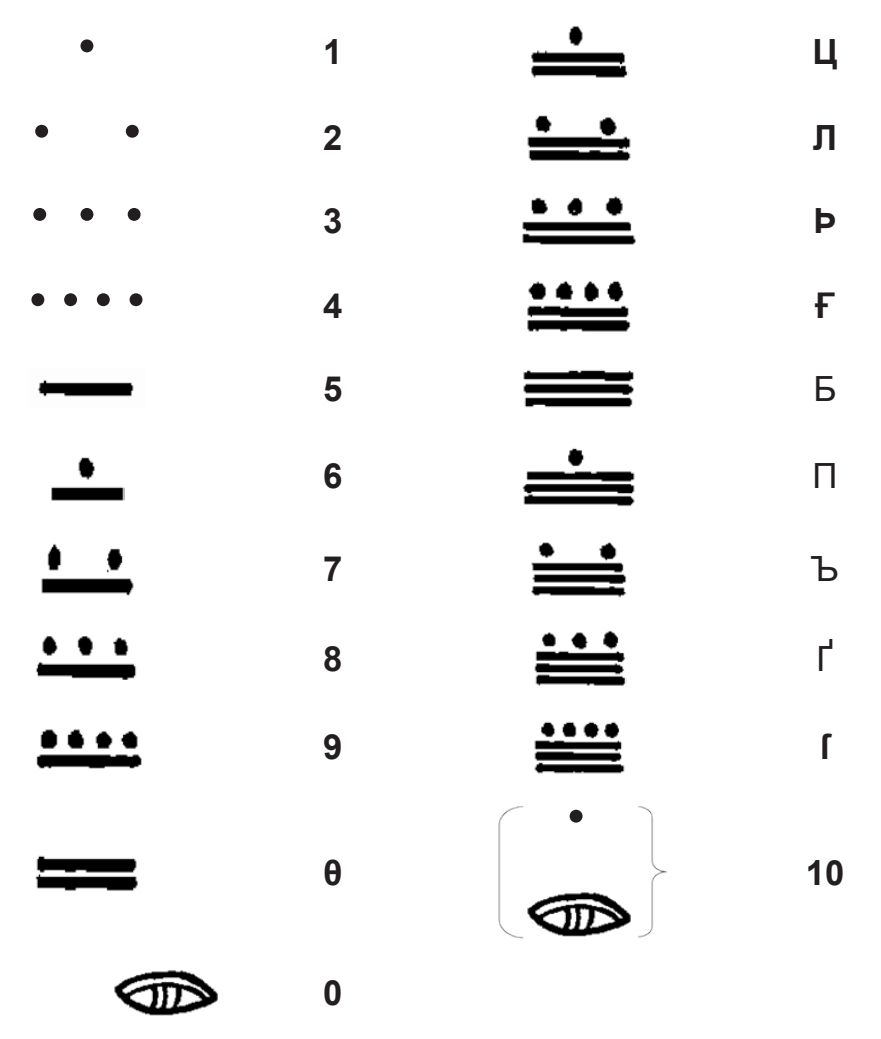


No hace falta aprenderse estos guarismos para continuar con esta lectura, bastará con tener a la mano la tabla aquí presente; pero el pensamiento aventurero que se los aprenda sacará mayor provecho a la lectura. Nótese los signos a la derecha del sistema de puntos y barras, son signos convencionales para manejar gráficamente los valores con facilidad. En palabras en idioma nahuatl: 1 se, 2 ome, 3 yei, 4 nahui, 5 makuilli, 6 cikuase ${ }^{17}, 7$ cikome,

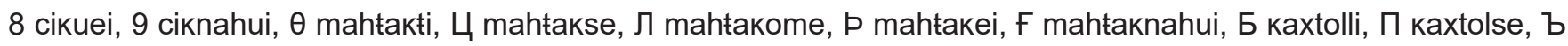
кaxtolome, ґ kaxtolei, 「 kaxtolnahui, 10 sempoalli.

El sistema numérico de puntos y barras -in tilteł in tilkuahuit- es conocido como numeración maya, pero no fueron los mayas quienes lo inventaron, por cierto. Los inventores fueron los olmecas y los zapotecas: los mayas tienen el mérito de haberlo desarrollado y plasmado en estelas (monumentos en piedra plana) y códices (libros antiguos); pero fue en Monte Albán donde tuvo sus inicios la escritura en Mesoamérica. Si bien no se sabe con precisión cuándo fue que se inventó, ni el proceso de invención, sí queda claro que por el año 600 a. C. los gobernantes de Monte Albán comenzaron a erigir estelas para conmemorar las victorias sobre sus enemigos y anotaron nombres y fechas. Como un efecto natural la numeración (y la escritura) se difundió de las tierras altas zapotecas a los olmecas tardíos de la costa del Golfo de México y entre los pueblos de los límites del oeste y suroeste de la zona maya peninsular; y de allí, el siguiente paso fue la difusión del sistema numérico de puntos y barras hacia todas las regiones mayas.

Y nosotros, estudiosos mexicanos, de cualquier nivel o grado, ¿por qué hemos de utilizar este sistema de escritura numérica? Se puede presentar varias razones para ello, a saber:

a) Es un sistema oriundo de Mesoamérica, inventado por zapotecas y olmecas, y desarrollado por mayas, que son de la misma cultura que los nahuas, o sea son toltecas;

b) Consiste de un conjunto de signos que se ajusta perfectamente al sistema numérico nahuatl y de todos los pueblos de Mesoamérica actuales, debido a que también éste es vigesimal;

c) Tiene un valor histórico, cuyo conocimiento puede ser motivante para el estudioso de nuestras tradiciones.

d) El uso del sistema árabe para representar la numeración nahuatl es inútil y estorboso porque es decimal, y faltarían signos para representar los veinte dígitos de la numeración de las lenguas mesoamericanas, de allí la necesidad de los signos a la derecha en el cuadro de dos páginas atrás; el hecho de que sea oriundo de la India no viene al caso.

Ahora estudiemos el sistema numérico:

Ya sabemos que un punto $(\bullet$ ) es uno, dos puntos $(\bullet \bullet)$ es dos, y así, sucesivamente hasta el cuatro, que

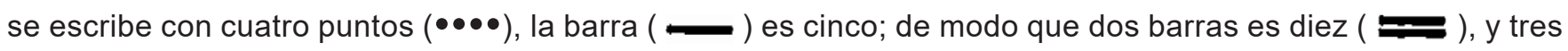
( $\equiv$ ), quince. Los intermedios entre cinco y diez, diez y quince, quince y veinte se expresan con puntos sobre las barras, teniendo cuidado que aquéllos vayan bien distribuidos ocupando todo el largo de éstas; el siete ( $)$ ), el trece (

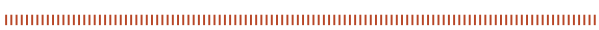

17 Recuérdese la pronunciación: ' $€$ ' se lee algo parecido a 'tl' del altiplano central de México; ' $z$ ' se lee como la 'z' alemana; 'c' se lee como la 'ch' castellana; ' $x$ ' se lee como la 'ch' francesa; 'll' se pronuncia como dos eles contiguas. La hache (h) representa un cierre glotal o una aspiración ligera. Todas las palabras son graves. En el texto en castellano, todas las palabras de origen nahuatl asimiladas a aquella lengua, son leídas como en castellano. 
Del veinte en adelante hay cambios notorios, pues este valor se expresa con un uno y un cero, ocupando el uno el sitio de las veintenas y el cero el sitio de las unidades, que por acomodarse los signos de manera vertical resulta que el uno queda encima del cero. La razón de esta manera de colocar los numerales es el hecho de que en las estelas y códices es muy frecuente el ordenamiento vertical; pero también se observa, de vez en cuando, una organización horizontal en la colocación de los numerales; en tal caso los ceros van a la derecha del uno, y cada espacio recorrido hacia la izquierda representa una multiplicación por veinte; igual como sucede en la organización vertical en la que cada espacio hacia arriba representa una multiplicación por veinte. En este ejercicio que usa la lengua nahuatl a la unidad la llamaremos 'senyoz'; al conjunto de veinte unidades lo llamaremos 'sempoalloz'; al conjunto de veinte sempoalloł lo llamaremos 'senzonyoł'; al de veinte senzonyot, 'senxikipilloł'; y así se obtiene, sucesivamente, las unidades de los distintos órdenes, que tal es el nombre que recibe cada uno de estos conjuntos, en castellano. La explicación que sigue la ejemplifico con el esquema vertical, porque es el que hemos venido utilizando hasta aquí:

El número uno (• ) 'se' es la unidad, que si se multiplica por veinte da otro tipo de unidad: la unidad de las veintenas, es decir, 'sempoallok', que al ser multiplicado por veinte da la unidad de los cuatrocientos 'senzonyoł', que al ser multiplicado por veinte da la unidad de los ocho miles 'senxikipillot'. Y con éstas tres se forman tres especies de unidades mayores, a saber: 'sempoalxiкipilli', о sea, ocho mil por veinte; 'senzonxiкipilli', о sea, ocho mil por cuatrocientos; 'sempoalzonxikipilli', o sea ocho mil por cuatrocientos por veinte, a cuyos órdenes llamaremos, respectivamente, 'sempoalxiкipilloł', 'senzonxiкipilloł', 'sempoalzonxikipilloł'. Ahora, como éste es un sistema posicional, cada tipo de unidad ocupa un lugar hacia arriba o hacia la izquierda, según si se ordena las cifras de manera vertical u horizontal; pero aquí seguiré explicando según el orden vertical, así que veamos la siguiente tabla:

\begin{tabular}{|l|l|}
\hline Ocho miles (de 8000 a 152 000) & $n^{*} \times 8000$ \\
\hline Cuatrocientos (de 400 a 7600) & $n^{*} \times 400$ \\
\hline Veintenas (de 20 a 380) & $n^{*} \times 20$ \\
\hline Unidades (de uno a diecinueve) & $n^{*} \times 1$ \\
\hline
\end{tabular}

* ' $n$ ' significa 'cualquier número'

Como se puede ver, cada nivel de esta escala numérica se alcanza multiplicando por veinte el valor del nivel anterior. Y, a partir de aquí, se puede acceder a los susodichos tres tipos de unidades superiores, que se obtienen, como arriba quedó dicho, multiplicando por veinte el valor anterior:

$\begin{array}{lll}\text { Sempoalхікіріlli } & = & (8000 \times 20) \\ \text { Senzonxiкipilli } & = & (8000 \times 400) \\ \text { Sempoalzonxikipilli } & = & (8000 \times 400 \times 20)\end{array}$

Ahora hagamos conciencia del significado de las posiciones. En este sistema, y considerando que cada veinte unidades de un orden forman una unidad del orden superior, se deduce que: una cifra colocada inmediatamente arriba de otra, representa unidades del orden inmediato superior. Por lo tanto, cada cifra tiene un valor intrínseco o propio, que es el número de unidades que tiene, considerada aisladamente, y un valor relativo, que es el número de unidades que representa por el lugar que ocupa. Así, consideremos los siguientes números: 


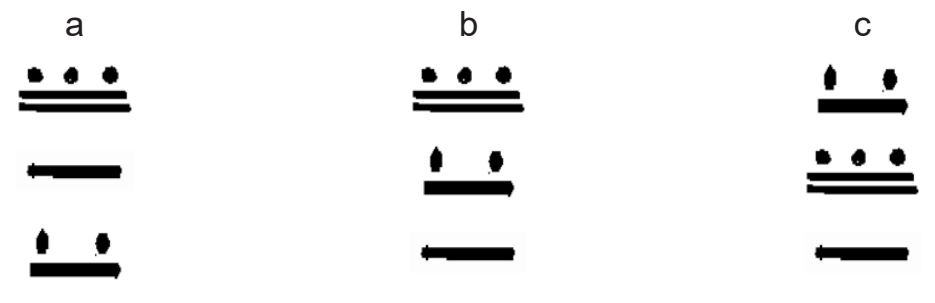

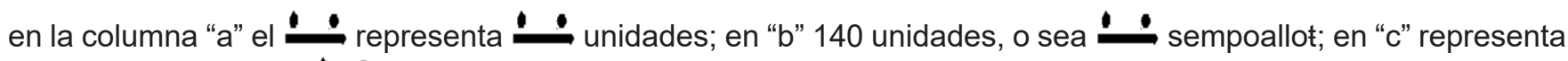

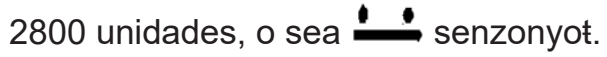

Hasta aquí, no se ha dicho nada del cero, pero también es necesario hacer aclaraciones al respecto; por lo tanto, veamos:

En este sistema numérico, el cero se representa con el símbolo ( estilizado, pero, en cuanto símbolo numérico, lo leeremos: ‘yuhкahti' o ‘ahmita'. En las estelas aparecen más de treinta formas diferentes de cero; pero las dos que aquí se presenta aparecen solamente en los códices; por ello, y porque son las más fáciles de dibujar, son las que, por ahora presentamos en este texto; pero, en definitiva, la segunda será la única forma que aquí utilizaremos: la primera también es correcta, pero la segunda es más común, y es la que me gusta más. De las otras treinta y tantas formas (Gates, W. 1978, pp. 86-92.) el lector podrá consultar la fuente aquí indicada, o yo lo trataré en trabajos posteriores.

Como quiera que sea, el símbolo rif representa el vacío del renglón en que se encuentra, es decir, significa que no hay ninguna unidad del nivel donde aparece. Por ejemplo, en el número:

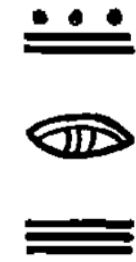

el está indicando que se tiene $\equiv$ senyoł, ningún sempoalloł y nahuatl: mahtakeizonti kaxtolli, lo que equivale a decir "trece veces cuatrocientos, cero veintenas más quince"; en sistema decimal: 5215. Otros ejemplos son:

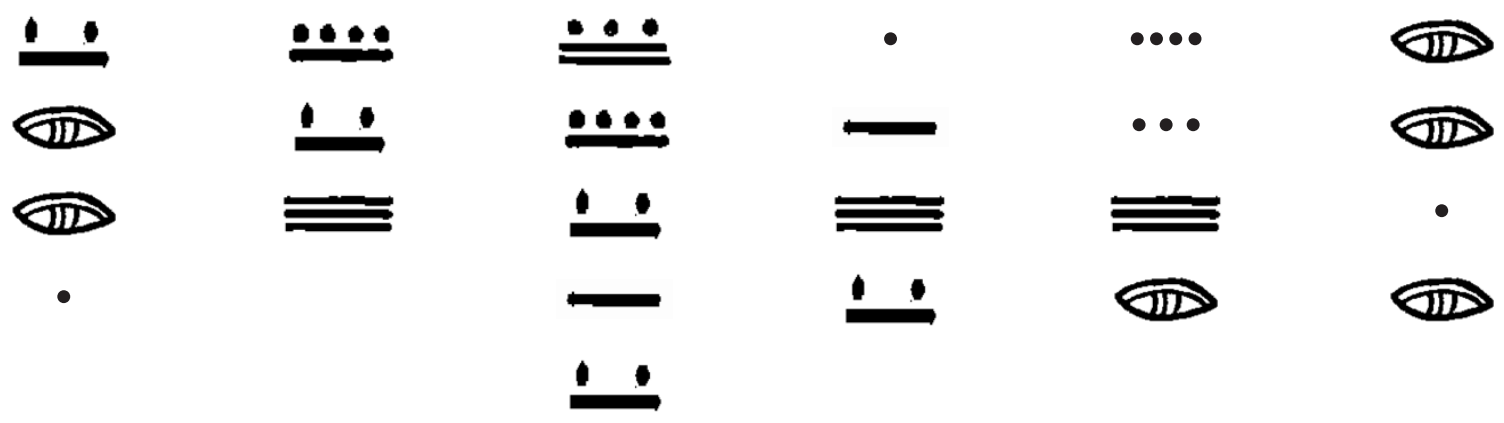


que se lee, respectivamente: ciкоnхікіріlli se, ciкnauhzonti cікотроаlli каxtolli, mahłакехроаাхікіріlli cікnаuhxiкіріlli cікоnzonti такиilpoalli сікоте, senxiкіріlli такuilzonti каxtolpoalli сікоте, nauhxiкipilli yeizonti каxtolpoalli, sempoalli ${ }^{18}$.

Una recomendación muy importante para dominar la numeración nahuatl: aprenda a contar de memoria, de modo que domine el automatismo de la numeración, sin conexión con la numeración en castellano. No intente ir convirtiendo la numeración nahuatl a la numeración castiza, so pena de caer en terribles confusiones, debido a la base veinte de una y la base diez de la otra. Se recomienda la consulta de La lengua nahuatl como modelo de cognición (Sánchez Barrera, José, en prensa) para estudiar estos temas.

Todos los sistemas numéricos posicionales tienen principio, pero no tienen fin, tanto los números positivos como los negativos. ¿Pero hasta qué número podríamos llegar a contar? Hasta donde o cuando la paciencia nos dure, después de recitar cifras y cifras. En este punto vale la pena citar el caso del googol y el googolplex, términos inventados por un niño de nueve años, el sobrino del Dr. Kasner (1940, p. 23). El googol es número compuesto de un 1 seguido de cien ceros, y el googolplex consiste de un 1 seguido de un googol de ceros.

En adelante todos los ejemplos numéricos serán en sistema decimal. Pero era necesaria una cita así de amplia porque se trataba de mostrar un sistema con el cual se escribía palabras comunes y grandes números utilizando y escribiendo el cero veinte siglos antes de que lo conocieran en Europa.

En efecto, es maravilloso enterarse de que el teorema de Pitágoras se desarrolló con un sistema que carecía de notación numérica con cero; pero se sustituía bien con geometría. El teorema de Pitágoras, en notación moderna lo conocemos como $a^{2}+b^{2}=c^{2}$; pero los pitagóricos lo representaron de la siguiente manera:

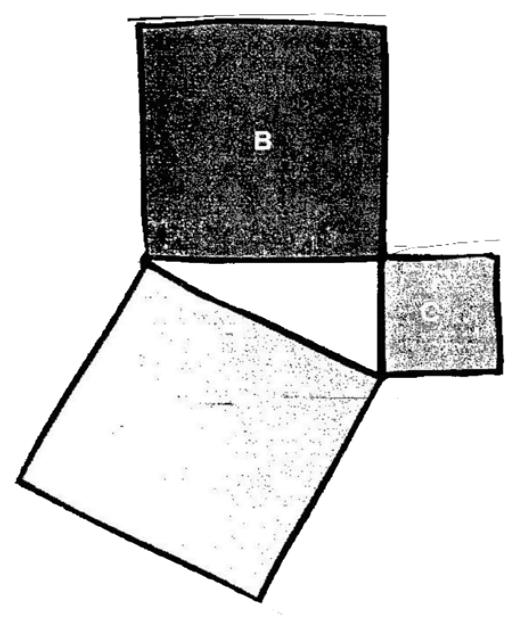

Donde se ve claramente que el cuadro de la hipotenusa es el cuadrado de la suma de los catetos.

Los currícula a nivel profesional incluyen programas de matemáticas porque se acepta la opinión de Galileo de que el lenguaje de la naturaleza es la matemática. Entonces, todo estudioso de ciencias naturales debe lograr un

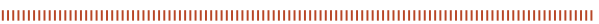

18 En los sistemas posicionales el cero, arriba o a la izquierda de cualquier dígito, dependiendo de si las cifras están organizadas vertical u horizontalmente, no tiene ningún valor. 
dominio alto de las - por citar una de tantas tradiciones del campo que aquí vengo comentando- cuatro estructuras madres de la matemática, a saber: aritmética, álgebra, cálculo, topología. Pero hay grande escasez de buenos profesores y de buenos libros en este rubro. Existen cursos de matemáticas donde el estudiante aprende a pesar de su maestro; quien frecuentemente se presenta frente a sus alumnos no con la intención de enseñar, sino de demostrarles que el único capacitado para aprender matemáticas es él. Además de que les hace trampa en los exámenes, en la clase, para facilitarse el trabajo, hace demostraciones sencillas, y en el examen pone ejercicios complejos. ¿Y qué hay de los libros? Normalmente éstos son voluminosos. ¿Pero de veras se necesita que los libros de cálculo sean bien gordos? Ímaz J., C. \& Moreno A., L. (2010, p. 64) citan Non-standart analysis de Abraham Robinson que comienza con lógica de alto nivel, sigue una parte de cálculo, y los siguientes seis capítulos tratan de topología general, medida, integración y distribuciones, variable compleja, grupos lineales, grupos topológicos y de Lie, principio de Dirichlet, flujos laminados, etc., “.... todo lo cual conforma un poderoso guiso extremadamente difícil de digerir". Esta cita es meritoria porque el libro de los autores citados (Ímaz y Moreno) sólo tiene 100 páginas. Sí, también hay libros de matemáticas voluminosos porque las editoriales, y ocasionalmente los autores, ganan más con libros gordos.

Cuando menos en la Facultad de Estudios Superiores Zaragoza de la Universidad Nacional Autónoma de México, hace falta una comisión de estudiosos de las matemáticas para diseñar programas para apoyar a los estudiantes de las diversas carreras en su necesidad de hacerse íntimo de las matemáticas. Y ello es necesario en todas las carreras. ¿Por qué razones los currícula de las ciencias sociales no incluyen el estudio del cálculo? Y una pregunta de familia, pues soy psicólogo: ¿por qué en psicología no se estudia cálculo? El objeto de estudio de la psicología es la conducta de los animales -se estudia al hombre porque éste forma parte del reino animal-; o sea, la acción, la actividad, el cambio; y el cálculo es la matemática del cambio.

Isaac Newton publica en 1687 su obra: Principia mathematica philosophiae naturalis (Los principios matemáticos de la filosofía natural), cuyo mensaje principal “.... no eran las 'leyes' de la naturaleza específicas que él descubrió y utilizó, sino la idea de que tales leyes existen, junto con la prueba de que la manera de modelar matemáticamente las leyes de la naturaleza es con ecuaciones diferenciales." (Stewart, I. 2008, p.133). Las ciencias sociales tienen un rezago de 329 años, si contamos los que han pasado desde 1687. O quizá no, si tomamos en cuenta de que existe, cuando menos, la psicología matemática (Luce, D. 1960); pero es necesario nutrir los currículos de psicología, cuando menos, con estos temas y un programa fuerte de lógica.

Una opinión de un estudioso de matemáticas:

"Las matemáticas son una ratonera. El que queda preso una vez en ella, difícilmente halla la salida que le permita volver a su estado anímico pre-matemático. [....]

La primera consecuencia de la "propiedad ratoneril" de las matemáticas es la gran escasez de pedagogos matemáticos. Rarísimas veces coinciden en la misma persona la capacidad matemática y un sistema de explicación fácilmente comprensible. De donde resulta, como segunda consecuencia, el "complejo de inferioridad matemática" de amplias zonas de intelectuales y de gente culta. [....] Además, las matemáticas permanecen ocultas en los modismos verbales de uso corriente. El periódico nos habla de "fascismo integral", de "promedios", de "temperaturas medias", de "potencias óptimas", de "puntos críticos de las curvas", de "campos de fuerzas", etc.; expresiones todas sacadas de las matemáticas y de la física matemática. 
No hay razón alguna para que tales palabras suenen en nuestros oídos como nueces vacías, y a causa de ellas haya quien experimente una sensación de inferioridad o de falta de cultura. Porque el contenido de tales palabras es tan majestuoso como simbólico y tan fácil de comprender como de aprender." (Colerus, E. 1954, pp. V, VI)

\section{CONCLUSIÓN}

La psicología no ha estado alejada de la matemática; pero no son íntimas éstas dos disciplinas. Más bien, parece como si los psicólogos le tuvieran miedo a las matemáticas. Los intentos de matematización en psicología son estigmatizados por buena parte de los psicólogos, tildándolos, a veces, de despreciables positivistas, descuidando con ello el hecho de que no se puede llegar al materialismo dialéctico si no se pasa por el territorio del positivismo. En fin, cualquier pretexto es bueno con tal de evitar el horror de la formalización.

Pero sí ha habido y existen psicólogos, cuya vida profesional marcha por o al lado del camino de la matemática, en alguna de sus manifestaciones. Díganlo si no, el trabajo de Ebbinghaus con su ley del olvido; la ley de Weber, completada por Fechner; el principio de isomorfismo de la Gestalt, o el campo odológico de Kurt Lewin, que son leyes topológicas. Otro ejemplo, y éste es el último que citaré, es el modelo matemático de Clark L. Hull (Sahakian, W. S. 1990, pp. 515-531). La matemática no forma parte de la psicología, como muchos otros temas; pero es herramienta indispensable y fuerza fundamental de la ciencia.

Y no es que el lenguaje de la naturaleza tenga un fundamento matemático, sino que la matemática como producto del cerebro humano está en consonancia con la naturaleza.

\section{Referencias}

IIII Alatorre-Padilla, R. (1980). Lógica. México: Porrúa.

IIII Aoki, Akira (1988). Vamos a estudiar japonés. México: Universidad Autónoma del Estado de México

IIII Birdwhistell, R. (1970). Introduction to Kinesics: An Annotation System for Analysis of Body Motion and Gesture. Pennsylvania: University of Pennsylvania Press.

IIII Bochner, Salomon. (1991). El papel de la matemática en el desarrollo de la ciencia. Madrid: Alianza Editorial

IIII Bourne, Jr. L.E., Ekstrand, B. R. \& Dominowski, R. I. (1976). Psicología del pensamiento, México: Trillas.

IIII Cantor, Georg (1999). Contributions to the founding of the theory of transfinite numbers. México: Instituto Politécnico Nacional.

IIII Coe, Michael D. (1996). El desciframiento de los glifos mayas. México: Fondo de Cultura Económica.

IIII Colerus, Egmont. (1954). De la tabla de multiplicar a la integral. Barcelona: Labor.

IIII Diamond, A. S. (1974). Historia y orígenes del lenguaje. Madrid: Alianza Editorial.

IIII Ducrot, O. \& Todorov, T. (1980). Diccionario enciclopédico de las ciencias del lenguaje. México: Siglo XXI. 
IIII Ediciones Shangwu (1963). Manual de lengua china moderna. (dos volúmenes) Pekín.

IIII Engels, F. (1968). El origen de la familia, la propiedad privada y el estado. Moscú: Progreso

IIII Gates, William. (1978). An outline dictionary of maya glyphs. New York: Dover.

IIII Gray, Jeremy J. (2000). El reto de Hilbert. Barcelona: Crítica.

IIII Haber, Audrey \& Runyon, Richard. (1990). Estadística general. México: Addison-Wesley.

IIII Haviland, J. B. (1981). El tzotzil de San Lorenzo Zinacantán, México: Universidad Nacional Autónoma de México.

IIII Hjelmslev, L. (1976). Principios de gramática general. Madrid: Gredos.

IIII Hockett, C. F. (1976). Curso de lingüística moderna. Buenos Aires: EUDEBA.

IIII Humboldt, W. von. (1991). Escritos sobre el lenguaje. Barcelona: Ediciones Península.

IIII Ímaz J., Carlos \& Moreno A., Luis (2010). La génesis y la enseñanza del cálculo / Las trampas del rigor. México: Trillas.

IIII Kasner, Edward \& Newman, James (1940). Mathematics and the imagination. New York: Simon and Schuster.

IIII Le Ny, J.F. (1971). El condicionamiento. Barcelona: Península.

IIII Luria, A. R. (1984). Conciencia y lenguaje. Madrid: Visor

IIII Luce, Duncan (editor) (1960). Developments in mathematical psychology. Illinois: Free Press of Glencoe.

IIII Martinet, A. (1968). La lingüística sincrónica. Madrid: Gredos.

IIII Ortuño-Martínez, M. (1999). Teoría y práctica de la lingüística moderna. México: Trillas.

IIII Perrott, D. V., (1978). Swahili. Gran Bretaña: Hodder \& Stoughton.

IIII Premack, A. J. \& Premack D. (1972). Scientific American. Teaching language to an ape. Vol. 227, pp. 92-99

IIII Real Academia Española (2001). Diccionario de la lengua española, Vigésima segunda edición, España: Espasa.

IIII Repetto, Celina H. et alia (1967). Matemática moderna (Aritmética 1). Buenos Aires: KAPELUSZ, S.A.

IIII Ruhlen, Merritt. (1994). The origin of language. New York: John Wiley \& Sons, Inc.

IIII Russell, Bertrand (s/f). Principles of mathematics. New York: W. W. Norton \& Company.

IIII Sánchez Barrera, José (s/f). La lengua nahuatl como modelo de cognición. (En prensa)

IIII Saussure, Ferdinand de (1979). Curso de lingüística general. Buenos Aires: LOSADA.

IIII Stewart, lan. (2008). Historia de las matemáticas en los últimos 10000 años. Barcelona: Crítica

IIII Valiente Barderas, Santiago. (1988). Diccionario de matemáticas. Madrid: Alhambra.

IIII Vygotsky, L.S. (1996). Pensamiento y lenguaje. México: Quinto Sol.

IIII Weil, Herman (1965). Filosofía de la matemática y de la ciencia natural. México: Universidad Nacional Autónoma de México. 


\section{CAPÍtULO 4}

\section{El uso de recursos semióticos como estrategia pedagógica}

en la enseñanza de la estadística

Valeria González Calixto

Guadalupe M. Corona Rafael

\section{Introducción}

Si se hablara de los distintos niveles educativos presentes en México, y de las materias que más problemática representan dentro de los mismos, no cabe duda que entre las primeras asignaturas mencionadas, estarían las matemáticas.

A principios del 2016 la Organización para la Cooperación y el Desarrollo Económico (OCDE) expuso los resultados del estudio titulado: "Estudiantes de bajo rendimiento: por qué quedan atrás y cómo ayudarlos a tener éxito", basado en los resultados de PISA 2012, evaluación internacional que examina el rendimiento de alumnos de 15 años en áreas temáticas clave: lectura, matemáticas y ciencias; se reportó que 1 de cada 4 estudiantes de 15 años en los 34 países de la OCDE no alcanzan el nivel básico de desempeño en por lo menos una de las tres áreas que PISA evalúa (OCDE, 2016); de acuerdo con este reporte, los estudiantes “...se encuentran atrapados en el círculo vicioso del bajo desempeño y la desmotivación, lo cual conduce a malos resultados y a una creciente desvinculación de la escuela" (OCDE, 2016, p. 1), tales problemáticas repercuten a nivel individual y social, pero también a corto y largo plazo.

A pesar de que en México el porcentaje de estudiantes de bajo rendimiento en matemáticas y en lectura disminuyó cerca de 11 puntos porcentuales entre 2003 y 2012, las dificultades en la enseñanza y aprendizaje de las matemáticas siguen presentes tal es el caso del nivel de ansiedad ante las matemáticas el cual es encabezado por México con más del 75\% del índice total, motivo de bajo rendimiento y deserción (OCDE. 2012).

De modo similar a PISA, diversas pruebas nacionales e internacionales que pretenden evaluar el desempeño y conocimientos de los alumnos en el ámbito escolar, sin embargo, todas ellas brindan sólo un acercamiento a las deficiencias y necesidades reales, por lo que continuamente se realizan investigaciones, programas de formación docente, se reestructuran planes y programas educativos, con el propósito de mejorar la enseñanza, principalmente de las matemáticas y de las disciplinas relacionadas con ella debido a la prevalencia de fracaso en su enseñanza y aprendizaje (Vega, 2012; Defior, 2000).

La matemática se encuentra en una posición nada envidiable, es una de las asignaturas más importantes y a la vez, una de las peor comprendidas (Bishop, 1999); saltan a la luz diversas interrogantes, ¿son en realidad las 
matemáticas las causantes de las dificultades? o ¿los profesores no facilitan la comprensión?, entonces ¿cuáles son los factores que inciden en el aprendizaje de esta ciencia?, resulta claro que tal asunto puede analizarse desde diferentes perspectivas.

En este sentido, Romero y Lavigne (2004) han identificado cinco factores principales que intervienen en el proceso enseñanza-aprendizaje: contenidos, alumno, docente, contexto escolar, familia y contexto social, en los cuales puede hallarse la clave de las dificultades y problemas que atañen el entorno educativo. Entre las investigaciones alrededor de estos factores, se encuentran aquellas que prestan atención al alumno, a sus competencias, habilidades o estrategias de aprendizaje (Chiecher, Danolo y Rinaudo, 2005; García, 2002), pero también aquellas que se interesan por el rol del docente, la evaluación de su desempeño, el uso de estrategias didácticas, (Arregui, 2015; Ruiz, Sánchez, Meraz y Suárez, 2007), y en menor proporción las que consideran ambas partes y su interacción, pero sin importar el abordaje, el objetivo común resulta ser la comprensión y mejora del proceso enseñanzaaprendizaje de las matemáticas.

El papel del docente en el contexto educativo representa al ser mediador en la generación del conocimiento del alumno, sin embargo muchos profesores parecen no darse cuenta de otros recursos útiles para lograr un aprendizaje significativo, ya que algunos todavía se empeñan en el predominio expositivo que desde siempre ha existido, con la creencia de que la mera palabra magistral permite que los alumnos dominen conceptos y procedimientos (Domínguez, 2010). Al parecer los docentes desconocen y no son conscientes de los mecanismos comunicacionales que emplean en el aula, del significado que adquieren en función del momento en que se presentan, ni de las interpretaciones que los alumnos hacen de los mismos. Debido a esta situación los docentes no adoptan estrategias es sus comportamientos comunicativos verbales, no verbales y prosódicos para facilitar el aprendizaje de los estudiantes (Cuadrado, 1993).

Debe superarse la concepción de la educación como simple "transmisión acumulación" de información (Tünnerman, 2011), ya que la crisis educativa actual remite su causa al modelo pedagógico tradicional. Aunado a esta situación, la sociedad actual atraviesa cambios constantes, al ser bombardeada por los medios masivos de comunicación y la tecnología, haciendo necesario mejorar el modelo tradicional basado en la repetición, memorización y mecanización (Tünnerman, 2011). De aquí parte el interés en las estrategias docentes, en especial el discurso, y su impacto en el aprendizaje de los alumnos, ya que el lenguaje representa el principal medio de construcción de significados y del conocimiento.

El lenguaje desde cualquier entorno y contexto conforma un aspecto fundamental del ser humano para comunicarse con otros y expresar ideas y pensamientos, ya sea de forma escrita u oral; la matemática, al igual que otras asignaturas hace uso de un lenguaje particular, compuesto por fórmulas, procedimientos, signos y símbolos que permiten comprender conceptos y contenidos matemáticos (Beiza, 2015), sin embargo, la expresión del lenguaje matemático ha resultado ser una de las causas de incomprensión de contenidos y fórmulas matemáticos, debido al nivel de abstracción necesario (Martín, Paralera, Romero y Segovia, 2008)

Domínguez (2010) recurre a un término al que denomina objetos semióticos, también llamados recursos semióticos, siendo aquellos que permiten la expresión y transmisión de información, tales como el lenguaje oral, escrito, corporal, aspectos visuales como una imagen o dibujo, elementos que en un entorno educativo son capaces de actuar como mediadores de la enseñanza y el aprendizaje. Diversas investigaciones han profundizado en el tema de los recursos semióticos en la enseñanza de las matemáticas, encontrando que tales objetos impactan en el 
aprendizaje del alumnado, en su rendimiento académico (Corona, Escotto, Sánchez, Baltazar, 2016; Mangui, 2010; Coll, 2001). Es así que el objetivo de este trabajo es brindar al lector un acercamiento al tema de los signos y construcción de significados a partir de los recursos semióticos en las matemáticas, mismos que pueden constituir una herramienta pedagógica de gran relevancia en la obtención del aprendizaje significativo en una ciencia de gran dificultad para muchos alumnos.

\section{Pedagogía y didáctica matemática}

La calidad de la educación depende, en gran medida, de la formación docente y de cómo dirige y orienta el proceso de enseñanza-aprendizaje (Torres y Girón, 2009), sin embargo, no sólo se trata del profesor, y el papel del alumno no puede considerarse pasivo; el aprendizaje debe representar un proceso activo construido en conjunto, más allá de basarse en la transmisión verbal sin considerar los procesos de aprehensión e interiorización, no se trata de que se aprenda poco o que se enseñe mal, sino que el contexto educativo muchas veces no está diseñado ni organizado teniendo en cuenta las características de los contenidos, de los aprendices ni de los profesores (Calero, 2009).

La pedagogía, tal como la concibe Florez (1944), constituye una disciplina cuya preocupación no es solamente indagar por el significado y los motivos de las acciones educativas, sino también por las causas de las mismas, que sucede con los alumnos que no entienden a los maestros, los que no aprenden o no desean aprender; el verdadero aprendizaje va más allá de la empatía alumno-profesor, resultando de gran importancia conocer el funcionamiento del proceso enseñanza-aprendizaje, y así comprender mejor, e incluso superar, algunas de las dificultades presentes en el entorno educativo adaptando las actividades educativas a los recursos y capacidades de alumnos y profesores, ya que la situación escolar y social requiere constantemente atención e innovación en sus diferentes campos.

El conocimiento no es estático, debe entenderse como un proceso dinámico en permanente desarrollo, en evolución, y como todo conocimiento es esquemático y parcial, siempre podemos realizar un nuevo progreso en el conocimiento (Florez, 1944); por tal motivo resulta importante promover y transformar el discurso de los profesores mediante un cambio de textos de apoyo, pero sobre todo que las estrategias de enseñanza se basen en un diálogo más colaborativo con los estudiantes (Radovic y Preiss, 2010).

Resulta prioritario preguntarse si las prácticas en el aula o si las estrategias docentes, representan en la actualidad un rutinario ejercicio profesional o si pueden constituir una estrategia pedagógica con efectos positivos en el aprendizaje escolar.

Y es precisamente en las matemáticas donde resulta más evidente la necesidad de mejorar el nivel y la calidad del aprendizaje y la enseñanza; pero algo debe quedar bien claro, el objetivo no es convertir a los alumnos en matemáticos, sino hacer que se sientan cómodos en un mundo en que que cada vez se utilizan más las matemáticas, ya que por mucho que las matemáticas sean universales, no significa que su enseñanza deba ignorar la individualidad del alumno o el contexto social y cultural del proceso educativo, sino que al igual que la enseñanza en general, la didáctica matemática debe ir más allá del simple hecho de comunicar las fórmulas o contenidos matemáticos (Bishop, 1999), una verdadera comprensión involucra experiencias e interacciones que 
generen un aprendizaje significativo, lo que se considera importante es que el alumno aprenda, domine y aplique matemáticas, más no que se esfuerce por memorizar.

El aprendizaje y la enseñanza no solamente se concentran en la adquisición de conocimientos y habilidades específicas de una materia, sino también en el desarrollo de la personalidad y las habilidades de los alumnos, y justo es dentro de las matemáticas donde se carece de aplicabilidad y contextualización de las fórmulas y procedimientos matemáticos en la vida cotidiana, conduciendo a la adquisición de "supuestos conocimientos" que terminarán olvidándose.

Dentro del proceso de enseñanza de las matemáticas, Ávila, Ibarra y Grijalva (2012) llegan a la conclusión de que los significados que los estudiantes asignan a los objetos matemáticos, están determinados en gran medida por el contexto educativo, entendido como el conjunto de elementos presentes en el proceso de estudio, entre los cuales están incluidos los sistemas de prácticas utilizados por los sujetos participantes en el proceso, es decir, por docentes y alumnos.

Por otro lado Blanco (1998) considera que la verdadera causa de las dificultades en matemáticas, es la representación de las ideas en sí, ya que es realmente un desafío establecer un puente entre los conocimientos previos y ordinarios con los conocimientos matemáticos que requieren un nivel considerable de abstracción y que muy pocas veces son relacionados con aspectos prácticos y aplicables en la vida cotidiana, no se trata simplemente de fórmulas y números por repetir y memorizar, sino de comprender su origen y lo que representan realmente:

"La imposición de unos conocimientos no comprendidos por el niño lleva a éste a memorizarlos, a repetirlos mecánicamente. La única utilidad de los conocimientos mecanizados es la de permitir al niño superar unas pruebas que le dan acceso a un curso superior. Nada más.” (Moreno, 2001, p. 34).

Lo importante no es reunir mucha información, sino, poder codificarla, integrarla, contextualizarla e interpretarla, darle sentido y significación, en palabras de Carbonell (2014): transformarla en verdadero conocimiento, siendo el lenguaje un factor primordial en todo este proceso, ya sea oral, escrito, corporal, representa una herramienta clave en la formación de representaciones y en la generación de significados. En este sentido, diversos autores mencionan que la verdadera causa de los defectos en la enseñanza matemática, se encuentra en su lenguaje, ya que la representación del mismo implica numerosas y graves imprecisiones y ambigüedades, hasta llegar al punto de que los estudiantes simplemente no pueden comprender los verdaderos significados (Kline, 1990).

\section{Lo "formal" del lenguaje matemático, ¿el verdadero problema?}

El lenguaje es una herramienta que no deja de estar vigente en la interacción del ser humano con la sociedad y mucho menos en el proceso de enseñanza del estudiante; permite una comunicación y es un instrumento indispensable para el afianzamiento de los conocimientos adquiridos en cualquier contexto (Herrero, 2012), sin embargo Solovieva y Quintanar (2013) consideran que el lenguaje no solo permite la comunicación, sino que también regula toda actividad, participando en la consolidación de procesos psicológicos previos al aprendizaje escolar tal como la adquisición simbólica. 
Para Godino, Contreras y Font (2006) los significados personales que desarrollan los estudiantes son influenciados directamente por los significados institucionales, refiriéndose a los constructos de sistemas de prácticas colectivas que frecuentemente están representadas por el docente, pues dichos significados no se desarrollan exactamente de forma individual, sino como resultado de las múltiples interacciones de los aprendices con su cultura.

Por lo que las matemáticas, al igual que otras asignaturas hace uso de un lenguaje particular para ser comprendido. El lenguaje matemático se compone no solo de fórmulas y procedimientos sino de signos y símbolos que permiten comprender las ideas que se expresan (Beiza, 2015). El conocimiento y uso del lenguaje matemático es necesario, pero resulta deficiente su manejo y aplicación en un nivel medio superior, por lo que al encontrarse en un nivel superior el desconcierto e incomprensión predominan en el alumnado, desconocimiento que conduce a una serie de deficiencias para el alumno que a su vez se traducen en problemas para la comprensión de los nuevos conceptos y deficiencias en los exámenes que llevan al fracaso (Ortega y Ortega, 2008). Es así, que la dificultad de su aprendizaje se presenta debido a la imposibilidad de codificar mensajes matemáticos, por lo que es importante saber descifrar los conceptos y saberlos utilizar, además de que es necesario tener un conocimiento previo que facilite la adquisición de un nuevo aprendizaje (Godino, 2002).

De acuerdo con Martín, Paralera, Romero y Segovia (2008), cuando se habla del lenguaje matemático se habla de dos cuestiones distintas pero interrelacionadas, por un lado la simbología utilizada en matemáticas, y por otro, la estructura y presentación de los contenidos matemáticos. Los símbolos matemáticos se deben conocer para poder interpretar lo que se quiere decir con ellos, tales términos, signos o caracteres gráficos tienen un significado concreto y particular, no hay cabida para ambigüedades en este punto. Por otro lado, al hablarse de la presentación de los contenidos matemáticos pueden existir errores en la expresión, en la manera en que se abordan y explican los conceptos, fórmulas o procedimientos matemáticos, por lo que los alumnos bajo esa situación tendrán muchas dificultades para avanzar en los conocimientos adquiridos al desconocer la base de las herramientas matemáticas (Ortega y Ortega, 2008).

Bajo estos principios Martín, Paralera, Romero y Segovia (2008), proponen una acción tutorial con el objetivo de motivar a los alumnos el interés por las matemáticas, relacionando a estas mismas con aspectos cotidianos de la vida, como libros y matemáticas, cine y matemáticas, pintura y matemáticas, contextualizando el uso y aplicación que tienen; tal propuesta resulta interesante ya que demuestra el hecho de que las matemáticas en sí no constituyen el problema, sino su explicación, expresión y con ello, su enseñanza.

Es en este punto que surge la importancia del discurso docente, representando una pieza clave en la formación de conceptos y significados en el alumnado, ya que el análisis del uso de estrategias discursivas en el ámbito escolar ha logrado relevantes contribuciones en la investigación y en la práctica educativa (Ruiz, Sánchez, Meraz y Suárez, 2007).

Mercer (2001) denomina estrategias discursivas a determinadas formas técnicas particulares de conversación que los profesores emplean al dirigir la construcción de conocimiento de sus alumnos. Azcárate y Camacho (2003) diferencian entre los conceptos matemáticos definidos formalmente y los que recurren a explicaciones más simples y sencillas, teniendo resultados de asimilación diferente. "Adquirir un concepto matemático se puede describir como construir un esquema conceptual del mismo." (Azcárate y Camacho, 2003, p. 141) Saber de memoria la definición de un concepto no garantiza comprender su significado, en realidad comprender significa tener un esquema conceptual de forma que se asocien ciertos significados a la palabra que designa el concepto: imágenes mentales, propiedades, procedimientos, experiencias, sensaciones. 
"Desde un punto de vista cognitivo, parece que los autores de libros de texto y muchos profesores dan por supuesto que se produce el aprendizaje a partir de las definiciones y que en la resolución de problemas y realización de tareas son estas las que se activan en la mente del estudiante y controlan el proceso". (Azcárate y Camacho, 2003, p. 141).

Sin embargo, lo que ocurre en la práctica, es que el esquema conceptual se construye a partir de la experiencia del estudiante, es decir a partir de situaciones muy variadas. Los alumnos tienden a realizar sus tareas de forma espontánea, de acuerdo con los hábitos adquiridos en la vida cotidiana, elaborando sus respuestas a partir de los elementos de sus esquemas conceptuales evocados por el contexto de la situación. Comprender significa percibir algo, captar su significado, entender con claridad lo que quiere decir alguien; justamente la semiótica, ciencia que estudia los signos y símbolos que expresan las representaciones (Beiza, 2015), colabora en el estudio y comprensión del lenguaje matemático, y al mismo tiempo, en el proceso enseñanza-aprendizaje de las matemáticas.

El tipo de estrategias, las técnicas o procedimientos a los que se recurra, es decir la didáctica, muchas veces es la que determina el nivel de atención y comprensión en el alumnado, porque no es lo mismo basar una clase en exposiciones y discurso unidireccional, que complementar con ejemplos, diagramas, dibujos y esquemas, los cuales son guardados de forma distinta en el cerebro y hay más posibilidad de recordarlos (Álvarez, 2012).

\section{Recursos semióticos como estrategia didáctica docente}

Dentro de los estudios e investigaciones lingüísticas se aborda el concepto de recursos u objetos semióticos, los cuales representan todos aquellos objetos que constituyen en sí mismos un sistema de signos, utilizados para significar el mundo, de gran relevancia en la enseñanza ya que permiten la construcción e intercambio de significados (Domínguez, 2010; Mangui, 2010).

Para Duval (1999) el comprender a través de las representaciones semióticas un objeto matemático (algo que represente valores, ya sean implícitos o explícitos) debe desarrollarse a través de tres funciones, la primera es la comunicación, refiriéndose a la relación social con el objeto, la segunda es el tratamiento, que está relacionada con el desarrollo de las matemáticas, es decir, son las nuevas ideas que surgen a partir del objeto matemático, y por último la objetivación, que se refiere a la toma de conciencia del sujeto sobre el objeto. Dicha transformación de la información es la que va a permitir tener mejor conocimiento acerca de la representación semiótica original.

Para pensar y comunicar ideas matemáticas se necesita representarlas de alguna manera, y la comunicación exige que la representación sea externa, tomando la forma del lenguaje hablado, símbolos escritos, dibujos u objetos físicos (Hiebert y Carpenter, 1992), es decir, representar de diferentes maneras (lenguajes) un mismo objeto matemático, en este sentido Duval (1999) considera que la comprensión de matemáticas requiere la coordinación de al menos dos registros de representación semiótica.

Rico (1997) destaca la importancia de las representaciones semióticas, considerándolas como el modo en que los sujetos expresan sus conocimientos a través de las notaciones simbólicas o mediante algún tipo de gráfico, ya que mediante las representaciones las personas organizan la información sobre un concepto u operación, con el fin de poder pensar en ellos, expresar su comprensión y utilizarla en problemas prácticos o en situaciones escolares. 
De este modo surgen diversos trabajos y líneas de investigación enfocadas al uso de los antes llamados recursos semióticos en el campo de la enseñanza matemática.

Tamayo (2006) destacó la importancia de orientar los procesos de enseñanza desde una perspectiva multimodal en la que se propicie la construcción de diferentes representaciones por parte de los estudiantes y frente a las cuales los profesores actúen de manera intencionada y consciente en su proceso de enseñanza, para ello habló de las representaciones semióticas, refiriéndose a aquellas construcciones de sistemas de expresión y representación que pueden incluir diferentes sistemas de escritura como números, notaciones simbólicas, representaciones tridimensionales, gráficas, diagramas, esquemas, etc., que cumplan funciones de comunicación y expresión.

En la investigación de Mangui (2010) sobre la enseñanza de matemáticas de dos profesores, identificó dos principales recursos semióticos: el habla o lenguaje verbal y los gestos deícticos, en concordancia con Hernando (2009), quien habló sobre el lenguaje verbal como instrumento matemático, concluyendo y recomendando involucrar en mayor proporción el lenguaje verbal en las clases de matemáticas, pues considera a ésta una poderosa herramienta para mejorar la comprensión, tanto matemática como lingüística. Del mismo modo, Macias (2014) menciona que una de las representaciones semióticas como lo es la lengua (lenguaje) natural, juega un papel importante en el proceso de enseñanza-aprendizaje, refiriendo también que en el caso de las matemáticas, el empleo de símbolos, tablas, gráficas, figuras, construcciones geométricas, etc., favorecen las operaciones cognitivas afianzando los conocimientos que se pretende que el estudiante adquiera, recursos que complementan el discurso docente.

Trabajos como el de González, Escotto, Sánchez y Baltazar (2016) quienes abordaron el uso de los recursos semióticos y la estadística, concluyeron que a pesar de que ésta se base en un lenguaje particularmente matemático, el discurso docente también tiene un bagaje de recursos semióticos no formales, como lo son: el lenguaje no formal, el uso de medios didácticos como el pizarrón, tablas, gráficas, dibujos, etc., que ayudarán a explicar temas que en un principio sólo tendían a explicar los aspectos formales en las matemáticas.

A su vez Velázquez, Escotto, Sánchez y Baltazar (2016) analizaron los recursos semióticos en el proceso enseñanza-aprendizaje de la estadística en dos profesores, encontrando que los recursos semióticos no formales como: contextualizar ejemplos, uso del lenguaje verbal natural y ejemplos de uso cotidiano o cualquier otro recurso que apoye a la integración de la información, favorecen al aprendizaje haciéndolo más accesible para los estudiantes.

Como se ha mencionado, el conocimiento matemático o mejor dicho las matemáticas se apoyan en un lenguaje formal específico, que presenta notables diferencias con el lenguaje natural, pues implican un conjunto particular de sistemas notacionales, busca la precisión, el rigor, la abreviación y la universalidad y su finalidad fundamental no es tanto la representación o comunicación de fenómenos o situaciones reales cuanto la posibilidad de obtener resultados internamente consistentes, pues para ello realiza inferencias válidas en términos del propio sistema axiomático que constituye el conocimiento matemático, por lo que la elaboración y el desarrollo del conocimiento matemático no se puede separar, en este último sentido, de la acción concreta sobre los objetos, de la intuición y de las aproximaciones inductivas ligadas a tareas, problemas y contextos particulares, ni tampoco de los instrumentos y tecnologías de representación culturalmente elaboradas en apoyo de la actividad matemática (Bishop, 1999). 


\section{Conclusiones}

El proceso enseñanza-aprendizaje de las matemáticas es uno de los más complejos, hace necesaria una expresión adecuada que se aleje de las ambigüedades; sin embargo, parece que los docentes no terminan de comprender, o pasar por alto, que en ellos y en su discurso se encuentra el poder para expresar de forma más sencilla los conceptos y fórmulas tan difíciles de entender.

Las características del modelo tradicional educativo se quedan cortas al tratar de mejorar la didáctica en la enseñanza de las matemáticas, ya que, de acuerdo a la opinión y rendimiento académico de alumnos en diversas investigaciones, se puede

concluir que clases con predominio de un lenguaje formal provocan en los alumnos una menor comprensión de contenidos matemáticos y bajas calificaciones, a diferencia de clases que integran diversos recursos semióticos para complementar su discurso, tales como dibujos, esquemas o ejemplos, que mejoran la codificación y asimilación de temas y contenidos que pareciera son de gran dificultad.

Por lo tanto, el factor primordial en la enseñanza matemática es el lenguaje, herramienta esencial en el intercambio y generación de significados, que a su vez permite y regula la consolidación de procesos psicológicos previos al aprendizaje escolar tal como la adquisición simbólica. Un lenguaje claro y común entre alumnos y docentes conduce a una mejor comprensión y una importante mejora del proceso enseñanza-aprendizaje, situación que indudablemente propicia el dominio de los conceptos y procedimientos para después generar habilidades.

El empleo de recursos semióticos viene a convertirse en una estrategia didáctica ideal para la generación de aprendizaje significativo en el campo de las matemáticas, resultando en una mejor comprensión, mediante representaciones semióticas desplegadas a través de la comunicación (relación social), el tratamiento (nuevas ideas desarrolladas del objeto matemático), y la objetivación (toma de conciencia del sujeto sobre el objeto). Con lo cual se obtiene una transformación de la información que permite tener mejor conocimiento acerca de la representación semiótica original, es decir, los recursos semióticos facilitan la enseñanza, cuestión que había representado múltiples dificultades para estudiantes de diferentes niveles educativos debido a la complejidad de los conceptos y de las tareas mismas, esto traducido en bajo rendimiento y desmotivación, que a su vez se liga con suposiciones que denotan incertidumbre ante las matemáticas.

Los diversos materiales e investigaciones que se han sido expuestos en páginas anteriores resaltan la importancia del empleo de recursos semióticos y su efecto en el proceso enseñanza-aprendizaje, evidenciando la necesidad de integrar mejoras al modelo tradicional de enseñanza en el aula basado en la repetición y memorización, sin una verdadera comprensión y aprehensión de los contenidos, es decir la incorporación de recursos semióticos en el discurso de los docentes es indispensable para que la educación se traslade del modelo basado en la generación de un aprendizaje mecánico a un modelo dinámico

Entonces regresamos a una de las preguntas principales, ¿el problema se encuentra o no en las matemáticas?, la información obtenida y analizada nos ha permitido corroborar que debido a su naturaleza universal y concreta, las matemáticas por sí mismas no representan la causa principal de las dificultades al aprender esta ciencia, se trata más bien de la manera en que son representados sus contenidos, porque no es lo mismo desarrollar una fórmula 
y su procedimiento en el pizarrón para que los alumnos la copien, que una explicación del mismo tema pero con ayuda de otros recursos, de ejemplos que permitan aplicar, de dibujos o imágenes que ejemplifiquen los datos.

Lo que si puede representar una causa de las dificultades, es el hecho de que los docentes desconocen el impacto de sus acciones, de que pueden encontrar nuevas maneras para explicar los temas que existen desde siempre; son los recursos semióticos una de esas alternativas, que el docente no solo es capaz debe utilizar, sino que tiene un gran impacto en el proceso educativo.

La importancia de los recursos semióticos es establecer una introducción de los contenidos (significados) complejos de las matemáticas, pero en un lenguaje claro y común para los estudiantes, lo cual requiere grandes habilidades y competencias del profesor así como compromiso y correspondencia de los estudiantes con su propio aprendizaje.

El uso de recursos semióticos debe difundirse a los profesionales de la educación y entonces diseñar de acuerdo a ello programas de formación docente, estructurar planes y programas educativos, con la principal finalidad de: mejorar la enseñanza, con ello reducir la prevalencia de fracaso en su enseñanza y aprendizaje de las matemáticas.

\section{Referencias}

IIII Álvarez, G. (2012). Hacia una propuesta de análisis semiótico integral de ambientes virtuales de aprendizaje. OMNOMÁZEIN, 25(1), 219-239.

IIII Arregui, I. (2015). Instrumento para evaluar el desempeño docente en educación secundaria desde la percepción de los estudiantes. 2do Congreso Latinoamericano de Medición y Evaluación Educacional colmee México.

IIII Ávila, R., Ibarra, S. \& Grijalva, A. (2012). El contexto y el significado de los objetos matemáticos. Revista Latinoamericana de Investigación en Matemática Educativa, 13(4), 337-354.

IIII Azcárate, C. \& Camacho, M. (2003). Sobre la Investigación en Didáctica del Análisis Matemático. Boletín de la Asociación Matemática Venezolana, 10(2), 135-149.

IIII Beiza, E. (2015). Semiótica en la comprensión del lenguaje matemático. Tesis maestría en Investigación Educativa. Universidad de Carabobo

IIII Blanco, L. (1998). Otro nivel de aprendizaje: perspectivas y dificultades de aprender a enseñar Matemáticas. Cultura y Educación, 9, 77-96-

IIII Calero, M. (2009). Aprendizaje sin límites. Constructivismo. México: Alfaomega.

IIII Caraballo, A., Paralera, C., Romero, E. \& Segovia, M. (2008). Una acción tutorial: mejora de la lectura y comprensión del lenguaje matemático. Revista Estatal de Docencia Universitaria (REDU).

IIII Chiecher, A., Danolo, D. \& Rianudo, M. (2005). Percepciones del aprendizaje en contextos presenciales y virtuales. La perspectiva de alumnos universitarios. Revista de Educación a Distancia, 5(13), 2-10.

IIII Coll, C. (2001). Estrategias discursivas y recursos semióticos en la construcción de sistemas de significados compartidos entre profesor y alumnos. Investigación en la escuela, 45, 21-32. 
IIII Corona, G., Escotto, E., Sánchez, G. \& Baltazar, A. (2016). Los recursos semióticos del profesor asociados al rendimiento académico de los estudiantes. Revista Electrónica de Psicología de la FES Zaragoza-UNAM, 6(11), 15-33.

IIII Cuadrado, I. (1992). Implicaciones de la comunicación no-verbal en el aula. Cáceres:Servicio de Publicaciones de la Universidad de Extremadura.

IIII Defior, S. (2000). Las dificultades de aprendizaje: un enfoque cognitivo: lectura, escritura, matemáticas. España: Aljibe.

IIII Díaz, E. (2012). Factores que podrían afectar el aprendizaje matemático. En L.Fierro (Presidencia), 1er Congreso Internacional de Educación. Universidad Autónoma de Chihuahua.

IIII Drouhard, J. \& Panizza, M. (2009). Aspectos semióticos y lingüísticos en didáctica de la matemática. II IIII IIII Jornadas de Enseñanza e Investigación Educativa en el campo de las Ciencias Exactas y Naturales. 28 al 39 de octubre de 2009.

IIII Duval, R. (1999). Semiosis y pensamiento humano. Registros semióticos de aprendizajes intelectuales. Universidad del Valle, Instituto de Educación y Pedagogía. Cali: Grupo de Educación Matemática.

IIII Espino, E. (sf). Semiótica y relación pedagógica: Hacia la cualificación ética de la práctica docente. Revista Iberoamericana de Educación.

IIII Florez, R. (1944). Hacia una pedagogía del conocimiento. Colombia: Mc Graw Hill.

IIII García, J. (2002). Motivación y autoaprendizaje elementos clave en el aprendizaje y estudio de los alumnos. Revista de la Facultad de Educación de Albacete, 17, 191-217.

IIII Giménez, J. (1994). Lenguaje verbal y matemáticas: separación sin relaciones. Estado de la investigación. SUMA Revista sobre la enseñanza y aprendizaje de las matemáticas, 16, 54-67.

IIII Godino, J. (2002). Un enfoque ontológico y semiótico de la cognición matemática. Recherches en Didactique des Mathématiques, 22(3), 237-284.

IIII Godino, J., Contreras, A. \& Font, V. (2006). Análisis de procesos de instrucción basado en el enfoque ontológicosemiótico de la cognición matemática. Departamento de Didáctica de la Matemática, Facultad de Ciencias de la Educación, Granada. 22(3), 237-284.

IIII González, V., Escotto, E., Sánchez, G. \& Baltazar, A. (2016). Recursos semióticos en la estadística: Alternancias de lenguaje en el discurso docente. Estudio de caso. Revista Electrónica de Psicología de la FES ZaragozaUNAM, 6(12), 45-63.

IIII Hernando, H. (2009). El lenguaje verbal como instrumento matemático. Investigación Pedagógica, 12(3), 1331.

IIII Herrero, P. (2012). La interacción comunicativa en el proceso de enseñanza-aprendizaje. ReiDoCrea. Revista electrónica de investigación Docencia Creativa, 1, 138-143.

IIII Hiebert, J. \& Carpenter, T. (1992). Learning and Teaching with Understanding, Grouws, DA. Handbook of Research on Mathematics Teaching and Learning.

IIII J. Bishop, A. (1999). Enculturación Matemática. La educación matemática desde una perspectiva cultural. España: Paidós. 
IIII Macías, J. (2014). Los registros semióticos en Matemáticas como elemento personalizado en el aprendizaje. Revista de Investigación Educativa Conect@2, 4(9), 27-57.

IIII Manghi, D. (2010). Recursos semióticos del profesor de matemática: funciones complementarias del habla y los gestos para la alfabetización científica escolar. Estudios pedagógicos. 36(2), 99-115.

IIII Mercer, N. (2001). Palabras y mentes. Cómo usamos el lenguaje para pensar juntos. Buenos Aires: Paidós.

IIII Organización para la Cooperación y Desarrollo Económico (OCDE) (2012). Programa para la Evaluación Internacional de Alumnos (PISA) PISA 2012 resultados.

IIII Organización para la Cooperación y Desarrollo Económico (OCDE) (2016). Estudiantes de bajo rendimiento: Por qué se quedan atrás y cómo ayudarles a tener éxito.

IIII Radovic, D. \& Preiss, D. (2010). Patrones de discurso observados en el aula de matemática de segundo ciclo básico en Chile. Psykhe, 19(2), 65-79.

IIII Rico, L. (1997). Bases teóricas del currículo de matemáticas en educación secundaria. Madrid: Síntesis.

IIII Romero, J. \& Lavigne, R. (2004). Dificultades en el aprendizaje: Unificación de Criterios Diagnóstico. VOL. 2. España: Junta de Andalucía.

IIII Ruiz, E., Sánchez, R., Meraz, S. \& Suárez, P. (2007). Análisis de estrategias discursivas en docentes, desde la aplicación del instrumento ESTI. Psicología y Ciencia Social, 9(2), 42-49.

IIII Solovieva, Y. \& Quintanar, L. (2013). Evaluación del desarrollo simbólico en niños preescolares mexicanos. Cultura y Educación, 5(2), 167-182.

IIII Torres, H. \& Girón, D. (2009). Didáctica general. Costa Rica: Coordinación Educativa y Cultural Centroamericana.

IIII Tünnermann, C. (2011). El constructivismo y el aprendizaje de los estudiantes. Universidades, 61(48), 21-32.

IIII Velázquez, J., Escotto, E., Sánchez, G. \& Baltazar, A. (2016). Análisis de recursos semióticos para el proceso de enseñanza-aprendizaje en clases de estadística. Revista Electrónica de Psicología de la FES ZaragozaUNAM, 6(11), 34-57. 


\section{CAPítulo 5}

\section{La escritura como herramienta en la resolución de problemas de geometría}

Luz Graciela Orozco Vaca

Ricardo Quintero Zazueta

\section{Introducción}

En este trabajo se describe un experimento de enseñanza para explorar si el escribir de forma sistematizada puede ser una herramienta que facilite a los estudiantes de secundaria la resolución de problemas. En el diseño de este experimento se plantea utilizar estrategias de escritura como organizador de los elementos que intervienen en distintas fases de un ciclo de actividades para la resolución de problemas de geometría en tercero de secundaria.

La aplicación de estas fases va enfocada directamente en la escritura, debido a que consideramos que la escritura guía a los estudiantes para hacer conjeturas, preguntas y reflexiones durante todo el proceso de las actividades, además les ayuda a organizar y evaluar las soluciones que obtienen en los problemas. Proyectamos que la escritura funcionaría como herramienta metacognitiva y nos ayudaría a provocar en los estudiantes un proceso de análisis de sus conceptos matemáticos y técnicas de trabajo.

Para auxiliar a los estudiantes en el desarrollo de las actividades, de acuerdo con las cinco fases del ciclo, se diseñaron preguntas sencillas, con la intención de inducirlos gradualmente para que a través de la escritura comenzaran un análisis de la información proporcionada en el problema, continuaran con la exploración y representaciones necesarias para interpretar la situación del problema y finalmente siguieran los procedimientos adecuados, verificando por medio de la justificación que llegaron a la respuesta correcta y se dieran cuenta cómo lo hicieron.

La presentación de los resultados de esta investigación está organizada de la siguiente manera: primero los fundamentos teóricos de la escritura y las herramientas metacognitivas que dieron sustento a esta investigación. Enseguida se detallan los objetivos del experimento realizado que incluyó el diseño de un taller de resolución de problemas, donde se dio el uso de las preguntas planteadas como guías para ayudar a los estudiantes en la búsqueda de resolución de problemas. Por último, se examinan los resultados de la aplicación de las actividades en los procesos aplicados por los estudiantes participantes en este experimento. 


\section{La escritura como una forma de pensamiento}

Al hablar de escritura, en algunos casos (Bolton, 2011), ésta se interpreta únicamente como un medio de expresión, para comunicar información; en otros (Henning, Gravett y van Resburg 2002), como parte de los procedimientos que se pueden usar para pensar con claridad y construir un conocimiento, en si la escritura es pensamiento en acción.

Esta investigación se enfoca en la segunda descripción, los procedimientos que siguen los estudiantes, con el seguimiento de las preguntas propuestas, para comunicar sus procesos a lo largo de la resolución del problema. La escritura puede ayudar a los estudiantes a consolidar lo que piensan, por ejemplo: representar con dibujos y diagramas la información de conocimientos nuevos, agregándoles explicaciones verbales realizadas con sus propias palabras, así como las narraciones o producciones de diálogos que requieren de la reflexión sobre lo que entendieron y la descripción de los elementos de cada concepto matemático.

La escritura tiene múltiples ventajas, ya que al trabajarla en la resolución de problemas permite identificar posibles fuentes de error y con ello la consideración de como remediarlo, además ayuda al docente a identificar la comprensión de los conceptos matemáticas que tienen los participantes, así como las dificultades que se les presentan para guiarlos a un razonamiento coherente en estas situaciones (Zaskis et al. 2014, Carter 2009).

\section{La visión de metacognición en la educación de acuerdo con Veenman}

Con el propósito de entender el papel que juega la metacognición en la educación científica (biología, química y física) Veenman (2012) hace un análisis de la literatura de investigaciones en educación donde ésta interviene. Examina las múltiples diferencias en cuanto a la descripción de este concepto por cada autor, así como la falta de acuerdo existente acerca de los componentes de la metacognición y la relación que se establece entre estos elementos (Veenman 2006). Encuentra útil hacer una distinción en el conocimiento metacognitivo y las habilidades metacognitivas.

El conocimiento metacognitivo lo describe como el conocimiento sobre el sistema cognitivo, como un conocimiento declarativo sobre la interacción entre la persona, la tarea que realiza y las características de la estrategia que utiliza. El conocimiento metacognitivo tiene sus raíces en las creencias de una persona y es un requisito para la obtención de habilidades metacognitivas.

Veenman está de acuerdo con Flavell (1970) en los dos sub-componentes del conocimiento metacognitivo: La meta-memoria que es el conocimiento declarativo sobre las capacidades y los procesos que afectan a la memoria. El Conocimiento Condicional que es el conocimiento declarativo de cuando aplicar una estrategia y con qué propósitos. Al aplicar una estrategia metacognitiva de forma consciente, paso a paso y gradualmente se transforma en una habilidad metacognitiva.

El conocimiento metacognitivo se evalúa a través de cuestionarios aplicados después de realizar la tarea, pregunta por pregunta o por medio de entrevistas retrospectivas, aunque no se puede reflejar el conocimiento que realmente se utiliza durante la realización de la tarea (Veenman 2005). 
Las habilidades metacognitivas las describe Veenman (2012) como la regulación de los procesos cognitivos, es decir la capacidad adquirida de la supervisión, orientación, dirección y control de la propia conducta en el aprendizaje y la resolución de problemas. En sí las habilidades metacognitivas son las propias actividades de aprendizaje y son el principal determinante de los resultados en el mismo.

Veenman hace una distinción entre las actividades que considera representativas de las habilidades metacognitivas y las separa en actividades en el inicio, durante la ejecución y al final de la realización de cada tarea, como podemos ver en la Tabla 1.

Estas habilidades metacognitivas, presentan una dificultad recurrente que se exterioriza cuando siendo actividades de orden superior se describen en gran medida en términos de procesos cognitivos de orden inferior. Por ejemplo: en el análisis de la asignación de una tarea se requiere un procedimiento de lectura y razonamiento, la toma de notas obedece a la línea de escritura, la evaluación y reflexión implica hacer comparaciones, las cuales son habilidades metacognitivas. En sí las habilidades metacognitivas constituyen la dirección mientras que los procesos cognitivos integran el medio para el empleo de esas habilidades.

TABLA 1. Habilidades Metacognitivas.

\begin{tabular}{|l|l|l|}
\hline \multicolumn{2}{c}{ Actividades de Aprendizaje } \\
\hline Al inicio de la ejecución de tarea & \multicolumn{1}{c|}{ Durante la ejecución de tarea } & \multicolumn{1}{l|}{ Después de la ejecución de tarea } \\
\hline Lectura & Seguir un plan & Evaluación del desempeño \\
Análisis de la asignación de tareas & Cambiar el plan & Recapitulación \\
Activación de los conocimentos & seguimiento & Reflexión sobre el proceso de \\
previos & Control & aprendizaje \\
Establecimiento de metas & Toma de notas & \\
Planificación & Tiempo y gestión de recursos & \\
\hline
\end{tabular}

El inconveniente de esclarecer las habilidades de orden superior (metacognitivas) y de orden inferior (cognitivas) está fijada en la teoría psicológica. Debido a ello el significado de metacognición tiene en común el enfoque de "cognición de orden superior sobre la cognición" (Flavell, 1979; Nelson, 1999). Estas concepciones enfatizan el papel de la metacognición en la supervisión del inicio y control de los procesos cognitivos.

A partir del modelo de Nelson, Veenman (2011) sugiere que la metacognición podría adoptar la perspectiva de un modelo de auto-instrucciones de arriba hacia abajo para la regulación de la ejecución de las tareas. Este proceso se puede activar como un programa adquirido mediante una lista de auto-instrucciones que se aplican cada vez que el estudiante se enfrenta a la realización de actividades. Veenman sugiere que este programa de autoinstrucciones podría ser representado por un sistema de producción de reglas condición-acción que trabajaron otros investigadores (Anderson 1996, Bluter y Winne 1995, Schunn y Anderson 1999):

- Si se encuentra con una tarea, entonces, busque la asignación de tareas y tome nota de ello.

- Si tiene una idea acerca de la asignación de tareas, entonces trate de buscar en su memoria todo lo que sabe del tema.

- Si entiende la asignación de las tareas, entonces, formule el objetivo que persigue.

- Si ha definido su meta, entonces, diseñe un plan de acción para lograr su objetivo. 
- Si tiene el plan de acción, entonces, continúe el plan de manera insistente.

- Si está ejecutando su plan de acción, entonces, mantenga estrecha vigilancia con lo que está haciendo y manifieste cualquier anomalía.

Este sistema incorpora una lista de instrucciones metacognitivas auto-inducidas en el sistema cognitivo. Por lo tanto va en línea con el modelo de Nelson, las auto-instrucciones incitan varias actividades cognitivas a nivel de objeto (la tarea).

Para Veenman es importante reconocer que tanto los procesos cognitivos como las auto-instrucciones metacognitivas que están involucrados en la ejecución de las instrucciones son parte del mismo sistema cognitivo. Siempre son necesarias las actividades cognitivas para la ejecución de cualquier proceso relacionado con una tarea en el nivel de objeto, mientras que la actividad metacognitiva representa el directivo en función de meta-nivel para la regulación de la actividad cognitiva.

Con el fin de explicar con más claridad la situación de las actividades cognitivas y metacognitivas en una tarea, Veenman compara las actividades cognitivas con los soldados y las auto-instrucciones metacognitivas con el general. Explicando que un general sin soldados no puede ganar la guerra y por otro lado todo el ejército desorganizado no podrá tener éxito. En sí las auto-instrucciones metacognitivas dirigen siempre las actividades cognitivas, y si no tienen esta orientación no puede lograrse la tarea propuesta.

Las habilidades metacognitivas son mecanismos que tienen lugar dentro de la cabeza y permanecen encubiertas (Veenman 2006) en consecuencia no se pueden evaluar directamente, pero tienen que ser deducidas de sus resultados conductuales (Veenman 2007). La forma de evaluar las habilidades metacognitivas es a través de dos métodos: en línea y fuera de línea (Veenman 2005). Los métodos en línea son las evaluaciones durante la realización de la tarea, como: la observación, el pensamiento en voz alta, el registro en una computadora del proceso de aprendizaje. Los métodos fuera de línea son cuestionarios o entrevistas que se pueden aplicar antes o después de la ejecución de las tareas, que adolecen los mismos problemas de validez como los de la evaluación del conocimiento metacognitivo.

Veenman (2012) detalla como las habilidades metacognitivas se afinan principalmente a través de cuatro tipos de procesos de aprendizaje: lectura de texto, resolución de problemas, aprendizaje por descubrimiento y escritura. Estas habilidades metacognitivas las relata el autor directamente enfocadas a la educación científica (Física, Química y Biología) puntualizando el desarrollo que se lleva a cabo en todos los cursos de estas materias: los estudiantes deben leer los libros de texto con el fin de adquirir la comprensión conceptual, para después aprender mediante el razonamiento y la aplicación de fórmulas, continuar con el diseño y planificación para llevar a cabo experimentos en los laboratorios y finalmente escribir los informes de los resultados obtenidos.

Veenman afirma que en el campo de la enseñanza de las ciencias las actividades de lectura, resolución de problemas, indagación y la escritura siempre están en conexión. La orientación, el establecimiento de objetivos, la planificación, el seguimiento y la evaluación son indispensables para todos los procesos de aprendizaje en la educación científica. Aunque aclara que la reflexión no siempre se menciona en las investigaciones, tal vez debido a que aparece después de la finalización de las tareas. 


\section{El trenzado de Hyde "Lenguaje, Pensamiento y Matemáticas"}

Hyde (2006) menciona que el proceso de preguntas (KWC, por sus siglas en inglés) ¿qué sé a ciencia cierta?, ¿qué es lo que quiero averiguar? y ¿hay algunas condiciones o reglas que debo tener en cuenta?, favorece a los estudiantes para analizar la situación del problema, agrega que la visualización ayuda a imaginar la situación y el contexto, hace hincapié en la creación de representaciones para poder identificar patrones en cada concepto o problema y cita las meta-estrategias utilizadas por los estudiantes, las cuales identificó en investigaciones anteriores (Hyde, 1991) en el proceso de resolución de problemas, como se ilustra en la Figura 1.

Hyde (2006) hace hincapié que el contexto del trenzado beneficia a los niños para imaginar, visualizar y conectar las matemáticas con el contexto. Afirma que este modelo se ha utilizado con eficacia en la instrucción de una clase con grupos pequeños y con el apoyo del maestro. Las preguntas son eficaces para discutir el problema en grupos pequeños, así como las estrategias de representación en el lenguaje oral, de esta manera los estudiantes comienzan a internalizar estas preguntas para utilizarlas por si mismos durante las tareas posteriores.

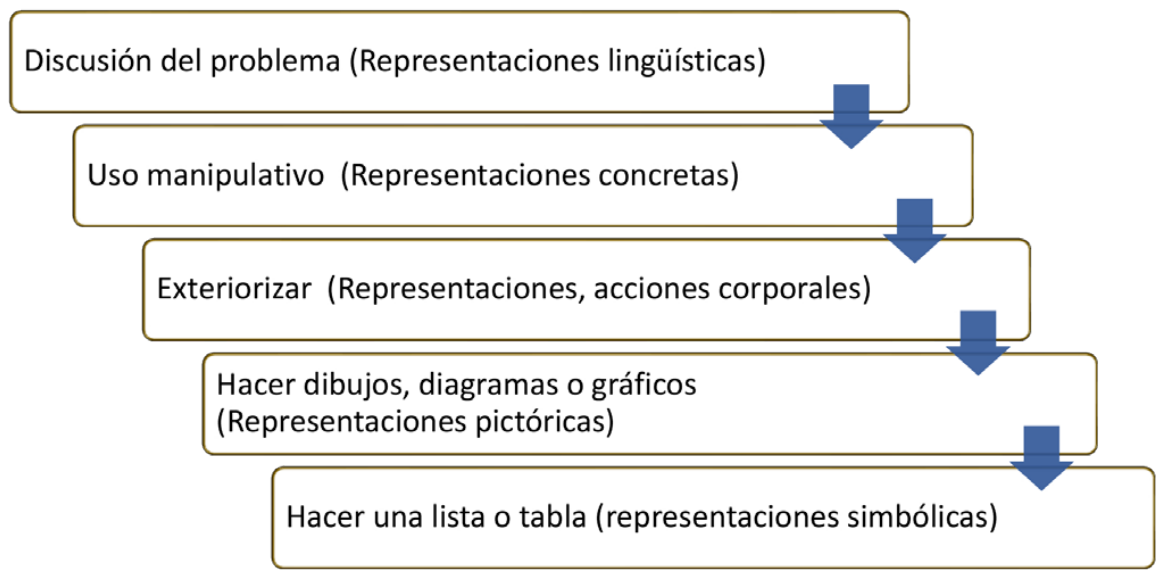

FIGURA 1. Meta-Estrategias de representación identificadas por Hyde y Hyde (1991).

Hyde (2006) se guía por los principios de la psicología cognitiva y utiliza el término de trenzado para indicar que el lenguaje, el pensamiento y las matemáticas pueden ser entrelazados en una sola entidad, logrando que, al hacer conexiones entre estos tres procesos importantes, el resultado sea más fuerte, durable y poderoso que si se trabajará cada uno de forma individual. Con el término trenzado sugiere que las tres componentes son inseparables de apoyo mutuo y necesario. Afirma que cuanto más fuerte son las conexiones entre las ideas relacionadas más profunda y más rica es la comprensión del concepto.

Una vez revisado el trabajo de Veenman (2012), que hace una distinción entre el conocimiento metacognitivo y las habilidades metacognitivas para orientar el desarrollo de éstas en la enseñanza de las ciencias; así como las investigaciones de Hyde $(2006,1991)$ quien aplica el Modelo del Trenzado en educación primaria, para la resolución de problemas en matemáticas; consideramos algunos elementos útiles de dichos trabajos para hacer el diseño del experimento de enseñanza que consiste en utilizar la escritura como herramienta metacognitiva en la resolución de problemas de geometría, lo cual se describe detalladamente en el siguiente apartado. 


\section{El experimento de enseñanza. Método y procedimientos}

El interés de este experimento de enseñanza es aplicar la escritura como herramienta metacognitiva para resolución de problemas de geometría con estudiantes de secundaria. Concebimos la enseñanza como un proceso para la adquisición del conocimiento y la actividad como una secuencia de acciones y preguntas encaminadas a un objetivo particular, con el fin de desarrollar las habilidades metacognitivas de los estudiantes; consecuentemente la escritura es considerada actividad metacognitiva, debido a que facilita al individuo un proceso de monitoreo y revisión de la reflexión del pensamiento que no permite el lenguaje oral.

\section{Diseño del experimento de enseñanza}

A partir de la lista de auto-instrucciones de Veenman (2012) y el modelo de trenzado de Hyde (2006), surge el interés de diseñar un experimento de enseñanza con un procedimiento menos detallado, que el estudiante pueda aplicar por sí mismo, sin la necesidad del apoyo total del docente; de manera que se le proporcione una orientación muy simple, pero útil para que logre llegar a la solución. Por lo tanto la experimentación consiste en apoyar a los estudiantes en la resolución de problemas de geometría, para ello establecemos un plan de cinco fases, poniendo especial atención en el uso de las representaciones y la escritura como herramientas metacognitivas (ver Figura 2).

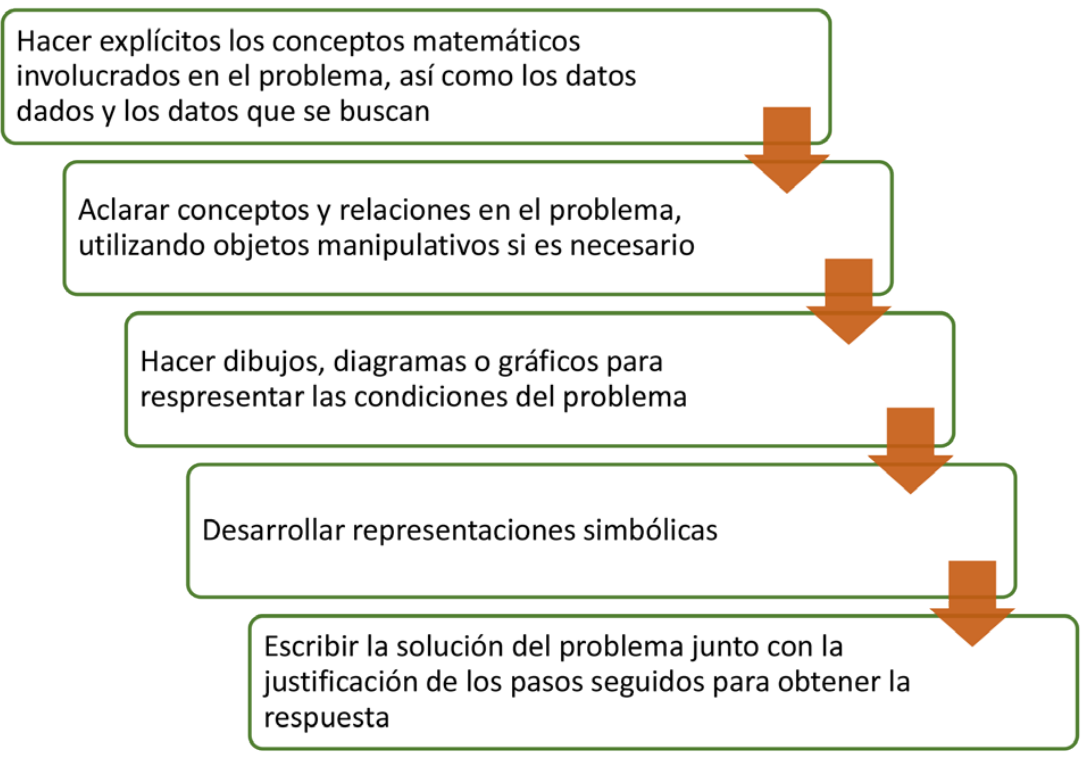

FIGURA 2. Fases del ciclo de actividades para la resolución de problemas.

Las cinco fases del ciclo de actividades de nuestro experimento de enseñanza surgen a partir de las estrategias identificadas por Hyde et al. (1991), en su libro Mathwise: Teaching Mathematical Thinking and Problem Solving, enfocadas en las representaciones que realiza el alumno, pero a diferencia de Hyde nosotros ponemos especial énfasis en la escritura; puntualizándola como medio de registro con el cual podemos exteriorizar lo que pensamos y transmitirlo a los demás, resaltando su funcionamiento como un instrumento para ampliar, explorar e innovar nuestro propio saber, es decir como una herramienta metacognitiva. 
Guiamos a los estudiantes por medio de preguntas sencillas, las cuales los conducen a pasar por cada una de las fases hasta llegar a obtener la solución; en si una lista de auto-instrucciones para la regulación del proceso como propone Veenman (2012). A través de las preguntas los estudiantes paulatinamente incorporan la escritura como instrumento de apoyo en el transcurso de las actividades. Se les invita a utilizarla todo el tiempo en sus hojas de trabajo, y si bien ellos pueden considerarla simplemente como un medio de comunicación, realmente les da todo el apoyo de control y regulación en el proceso de la resolución de los problemas.

Las preguntas (auto-instrucciones de acuerdo con Veenman 2012) designadas en este experimento se enfocan, en primer lugar, en la escritura de los datos que presenta un problema, de manera que ayude a esclarecer lo que sabemos del problema y lo que se entiende del mismo. A continuación la escritura de lo difuso, en lo que se debe profundizar. Posteriormente la escritura de lo que es necesario conocer y finalmente a donde se va a llegar (Tabla 2).

TABLA 2. Relación de las preguntas con las habilidades metacognitivas de Veenman.

\begin{tabular}{|c|c|c|}
\hline $\begin{array}{c}\text { Preguntas diseñadas para utilizar la escritura } \\
\text { como Herramienta Metacognitiva en la Resolución } \\
\text { de Problemas }\end{array}$ & $\frac{\mathbb{4}}{\frac{\mathbb{\alpha}}{\alpha}}$ & $\begin{array}{l}\text { Actividades de Aprendizaje } \\
\text { representativas de } \\
\text { Habilidades Metacognitivas }\end{array}$ \\
\hline ¿Cuáles son los datos que me da el problema? & \multirow{4}{*}{$\frac{0}{\frac{0}{0}}$} & Lectura \\
\hline ¿Qué necesito encontrar? & & Análisis de la tarea \\
\hline ¿Qué conocimientos tengo acerca del tema? & & Activación de los conocimientos previos \\
\hline ¿Cómo le voy hacer? & & Planificación \\
\hline ¿Qué pasos voy a seguir? & \multirow{2}{*}{ 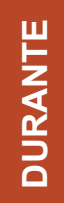 } & Seguir el plan o cambiar el plan \\
\hline $\begin{array}{l}\text { ¿Qué dibujos me pueden ayudar para llegar a la } \\
\text { solución? }\end{array}$ & & Toma de notas \\
\hline ¿Cómo justifico la respuesta que encontré? & \multirow{3}{*}{$\begin{array}{l}\text { 㟔 } \\
\frac{2}{3} \\
\text { 㟔 }\end{array}$} & Evaluación del desempeño \\
\hline $\begin{array}{l}\text { ¿Es el único camino que se puede seguir para llegar a } \\
\text { la respuesta? }\end{array}$ & & Recapitular \\
\hline ¿Qué otras formas puedes aplicar? & & Reflexión sobre el proceso \\
\hline
\end{tabular}

Durante todo el proceso de la resolución del problema se trabaja la escritura de representaciones, las cuales ayudan a recorrer el camino para llegar a la solución. Así se plasma en el papel la comprensión y las reflexiones sobre la información que se tiene, la información que se pide y el proceso que se debe seguir para resolver el problema. Finalmente, el estudiante debe concretar por escrito, la justificación de los resultados obtenidos y la comprobación de que es la solución del problema. Cuando recorre este camino en la resolución del problema -basándose en la escritura- el estudiante monitorea, codifica y establece sus procesos de manera reflexiva, fortaleciendo su aprendizaje. En sí, es un proceso de auto-regulación.

Las preguntas para los estudiantes, son en sí auto-instrucciones para que él trabaje las actividades de aprendizaje necesarias para el desarrollo de sus habilidades metacognitivas durante el proceso de solución de un problema. Cada pregunta va enfocada a una actividad de aprendizaje como se describe en la Tabla 2. Todas las respuestas a las preguntas, así como las veredas que decida seguir el estudiante quedarán plasmadas con la escritura en 
las hojas de trabajo, las cuales serán, junto con el material didáctico manipulado, las fuentes de datos para mirar y analizar la influencia de las representaciones en el proceso de resolución de problemas. El análisis de las respuestas se hará de acuerdo con el enfoque de Veenman (2012).

\section{Descripción y selección de los problemas}

Con el fin de elegir el repertorio de problemas para el experimento de enseñanza buscamos problemas con ciertas características. La principal que no sean ejercicios o problemas que sólo requieren la traducción de los enunciados verbales en operaciones matemáticas para llegar a la solución, sino problemas que necesiten un proceso de indagación, que no demanden procedimientos rutinarios para llegar a la respuesta.

El interés de esta investigación era analizar las producciones escritas de los estudiantes en la resolución de los problemas con el fin de conocer por una parte su pensamiento y por otra parte como está funcionando el uso de las preguntas para movilizar la función de la escritura como herramienta metacognitiva. Para ello seleccionamos problemas donde los estudiantes incorporaran:

a) la justificación y explicación de las acciones propuestas, así como predecir sus consecuencias,

b) el seguimiento y la evaluación del progreso,

c) la integración y la comunicación de los resultados de forma útil a los demás.

Los problemas propuestos por la Secretaría de Educación de Jalisco para el entrenamiento de las Olimpiadas Estatales de Matemáticas en Educación Primaria y Secundaria (OEMEPS), cumplen los tres incisos anteriores, debido a que estos problemas requieren razonamiento y creatividad del estudiante, en los cuales se deben trabajar descripciones, explicaciones y justificaciones en su resolución y se pueden seguir diferentes caminos para obtenerla.

Para el trabajo con los participantes en el experimento de enseñanza hicimos la selección de doce problemas que correspondían a geometría, del nivel de secundaria, considerando los cuadernillos de entrenamiento para las OEMEPS DEL AÑo 2010, 2011 Y 2012.

\section{Características e importancia del estudio}

La investigación es, principalmente de corte cualitativo, donde se utilizó el método en línea, que Veenman propone para la evaluación de las habilidades metacognitivas, a través de la compilación por escrito de todo el proceso seguido por los estudiantes durante la resolución del problema (que este autor describe como la ejecución de la tarea) en sus hojas de trabajo. Todas las anotaciones que hicieron los estudiantes en las hojas de trabajo facilitaron analizar las expresiones en el proceso, además de considerar la influencia del contexto durante el desarrollo de la resolución de cada problema. Otra fuente de datos fue el registro de las observaciones del investigador a lo largo de las sesiones de trabajo.

El experimento de enseñanza se aplicó a estudiantes de tercer grado de secundaria, cuarto bloque de educación básica, enfocándonos en la interpretación de escritura de Henning et al. (2002), con el interés de utilizar la escritura 
La escritura como herramienta en la resolución de problemas de geometría

como herramienta metacognitiva en la resolución de problemas esperando como resultado generar un pensamiento claro y ordenado durante todo el proceso de las actividades, así como desarrollar el hábito de formular explicaciones, para compartir e intercambiar ideas sobre los diferentes procedimientos que se utilicen al resolver problemas.

La escritura funcionó para los estudiantes como ayuda en la construcción y monitoreo de los procesos durante la resolución de los problemas y nos fue útil, ya que quedó plasmada en las hojas de trabajo, para obtener los resultados, analizarlos y observar los efectos de un uso sistemático de la escritura como apoyo en este proceso.

\section{Implementación de la experimentación}

Para llevar a cabo el experimento de enseñanza se propuso al director de la escuela Secundaria Diurna 99, un taller de resolución de problemas para trabajar con los estudiantes motivándolos para preparar sus exámenes de admisión al bachillerato. La investigación fue llevada a cabo con alumnos de tercer grado. Cabe mencionar que debido a las normas de acceso que actualmente tienen las escuelas públicas de educación básica, se complica lograr que en cualquier escuela secundaria los directivos permitan realizar un experimento de enseñanza, por lo cual, para esta investigación el plantel se seleccionó mediante un procedimiento de muestreo no probabilístico.

La toma de datos se realizó con un conjunto de 10 estudiantes seleccionados de un grupo de 50 estudiantes de tercer grado. Los diez estudiantes participantes en el taller, fueron elegidos por su profesor de matemáticas, para la selección él se apoyó en la información otorgada por la cartilla de cada uno y esencialmente como primer requisito deberían ubicarse en los tres principales niveles de desempeño: suficiente, satisfactorio y destacado ${ }^{1}$, con el fin de contar con estudiantes de condiciones diferentes. Como segundo requisito el conjunto de participantes debería estar conformado en igual número por hombres y mujeres, coincidiendo con la distribución de la población. Las características de los estudiantes participantes que integraron el taller se muestran en la Tabla 3.

TABLA 3. Descripción de los estudiantes participantes.

\begin{tabular}{|c|c|c|c|c|c|c|c|}
\hline Participantes & Edad & Sexo & $\begin{array}{c}\text { Nivel de } \\
\text { desempeño }\end{array}$ & Participantes & Edad & Sexo & $\begin{array}{c}\text { Nivel de } \\
\text { desempeño }\end{array}$ \\
\hline $\begin{array}{l}\text { Estudiante } 1 \\
\text { (E1) }\end{array}$ & 14 & $\mathrm{~F}$ & A & $\begin{array}{l}\text { Estudiante } 6 \\
\text { (E6) }\end{array}$ & 15 & M & C \\
\hline $\begin{array}{l}\text { Estudiante } 2 \\
\text { (E2) }\end{array}$ & 14 & $M$ & $A$ & $\begin{array}{l}\text { Estudiante } 7 \\
\text { (E7) }\end{array}$ & 14 & $\mathrm{~F}$ & $A$ \\
\hline $\begin{array}{l}\text { Estudiante } 3 \\
\text { (E3) }\end{array}$ & 14 & M & B & $\begin{array}{l}\text { Estudiante } 8 \\
\text { (E8) }\end{array}$ & 15 & $F$ & B \\
\hline $\begin{array}{l}\text { Estudiante } 4 \\
\text { (E4) }\end{array}$ & 14 & $\mathrm{~F}$ & $A$ & $\begin{array}{l}\text { Estudiante } 9 \\
\text { (E9) }\end{array}$ & 15 & $M$ & C \\
\hline $\begin{array}{l}\text { Estudiante } 5 \\
\text { (E5) }\end{array}$ & 14 & $F$ & A & $\begin{array}{l}\text { Estudiante } 10 \\
\text { (E10) }\end{array}$ & 15 & M & B \\
\hline
\end{tabular}

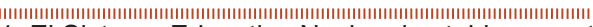

1 El Sistema Educativo Nacional establece cuatro rangos para calificar el nivel de desempeño de los estudiantes de educación básica:

Nivel A: Muestra un desempeño destacado en los aprendizajes que se esperan en el bloque.

Nivel B: Muestra un desempeño satisfactorio en los aprendizajes que se esperan en el bloque.

Nivel C: Muestra un desempeño suficiente en los aprendizajes que se esperan en el bloque.

Nivel D: Muestra un desempeño insuficiente en los aprendizajes que se esperan en el bloque. 


\section{Diseño de la hoja de trabajo}

Para que los estudiantes pudieran trabajar las preguntas diseñadas para este experimento, con el fin de que utilicen la escritura como herramienta metacognitiva en la resolución de problemas, se diseñó una hoja de trabajo, en la cual se colocaba la presentación del problema en un primer apartado y enseguida todas las preguntas a contestar por el estudiante con la finalidad de seguir la propuesta para llegar a la respuesta.

En las primeras hojas de trabajo se eligieron problemas que eran asignados a los estudiantes de sexto grado de primaria en el entrenamiento de las olimpiadas (OEMEPS) para que comenzaran aplicar las preguntas en un nivel más sencillo. Para graduar la complejidad de la aplicación, en las hojas donde trabajaron de manera individual, se tomaron los problemas del nivel de secundaria.

\section{Escenarios de la toma final de datos}

En la Secundaria Diurna No. 99 se dispuso del aula de computación para trabajar las sesiones durante el tiempo de clase asignado a la materia de matemáticas (45 minutos). Las sesiones de trabajo fueron en total 20, tres sesiones a la semana (lunes, miércoles y viernes) de acuerdo con los días laborables del calendario escolar 2013 - 2014.

En las primeras tres sesiones se construyó un glosario para apoyo de los conceptos fundamentales que los estudiantes deben poseer en tercer grado de secundaria: punto, segmento, recta, triángulos, cuadriláteros, entre otros. Cada estudiante describió los conceptos básicos y las características que se cumplen en las figuras de acuerdo a sus conocimientos de geometría, guiados por el investigador. Esta actividad fue muy importante ya que los diez participantes consensaron una base común para la resolución de problemas. El principal propósito de realizar el glosario era activar sus conocimientos previos en conjunto con darles confianza, ya que ellos lo elaboraron y lo aprecian como un trabajo propio.

En la cuarta sesión del taller de resolución de problemas, los estudiantes comenzaron la resolución de un problema tomado de la OEMEPS PARA SEXTO GRADO, CON EL APOYO de la hoja de trabajo donde se presentan las preguntas. En el diseño de la hoja de trabajo de esta actividad se designó un espacio para cada una de las preguntas planteadas, con el fin de que los estudiantes siguieran las indicaciones en cada etapa de la resolución del problema.

Al terminar de resolver el problema de acuerdo con las preguntas planteadas se revisó cada hoja de trabajo, se comentaron los diferentes caminos que utilizaron para llegar a la solución y se acordó que había varias formas de llegar a la respuesta, la única condición era seguir siempre las preguntas, por lo cual en las siguientes sesiones se exhibió en el pizarrón un cartel con las mismas en una lista, las cuales les servirían a los estudiantes como guía para que ellos continuaran la resolución de 12 problemas diferentes.

En la quinta sesión se continuó con otros tres problemas de sexto grado de la OEMEPS para comprobar si había quedado claro el proceso que debía seguirse. Las 15 sesiones restantes los estudiantes trabajaron individualmente la solución de los problemas, cada uno a su ritmo, durante los 45 minutos para la sesión de trabajo. Tenían material manipulable para experimentar las intuiciones que surgieran en cada problema, como el geoplano, el juego de geometría, papel, tijeras, lápiz adhesivo, colores, entre otros, y podían utilizarlo en la resolución de cada problema. 


\section{Análisis de los datos}

Así como para el diseño de las preguntas presentadas en la Tabla 2 seguimos el orden de las actividades que para Veenman (2012) promueven el desarrollo de las habilidades metacognitivas en la realización de una tarea, el análisis de los resultados obtenidos en la resolución de problemas seguirá el mismo orden. Por lo tanto, este apartado se dividirá en tres partes, enfocándose primero en las actividades de inicio, enseguida en las actividades desarrolladas durante la resolución del problema y finalmente en las actividades llevadas a cabo después de resolverlo.

Consideramos las actividades de inicio: lectura, análisis de la tarea, activación de los conocimientos previos y planificación, como esenciales para desarrollar las componentes de orientación y planificación. El seguimiento estará determinado por las actividades alcanzadas durante la resolución del problema: seguir el plan, cambiar el plan y toma de notas, mientras que la evaluación se apoyará en las actividades después de obtener el resultado: valoración del desempeño, recapitulación, reflexión sobre el proceso.

Como evidencia para demostrar que se han desarrollado habilidades metacognitivas es necesario tener información sobre lo que el estudiante dice que hace cuando resuelve un problema y lo que realmente hace para resolverlo. Por lo tanto, el análisis presentado en este escrito se enfocará directamente en la escritura que hicieron durante el transcurso de la resolución (todas las anotaciones, representaciones y narraciones) en uno de los doce problemas (Figura 3 ) trabajados por los estudiantes participantes en el taller de acuerdo con las preguntas proporcionadas.

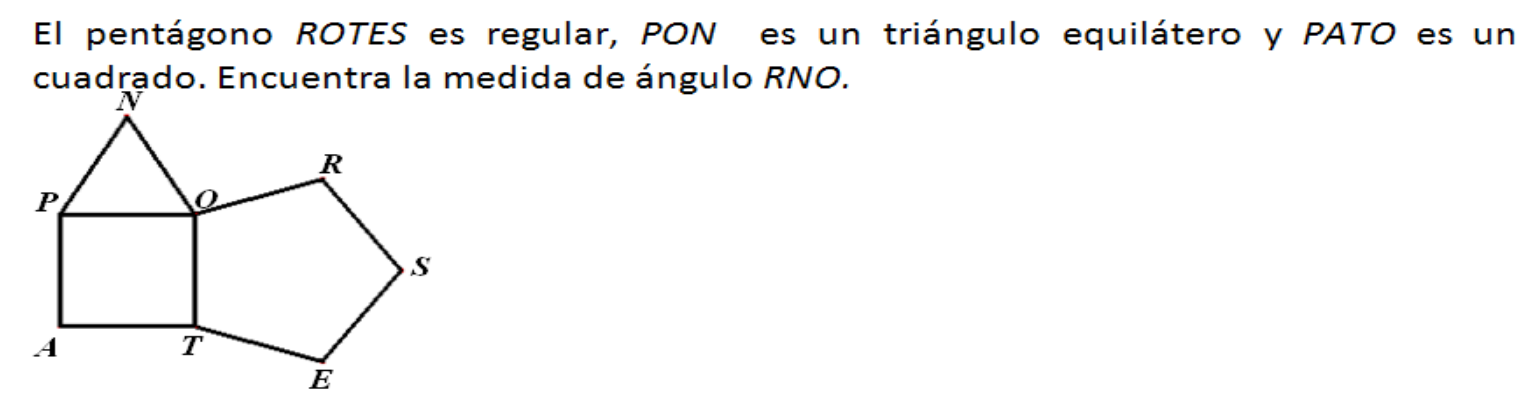

FIGURA 3. Problema 9 trabajado por los estudiantes durante el experimento de enseñanza.

\section{Actividades al inicio de la resolución del problema}

Analizaremos las primeras cuatro actividades consideradas como habilidades metacognitivas (Veenman 2012), las cuales corresponden al inicio de la tarea y están directamente enlazadas con las preguntas diseñadas para cubrirlas (Tabla 4). Para trabajar el análisis fue necesario conjuntar algunas actividades debido a que en ciertos momentos se trabajan al mismo tiempo, como es el caso de la lectura y el análisis de la tarea, ya que el estudiante tuvo la necesidad de leer el problema para definir cuál era su tarea a resolver, así como la actividad de seguir el plan y el cambio de plan, debido a que en el momento de realizar el plan de trabajo puede decidir hacer algún cambio o no. 
Las cuatro actividades de inicio: lectura, análisis de la tarea, activación de los conocimientos previos y planificación, son preparatorias para la realización de la resolución de cada problema y en algunos casos se entrelazan; una actividad impulsa a la otra; lo cual podremos ver en los procesos seguidos por los estudiantes en la resolución del problema.

TABLA 4. Actividades de Inicio en la resolución del problema.

\begin{tabular}{|l|l|}
\multicolumn{2}{c}{ Actividades de Inicio } \\
\hline Lectura & ¿Cuáles son los datos que me da el problema? \\
\hline Análisis de la tarea & ¿Qué necesito encontrar? \\
\hline Activación de los conocimientos previos & ¿Qué conocimientos tengo acerca del tema? \\
\hline Planificación & ¿Cómo le voy hacer? \\
\hline
\end{tabular}

\section{Lectura y análisis de la tarea}

La primera pregunta para el proceso de resolución de problema es ¿cuáles son los datos que me da el problema? Para poderla contestar es necesario realizar la lectura cuidadosa de los enunciados de la tarea, la cual en este contexto se refiere a la decodificación del planteamiento del problema; pero como en la segunda pregunta se les pide distinguir ¿qué necesito encontrar? origina que los estudiantes determinen los datos que se tienen y los datos que se buscan.

Aunque en las dos primeras preguntas se tiene el propósito específico de que los estudiantes hagan explícitos los datos dados y los datos buscados, lo cual les funcionó como un elemento orientador y lo tuvieron a la vista para los pasos subsecuentes en la resolución de problemas, también ocasionó que los estudiantes nos regresen información de la comprensión lograda a través de la lectura del enunciado del problema.

En sí estas dos primeras preguntas del experimento de enseñanza están definidas para trabajar el primer proceso metacognitivo en la resolución de problemas "el análisis de la tarea". En el caso de éste experimento de enseñanza la tarea es resolver el problema, y para desarrollar el análisis de cómo resolver el problema son necesarios los procesos de lectura y razonamiento como actividades cognitivas. Pero al trabajarlas conjuntamente cambian su enfoque a una herramienta metacognitiva, ya que la lectura es la parte principal del control de comprensión -todo basándose en el vocabulario y los procesos verbales- ésta se conjunta con el razonamiento de la meta a ejecutar -qué necesito encontrar- la cual activa indirectamente parte de los conocimientos previos para la decisión de sus respuestas.

Las respuestas, de los 10 estudiantes, a las dos primeras preguntas se clasificaron en tres grupos. En el primer grupo tenemos a los estudiantes que recuperan y despliegan los datos que da el problema de manera sencilla, pero demostrando la comprensión de la información. En el segundo y tercer grupo, además de realizar el análisis de la tarea, presentan activación de los conocimientos previos y cuestiones inferidas que fortalecen sus herramientas metacognitivas. Mientras que los estudiantes del segundo grupo además de recuperar la información hacen afirmaciones donde recurren a sus conocimientos previos y se orientan a la solución, los estudiantes del tercer grupo aplican diferentes representaciones para dar explicaciones derivadas de un primer análisis de la tarea que tienen que desarrollar. 
El análisis de las actividades, con el fin de detallar lo que el estudiante hace en su proceso de resolución, lo ilustraremos con fragmentos de sus respuestas, cabe aclarar que no presentamos las respuestas de los diez por cuestiones de espacio, pero los de cada grupo de respuestas coinciden en la forma de representar la información.

El primer grupo de respuesta es la de 3 estudiantes los cuales contestan con la información principal "los nombres de las figuras" "la medida del ángulo RNO que se encuentra en el triángulo isósceles", lo cual podemos ver en la primera parte de la Figura 4, los participantes dan la descripción e interpretación correcta de la información, los datos dados en el problema y lo que deben buscar.

En el segundo grupo de respuestas están las 5 estudiantes que hacen afirmaciones con la misma información del problema -"ROTES es un pentágono regular, PON un triángulo equilátero y PATO es un cuadrado. Necesito encontrar el ángulo RNO". Los estudiantes interpretan correctamente los datos dados en el problema (segunda parte de la Figura 4) y lo que deben encontrar "la medida del ángulo RNO".

En el tercer grupo de respuestas está la de 2 estudiantes quienes anotan los datos identificados de la información del problema, con la simplificación de los enunciados y añaden las representaciones, las cuales les son útiles para tener a la vista los datos necesarios al resolver el problema. En el último caso de la Figura 4 vemos que además de los datos mencionados por los otros estudiantes agrega la descripción de "... RNO es un triángulo isósceles" y completa la información con la representación de cada una de las figuras y las medidas de sus ángulos para reafirmar la información. Este tipo de anotaciones nos confirma que para los estudiantes es claro el análisis de la información del problema, así como lo que necesitan encontrar como solución.

\begin{tabular}{|c|c|}
\hline $\begin{array}{l}\text { Primer grupo de } \\
\text { respuestas }\end{array}$ & 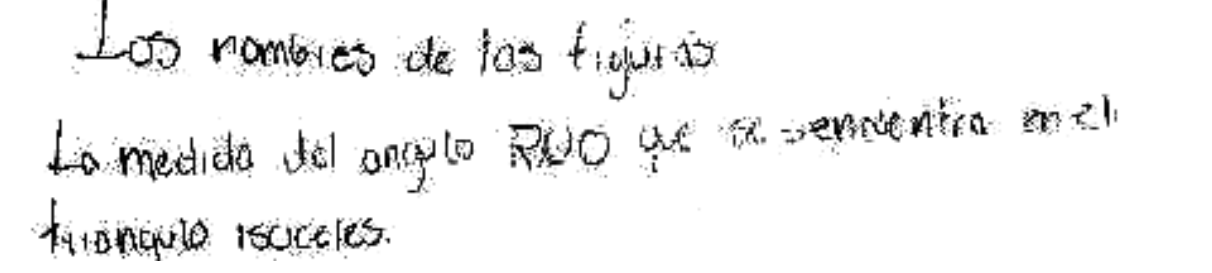 \\
\hline $\begin{array}{l}\text { Segundo grupo de } \\
\text { respuestas }\end{array}$ & 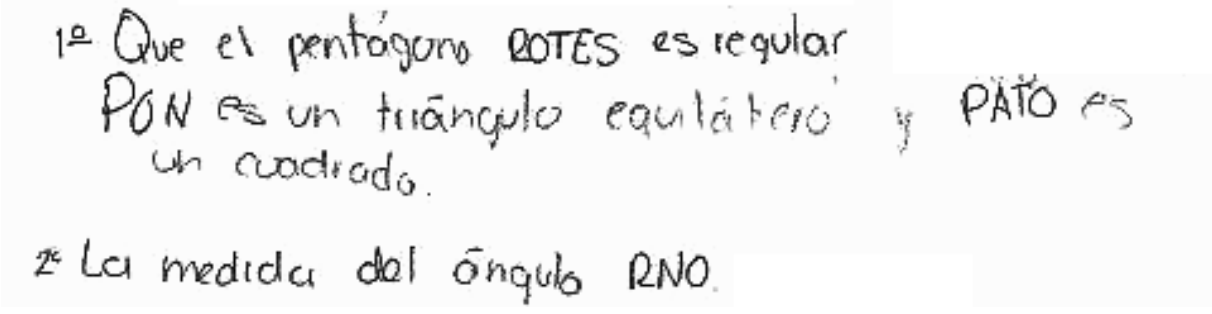 \\
\hline $\begin{array}{l}\text { Tercer grupo de } \\
\text { respuestas }\end{array}$ & $\begin{array}{l}\text { - ROTES es regular, PON es un triángulo equilátero } \\
\text { PATD es un cuadrado y BNO es untriángulo isesceles. } \\
\text { - Necesito encontrar d ánoulo RNO. }\end{array}$ \\
\hline
\end{tabular}

FIGURA 4. Problema 9 trabajado por los estudiantes durante el experimento de enseñanza. 
En este problema, al igual que en los otros once, vemos como a partir de las dos primeras preguntas se da la activación de las habilidades metacognitivas, en especial la activación de la comprensión lectora y la interpretación de la información basándose en la lectura, así como el uso de los dibujos a modo de representaciones, las cuales les sirvieron de apoyo durante todo el proceso de resolución del problema. De igual manera en algunos casos se activan parte de sus conocimientos previos, que aún no ha sido agregado en las preguntas, pero lo hacen automáticamente con la lectura y el análisis del problema. En el siguiente apartado se revisa detenidamente ésta tercera actividad de inicio representativa de las habilidades metacognitivas.

\section{Activación de los conocimientos previos}

La habilidad metacognitiva identificada a través de esta tercera pregunta es la activación de los conocimientos previos, impulsada por los procesos de memoria de cada estudiante, los cuales se activan cuando establece relaciones entre los datos aportados por el problema, lo que tiene que encontrar como respuesta y los conocimientos de los temas que el considere necesarios para obtener la solución del problema. En sí es un proceso de recordar la información guardada en su mente, relacionarla con los datos que debe trabajar y decidir cuál proceso aplicará para obtener la solución, lo cual indagamos en este apartado.

En la elaboración del glosario se activaron los conocimientos previos de los estudiantes con la revisión de los conceptos básicos de geometría trabajados hasta este nivel escolar; pero el análisis que se presenta se relaciona directamente con la activación de conocimientos previos observados durante el proceso de la resolución de problemas. Como comentamos en el apartado anterior la activación de los conocimientos previos comienza desde el momento en el cual se hace la lectura así como el análisis de la tarea, pero continúa con la tercera pregunta ¿qué conocimientos tengo acerca del tema?

Al explorar las respuestas de la tercera pregunta observamos que, aunque fueron más cortas y en algunos momentos se conjuntaron con la planificación, se activaron los conocimientos de los estudiantes; lo cual es impulsado por los procesos de memoria de acuerdo con Veenman (2012), y lo podemos comprobar con las diferentes afirmaciones obtenidas en la tercera pregunta del proceso de resolución de problemas.

En este problema la activación de los conocimientos previos se demuestra con tres grupos diferentes de respuestas de los estudiantes. En un primer grupo tenemos 3 estudiantes que describen y afirman los conocimientos de los temas relacionados con el problema. Anotan: "Que el triángulo forma $180^{\circ}$ con sus 3 ángulos, el cuadrado $360^{\circ}$ y el pentágono $540^{\circ}$ ". "cómo sacar sus ángulos y cuánto miden los ángulos interiores". Este tipo de anotaciones nos confirma como ellos tienen conocimiento de los datos necesarios para trabajar los datos del problema y llegar a la solución. (Figura 5).

En el segundo grupo, tenemos 4 estudiantes que aplican el uso de fórmulas y la escritura simbólica. Los cuales en este problema anotaron las medidas de cada ángulo dependiendo de la figura, como podemos ver en el segundo grupo de la Figura 5. El estudiante además de describir cómo sacar la medida de los ángulos, anota en forma abreviada que la suma de los ángulos internos de un triángulo es igual a $180^{\circ}$ y añade que cada ángulo va a medir $60^{\circ}$ enseguida los ángulos del pentágono $\left(180^{\circ} \times 3\right) \div 5=540 \div 5=108$, por lo tanto, cada uno de ellos medirá $108^{\circ}$. Estas notas tienen una forma simbólica, sin describir ningún concepto o usar alguna palabra y en algunas ocasiones una de más o una de menos, como en este caso no anota las condiciones del cuadrado debido a que no lo considera necesario porque ya sabe que mide $90^{\circ}$ cada uno de sus ángulos. 
Un tercer grupo de respuestas es la de 3 estudiantes que combinan la descripción escrita de sus conocimientos y afirmaciones con escritura simbólica de los datos, así como representaciones, las cuales vemos en la tercera parte de Figura 5, el caso de anotar el dibujo del triángulo, del cuadrado y del pentágono con un signo de igualdad a la suma de todos sus ángulos interiores, enseguida una flecha para establecer la relación c/a (cada ángulo) y luego la medida. Después, para complementar su respuesta, agrega la afirmación de "sé cómo sacar sus ángulos y cuánto miden sus ángulos interiores".

\begin{tabular}{|c|c|}
\hline $\begin{array}{l}\text { Primer grupo de } \\
\text { respuestas }\end{array}$ & "Se las medidas internas de cada figura \\
\hline $\begin{array}{l}\text { Segundo grupo de } \\
\text { respuestas }\end{array}$ & 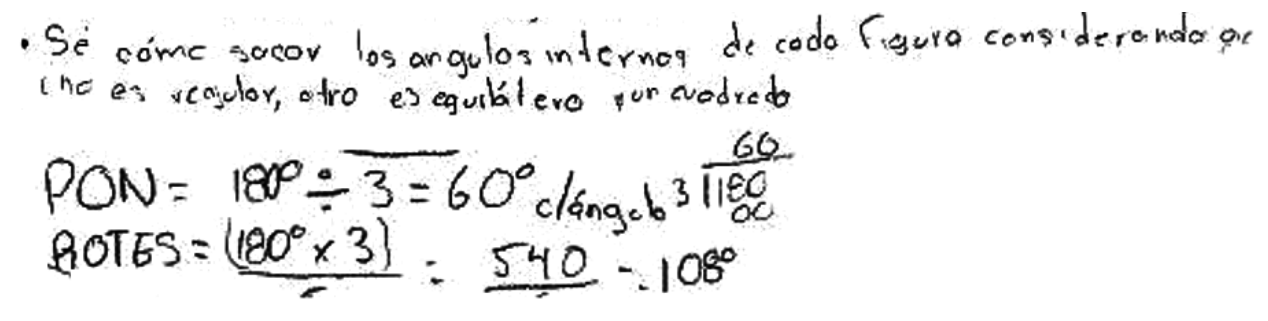 \\
\hline $\begin{array}{l}\text { Tercer grupo de } \\
\text { respuestas }\end{array}$ & 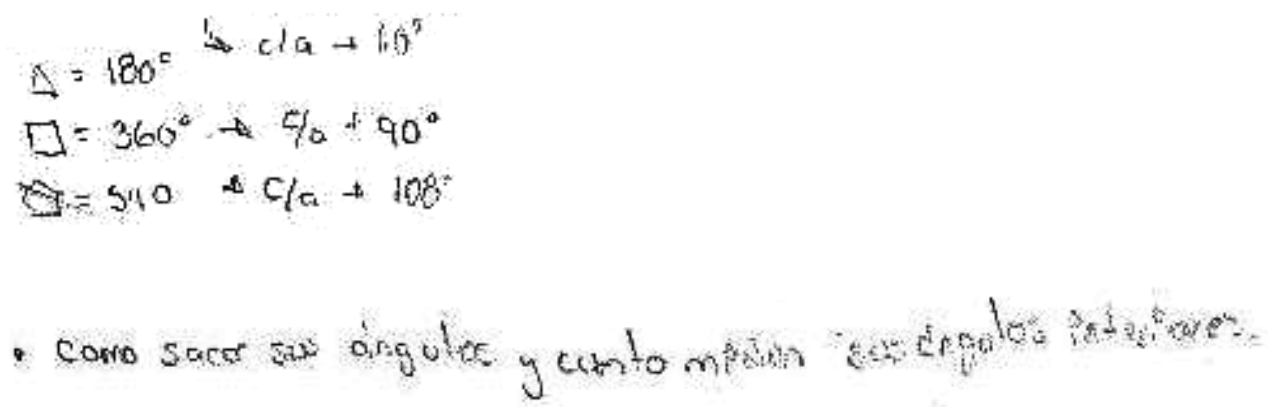 \\
\hline
\end{tabular}

FIGURA 5. Problema 9 trabajado por los estudiantes durante el experimento de enseñanza.

A través del proceso de trabajo en relación con la tercera pregunta, vemos que los diez estudiantes completan la activación de sus conocimientos de acuerdo con lo que consideran necesario para resolver cada problema y en conjunto con las dos primeras preguntas se cubrió lectura y análisis de datos complementándose así la claridad en el proceso de solución para aplicar en cada problema.

\section{Planificación de la tarea}

La cuarta pregunta ¿cómo le voy hacer? va enfocada directamente a la última actividad de inicio de la ejecución de una tarea -la planificación- de acuerdo con Veenman (2012). Esta parte de la actividad implica que el estudiante prepare el proceso de organización de los pasos a seguir para llegar a obtener la respuesta, cuales pasos realizará primero y cuales después para alcanzar su objetivo. La organización del camino a seguir en conjunto con un orden determinado, el cual debe respetar el estudiante para obtener la solución del problema, es un indicativo del comportamiento planificado (Veenman, 2006). 
Las actividades que evidenciaron la planificación de la tarea se registraron en la respuesta a la pregunta ¿cómo le voy hacer? cuando el estudiante reconoce, comprende y relaciona la información importante dada en el problema para decidir el procedimiento, de tal manera que se puedan aplicar los conocimientos previos que se activaron y logre llegar a la solución. Las respuestas al problema, dadas por los estudiantes en la planificación de la tarea se pueden clasificar en tres grupos de narraciones.

En el primer grupo de narraciones aparece la descripción de la decisión tomada por 1 estudiante y el orden de los pasos a seguir, como podemos ver en la Figura 6, donde indica "sumar todos los grados que entran en el círculo con centro "O", después restársela a $360^{\circ}$, lo que sobre es la medida del ángulo RON después sacar la medida del ángulo RNO que es igual a la de NRO porque es un triángulo isósceles". Todas las palabras que subrayamos nos indican la seguridad y claridad que tiene el estudiante de los pasos a seguir para llegar a obtener la respuesta correcta.

El segundo tipo de respuestas obtenidas con esta pregunta es la descripción del procedimiento con afirmaciones de cómo lo van a aplicar "sé que las medidas de los ángulos interiores de un triángulo isósceles es $180^{\circ}$, pero dos ángulos son iguales y otro es diferente, debo de ver cuánto me falta para llegar a 180, iré restando los ángulos de las diferentes figuras y así me dará la medida del ángulo RNO”. Recalcamos las afirmaciones del estudiante, aunque su redacción no es muy clara, se distingue la seguridad que tiene tanto de su procedimiento como de obtener la respuesta correcta, la cual coincide con las respuestas presentadas por otros 4 estudiantes (Figura 6).

En el tercer grupo de respuestas, 5 estudiantes utilizan verbos en presente y en infinitivo para indicar el procedimiento a seguir para resolver el problema. Presentamos en la última parte de la Figura 6 la respuesta de uno de ellos que especifica en primer lugar "voy a buscar... voy a dibujar... y sumar... y después a restar a $360^{\circ} \ldots$ y ... restar a $180 \ldots$ y el resultado lo voy a dividir entre dos..." A través de este tipo de respuestas observamos como los estudiantes han decidido el proceso que van aplicar para llegar a la respuesta del problema y no tienen ninguna duda de obtenerla.

Notamos, que hasta este momento han trabajado igual los diez participantes, correctamente con las primeras cuatro preguntas: los datos dados, lo que necesito encontrar, la activación de sus conocimientos y la decisión de un procedimiento para obtener la solución. Las cuatro preguntas son enfocadas directamente a las actividades al inicio de la ejecución de una tarea de acuerdo con Veenman, en ellas se presenta el desarrollo de las habilidades metacognitivas y todas son preparatorias para la ejecución de la tarea real, la resolución del problema.

Percibimos como las habilidades de cada uno de los estudiantes, se han establecido en sus respuestas a las cuatro preguntas iniciales en el problema ilustrado, con ello se cumple la habilidad metacognitiva de la orientación, la cual para Veenman abarca leer el enunciado del problema, la activación de los conocimientos previos así como la especificación de lo que se da y lo que se pide. A través de las Figuras 4, 5 y 6 donde se presentan las respuestas escritas por los estudiantes a estas cuatro preguntas podemos analizar cómo se manifiestan el cumplimiento de las habilidades metacognitivas el inicio de la ejecución de una tarea, la cual en este experimento de enseñanza es la resolución de cada problema.

El trabajo de los estudiantes participantes muestra también evidencia del uso de la habilidad metacognitiva de planificación, ya que se observa como trazan su procedimiento a seguir, organizado en un orden determinado, así como la manera correcta para llegar a la respuesta. Otros componentes de la habilidad metacognitiva de planificación aparecen con las actividades durante la resolución del problema, las cuales implican seguir el plan 
La escritura como herramienta en la resolución de problemas de geometría

hasta llegar a la respuesta o si es necesario cambiar el plan durante el procedimiento, así como la toma de notas durante toda la marcha. En el siguiente apartado revisaremos los resultados alcanzados en esta parte del proceso, nombrada por Veenman (2012) "durante la ejecución de la tarea".

\begin{tabular}{|c|c|}
\hline $\begin{array}{l}\text { Primer grupo de } \\
\text { respuestas }\end{array}$ & 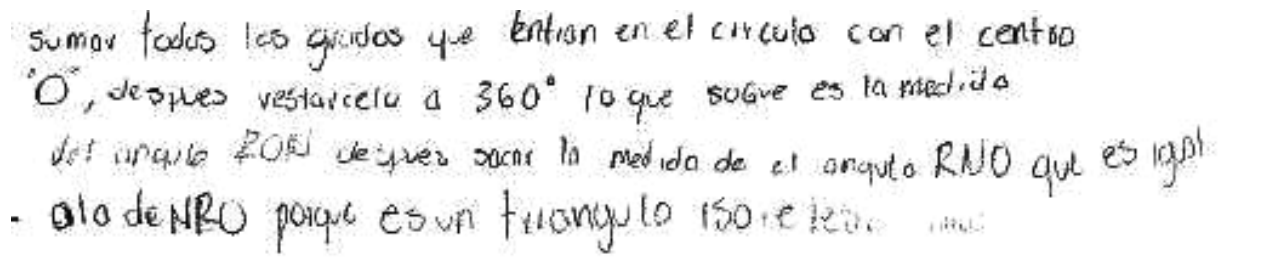 \\
\hline $\begin{array}{l}\text { Segundo grupo de } \\
\text { respuestas }\end{array}$ & 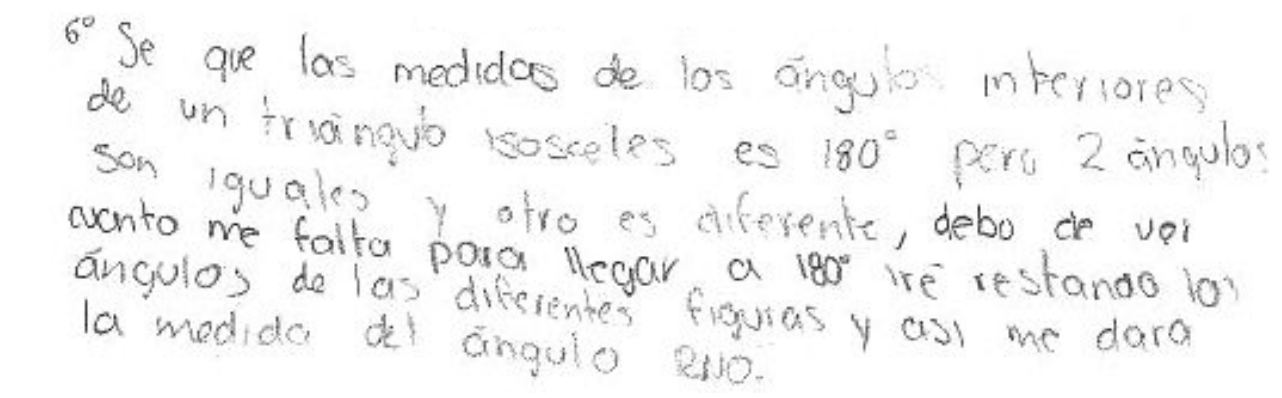 \\
\hline $\begin{array}{l}\text { Tercer grupo de } \\
\text { respuestas }\end{array}$ & 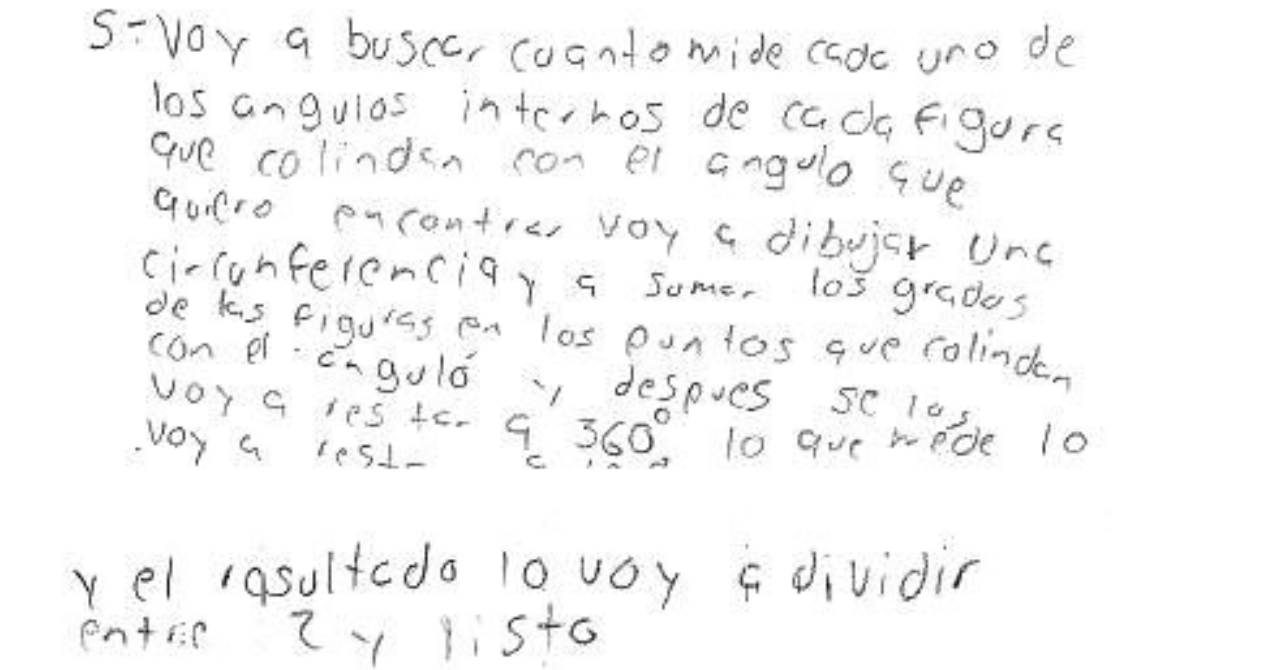 \\
\hline
\end{tabular}

FIGURA 6. Problema 9 trabajado por los estudiantes durante el experimento de enseñanza.

\section{Actividades durante la resolución del problema}

Para Veenman las actividades durante la ejecución de la tarea son: el seguimiento del plan, cambiar el plan si es necesario, la toma de notas, el tiempo y gestión de los recursos. Todas estas actividades guían y controlan la ejecución de la tarea. Debido a que la tarea en este experimento de enseñanza es la resolución de problemas decidimos conjuntar las actividades del seguimiento del plan con el cambio del plan y la toma de notas con la gestión de los recursos, ya que los recursos utilizados se prueban en las representaciones realizadas por los estudiantes en sus hojas de trabajo. 
Los indicadores de habilidades metacognitivas durante la ejecución de tareas se evidencian a través de los procesos de seguimiento que el estudiante da al plan de acción diseñado al inicio, poniendo en operación paso a paso cada una de las actividades necesarias para la resolución del problema. Estas acciones lo guían durante la resolución del problema y controlan la realización de la tarea (Veenman 2012).

Los procesos de seguimiento examinados en los siguientes dos apartados demuestran como los estudiantes usaron procesos metacognitivos de control y toma de notas en la resolución de problemas, de acuerdo con las dos actividades -seguir el plan y la toma de notas- guiados por la preguntas que se muestran en la Tabla 5 y se describen a continuación.

TABLA 5. Actividades durante la resolución del problema.

Actividades durante

Seguir el Plan o Cambiar el Plan

Toma de notas
Preguntas diseñadas para cubrir estas actividades

¿Qué pasos voy a seguir?

¿Qué dibujos me pueden ayudar para llegar a la solución?

\section{Seguir el plan o cambiar el plan}

En el experimento de enseñanza aparecen dos preguntas que van entrelazadas, aunque una pertenece a las actividades de inicio ¿cómo le voy hacer? y la otra concierne a las actividades durante la resolución del problema ¿qué pasos voy a seguir? La primera va enfocada directamente a la elaboración del plan de trabajo y la segunda al seguimiento que da el estudiante a ese plan hasta obtener la respuesta.

Esta segunda pregunta ¿qué pasos voy a seguir? para resolver el problema lleva al estudiante a efectuar la planeación que había diseñado en la pregunta anterior, comienza con hacer deducciones, progresa durante todo el proceso y corrige si en algún momento se presenta un error. Aquí el seguimiento del estudiante, a su plan elaborado, manifiesta como los procesos metacognitivos son la acción paso a paso de su plan en conjunto con la comprobación de sus resultados a través de procesos numéricos, esta segunda parte muestra el control que tenían de su trabajo y la seguridad de que su respuesta es correcta.

En este problema los estudiantes aplicaron los procedimientos necesarios para dar un seguimiento al plan planteado con la pregunta anterior. Podemos observar en la Figura 7 el proceso de seguimiento del plan de un estudiante, lo mismo que indica del lado izquierdo, lo va haciendo en las operaciones que se presentan del lado derecho, hasta llegar a obtener la solución. A partir de este proceso se evidencian los resultados al seguir el plan, coincide tanto esta respuesta con la de los otros 9 participantes, por ello solo se presenta un caso del seguimiento del plan y se muestra este proceso, en las demás respuestas, con la toma de notas en el siguiente apartado.

Hasta este momento hemos revisado la primera parte de las actividades originadas durante la resolución el problema, todas enfocadas al plan diseñado por los estudiantes al final de las actividades de inicio y observamos como en ellas se manifiesta el convencimiento que tienen tanto en su interpretación geométrica de las figuras, como en los cálculos aritméticos para llegar a la respuesta. Pero todos exponen la confianza y control de todos los pasos a seguir hasta llegar a la respuesta acertada como lo hemos visto en el problema anterior. La segunda parte de las actividades, durante la resolución del problema, es la toma de notas que hicieron los estudiantes como apoyo para sus narraciones. 


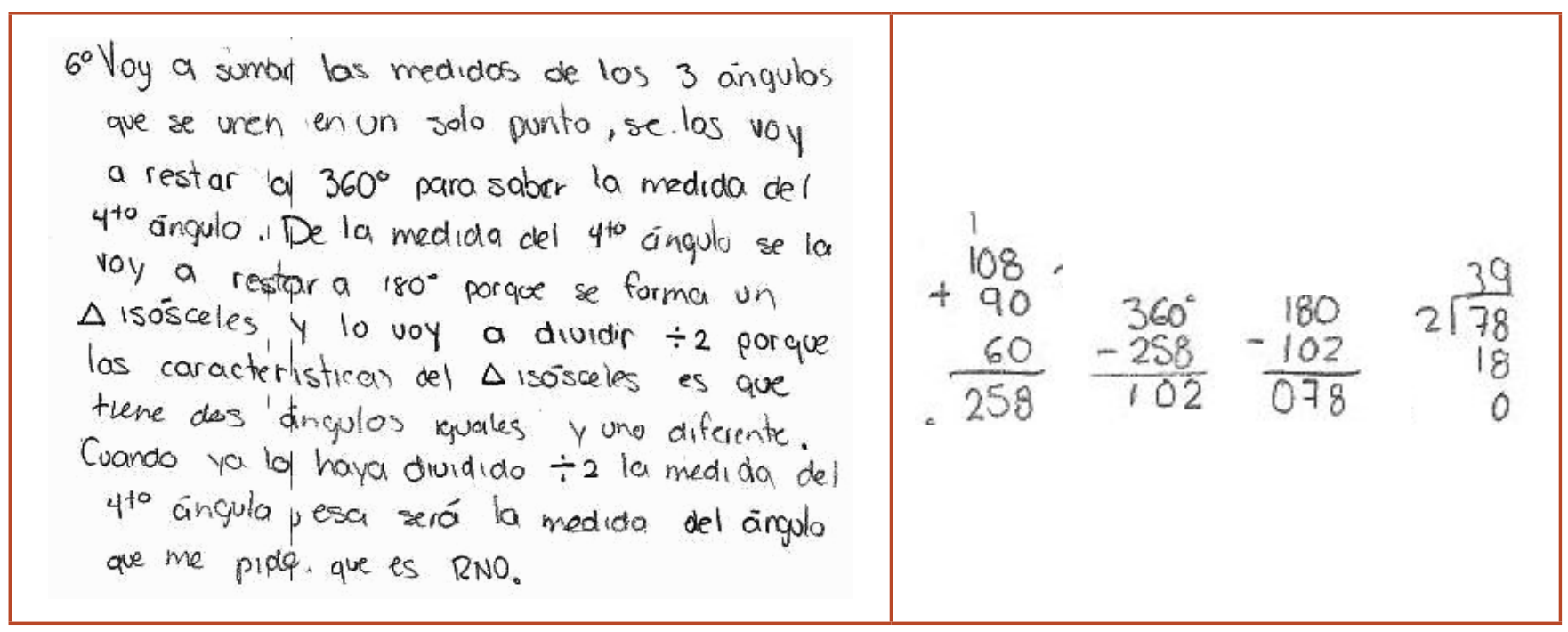

FIGURA 7. Problema 9 trabajado por los estudiantes durante el experimento de enseñanza.

\section{Toma de notas}

Para Veenman (2012) la toma de notas es un proceso metacognitivo el cual depende de procesos cognitivos como la escritura y representaciones realizadas por los estudiantes durante la ejecución de una tarea, las notas amplían la descripción del desarrollo de los pasos seguidos en la resolución del problema. En esta investigación nos enfocaremos a las anotaciones plasmadas por los estudiantes fuera de la narración del proceso, comenzando por las notas efectuadas en la representación dada en cada problema, para continuar con las representaciones que ellos agregan en cada descripción de acuerdo con la pregunta ¿qué dibujos me pueden ayudar para llegar a la solución? Adicionalmente se tomarán en cuenta los apuntes de fórmulas y de operaciones que anotaron para obtener el resultado, los cuales no teníamos la expectativa de encontrar, pero se presentaron como una oportunidad de análisis brindada por los educandos.

Identificamos como la mayoría de los estudiantes comenzó por utilizar la representación dada en cada problema y ésta les ayudó a guiarse para seguir el proceso, cuando no les era suficiente elaboraron otras representaciones para clarificar la situación del problema y agregar los datos que consideraron necesarios, así como para comprobar como su procedimiento iba de manera correcta. Además de las diferentes situaciones proporcionadas en las representaciones, los diez estudiantes trabajaron el repertorio de fórmulas y operaciones de acuerdo con el orden en que las aplicaron para obtener el resultado de cada problema, por lo cual, las separamos en tres grupos, pero todas incluyen las anotaciones y operaciones, así como el resultado obtenido en cada problema.

En el primer grupo de respuestas tenemos a 4 estudiantes, quienes trabajaron directamente anotaciones a partir de las representaciones dadas en el problema. Como podemos ver en la Figura 8 uno de ellos estableció la medida de los ángulos de cada polígono a partir de las dos primeras preguntas, como se mostró en la Figura 5 (tercer grupo de respuestas). Enseguida utiliza la representación dada en el problema para anotar en ella cada medida en su lugar, completa el triángulo NOR y aplica las operaciones necesarias para obtener la medida del ángulo $\mathrm{RON}=108^{\circ}$ y a partir de ella obtiene la del ángulo RNO $=39^{\circ}$. 
En el segundo grupo de respuestas tenemos a otros 4 estudiantes que, además de utilizar la representación dada en el problema para anotar la información, agregaron otras representaciones para clarificar la situación del problema y ayudarse en el proceso de resolución. Mostramos en la segunda parte de la Figura 8, la respuesta de uno de ellos, quien dibuja cada uno de los polígonos que forman la figura, anotando la medida de sus ángulos en cada representación para ir explicando a través de la narración, los pasos aplicados en su procedimiento hasta llegar a obtener la medida del ángulo RNO. Durante su narración indica el argumento de cada operación, a continuación, la realiza y agrega al final la explicación de cómo obtiene la medida del ángulo solicitado "...y como es isósceles lo dividimos entre $2 \ldots .$.

En el tercer grupo de respuestas tenemos las de 2 estudiantes, quienes hicieron una representación más, al igual que el segundo grupo, pero ellos la utilizaron para comprobar que su razonamiento y la respuesta eran correctas. En la última parte de la Figura 8 presentamos la respuesta de uno de ellos, observamos que anotó las medidas de los ángulos en la figura original, enseguida apunta el procedimiento que siguió para llegar a la respuesta (en el cual, aunque comete un error en la escritura de la operación 258 - 360, la hace correctamente y obtiene que el ángulo RON mide $102^{\circ}$ ), el ángulo RNO mide $39^{\circ}$. Y por último para explicar la justificación del procedimiento agrega la representación de la unión de los polígonos y traza la circunferencia que se forma a partir del punto O, para argumentar que la unión de todos los ángulos que coincidían en ese vértice era igual a $360^{\circ}$ y con la medida del ángulo desigual del triángulo isósceles encuentra la medida de los dos ángulos iguales, la cual era la respuesta del problema.

En estas descripciones, vemos que, con la toma de notas, los dibujos construidos por los estudiantes y las representaciones dadas en el problema, en conjunto con las anotaciones y las operaciones, ellos dirigen y controlan todo el proceso aplicado en la resolución de cada problema. Con esta actividad concluye la segunda parte de la ejecución de la tarea, en la resolución del problema. En este punto todos han llegado a obtener la respuesta correcta de este problema, así como en los 11 restantes, trabajados en el taller de resolución de problemas.

Ciertas actividades reflejadas en las anotaciones de los estudiantes podrían considerarse como actividades cognitivas, pero para efectos de esta investigación son consideradas como metacognitivas, debido a que a través del seguimiento de las preguntas planteadas a los estudiantes se puede observar en el proceso de la toma de notas, el entramado de la escritura, la elaboración de los dibujos, las anotaciones dentro de los dibujos y las operaciones numéricas que les permiten llegar al resultado.

Con estas dos primeras partes, las actividades de inicio y las de durante la resolución del problema, se proporciona una entrada a la adquisición de habilidades, donde una estrategia metacognitiva tiene que ser aplicada conscientemente, paso a paso, y así se transforma gradualmente en una habilidad a partir de un proceso de seguimiento.

En las actividades de inicio se refleja a través de las respuestas de los estudiantes participantes en el taller desde la orientación profunda dada a la lectura, para de ahí continuar con el diseño de su plan de trabajo con el fin de llegar a la solución del problema paso a paso y no simplemente con la lectura del enunciado del problema en conjunto con el trabajo por ensayo y error para solucionarlo. 
La escritura como herramienta en la resolución de problemas de geometría

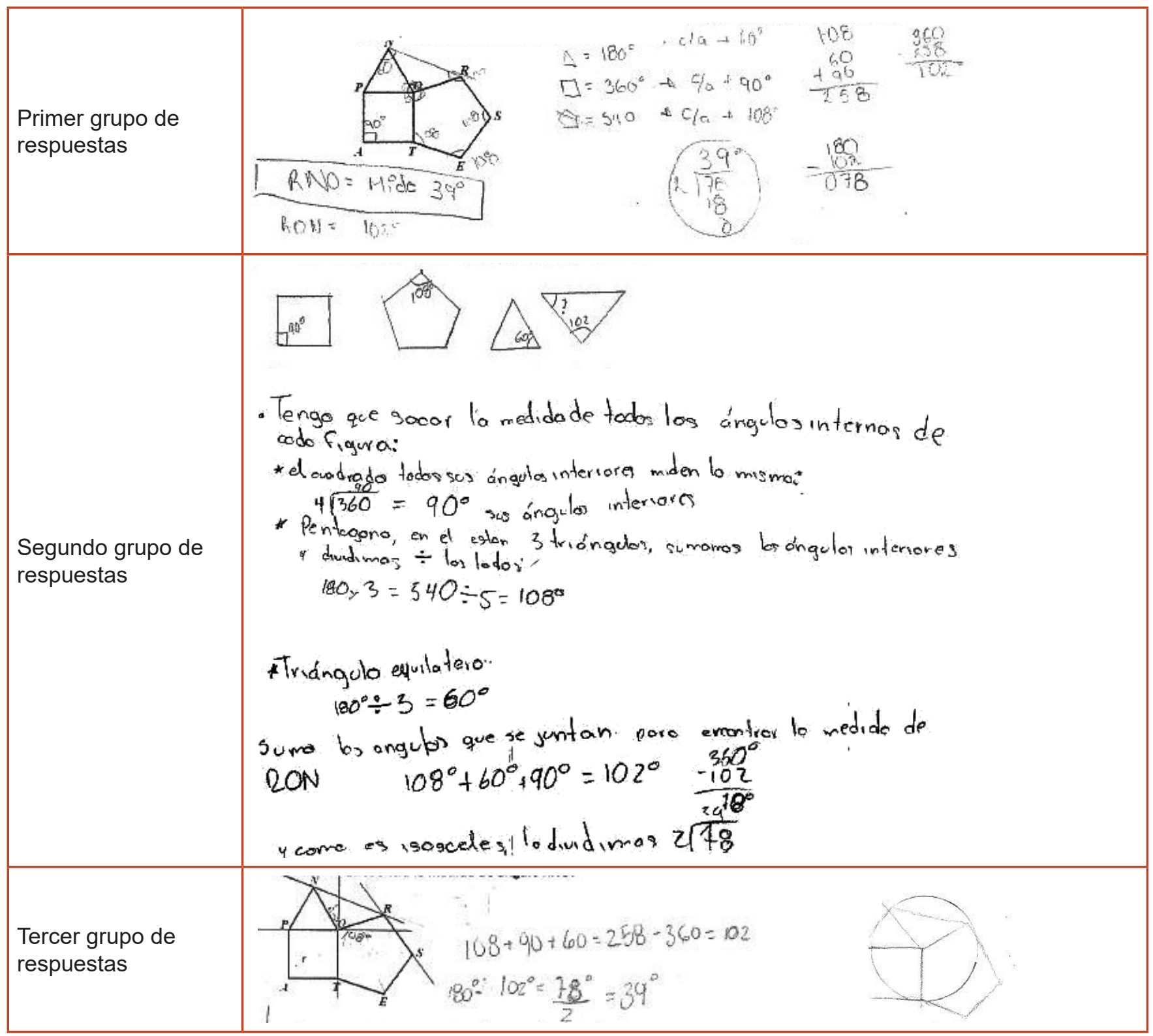

FIGURA 8. Problema 9 trabajado por los estudiantes durante el experimento de enseñanza.

En las actividades durante la resolución del problema las habilidades metacognitivas se evidencian con la toma de notas, comenzando con los dibujos de apoyo para aplicar los pasos, la anotación de las operaciones paso a paso, así como los comentarios agregados a las representaciones y la comprobación de sus respuestas recalculando el resultado.

La parte condicional de trabajar la escritura y seguir las preguntas ha originado ciertas acciones en los estudiantes, como la descripción de todos los pasos aplicados para obtener la respuesta al igual que la presentación de una manera ordenada, la cual les permite monitorear y reflexionar sus procesos. 
Hasta este momento hemos examinado las actividades de los estudiantes antes y durante la resolución del problema, fijándonos en el seguimiento de sus procedimientos para llegar a obtener las respuestas, lo cual Veenman señala como componentes de las actividades necesarias para desarrollar las habilidades metacognitivas. Las preguntas para el inicio y desarrollo de la resolución de un problema proporcionadas a los estudiantes son favorables para obtener las respuestas correctas de cada problema, algunos con más pasos otros con menos, pero siempre con la certeza de que su procedimiento era el más adecuado y así como su respuesta es la correcta.

En el siguiente apartado revisamos cómo los estudiantes recapitulan su trabajo después de haber resuelto el problema, por medio de las últimas tres preguntas planteadas. A través de estas preguntas intentamos que se lleve a cabo una reflexión sobre el procedimiento aplicado y evalúen sus pasos, así mismo, si les es posible indiquen otro camino, el cual los conduzca también a la respuesta.

\section{Actividades después de la resolución del problema}

La reflexión sobre el proceso de solución de un problema hecha por los estudiantes es una actividad que muchas veces se omite, tal vez, porque se manifiesta al terminar la tarea y no la comunican, ni tienen la oportunidad de expresarla. En esta investigación después de obtener la solución al problema, planteamos tres preguntas enfocadas a hacer una recapitulación o dar una interpretación de los resultados, debido a que generalmente los estudiantes dan por concluida la actividad al llegar a obtener las respuestas de cada problema.

La primera pregunta -¿cómo justifico la respuesta que encontré?- va enfocada a que el estudiante evalúe su procedimiento e interprete sus logros, comprobando que la respuesta y los pasos que decidió seguir para obtenerla son correctos, estos procesos son indispensables para su aprendizaje. La segunda y la tercera preguntas guían a los estudiantes a hacer una reflexión sobre el proceso y en especial a encontrar otro camino para llegar a la misma respuesta, como se ilustra en la Tabla 6 . En los siguientes dos apartados veremos los resultados que se obtuvieron en cada una de ellas.

TABLA 6. Actividades después de la resolución del problema.

\begin{tabular}{|c|c|}
\hline Actividades después & Preguntas diseñadas para cubrir estas actividades \\
\hline Evaluación del desempeño & ¿Cómo justifico la respuesta que encontré? \\
\hline Recapitulación & ¿Es el único camino que se puede seguir para llegar a la respuesta? \\
\hline Reflexión sobre el proceso & ¿Qué otras formas puedes aplicar? \\
\hline
\end{tabular}

\section{Evaluación del desempeño}

En este apartado revisamos las justificaciones proporcionadas por los estudiantes a sus respuestas, haciendo una valoración tanto de los resultados obtenidos como de los procedimientos aplicados. Encontramos tres tipos diferentes de respuestas, el primero grupo son los estudiantes que únicamente recapitulan los pasos utilizados para obtener la solución del problema. El segundo grupo de quienes justificaron sólo una parte del procedimiento aplicado para llegar a un dato importante con el fin de alcanzar la respuesta y olvidaron narrar los siguientes pasos para obtenerla. 
Un tercer grupo hace la justificación de manera completa, agregan también operaciones y representaciones, las cuales evidencian como su procedimiento era el más indicado para conseguir la respuesta. A continuación, presentamos en la Figura 9 las diferentes respuestas que se obtuvieron en éste problema de acuerdo con la justificación de la solución.

\begin{tabular}{|c|c|}
\hline $\begin{array}{l}\text { Primer } \\
\text { grupo de } \\
\text { respuestas }\end{array}$ & $\begin{array}{c}7^{\circ} \text { Las medidas de los ängulos del } \square \text { son } 360^{\circ}, \triangle 180^{\circ} \\
\text { y } \triangle 540^{\circ}\end{array}$ \\
\hline $\begin{array}{l}\text { Segundo } \\
\text { grupo de } \\
\text { respuestas }\end{array}$ & 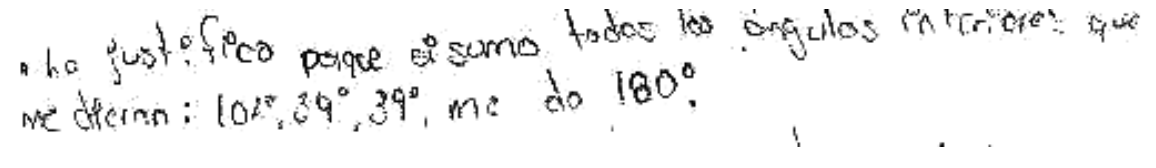 \\
\hline $\begin{array}{l}\text { Tercer } \\
\text { grupo de } \\
\text { respuestas }\end{array}$ & - Di medimos los ángolos internos me derón $180^{\circ}$ \\
\hline
\end{tabular}

FIGURA 9. Problema 9 trabajado por los estudiantes durante el experimento de enseñanza.

Percibimos en las respuestas cómo los estudiantes no tienen la costumbre de hacer justificaciones en la solución de un problema, lo cual les ocasiono algunas limitaciones. De acuerdo con el diccionario de la real academia española la justificación se define como "probar algo con razones convincentes", por tal motivo algunos estudiantes solo hicieron la narración de los pasos seguidos durante el proceso de solución, como podemos ver en el primer grupo de respuestas (Figura 9), donde el estudiante sólo hace una recapitulación de los pasos seguidos al principio "Las medidas de los ángulos del cuadrado son $360^{\circ}$, los del triángulo $180^{\circ}$ y los del pentágono $540^{\circ}$ " y olvida narrar las demás partes del procedimiento, dando una justificación parcial, con el coinciden otros 3 compañeros.

El segundo grupo de respuestas fueron la de otros 4 estudiantes, quienes hacen solo una justificación parcial del final del proceso o el último paso que dieron para llegar a la respuesta. Como podemos ver la justificación de uno de ellos "lo justifico porque si sumo todos los ángulos interiores que me dieron: $102^{\circ}, 39^{\circ}, 39^{\circ}$, me da $180^{\circ}$. . A partir de esta afirmación establece que el triángulo formado por la unión de los tres polígonos era un triángulo isósceles y las medidas cumplen las condiciones.

En el tercer grupo de respuestas obtuvimos una justificación completa, dada por 2 estudiantes, una de ellas se presenta en la última parte de la Figura 9, aunque solo aparece "si medimos los ángulos internos me darán $180^{\circ}$ ", únicamente representa la última parte del procedimiento para llegar a la solución, pero si la juntamos con la respuesta de la segunda parte de la Figura 8, debido a que pertenece al mismo estudiante quien describe paso a paso su procedimiento, a partir de las representaciones, afirmaciones y operaciones aplicadas, podría considerarse una justificación completa.

Luego de revisar los tres tipos de respuesta a esta pregunta, observamos algunas dificultades en los diez estudiantes, como los primeros cuatro estudiantes quienes trabajaron únicamente la recapitulación de los pasos seguidos para obtener al resultado y los otros seis estudiantes no hicieron la narración perfecta de su justificación, pero todos realizan una evaluación positiva de su desempeño y están seguros de que la respuesta obtenida y el procedimiento aplicado fueron los más indicados para obtener la solución de cada problema. 
Consideramos que esta situación es debido a que no siempre se trabajan actividades después de solucionar un problema, la mayor parte de las veces los estudiantes llegan a la respuesta y ahí termina la tarea. Por lo cual creemos que si se fomenta continuamente la evaluación siempre que los estudiantes trabajen con resolución de problemas ellos podrán desarrollar habilidades para mejorar sus procedimientos en futuras ocasiones y aumentar la certidumbre en sus actividades. A continuación analizamos el tipo de respuestas alcanzadas con las dos últimas preguntas donde los estudiantes reflexionan si hay otros procesos con los cuales también podrían llegar a la solución.

\section{Recapitulación y reflexión sobre el proceso de solución del problema}

En esta última parte de la resolución del problema se activa otra actividad representativa de habilidades metacognitivas "la comprobación del resultado", la cual se realiza comparándolo con una estimación del mismo o volviendo a calcular el resultado de otro modo (Veenman 2006). En el experimento de enseñanza se optó por la segunda opción pidiendo a los estudiantes que encontraran otra estrategia con la cual pudieran llegar de igual manera a la respuesta, esto con las últimas dos preguntas. A través de esta petición intentamos conducir a los estudiantes a la reflexión y evaluación del proceso realizado, así como hacer comparaciones de los diferentes procedimientos que se pueden seguir para llegar a la solución.

Conjuntamos el análisis de las respuestas a las últimas dos preguntas debido a que la primera originaba una respuesta cerrada de un sí o un no -¿es el único camino que se puede seguir para llegar a la respuesta?- y el no conducía a la última pregunta ¿qué otras formas puedes aplicar?, pero cuando se daba el caso de que la respuesta era un sí, la última pregunta la excluían los estudiantes.

Las respuestas a estas dos últimas preguntas fueron dos grupos diferentes, el primero 6 estudiantes que dieron la negación a la primera pregunta y los conducía a la aplicación de otro procedimiento y el segundo 4 estudiantes que dieron la afirmación y por ello se limitaban a dar la respuesta de la segunda pregunta.

A partir del primer grupo de respuestas sé evidencio la activación de la reflexión en la resolución del problema, aunque los 6 estudiantes escribieron una solución más simple "podíamos medir el ángulo con el transportador", todos tenían la confianza de que la opción era acertada, pero cambia la explicación dada al procedimiento y así comprobar nuevamente su resultado, lo cual podemos ver en la primera parte de la Figura 10, en tres de sus respuestas. En cambio en el segundo grupo de respuestas 4 de los estudiantes coinciden con "si es el único camino que yo sé" o "es el único camino que se puede seguir".

Con éstas últimas dos preguntas se logró que algunos estudiantes reflexionaran si había otro camino diferente de llegar a la respuesta, aunque ya la hubieran obtenido y tenían la seguridad que era correcta.

Hasta este momento hemos revisado los resultados alcanzados con la aplicación de las últimas tres preguntas, las cuales abarcan los procesos de evaluación e interpretación de resultados en la resolución de problemas, señaladas por Veenman (2012) como "las ejecuciones al final de la tarea". En estas actividades vemos como los diez estudiantes tienen la seguridad de que llegaron a la respuesta correcta y con ello se refleja como adquieren autonomía en los procedimientos, los cuales aplican en la resolución de problemas. 


\begin{tabular}{|c|c|}
\hline \multirow{3}{*}{$\begin{array}{l}\text { Primer grupo de } \\
\text { repuestas }\end{array}$} & 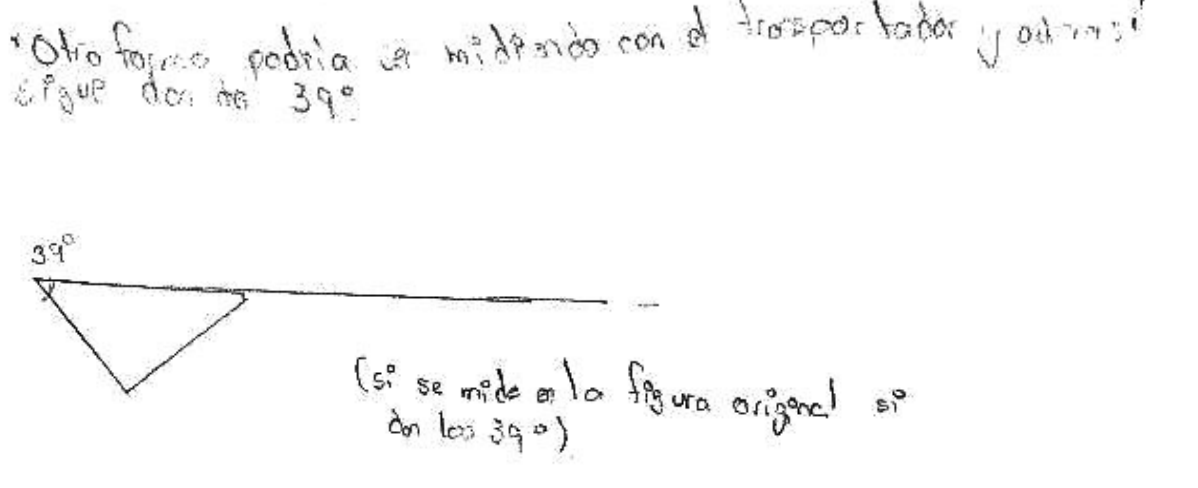 \\
\hline & 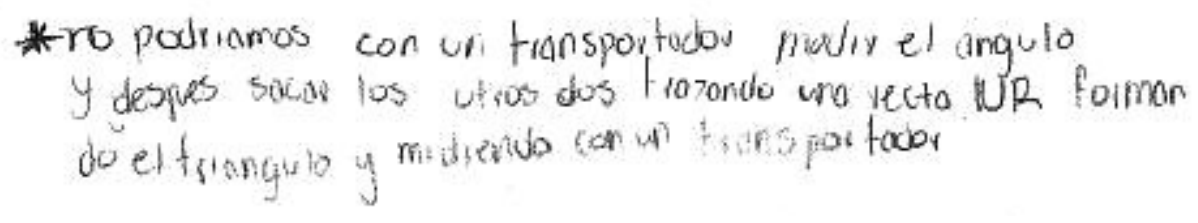 \\
\hline & $\begin{array}{l}\text { - Puedo medir el ángulo con el compas } \\
\text { (4a la hice, do } 39^{\circ} \text {, protongando blimen NR) }\end{array}$ \\
\hline $\begin{array}{l}\text { Segundo grupo de } \\
\text { respuestas }\end{array}$ & $8^{\circ}$ Si es el unira cammo rive to se. \\
\hline
\end{tabular}

FIGURA 10. Problema 9 trabajado por los estudiantes durante el experimento de enseñanza.

A lo largo del análisis de la información, se han revisado las actividades realizadas, por los 10 estudiantes participantes en el experimento de enseñanza, al inicio, durante y después de la resolución de 1 de los 12 problemas. Observamos que todos siguieron las preguntas propuestas en el taller de resolución de problemas, sin embargo, con diferentes habilidades, algunos siguen un camino más extenso y otros más estrecho. De igual manera encontramos algunas diferencias en la escritura de la justificación de sus respuestas, unos estudiantes van directo a la narración de la ejecución del problema, otros explican paso a paso cada cambio realizado hasta llegar a la respuesta.

Así mismo, en algunos casos, para facilitar el proceso los estudiantes trabajaron preguntas en conjunto, pero cubrieron todos los requisitos que éstas solicitaban; lo cual indica cómo se guiaron con las preguntas (auto instrucciones) de manera inducida en la resolución del problema, consiguiendo así una regulación activa de sus habilidades metacognitivas y resultados favorables en cada actividad, lo cual pudimos comprobar con sus narraciones en las hojas de trabajo. 


\section{Conclusiones y sugerencias}

A partir de los datos presentados en el análisis del problema 9 y las respuestas en los otros once problemas trabajados en el taller, observamos el desarrollo de habilidades metacognitivas en los estudiantes durante el experimento de enseñanza, las cuales se alcanzaron gradualmente a través de poner en práctica el uso de las preguntas descrito en la Tabla 2. Los diez estudiantes adquirieron una capacidad de orientación y planificación durante la resolución de cada problema, lo cual podemos ver cuando ellos escriben los pasos efectuados durante la resolución, describen como se hizo el procedimiento, porque se hizo y establecen además una justificación de su proceso.

La escritura les ayudó a tomar conciencia de los procesos que desarrollaron durante la solución de cada problema. Así mismo con las primeras preguntas, cuando anotan los datos principales y dicen cómo van a resolver el problema cumplen con el "saber qué". Posteriormente consiguieron tener dirección y control de sus procedimientos, al explicar cómo llegaron al resultado hacen explícito el "saber cómo" y al escribir su justificación o valoración los estudiantes cumplen con el "saber porque" ya que dan sustento a su procedimiento utilizado en la resolución y confirman si es correcto su resultado comprobándolo por medio de otros procesos para obtener la misma respuesta, obteniendo así una auto-regulación.

Recordando la descripción de Schoenfeld (1985), el proceso metacognitivo se exterioriza con la reflexión que hace el estudiante sobre lo pensado al realizar una tarea matemática, por consiguiente, podemos afirmar que, en el taller de resolución de problemas se dio la metacognición cuando al seguir las preguntas como auto-instrucciones en la resolución de todos los problemas de geometría los estudiantes:

- Reflexionaron sobre cómo proceder en el problema y los procesos que se generaron al resolverlo.

- Elaboraron las justificaciones en las que sustentan su procedimiento para la resolución de cada problema.

- Establecieron evaluaciones sobre sus resultados y reflexionaron si hay otros caminos con los cuales puedan alcanzar la solución correcta.

Si esto se logró con los doce problemas de geometría podría trabajarse las mismas preguntas para guiar a los estudiantes en la resolución de problemas pertenecientes al eje de sentido numérico y pensamiento algebraico, como en el eje de manejo de la información. De esta manera se brindaría mayor atención al desarrollo de las habilidades metacognitivas en conjunto con la resolución de problemas, con lo cual se conseguiría completar los propósitos del programa de estudios de la SEP al término de los nueve años de educación básica, atendiendo con las cuatro competencias matemáticas propuestas a desarrollar, pero dando un especial énfasis a la última: manejar técnicas eficientemente, para lo cual la SEP reconoce "es necesario que los alumnos la sometan a prueba en muchos problemas distintos, así adquirirán confianza en ella y la podrán adaptar a nuevos problemas" (SEP, 2011). 


\section{Referencias}

IIII Anderson, J. R. (1996). The architecture of cognition. Mahwah: Erlbaum.

IIII Bolton, G. (2011). Write yourself. Creative writing and personal development. Londres y Filadelfia: Jessica Kingsley Publishers.

IIII Butler, D. L. \& Winne, P. H. (1995). Feedback and self-regulated learning: A theoretical synthesis. Review of Educational Research 65 (3) 245-281.

IIII Carter, S. (2009). Connecting Mathematics and Writing Workshop: It's Kinda Like Ice Skating. The Reading Teacher 62 (7), pp. 606-610. DOI: 10.1598/rt.62.7.7.

IIII Fernández, I., y Cuadrado, I. (2008) ¿Son conscientes los profesores de secundaria de los recursos comunicativos verbales y no-verbales que emplean en el aula? Revista Iberoamericana de Educación 46: $1-13$.

IIII Flavell, J. H. (1970). Developmental studies of mediated memory. En H. W. Reese y L. P. Lipsitt (Eds.), Advances in child development and behavior (Vol. 5, pp. 181-211). New York: Academic.

IIII Flavell, J. H. (1979). Metacognition and Cognitive Monitoring. A New Area of Cognitive- Developmental Inquiry. American Psychologist, Vol. 34, No. 10, 906 - 911.

IIII Henning, E., Gravett, S., \& van Resburg, W. (2002). Finding your way in academic writing. Cape Twon: Van Schaick Publishers.

IIII Hyde, A. \& Hyde, P. (1991). Mathwise: teaching mathematical thinking and problem solving. Portsmouth, NH: Heinemann.

IIII Hyde, A. A. (2006). Comprehending math adapting reading strategies to teach mathematics, K-6. Portsmouth, $\mathrm{NH}$ : Heinemann.

IIII Nelson, T. O. (1999). Cognition versus métacognition. En R. J. Sternberg (Ed.), The nature of cognition (pp. 625-641). Cambridge: MIT Press.

IIII Sastre, V. P., Boubée, C., Cempio, V. (2013). Signos y matemática: un poco de historia. Flores, Rebeca (Ed), Acta Latinoamericana de Matemática Educativa, (79-87). México, Comité Latinoamericano de Matemática Educativa A. C. http://funes.uniandes.edu.co/3779/

IIII Schoenfeld, A. H. (1985). Metacognitive and epistemological issues in mathematical understanding. En E. A. Silver (Ed.), Teaching and learning mathematical problem solving: Multiple research perspectives (pp. 361379). Hillsdale. NJ: Erlbaum.

IIII Schunn, C. D., y Anderson, J. R. (1999). The generality/specificity of expertise in scientific reasoning. Cognitive Science, 23, 337-370.

IIII Secretaría de Educación Pública (2013). Invitación a las Olimpiada Estatal de Educación Primaria y Secundaria. Available at: http://portalsej.jalisco.gob.mx/sites/default/files/cuadernillo_secundaria_2013.pdf

IIII Secretaría de Educación Pública (2013) Invitación a las Olimpiada Estatal de Educación Primaria y Secundaria. Available at: http://portalsej.jalisco.gob.mx/cuarta-olimpiada-estatal-de-matematicas-en-educacion-primaria-ysecundaria 
IIII Veenman, M. V. J. (2005). The assessment of metacognitive skills: What can be learned from multi-method designs? In C. Artelt y B. Moschner (Eds.), Lernstrategien und Metakognition: Implikationen für Forschung und Praxis (pp. 75-97). Berlin: Waxmann.

IIII Veenman, M. V. J. (2006). Self-questioning as a metacognitive skill. In H. Pedrosa de Jesus and H., van der Meij (Eds.), Research on questioning. Aveiro: University of Aveiro.

IIII Veenman, M. V. J. (2007). The assessment and instruction of self-regulation in computer-based environments: A discussion. Metacognition and Learning, 2, 177-183.

IIII Veenman, M. V. J. (2011). Learning to self-monitor and self-regulate. In R. Mayer y P. Alexanders (Eds.), Handbook of Research on Learning and Instruction (pp. 197-218). New York: Routledge.

IIII Veenman, M. V. J. (2012). Metacognition in Science Education: Definitions, Constituents, and Their Intricate Relation with Cognition. A. Zohar y Y. J. Dori (Eds.), Metacognition in Science Education: Trends in Current Research. Contemporary Trends and Issues in Science Education 40, (21-36). DOI 10.1007/978-94-007-21326_2. (pp. 21-36).

IIII Vile, A. (1999) What can semiotics do for mathematics Education?, Advances in Mathematics Education, 1:1, 87-102, DOI: 10.1080/14794809909461548 


\title{
CAPítulo 6
}

\section{El papel de la representación en la formación del lenguaje gráfico}

\author{
Ricardo Arnoldo Cantoral Uriza \\ Rosa María Farfán Márquez
}

\section{Resumen}

En este capítulo proponemos una forma de articular el conocimiento matemático que favorece su apropiación por parte del estudiante. Para ello se moviliza una metodología, la ingeniería didáctica basada en la anidación de prácticas y una particular conceptualización de la representación en Matemáticas. En un sentido amplio, digamos que tradicional, la teoría del conocimiento ha considerado a la representación como una imagen, una idea, una noción o más ampliamente, un pensamiento que se expresa, es formado al nivel mental y que está presente al nivel de la consciencia. En este sentido la representación precisa de aquello que habrá de ser re-presentado - es decir, vuelto a presentar-, requiere por tanto de un objeto con existencia previa cuya captación intelectual reproduzca mentalmente a través de traer al presente las situaciones vividas, o de construir en la mente los escenarios que anticipan eventos por venir que condensen la experiencia adquirida.

\section{Introducción}

Bajo ese enfoque, la actividad semiótica no puede crear al objeto, pues solo lo re-presenta, es por ello que algunos autores han señalado críticas a su sustento epistemológico, particularmente Cantoral (2016) señala que no hay semiosis sin práxis. Radford (2004), por ejemplo, citando a Peirce, decía que el signo no crea al objeto: aquel es solamente afectado por este. En pocas palabras, en las diferentes escuelas de pensamiento que adoptan una perspectiva trascendental respecto a los objetos matemáticos como en la Ontosemiosis (que sea el caso del idealismo o del realismo), para ellos los signos constituyen el puente de acceso a esos objetos conceptuales vistos como situados más allá de las peripecias de la acción humana y la cultura, en este sentido su interés es clasificarlos en virtud de su pre-existencia. Para Radford es la actividad humana la que produce al objeto. El signo y la forma en que este es usado (esto es, su sintaxis) -forma necesariamente cultural en tanto que inmersa en Sistemas Semióticos Culturales de significación-son considerados como constitutivos del objeto conceptual: estos objetivan al objeto (Op. Cit., p. 14).

El marco teórico de la Socioepistemología comparte la tesis, de la semiótica cultural, que confiere a la actividad humana la función de producción del objeto, aunque el énfasis socioepistemológico no está puesto ni en el objeto 
preexistente o construido, ni en su representación producida o innata; sino más bien se interesa por modelar el papel que tiene la práctica social en la producción de conocimientos a fin de diseñar situaciones de aprendizaje para la intervención didáctica. Claramente, ello exige de un posicionamiento sobre el sentido que adquiere la expresión práctica social, en este enfoque.

Se asume como tesis fundamental que existe una profunda diferencia entre "la realidad del objeto" -la llamada realidad implicada-y "la realidad descrita" que producen los seres humanos en su acción deliberada para construir su "realidad explicada". La Socioepistemología ha tratado el problema de la representación de un modo singular, pues no busca discurrir teóricamente sobre la acción de representar al objeto mediante artefactos, herramientas o signos como hacen otros enfoques teóricos, sino que se ubica "a ras" de las acciones, actividades y prácticas, es decir de las prácticas socialmente compartidas, de la forma en que estas son reguladas por prácticas de referencia y normadas por prácticas sociales.

En primer término, es importante que se distinga la noción de práctica en un sentido llano, de aquella que usamos en el marco socioepistemológico. La práctica social la entendemos como normativa de la actividad humana, más que como actividad humana reflexiva o reflexión sobre la práctica; o aun como se señala en (Radford, 2004), como "interiorización reflexiva de prácticas sociales históricamente constituidas". Esas prácticas de las que ahí se habla son para la Socioepistemología prácticas socialmente compartidas, no así prácticas sociales. Más allá de un juego de palabras, esa distinción encarna una profunda conceptualización sobre lo que es la matemática y cómo se construye. Ahí radica una de las principales distinciones teóricas del enfoque socioepistemológico: la práctica social no es lo que hace en sí el individuo o éste en sus interacciones con el grupo, sino aquello que les norma y los hace hacer lo que hacen (Cantoral, 2016). Es así que decimos, la práctica social no se filma, se infiere, se postula. De este modo, se pretende explicar los procesos de construcción, adquisición y difusión del saber matemático con base en prácticas sociales. En sus investigaciones, los socioepistemólogos reportan más bien caracterizaciones del ejercicio de las prácticas que anteceden a la producción o construcción de conceptos y al desarrollo del saber.

Según este encuadre teórico, es preciso modificar el foco: "pasar de los objetos a las prácticas". Los enfoques reificacionistas centrados en objetos, buscan explicar el proceso mediante el cual se llega a la construcción del objeto y minimizan el papel que desempeña la triada: "herramientas, contextos y prácticas". El cambio de centración producirá un deslizamiento de orden mayor hacia explicaciones sistémicas, holísticas, complejas y transdisciplinarias, en virtud de que la acción cognitiva no busca la apropiación de objetos a través de sus partes, sino que asume que estos no existen objetiva y previamente, "ahí afuera", previos a la experiencia, sino que -más bien- los objetos son "creados" en el ejercicio de prácticas normadas (tesis compartida con la semiótica cultural). En consecuencia, se cuestiona la idea de que la cognición se reduzca a la acción de recobrar el entorno inmediato mediante un proceso de representación, para asumir que la cognición sea así entendida como la capacidad de "hacer emerger" el significado a partir de realimentaciones sucesivas entre el humano y su medio ambiente próximo, tanto físico como cultural, a partir de una interacción "dialéctica" entre protagonistas. Esta interacción, socialmente normada, da a la práctica, inevitablemente, una connotación de práctica social. El conocimiento entonces, como se ha señalado en (Varela et al., 1997) depende de las experiencias vividas que, a su vez, modifica las propias percepciones y creencias.

En este capítulo mostramos cómo opera el enfoque socioepistemológico al centrar su atención en prácticas más que en objetos. Su centración en las prácticas arroja una luz distinta de aquella que produce la centración en objetos, procesos o mediadores. En lo que sigue presentamos, mediante ejemplos, el papel que juega la práctica 
social en la construcción del conocimiento matemático y de cómo se articula con los procesos de representación.

Ahora bien, como se señala en Farfán y Romero (2016), el fenómeno educativo es eminentemente social y compete globalmente a la cultura en la que se sucede, por tanto, a los "puntos de vista" específicos del entorno social en el que se desarrolla, por lo que, de manera natural, la investigación en matemática educativa se desarrolla al abrigo de diferentes paradigmas. Particularmente para la Socioepistemología,

... "El punto de partida para la construcción de saberes es la actividad normada por emergentes de naturaleza social que denominamos prácticas sociales. Éstas regulan el ejercicio de prácticas compartidas a través de las cuales, los sujetos (individuales o colectivos) nos relacionamos intra e ínter psicológicamente. En este sentido, los saberes son las diferentes formas de comprender y explicar las realidades y se encuentran vinculados con las prácticas socialmente compartidas, las que a su vez están normadas por las prácticas sociales” ... (Cantoral, 2013, p. 48).

Indudablemente, los saberes matemáticos han sido constituidos socialmente, en ámbitos no escolares que, al introducirlos al sistema didáctico les obliga a modificarse afectando tanto su estructura como su funcionalidad y se establecen relaciones entre estudiantes y profesores. De ahí que se precise entender los mecanismos de la adaptación del saber matemático y científico a las prácticas tanto de los docentes como de sus estudiantes. La Socioepistemología ha construido una categoría para abordar teórica y metodológicamente ese proceso: el discurso matemático escolar ( $d M E)$,

..."La Socioepistemología tiene una mirada crítica al discurso matemático escolar, ya que éste tiene una centración en los objetos matemáticos y no en las prácticas sociales. Uno de sus planteamientos consiste en hacer que la matemática escolar sea funcional y deje de ser utilitaria, entendiendo la matemática funcional como un conocimiento incorporado orgánicamente en el humano que lo transforma y que le transforma su realidad, todo ello en oposición al conocimiento utilitario"... (Morales y Cordero, 2014, p. 327).

Dada la naturaleza del dME como ente inmóvil, carente de significados y utilitario que propicia la exclusión de la construcción social del conocimiento se pretende, desde la Socioepistemología y con el fin de proveer una epistemología que posibilite el aprendizaje, el rediseño del dME a partir de la problematización del saber matemático.

En este escrito nos proponemos hacer una revisión de nuestros resultados de investigación en la construcción de un lenguaje gráfico, con el fin de posibilitar al profesorado el conocimiento de las herramientas indispensables que le permitan realizar pertinentemente el diseño e implementación de situaciones de aprendizaje en el aula de matemáticas, lo que investigaciones recientes (Reyes, 2016) han reportado que se favorece un empoderamiento de los docentes. Haremos una presentación de nuestros resultados de manera resumida precisando tres aspectos importantes de nuestros diseños, a saber, operaciones gráficas, resolución gráfica de desigualdades y construcción de funciones.

Con ello creemos que el lector estará en condiciones de apropiarse de una visión global del quehacer de investigación en Matemática Educativa junto con su aplicación dentro del aula de matemáticas con el fin de diseñar e implementar, pertinentemente, proyectos de investigación en la clase de matemáticas a propósito del tema que aquí discutiremos: el lenguaje gráfico. 


\section{Sobre la propuesta para de diseño}

Tradicionalmente el curso de Precálculo suele ser un repertorio de procedimientos y algoritmos provenientes, esencialmente, del álgebra y de la geometría analítica, tocando con mayor o menor énfasis al estudio de función, habitualmente sobre la definición de Dirichlet-Bourbaki, es decir, "el concepto general de función se refiere a una regla que asigna a cada elemento de un primer conjunto un único elemento de un segundo conjunto". La enseñanza tiende a sobrevalorizar los procedimientos analíticos y la algoritmización, dejando de lado a los argumentos visuales, por no considerarlos como matemáticos, entre otras causas. Es decir, la concepción que de la matemática se tenga, permea la de su enseñanza, independientemente de los estudiantes a los que se dirige. A ello se aúna el contrato didáctico establecido, que como parte de la negociación impide que el status del profesor sea demeritado, si éste no resuelve satisfactoriamente los problemas planteados en el curso; el recurso algorítmico permite subsanar decorosamente lo establecido en el contrato y "aligera", eliminando dificultades subyacentes al contenido matemático.

La investigación sobre las premisas que sustenta la instalación de un lenguaje gráfico que permita el tránsito entre varios contextos ha sido reportada en (Farfán, 2012; Cantoral y Farfán, 1998). En síntesis, hemos sostenido que, para acceder al pensamiento y lenguaje variacional, elementos centrales del estudio del precálculo y cálculo, se precisa entre otras del manejo de un universo de formas gráficas extenso y rico en significados por parte del que aprende. El conocimiento de la recta y la parábola no resultan suficientes para desarrollar las competencias esperadas en los cursos de análisis.

En términos escolares la modificación del curso de precálculo al inicio de los estudios universitarios y un diseño para la escuela lo presentamos en Farfán (2013). En lo que sigue expondremos grosso modo los elementos del análisis preliminar en términos de ingeniería didáctica, en el sentido de Artigue (1992), así como los elementos sustantivos del diseño a fin de proporcionar un ejemplo de innovación para la escuela obtenida de la investigación en matemática educativa.

- Estudio epistemológico. La naturaleza del concepto de función es en extremo compleja, su desarrollo se ha hecho casi a la par del humano, es decir, encontramos vestigios del uso de correspondencias en la antigüedad, y actualmente se debate sobre la vigencia, en el ámbito de las matemáticas, del paradigma de la función como un objeto analítico. Empero, el concepto de función devino protagónico hasta que se le concibe como una fórmula, es decir hasta que se logró la integración entre dos dominios de representación: el álgebra y la geometría. La complejidad del concepto de función se refleja en las diversas concepciones y diversas representaciones con las que se enfrentan los estudiantes y profesores. Una lista exhaustiva de obstáculos epistemológicos del concepto de función se encuentra en (Sierpinska, 1992).

- Estudio cognitivo. Los objetos inmersos en el campo conceptual del cálculo (análisis) son particularmente complejos a nivel cognitivo pues, como en el caso que nos ocupa, la función se presenta como un proceso cuyos objetos son los números; este mismo concepto deviene en objeto al ser operado bajo otro proceso como la diferenciación (ó integración) y así sucesivamente. De modo que al iniciar un curso de cálculo el estudiante debe concebir a la función como un objeto y por ende susceptible de operación; de otro modo, ¿qué significa operar un proceso? En nuestras experiencias con profesores y estudiantes hemos constatado que si logran incorporar elementos visuales como parte de su actividad matemática al enfrentar problemas, 
no sólo manejan a la función como objeto sino que además transitan entre los contextos algebraico, geométrico y numérico versátilmente, es decir, si se tiene dominio del contexto geométrico/visual tanto en la algoritmia, la intuición como en la argumentación es posible el tránsito entre las diversas representaciones. El problema estriba en la dificultad cognitiva para adquirir maestría en el contexto geométrico, por ejemplo, en el plano de la argumentación es mucho más fácil mostrar la existencia de una raíz doble algebraicamente que geométricamente, por lo que se acude al refugio algorítmico fácilmente.

A partir de estos elementos nos proponemos un diseño con el objetivo explícito de construir un lenguaje gráfico basado en el pensamiento funcional. La hipótesis central, después de un análisis socioepistemológico a profundidad como el que se desarrolla en Farfán (2012) consiste en asumir que: previo al estudio del Cálculo se precisa de la adquisición de un lenguaje gráfico que posibilite, esencialmente, la transferencia de campos conceptuales virtualmente ajenos, a causa de las enseñanzas tradicionales, estableciendo un isomorfismo operativo entre el Álgebra básica y el estudio de curvas, mejor aún, entre el lenguaje algebraico y el lenguaje gráfico.

Esta hipótesis ha sido desarrollada tomando las siguientes directrices; en primer término, se presenta la posibilidad de operar gráficas en analogía con los números o las variables, dando sentido a operaciones fundamentales tales como:

\begin{tabular}{|c|c|}
\hline - $-f(x)$ y $f(-x)$ & Reflexión respecto del eje $x$ y del eje $y$ respectivamente. \\
\hline - $f(x+a)$ y $f(x-a)$ con $a>0$ & Traslación en la dirección del eje $x$. \\
\hline - $f(x)+a$ y $f(x)-$ a con $a>0$ & Traslación en la dirección del eje $y$. \\
\hline - $a f(x)$ & Contracción o dilatación respecto del eje $y$. \\
\hline - $f^{-1}(x)$ & Reflexión respecto de la recta $y=x$. \\
\hline - $\frac{1}{f(x)}$ & $\begin{array}{l}\text { Invierte ceros en asíntotas y viceversa, y las abscisas tales que }|y|>1 \\
\text { corresponderán con aquéllos donde }|y|<1 \text { y viceversa, dejando intactos } \\
\text { los puntos sobre las rectas } y=1 \text { y } y=-1 \text {. }\end{array}$ \\
\hline - $|f(x)|$ y $f(|x|)$ & $\begin{array}{l}\text { Respectivamente reflexión de las imágenes negativas al simétrico } \\
\text { positivo respecto del eje } x \text { y reflexión de sustitución del lado de la } \\
\text { gráfica con ordenadas negativas por la reflexión del lado de la gráfica } \\
\text { con ordenadas positivas. }\end{array}$ \\
\hline
\end{tabular}

El segundo aspecto relevante lo constituye la posibilidad de construir un universo amplio de funciones a partir de tres funciones primitivas de referencia: la identidad $(f(x)=x)$, la exponencial $\left(f(x)=a^{x}\right)$ y la sinusoidal $(f(x)=$ $\operatorname{sen} x$ ), todas ellas para construir las funciones elementales en el sentido de Cauchy. Respectivamente, ellas sirven para construir operando las gráficas a las funciones algebraicas, logarítmicas y exponenciales y las trigonométricas gráficamente. 
IMAGEN 1. Diseño de una ingeniería didáctica.

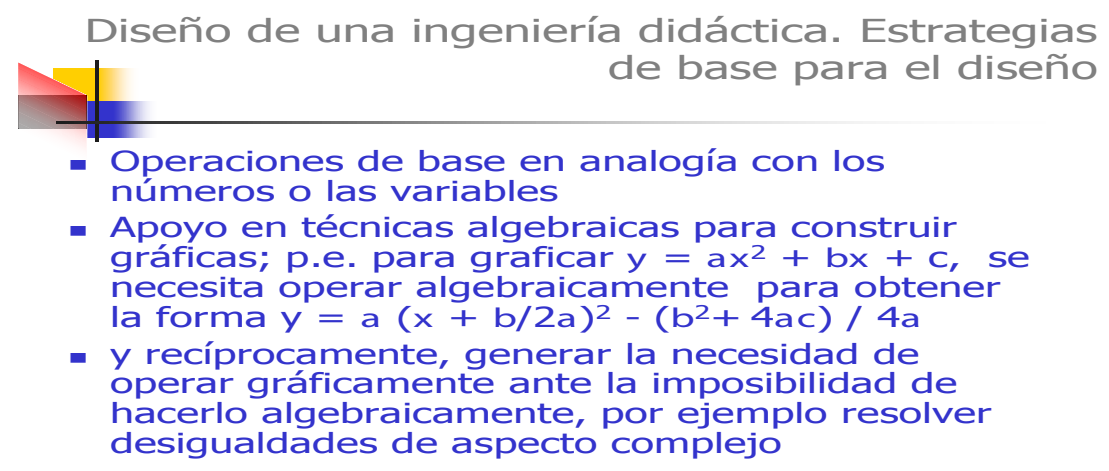

En este acercamiento ha resultado importante plantear situaciones de aprendizaje que involucren enunciados algebraicos que favorezcan el uso del lenguaje gráfico, por ejemplo, la tarea:

Resuelve la desigualdad $\frac{|x-a|+|x-b|}{|x+b|+|x+a|} \leq k x$

Es ampliamente desarrollada como estrategia de enseñanza en (Farfán, 2013) en donde el recurso de plantear la resolución de desigualdades es precisamente la variable didáctica de control del diseño que nos permite que el aprendiz deje el recurso algebraico que le ha funcionado escolarmente. Para todo ello es necesario operar algebraicamente a fin de obtener la gráfica de las funciones involucradas para que finalmente sean comparadas y resolver de este modo los sistemas de ecuaciones a que haya lugar. Del mismo modo el buscar los extremos de funciones como $\frac{x}{a x^{2}+b}$ con $a$ y $b$ positivos, permite avanzar en la construcción del puente entre contextos, pues la tarea en este contexto sirve de guía a la sintaxis algebraica, de modo que ésta se refuerza en su significado.

Describimos enseguida un ejemplo:

Resolución de la desigualdad $-x^{2}+x+2 \leq|x-2|$

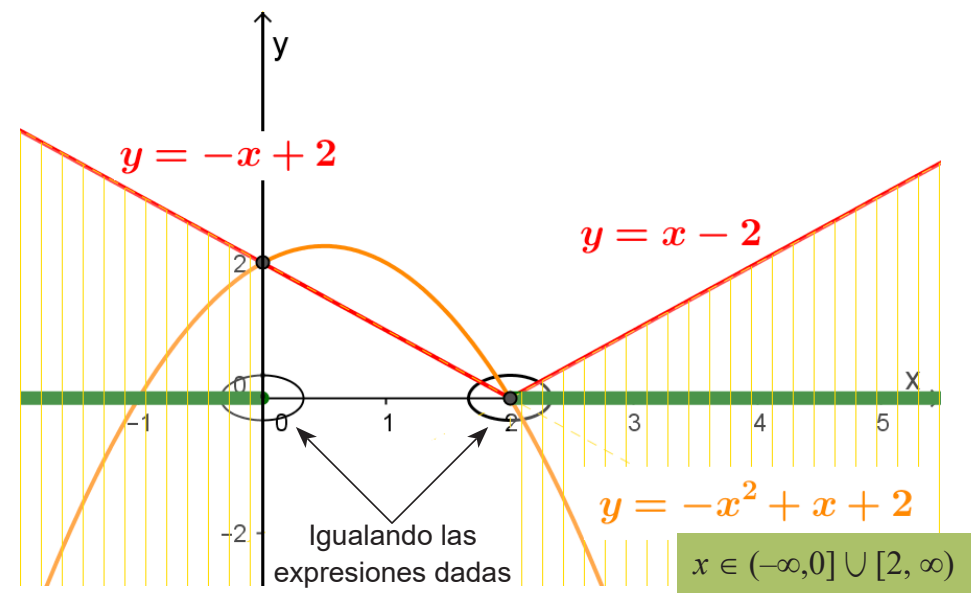

IMAGEN 2. Resolución gráfica de desigualdades. 
En la imagen 2 pueden notarse las gráficas tanto de $y=-x^{2}+x+2$ como de $y=|x-2|$. El método usado es encontrar los puntos de corte de ambas gráficas, es decir, los valores para los cuales la gráfica de la función cuadrática es igual a la gráfica del valor absoluto, específicamente: $-x^{2}+x+2=-x+2$. La importancia de estos puntos radica en que marcan un cambio en las imágenes de una función con respecto a la otra. Esto es, en el primer punto de corte entre las gráficas, $x=0$, las imágenes de la cuadrática pasan de ser menores a ser mayores que las imágenes del valor absoluto. En el segundo punto de corte, $x=2$, las imágenes de la cuadrática pasan de ser mayores a ser menores que las imágenes del valor absoluto. Con este análisis es que se obtiene que en los intervalos $(-\infty, 0] \cup[2, \infty)$ la gráfica de $y=-x^{2}+x+2$ es menor o igual que la gráfica de $y=|x-2|$, es decir, se satisface la desigualdad.

En síntesis, estas son las premisas de nuestro acercamiento, cuyos ejemplos se expondrán en lo que sigue. Antes, es importante señalar que el desarrollo del pensamiento y el lenguaje variacional entre los estudiantes precisan de procesos temporalmente prolongados a juzgar por los tiempos didácticos habituales. Supone, por ejemplo, del dominio de la matemática básica y de los procesos del pensamiento asociados, pero exige simultáneamente de diversas rupturas con estilos del pensamiento pre-variacional, como el caso del pensamiento algebraico ampliamente documentado por (Artigue, 1998). Esa ruptura, además, no puede ser sostenida exclusivamente al seno de lo educativo con base en un nuevo paradigma de rigor que se induce simplemente de la construcción de los números reales como base de la aritmetización del análisis, ni tampoco puede basarse sólo en la idea de aproximación, sino que debe ayudar también a la matematización de la predicción de los fenómenos de cambio.

\section{Operaciones gráficas}

Creemos que es necesario rescatar algunos "mecanismos" que permitan generar conocimiento y darles significado a ciertos contenidos matemáticos. En este sentido, es importante que el estudiante logre un buen manejo del lenguaje gráfico y un pasaje fluido del contexto algebraico al gráfico. Con ello, estaremos proporcionándole una base más sólida donde asentar otros conceptos de Cálculo, como, por ejemplo, comportamiento de funciones, obtención de áreas, etc., y aportándole herramientas que le permitirán una mejor comprensión y, por ende, apropiación de conocimientos en niveles más abstractos.

Con el manejo de este tipo de operaciones intentamos dotar al alumno de un manejo del "lenguaje gráfico" que implica, por un lado, inducirlo a la "semántica gráfica", es decir, a la construcción de significados previos de las operaciones gráficas; y por otro, a la "sintaxis gráfica", vale decir, a su simbolización respetando ciertas reglas. En este espacio presentamos sólo el estudio de una operación, sin embargo, en (Farfán et al., 2000) es posible consultar otras.

\section{Estudio de $\frac{1}{f(x)}$ a partir de $f(x)$}

Para construir la gráfica del recíproco de una función, partiremos de $f(x)=x$, pues se considera que es reconocida por el alumno. Así, se intenta que, de un análisis exhaustivo de la construcción de $\frac{1}{x}$, se logre la generalización a cualquier función mediante la detección de propiedades comunes.

Partimos entonces, de la forma elemental $f(x)=x$. 
Sus características son, entre otras:

- $\operatorname{Dom} f=R$.

- Es creciente, pues si $a<b$ entonces $f(a)<f(b)$.

- Es continua.

- Es simétrica respecto al origen de coordenadas, por tanto es una función impar, es decir que $f(-x)=-f(x)$ ya que $f(-x)=-x=-f(x)$.

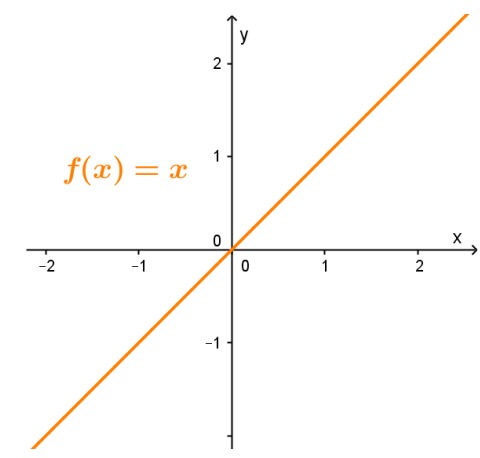

- $f(x)$ es positiva si $x>0$, es decir, $f(x)>0$ sí y solo si $x>0$.

- $f(x)$ es negativa si $x<0$, es decir, $f(x)<0$ sí y solo si $x<0$.

- $f(x)=0$ sí y solo si $x=0$.

El identificar características de $f(x)$ es relevante en cuanto se desea establecer cómo se modifican o conservan estas propiedades al calcular el recíproco de $f(x)$.

a) Estudio de los puntos $(1,1)$ y $(-1,-1)$

$$
\text { Definimos } g(x)=\frac{1}{f(x)} \quad \begin{aligned}
\text { Si } x=1 & \Rightarrow f(1)=1 \\
& \Rightarrow g(1)=\frac{1}{1}=1 \\
\text { Si } x=-1 & \Rightarrow f(-1)=-1 \\
& \Rightarrow g(-1)=\frac{1}{-1}=-1
\end{aligned}
$$

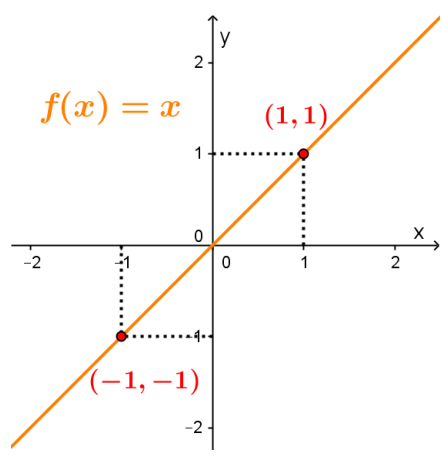

Es decir, los puntos $(1,1)$ y $(-1,-1)$ pertenecen tanto a la gráfica de $f$ como a la de $g$.

b) Estudio de puntos $a, b \in(0,1)$

Para los puntos del intervalo $(0,1)$ haremos las siguientes consideraciones:

- Sean $a, b \in(0,1)$ de modo tal que $a<b<1$.

- Como $f(a)=a$ y $f(b)=b$, entonces, $f(a)<f(b)$, ya que $f(x)$ es creciente.

- Pero, $g(a)=\frac{1}{a}$ y $g(b)=\frac{1}{b}$. Si recordamos que $0<a<b<1$, al dividir por $a>0$ las desigualdades no se alteran, por tanto:

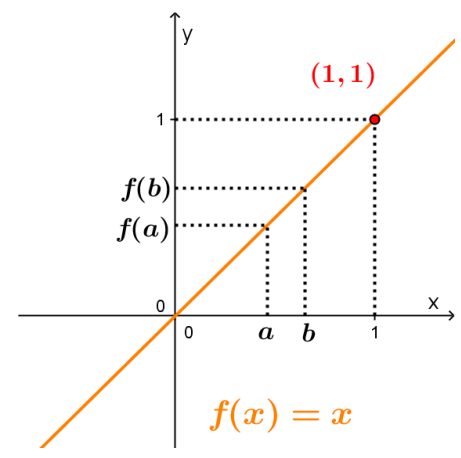

$$
1<\frac{b}{a}<\frac{1}{a}
$$


Si dividimos ahora por $b>0$ obtenemos:

$$
\frac{1}{b}<\frac{1}{a}<\frac{1}{a b}
$$

- Además, $b<1 \Rightarrow 1<\frac{1}{b}$

$$
\text { Entonces } \quad 1<\frac{1}{b}<\frac{1}{a}
$$

Es decir $1<g(b)<g(a)$

Por tanto $g(x)$ decrece y se ubica por encima de $y=1$.

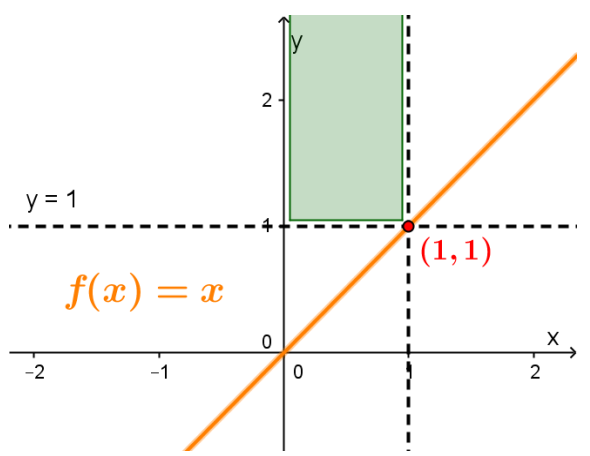

Como ejemplo calculemos algunos puntos para comenzar a trazar la gráfica:

$$
\begin{array}{lllll}
\text { - } x=\frac{1}{2} & \Rightarrow f(x)=\frac{1}{2} & \text { y } & g(x)=\frac{1}{\frac{1}{2}}=2 \\
\text { - } x=\frac{1}{3} \quad \Rightarrow & f(x)=\frac{1}{3} & \text { y } & g(x)=\frac{1}{\frac{1}{3}}=3
\end{array}
$$

Si hacemos $x$ cada vez más pequeño:

$$
\text { - } x=\frac{1}{100} \Rightarrow f(x)=\frac{1}{100} \quad \text { y } \quad g(x)=\frac{\frac{1}{\frac{1}{100}}}{100}=100
$$

en general, para $n$ cada vez más grande:

$$
\text { - } x=\frac{1}{n} \Rightarrow f(x)=\frac{1}{n} \quad \text { y } \quad g(x)=\frac{1}{\frac{1}{n}}=n
$$

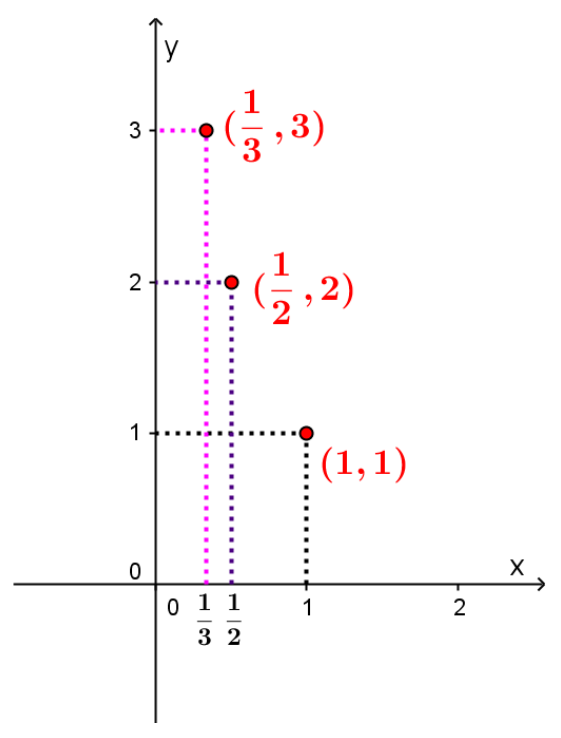

Observamos que, a medida que $f(x)$ se hace más pequeño, $g(x)$ se hace más grande. Es decir, si hacemos tender $x$ a cero, $f(x)=x$ también se acercará tanto como deseemos a cero, y por lo tanto, $g(x)=\frac{1}{x}$ tenderá a infinito, esto es, se hará tan "grande" como queramos.

Tomemos ahora dos puntos de $f(x):(a, f(a))$ y $(b, f(b))$ tales que $a, b \in(0,1)$ con $a<b$, entonces $f(a)<f(b)$ y, por lo visto anteriormente, $g(a)>g(b)$.

Además, $b-a>0$ y $g(b)-g(a)<0$. Efectivamente:

$g(b)-g(a)=\frac{1}{b}-\frac{1}{a}=\frac{a-b}{a b}=-\frac{(b-a)}{a b}$. 
La pendiente de la recta que pasa por los puntos $(a, g(a))$ y $(b, g(b))$ es:

$m=\frac{g(b)-g(a)}{b-a}=\frac{\frac{1}{b}-\frac{1}{a}}{b-a}=\frac{\frac{a-b}{a b}}{b-a}=-\frac{1}{a b}$

Conforme a y $b$ sean más pequeños $g(a)=\frac{1}{a}$ y $g(b)=\frac{1}{b}$ serán cada vez más grandes. Por otro lado, el producto de $a b$ también está acercándose a cero, por tanto, $-=\frac{1}{a b}$ se está haciendo "muy grande", es decir, este valor tiende a infinito (negativo).

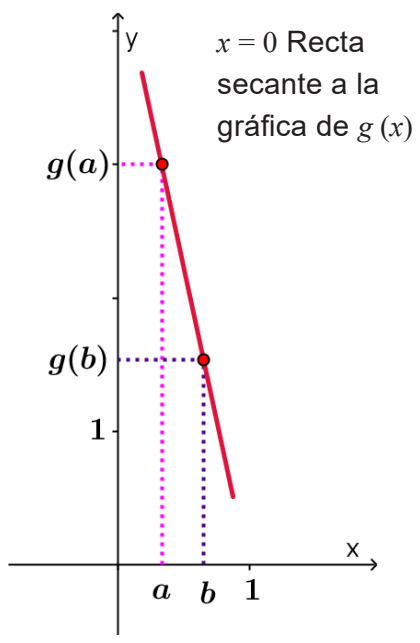

Luego, como la pendiente de la recta secante a la gráfica de $g(x)$ es $-=\frac{1}{a b}$, esta recta se va haciendo cada vez mas paralela al eje $y$ a medida que nos acercamos a $x=0$. Esto nos lleva a pensar que los puntos de la gráfica de $g(x)$ no atravesarán el eje vertical. Podemos deducir entonces que: $x=0$ es una asíntota de la gráfica $\operatorname{de} g(x)=\frac{1}{x}$.

c) Estudio de puntos $a, b \in(0,+\infty)$

Ahora consideremos el intervalo $(1,+\infty)$ y sean $a, b \in(1,+\infty)$ tales que: $1<a<b$, al dividir por $a>0$ las desigualdades no se alteran y obtenemos: $\frac{1}{a}<1<\frac{b}{a}$

de igual manera, si dividimos ahora por $b>0$ nos queda

$$
\frac{1}{a b}<\frac{1}{b}<\frac{1}{a}<1
$$

Luego,

$\left.\begin{array}{l}f(a)=a \\ f(b)=b\end{array}\right\}$ por tanto $1<f(a)<f(b)$, y $f$ crece y se mantiene por encima de la recta $y=1$.

$\left.\begin{array}{l}g(a)=\frac{1}{a} \\ g(b)=\frac{1}{b}\end{array}\right\}$ por tanto $g(a)<g(b)<1, g$ decrece y se mantiene por debajo de la recta $y=1$. 
Por otro lado, si

$x \in(1,+\infty) \Rightarrow x>0 \Rightarrow \frac{1}{x}>0 \Rightarrow g(x)>0$,

es decir, $g(x)$ se mantiene por encima de la recta $y=0$, luego $0<g(x)<1$ para todo $x \in(1,+\infty)$.

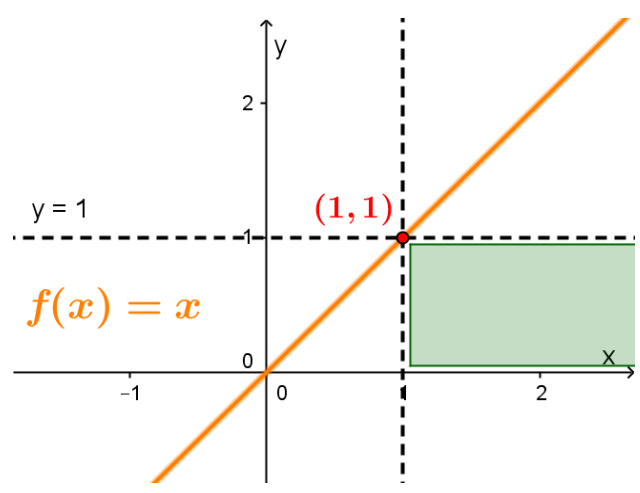

Anteriormente vimos que la pendiente de la recta que une dos puntos $(a, g(a))$ y $(b, g(b))$ es: $m=\frac{g(b)-g(a)}{b-a}=-\frac{1}{a b}$.

Si ahora hacemos que a y $b$ sean cada vez más grandes, es decir, que ambos tiendan a infinito, la pendiente de esta recta a la gráfica de $g(x)$ tenderá a cero, es decir, será cada vez más horizontal o paralela al eje $x$. Esto nos hace pensar que los puntos de la gráfica de $g(x)$ no atravesarán la recta $y=0$. Así, el eje $x$ será una asíntota horizontal de la gráfica de $g(x)$.

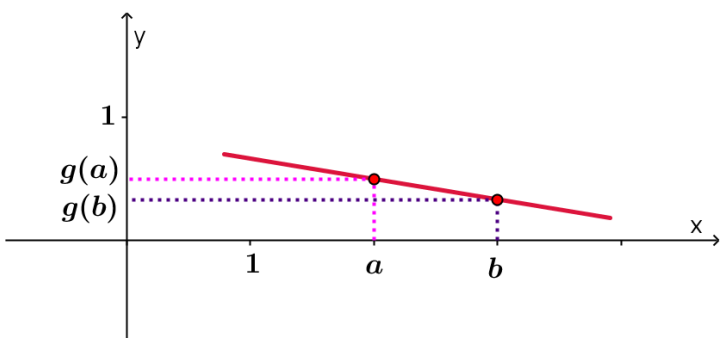

Del análisis de las características de $f(x)$, sabemos que $f$ es una función impar. Ahora, como $g(x)=\frac{1}{x}$ entonces $g(-x)=-\frac{1}{x}=-g(x)$ de lo que concluimos que $g(x)$ es impar, por lo tanto, la gráfica de $g(x)$ es simétrica respecto al origen de coordenadas.

Entonces, con lo estudiado hasta ahora, estamos en condiciones de trazar la gráfica completa. Gráfica de $f(x)=x$ y de su recíproca $g(x)=\frac{1}{x}$.

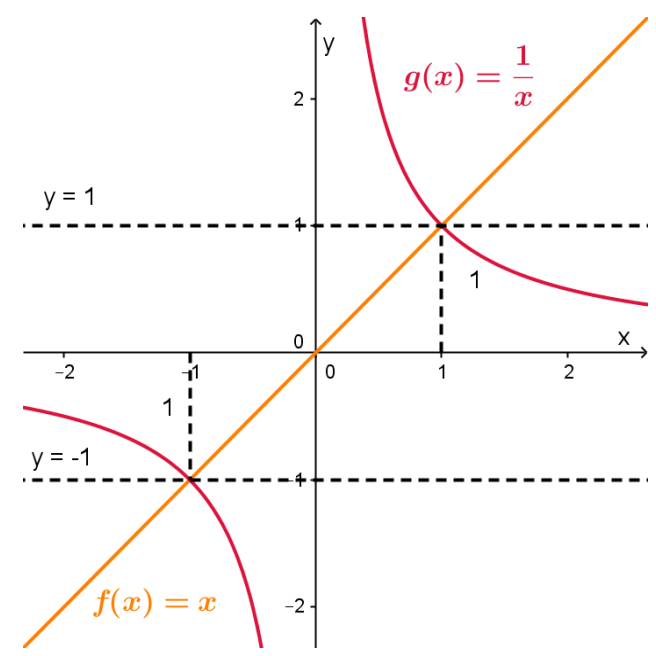

Analicemos ahora, la manera en que se puede construir la gráfica del recíproco de una función arbitraria a partir de su gráfica. Para ello utilizaremos los resultados que obtuvimos en el estudio del recíproco de la función elemental $f(x)=x$. 
Generalización de la construcción de $\frac{1}{f(x)}$ a partir de cualquier $f(x)$.

1) Signo de $\frac{1}{f(x)}$

Por tanto, se mantiene el signo de $\frac{1}{f(x)}$ respecto del signo de $f(x)$.

\section{2) Puntos invariantes.}

Sabemos que el recíproco de 1 es él mismo.

Por lo tanto, si $f(x)=1$ para algún $x \in \operatorname{Dom} f \Rightarrow \frac{1}{f(x)}=1$

Lo mismo ocurre con -1 .

En conclusión, los puntos de la forma $(x, 1)$ y $(x,-1)$ que pertenecen a la gráfica de $f(x)$, pertenecen también a la gráfica de $\frac{1}{f(x)}$.

Todas las consideraciones anteriores quedan resumidas en la siguiente tabla:

\begin{tabular}{|c|c|c|c|c|}
\hline$f(x)$ & Significado gráfico & $\frac{1}{f(x)}$ & Significado gráfico & Observaciones \\
\hline $0<f(x)<1$ & $\begin{array}{l}y=1 \\
y=0\end{array}$ & $\frac{1}{f(x)}>1$ & $y=1$ & $\begin{array}{l}\text { La gráfica de } \frac{1}{f(x)} \text { se halla } \\
\text { por encima de la recta } y=1\end{array}$ \\
\hline$f(x)>1$ & $y=1$ & $0<\frac{1}{f(x)}<1$ & $\begin{array}{l}y=1 \\
y=0\end{array}$ & $\begin{array}{l}\text { La gráfica de } \frac{1}{f(x)} \text { se halla } \\
\text { por debajo de la recta } y=1 \text { y } \\
\text { por encima del eje } x\end{array}$ \\
\hline$-1<f(x)<0$ & $\begin{array}{l}y=0 \\
y=-1\end{array}$ & $\frac{1}{f(x)}<-1$ & $y=-1$ & $\begin{array}{l}\text { La gráfica de } \frac{1}{f(x)} \text { se halla } \\
\text { por debajo de la recta } y=-1\end{array}$ \\
\hline$f(x)<-1$ & $y=-1$ & $-1<\frac{1}{f(x)}<0$ & $\begin{array}{l}y=0 \\
y=-1\end{array}$ & $\begin{array}{l}\text { La gráfica de } \frac{1}{f(x)} \text { se halla } \\
\text { por encima de la recta } y=-1 \text { y } \\
\text { por debajo del eje } x\end{array}$ \\
\hline
\end{tabular}


De la tabla anterior, se deduce la importancia de graficar las rectas $y=1$ y $y=-1$ pues, dan una primera aproximación de las regiones donde se encontrará la gráfica de $\frac{1}{f(x)}$

\section{3) Ceros de $f(x)$}

Si existe $a \in \operatorname{Dom} f$, tal que $f(a)=0$ entonces $\frac{1}{f(a)}$ no está definida

Por tanto, un cero de $f(x)$ se convierte en una asíntota de $\frac{1}{f(x)}$
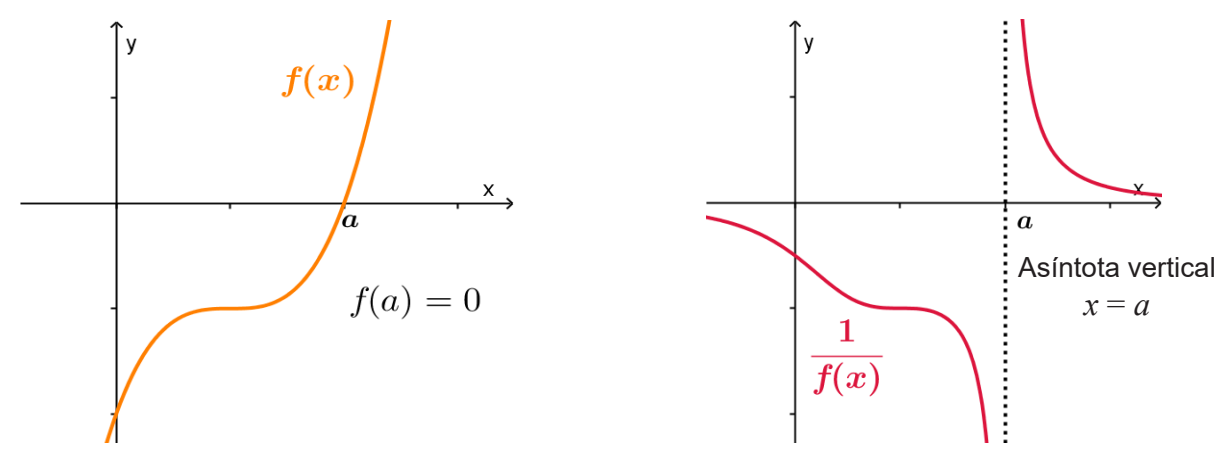

\section{4) Asíntotas verticales de $f(x)$}

Si $f(x)$ tiene una asíntota vertical en algún $x$, entonces, $f(x)$ tiende a infinito.

Por tanto, una asíntota vertical de $f(x)$ se convierte en un cero de $\frac{1}{f(x)}$
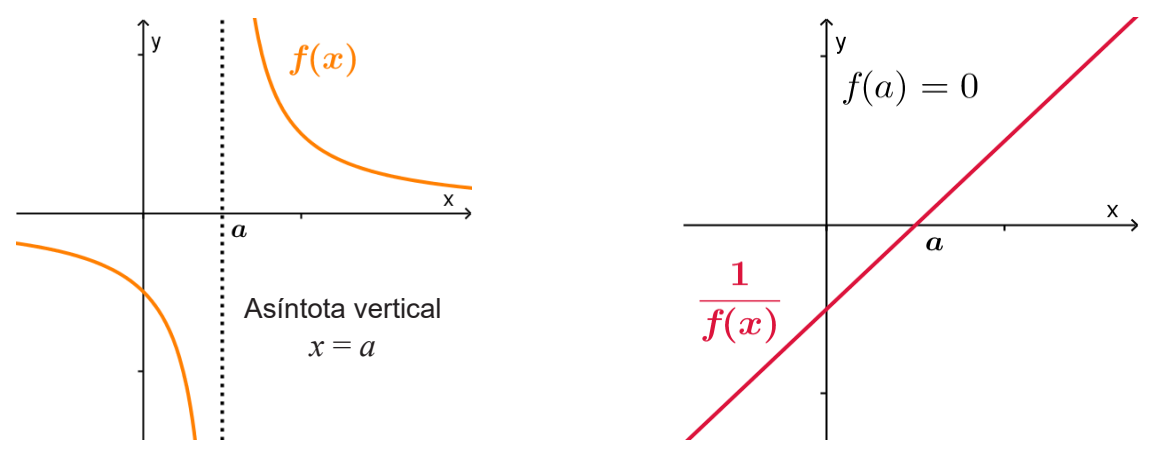

\section{5) $f(x)$ creciente o decreciente}

$f(x)$ es creciente sí y solo si, para todo $a, b \in \operatorname{Dom} f$ tales que $a<b$, se cumple que $f(a)<f(b)$. Luego, si $a, b \in \operatorname{Dom} f$ tales que $a<b$, vimos que $\frac{1}{f(b)}<\frac{1}{f(a)}$ por lo tanto, podemos concluir que:

Si $f(x)$ es creciente $\frac{1}{f(x)}$ es decreciente 

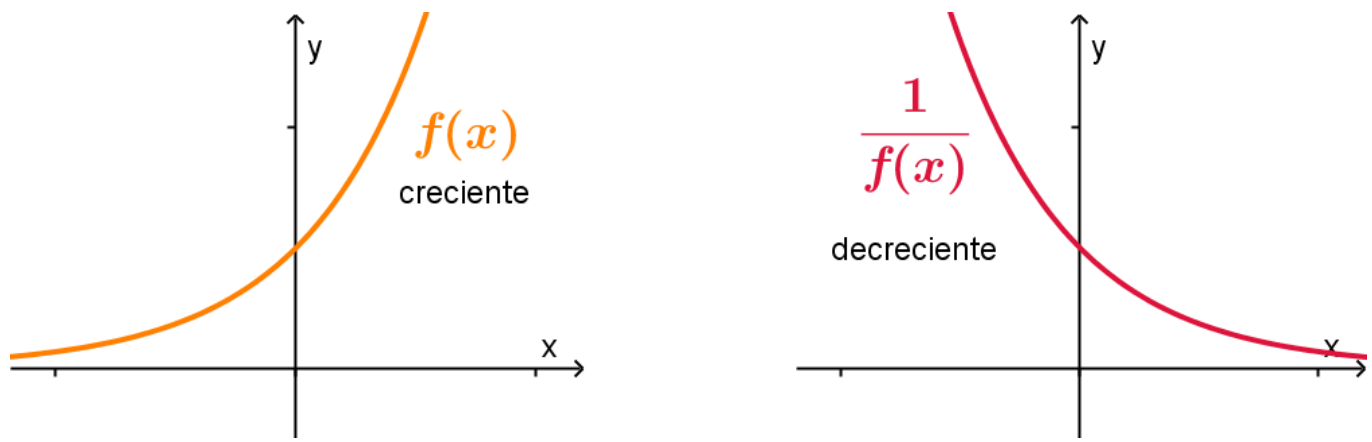

Análogamente,

Si $f(x)$ es decreciente $\Rightarrow \frac{1}{f(x)}$ es creciente

6) Simetría respecto al eje $\boldsymbol{y}$, es decir, $f(x)$ es una función par

$f(x)$ es una función par, sí y solo si, para todo $x \in \operatorname{Dom} f$ se cumple que $f(-x)=f(x)$.

Vemos que $\frac{1}{f(-x)}=\frac{1}{f(x)}$ y podemos entonces concluir lo siguiente:

Si $f(x)$ es una función par, entonces $\frac{1}{f(x)}$ es una función par. Por lo tanto, $\frac{1}{f(x)}$ también es simétrica respecto al eje $y$.

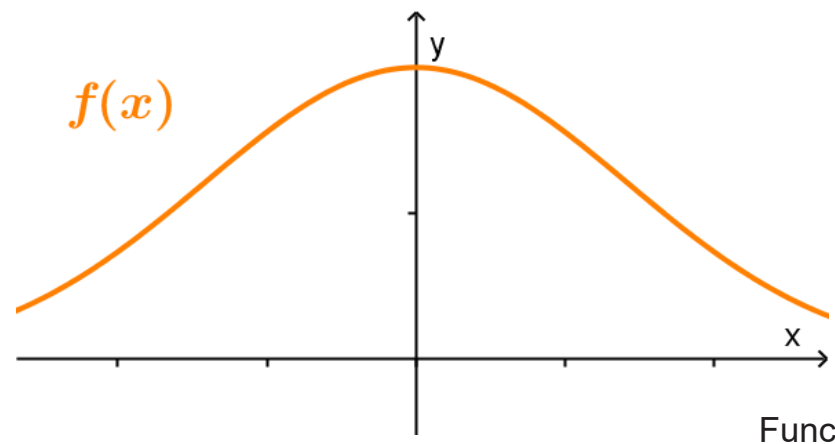

Funciones pares

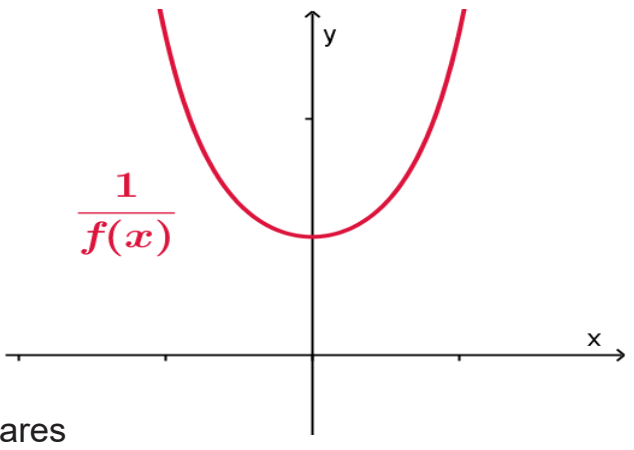

7) Simetría respecto al origen de coordenadas, es decir, $f(x)$ es una función impar

$f(x)$ es una función impar, sí y solo si, para todo $x \in \operatorname{Dom} f$ se cumple que $f(-x)=-f(x)$.

Luego $\frac{1}{f(-x)}=-\frac{1}{f(x)}$ y podemos entonces concluir que: 
Si $f(x)$ es una función impar $\Rightarrow \frac{1}{f(x)}$ es una función impar. Por lo tanto, $\frac{1}{f(x)}$ también es simétrica respecto al origen de coordenadas.

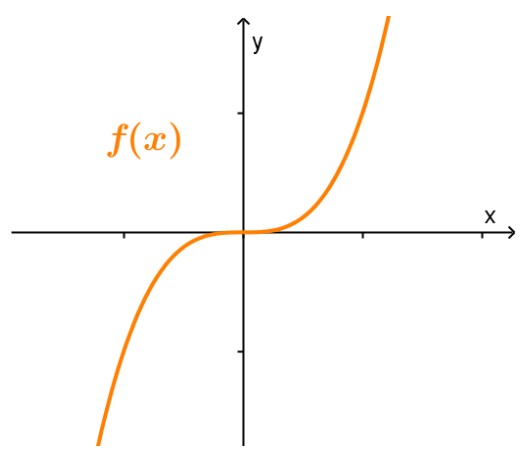

Funciones impares

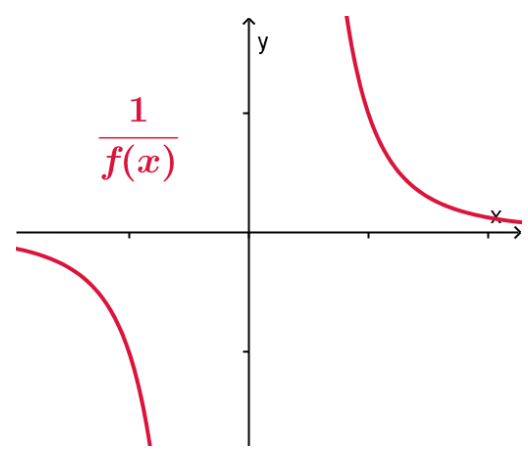

\section{8) Continuidad de $f(x)$} Que $f(x)$ sea una función continua en todo su dominio, no implica que $\frac{1}{f(x)}$ también lo sea. En efecto, puede
ocurrir que:

- $f(x)$ sea continua, como por ejemplo $f(x)=x$, pero su recíproca ser discontinua, tal el caso de $\frac{1}{f(x)}=\frac{1}{x}$.
Observemos sus gráficas:
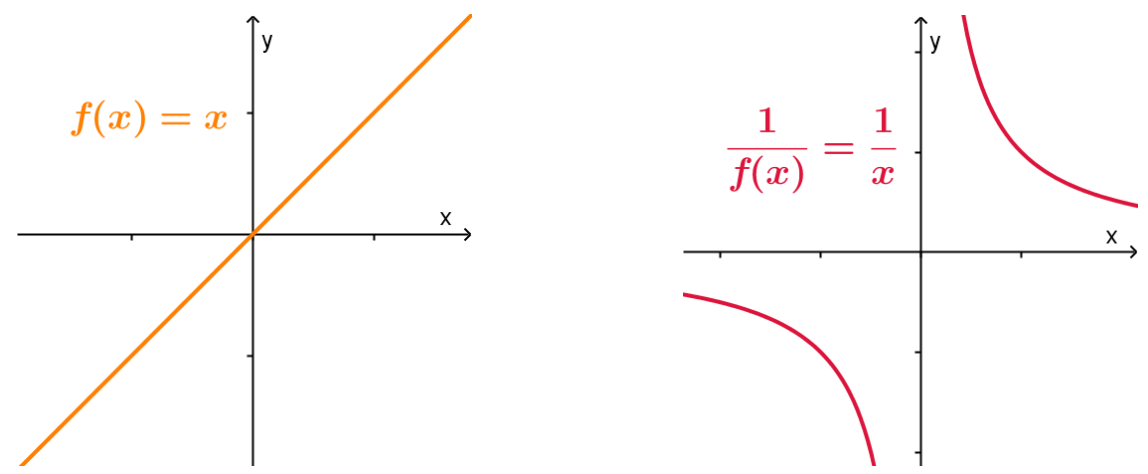

- Puede ocurrir que tanto $f(x)$ como $\frac{1}{f(x)}$ sean continuas en su dominio, como por ejemplo, $f(x)=e^{x}$ y $\frac{1}{f(x)}=e^{-x}$. Observemos sus gráficas:
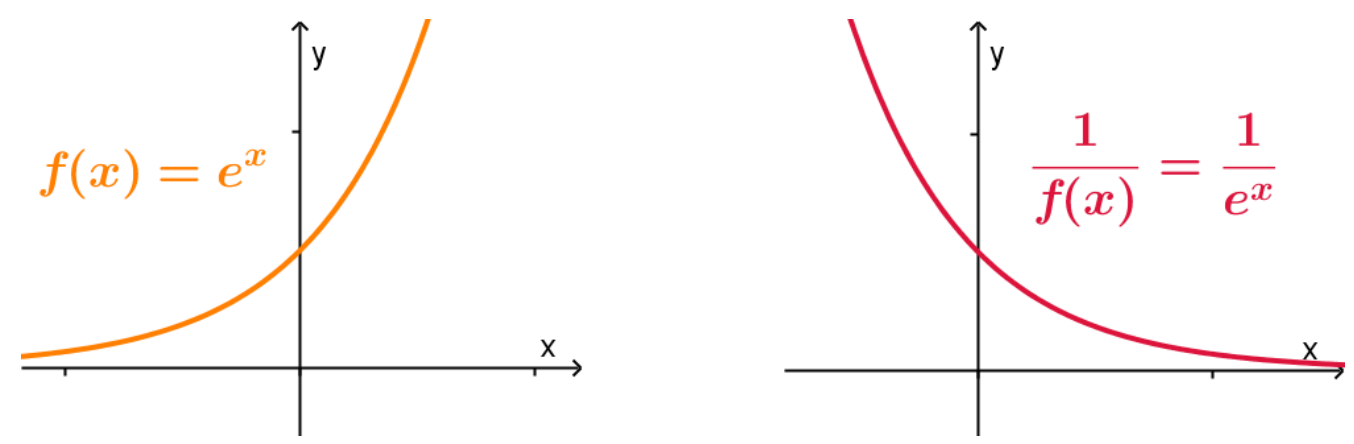
En conclusión, podemos asegurar que:

- Si $f(x) \neq 0$, para todo $x \in \operatorname{Dom} f$, y $f(x)$ es continua entonces $\frac{1}{f(x)}$ es continua.

- Si $f(x)=0$ para algún $x \in \operatorname{Dom} f$, entonces $\frac{1}{f(x)}$ es discontinua.

Consideramos, que la pertinencia de este tipo de problemas, respecto a su inclusión en los programas de precálculo, radica en que, dotar al alumno de un buen manejo del lenguaje gráfico, facilita la comprensión y apropiación de nuevos conceptos de cálculo.

En particular, el estudio del recíproco de una función permite reflexionar acerca de ciertas nociones, como asíntotas, ceros, máximos y mínimos, continuidad y sobre lo que sucede con ellas al aplicar esta operación.

Al resolver este tipo de ejercicios, el alumno se ve obligado a pensar qué sucede ante, por ejemplo, un cero o asíntota. Este hecho lo acerca a conceptos de límite y sucesiones, sin estar trabajando con ellos de manera explícita. Debe analizar lo que ocurre cuando $f(x)$ se hace cada vez más pequeña (cero), o cada vez más grande (asíntotas) y al aplicarle el recíproco, manejar ideas de "tiende a...", "se acerca a...". Por tanto, contribuye a formar una "base" donde sustentar nociones tales como límite, continuidad, máximos y mínimos, etc., inherentes al cálculo. El lograr un pasaje fluido y espontáneo entre estos dos lenguajes (gráfico y analítico), permite una mayor comprensión de las ideas subyacentes.

\section{Resolución de desigualdades}

Es innegable que la dificultad técnica que se presenta al resolver desigualdades obstaculiza su comprensión y su enseñanza reduciendo su presentación escolar a unos cuantos ejemplos "complejos" a fin de completar el programa establecido. Por otra parte, las habilidades algebraicas y lógicas que desarrolla la minoría no contribuyen, substancialmente, a un posterior estudio del cálculo. Nuestra estrategia para abordar en la escuela este tema estriba en el cambio de centración del contexto protagónico de la discusión, es decir, iniciamos el tratamiento en el contexto gráfico haciendo una traslación hacia el contexto algebraico cuyo fin es el de apoyar argumentaciones o construcciones gráficas. También involucramos el contexto numérico usando la calculadora para conjeturar soluciones e ir estableciendo márgenes de aproximación que propician el fortalecimiento de la intuición numérica de los estudiantes. En lo que sigue veremos algunos ejemplos que el lector puede consultar en (Farfán, 2013) para mayores detalles.

El problema de resolver una desigualdad de incógnita $x$, radica en encontrar todos los números reales que, al sustituirlos por $x$, verifican la desigualdad dada. Tales números son las soluciones de la desigualdad, ellos forman el conjunto de soluciones que generalmente es un intervalo. Hagamos una analogía con la resolución de ecuaciones. 
Resolver la ecuación $3 x-1=0$

es encontrar el valor de " $x$ " para el cual el término $3 x-1$ es nulo; el problema planteado en una gráfica se interpreta como el de encontrar la intersección de la recta $y=3 x-1$ con el eje $x$.

El valor de $x$ requerido es $1 / 3$, es decir, que para dicho valor el término $3 x-1$ se anula; en la gráfica, para ese valor de $x$, la recta y el eje coinciden y la solución se expresa como $x=1 / 3$.

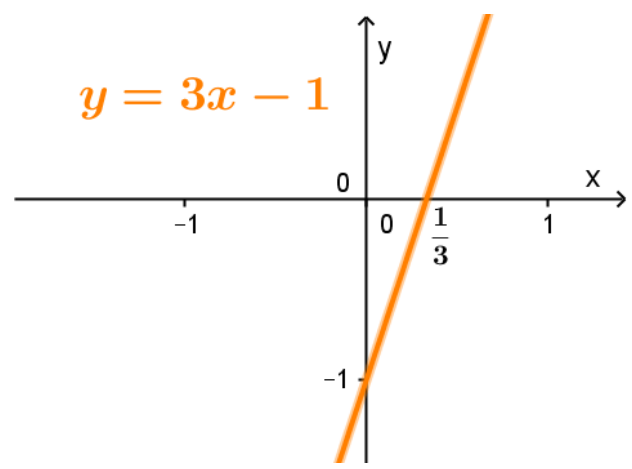

Al introducir el término "desigualdad" se introducen los símbolos " < " (menor que), "> " (mayor que), " $\leq$ " (menor o igual que) y " $\geq$ " (mayor o igual que), que permiten que la solución sea un número, como en el caso de las ecuaciones, o bien, un conjunto de números e incluso varios conjuntos. De modo que al solicitar la solución de la desigualdad

$$
3 x-1<0,
$$

observamos en la gráfica que para todos los números del eje $X$ situados a la izquierda de $1 / 3$ (es decir, menores que $1 / 3$ ) los valores del término $3 x-1$ están por debajo del eje $x$ (es decir, son menores que cero), por lo que la solución requerida es un conjunto de números, a saber, el constituido por todos los números reales que sean estrictamente menores que $1 / 3$. Así la solución es el intervalo $(-\infty, 1 / 3)$.

Reflexionemos sobre el procedimiento anterior: hemos establecido una comparación entre la gráfica de la recta $y=3 x-1$ y el eje de las $x$ 's cuya ecuación es $y=0$; la comparación fue dada por el símbolo "<" y nos preguntamos ¿a partir de qué número, la gráfica de la recta $y=$ $3 x-1$ está por debajo de la gráfica de la recta $y=0$ ?

Hemos traducido "<", usado en la expresión algebraica por "debajo de" y se puede inferir la traducción de ">" por "arriba de" en el contexto gráfico, del mismo modo en que la igualdad se traduce como

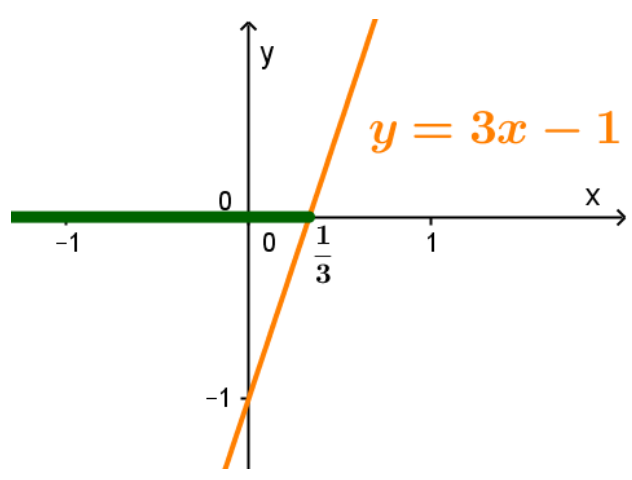
intersección (coincidencia).

De este ejemplo observamos que, en general, a diferencia de las ecuaciones, al resolver una desigualdad nos vemos obligados a exhibir un conjunto de números y que, en el contexto gráfico que usaremos en este escrito como ambiente de trabajo, resolver la desigualdad será localizar a partir de qué número (sobre el eje de las x's) la

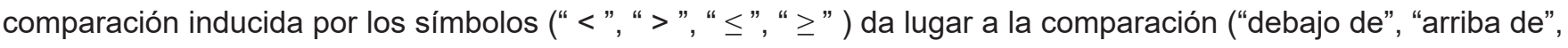
"debajo de y en la intersección”, "arriba de y en la intersección”) de los lugares geométricos involucrados. 
Resolver la desigualdad $1-x \geq 3-2 x \geq x-6$

Como antes, graficamos las rectas $y=1-x, y=3-2 x$ e $y=x-6$ en un mismo sistema de ejes.

La gráfica de $y=1-x$ está por encima de la gráfica de la recta $y=3-2 x$ a partir del punto de intersección cuya abscisa es 2.

En tanto que la gráfica de la recta $y=3-2 x$ estará por arriba de la recta $y=x$ - 6 hasta el punto de intersección que tiene por abscisa 3, después de tal valor la situación se invertirá; así que de ambas partes tenemos que la solución es el intervalo [2,3], que también puede expresarse como $(-\infty, 3] \cap[2, \infty)$.

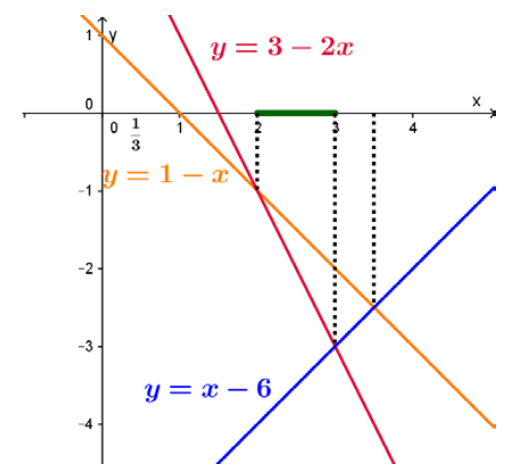

\section{Problemas de optimización sin Cálculo}

En general, cuando el modelo del problema es un modelo cuadrático, tendremos como gráfica a una parábola que tiene un máximo o un mínimo según el signo del coeficiente de $x^{2}$. Este máximo o mínimo coincide con las coordenadas del vértice.

En general, una función cuadrática es de la forma $f(x)=a x^{2}+b x+c$ con $a \neq 0$; al completar el cuadrado obtenemos una expresión equivalente $f(x)=a\left(x+\frac{b}{2 a}\right)^{2}+\frac{4 a c-b^{2}}{4 a}$.

Los parámetros $\frac{b}{2 a}$ y $\frac{4 a c-b^{2}}{4 a}$ de esta función pueden identificarse con un desplazamiento horizontal y otro vertical respectivamente de la gráfica de la parábola $y=a x^{2}$. Ilustremos esta afirmación considerando dos casos, a saber, a positivo y a negativo. Partimos de la parábola $y=a x^{2}$ :

i) Si $a>0$ :

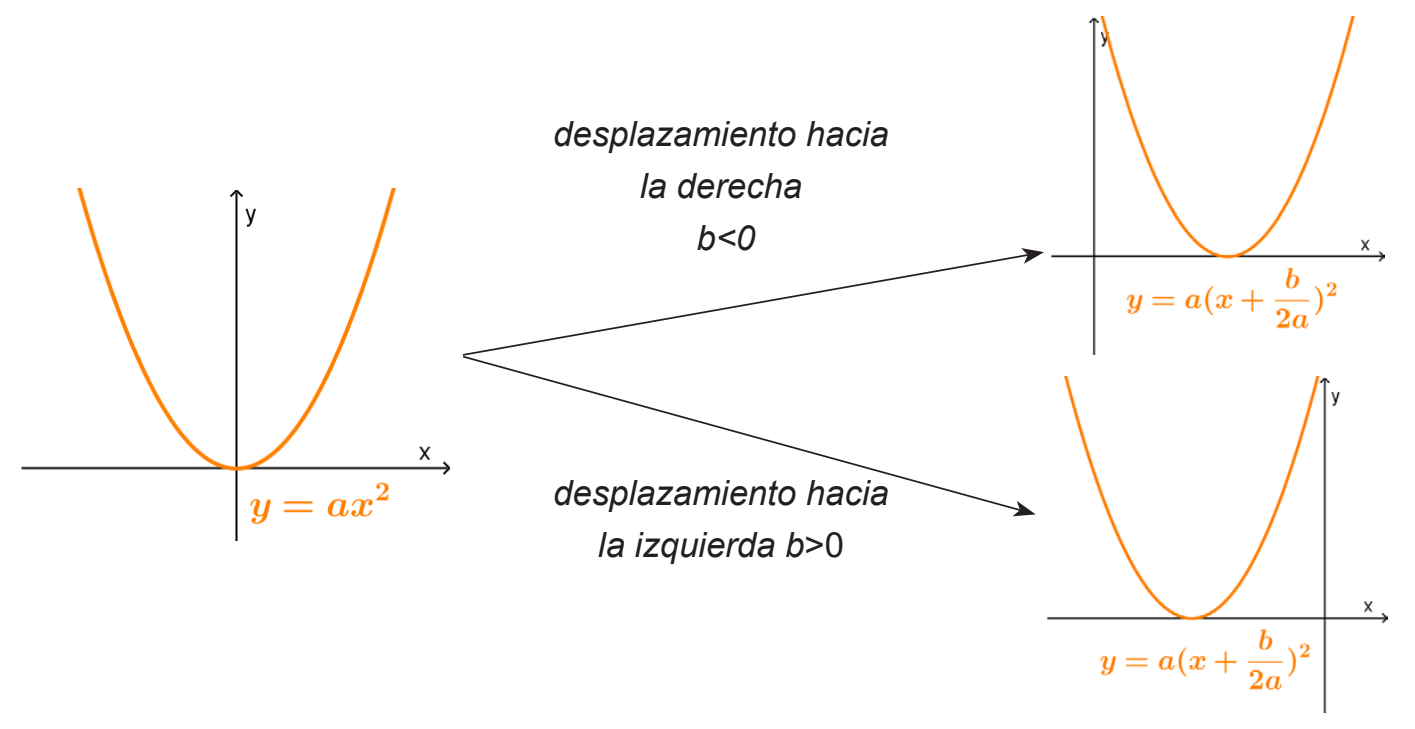


El desplazamiento de la parábola hacia arriba o hacia abajo está en función del signo de $4 a c-b^{2}$, sí éste es positivo, el desplazamiento será hacia arriba, si $4 a c-b^{2}$ es negativo el desplazamiento será hacia abajo:

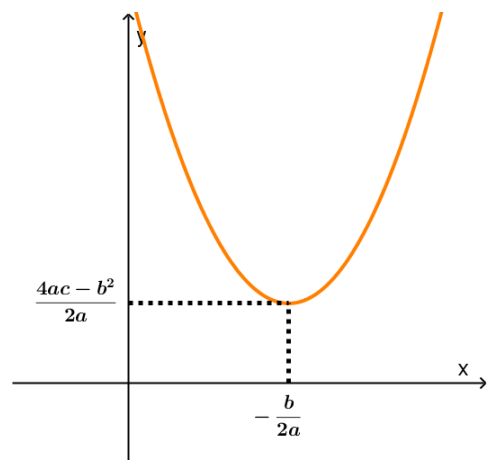

$$
f(x)=a\left(x+\frac{b}{2 a}\right)^{2}+\frac{4 a c-b^{2}}{4 a}
$$

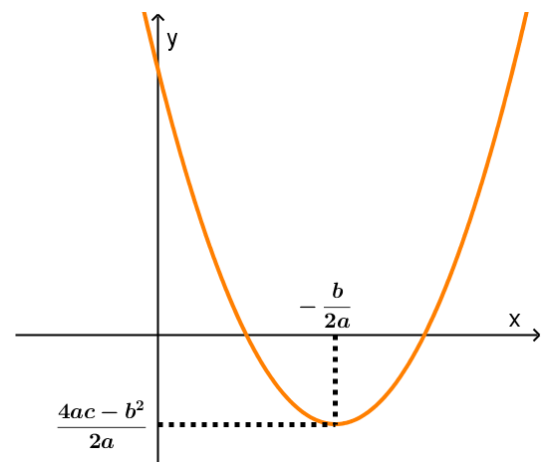

Observe que en ambos casos el valor de la ordenada del vértice es la evaluación de la función $f$ en $x=\frac{b}{2 a}$ :

$$
f\left(-\frac{b}{2 a}\right)=a\left(-\frac{b}{2 a}+\frac{b}{2 a}\right)^{2}+\frac{4 a c-b^{2}}{4 a}=\frac{4 a c-b^{2}}{4 a}
$$

En resumen, si $a>0$ se tiene un mínimo, que es el vértice de la parábola, cuyas coordenadas son $\left(-\frac{b}{2 a}, \frac{4 a c-b^{2}}{4 a}\right)$.

ii) Para cuando $a<0$ se tiene un máximo, que es el vértice, y cuyas coordenadas son $\left(-\frac{b}{2 a}, \frac{4 a c-b^{2}}{4 a}\right)$.

Ejemplo: ¿Cuál es el número positivo tal que al sumarle su recíproco, su suma es mínima?

Denotamos por $x$ dicho número; su recíproco es $\frac{1}{x}$, de modo que la suma será $x+\frac{1}{x}$. Esta suma es una función de $x$ :

$$
f(x)=x+\frac{1}{x}
$$

debemos encontrar el número que minimiza a esta función. Trabajemos con $f$ como la suma de una recta y una hipérbola y planteamos como hipótesis que la abscisa de la intersección es el número que minimiza la función.

Tracemos las gráficas de las funciones $y_{1}=x ; y_{2}+\frac{1}{x}$ y $y_{3}=y_{1}+y_{2}$, encontremos el punto de intersección de $y_{1}$ y $y_{2}$, éste es $(1,1)$, de modo que $y_{3}(1)=2$.

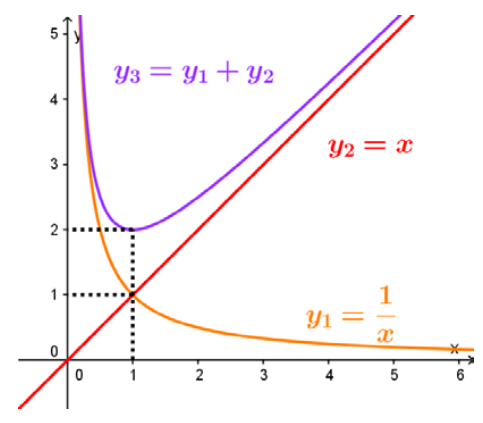


Hagamos una tabla para valores de $x$ menores y mayores que 1.

valores de $x<1$

\begin{tabular}{|c|c|c|c|}
\hline$x$ & $y_{1}$ & $y_{2}$ & $y_{3}$ \\
\hline .84 & .84 & 1.18 & 2.02 \\
.57 & .57 & 1.72 & 2.30 \\
.36 & .36 & 2.71 & 3.08 \\
.15 & .15 & 6.33 & 6.49 \\
.05 & .05 & 19.0 & 19.05 \\
\hline
\end{tabular}

valores de $x>1$

\begin{tabular}{|c|c|c|c|}
\hline$x$ & $y_{1}$ & $y_{2}$ & $y_{3}$ \\
\hline 1.21 & 1.21 & .82 & 2.03 \\
1.52 & 1.52 & .65 & 2.18 \\
2 & 2 & .5 & 2.5 \\
3 & 3 & .33 & 3.33 \\
10 & 10 & .1 & 10.1 \\
\hline
\end{tabular}

Para valores de $x$ entre 0 y 1 observamos que conforme $x$ es más pequeño, la diferencia entre $y_{2}$ y $y_{3}$ disminuye; en otras palabras, $y_{2}$ y $y_{3}$ se parecen, tienen la misma tendencia a crecer, de suerte tal que en el intervalo $(0,1)$ no habrá un punto cuya imagen sea menor que $y_{3}(1)=2$. A la derecha de 1 , vemos en la tabla (y también en la gráfica) que la diferencia entre $y_{1}$ y $y_{3}$ es menor a medida que $x$ es más grande, es decir, $y$ se acerca cada vez más a la recta (a eso se le llama comportamiento asintótico), por lo que no hay un mínimo de $y_{3}^{3}$ en el intervalo $(1, \infty)$. Así, el único valor mínimo de $y_{3}$ para $x>0$ es el punto $(1,2)$. El número que resuelve nuestro problema es $x=1$.

\section{Reflexiones finales}

La enseñanza tradicional sostiene que los aprendizajes se dan como resultado de "buenas prácticas" de enseñanza del docente, quien evalúa los aprendizajes a través de mecanismos de aprobación o reprobación de determinado curso; se confunde acreditar con aprender. En contraparte, los enfoques constructivistas nutren la idea de que el aprender matemáticas requiere de su construcción por parte del estudiante y que el aprendizaje se da con éxito cuando se logra poner en funcionamiento para resolver ciertas tareas en determinadas situaciones.

Desde la perspectiva de la teoría Socioepistemológica se hace necesario que la gestión didáctica responda a las exigencias del pensamiento, del aprendizaje y de los escenarios (culturales, históricos e institucionales) que requiere la actividad matemática, para lo cual se considera que la actividad matemática se debe apoyar en los propios procesos mentales del estudiante: sus conjeturas, sus procesos heurísticos, sus ensayos y exploraciones; permitiendo que la intuición sirva como punto de partida para el trabajo en la clase (Cantoral, 2013, 2016). Pero ¿cómo asegurar que se genera el ambiente propicio para esto? Respecto de la situación de aprendizaje se asegura que:

... "suele plantear un reto especial, tanto a los estudiantes como a los profesores, pues, aunque entiendan efectivamente el enunciado del problema, no pueden construir una respuesta que les parezca convincente [...] dado que se carece de elementos cognitivos y didácticos que les permitan construir una respuesta adecuada. Consideramos que es hasta este momento en que ellos se encuentran en situación de aprendizaje [...], pues la respuesta habrá de ser construida” ... (Cantoral, 2013, p. 201). 
Desde esta mirada, se puede asegurar, que un sujeto (individual o colectivo) no siempre está en situación de aprender, las situaciones de aprendizaje se deben propiciar, proponiendo una situación problema que enfrente al sujeto a un escenario en el que deba poner en juego los saberes que se requieren; se dice entonces que el individuo está en situación de aprendizaje cuando entra en conflicto, es decir, el diseño provoca que su respuesta inicial a la tarea encomendada sea errónea y el mismo diseño lo hace percatarse de ello (Reyes, 2011).

La propuesta de diseño presentada busca construir un lenguaje gráfico de funciones extenso y rico en significados para quien aprende, el cual permita ir más allá de los procedimientos y algoritmos propios del álgebra y de la geometría analítica, para dar paso a argumentos visuales a partir del uso de la gráfica al resolver situaciones problema, específicamente, las desigualdades.

Este tipo de tratamiento de las funciones, donde se incorporan fuertemente los elementos visuales, permite el tránsito entre los distintos contextos de la función: algebraico, geométrico, numérico, icónico y verbal. Esta herramienta le sirve al docente como nuevo punto de partida para que realicen nuevas situaciones en el aula, pues al conocer nuevas investigaciones relacionadas con los diferentes temas, esto contribuirá a que se promueva una actitud de liderazgo, confianza y mejora en sus prácticas para la enseñanza, favoreciendo un empoderamiento del docente (Reyes y Cantoral, 2014) y por ende el enriquecimiento de la profesionalización docente.

\section{Referencias}

IIII Alanís, J. et al. (2000). Desarrollo del Pensamiento Matemático. México: Trillas.

IIII Arrieta, J. (2003). Las prácticas de modelación como proceso de matematización en el aula. Tesis doctoral no publicada. México: Cinvestav.

IIII Artigue, M. (1992). Ingénierie didactique, Recherches en Didactique des Mathématique, vol. 9, núm. 3, pp. 281308

IIII Artigue, M. (1998). Enseñanza y aprendizaje del análisis elemental: ¿qué se puede aprender las investigaciones didácticas y los cambios curriculares?, Revista Latinoamericana de Investigación en Matemática Educativa, 1(1). 40-55.

IIII Bos, H. (1975). Differentials, Higher-Order Differentials and the derivative in the Leibnizian Calculus. Archive for History of Exact Sciences, 14, 1 - 90.

IIII Cantoral, R. (1999). Approccio socioepistemologico a la ricerca in matemática educativa. La matemática e la sua didattica, 3, $258-273$.

IIII Cantoral, R. (2001). Matemática Educativa: Un estudio de la formación social de la analiticidad. México: Grupo Editorial Iberoamérica.

IIII Cantoral, R. (2013). Teoría Socioepistemológica de la Matemática Educativa. Estudios sobre construcción social del conocimiento matemático, Barcelona, España, Gedisa.

IIII Cantoral, R. \& Farfán, R. (1998). Pensamiento y lenguaje variacional en la introducción al análisis. Epsilon, 42, 14(3), 353 - 369. 
IIII Cantoral, R. \& Farfán, R. (2004). La sensibilité à la contradiction: logarithmes de nombres négatifs et origine de la variable complexe. Recherches en Didactique des Mathématiques, 24 (2.3), 137 - 168.

IIII Cantoral, R. y Farfán, R. M. (1998). Pensamiento y lenguaje variacional en la introducción al análisis, Epsilon, núm. 42, pp. $353-369$.

IIII Cordero, F. (2001). La distinción entre construcciones del cálculo. Una epistemología a través de la actividad humana. Revista Latinoamericana de Investigación en Matemática Educativa 4(2), 103 - 128.

IIII Covián, O. (2005). El papel del conocimiento matemático en la construcción de la vivienda tradicional: El caso de la Cultura Maya. Tesis de maestría no publicada. México: Cinvestav.

IIII Farfán, R. M. (2013). Lenguaje gráfico de funciones. Elementos de precálculo, México, Subsecretaría de Educación Media Superior. Secretaría de Educación Pública.

IIII Farfán, R. M. (2012). Socioepistemología y ciencia. El caso del estado estacionario y su matematización. Barcelona, España: Gedisa.

IIII Farfán, R. M., Ferrari, M., Martínez, G. (2000). Lenguaje algebraico y pensamiento funcional, en R. Cantoral (coordinador). Desarrollo del pensamiento matemático. México, Trillas, pp. 89-144.

IIII Farfán, R., Cantoral, R. (2003). Mathematics Education: A Vision of its Evolution. Educational Studies in Mathematics 53(3), 255-270.

IIII Farfán, R., Romero, F. (2016). El diseño de situaciones de aprendizaje con elementos para el enriquecimiento de la profesionalización docente. Perfiles Educativos. XXXVIII, número especial. IISUE-UNAM. 116-139.

IIII López, I. (2005). La socioepistemología. Un estudio sobre su racionalidad. Tesis de maestría no publicada. México: Cinvestav.

IIII Minguer, L. (2004). Entorno sociocultural y cultura matemática en profesores del nivel superior de educación. Un estudio de caso: El Instituto Tecnológico de Oaxaca. Acta Latinoamericana de Matemática Educativa, 17(2), $885-889$.

IIII Morales, A., Cordero, F. (2014). La graficación-modelación y la Serie de Taylor. Una Socioepistemología del cálculo, Revista Latinoamericana de Investigación en Matemática Educativa, vol. 17, núm. 3, pp. 319-345

IIII Radford, (2004). Semiótica cultural y cognición. Conferencia dictada en la Reunión Latinoamericana de Matemática Educativa. Tuxtla, Chiapas México. [En red] Disponible en http://laurentian.ca/educ//radford/ Tuxtla3.pdf

IIII Reyes, D. (2011). Empoderamiento docente desde una visión socioepistemológica: estudio de los factores de cambio en las prácticas del profesor de matemáticas. Tesis de maestría, Centro de Investigación y de Estudios Avanzados del IPN, (México).

IIII Reyes, D. (2016). Empoderamiento docente desde una visión socioepistemológica: una alternativa para la transformación y la mejora educativa. Tesis de doctorado, Centro de Investigación y de Estudios Avanzados del IPN, (México).

IIII Reyes, D., Cantoral, R. (2014). Socioepistemología y empoderamiento: la profesionalización docente desde la problematización del saber matemático, Bolema, vol. 28, núm. 48, pp. 360-382.

IIII Sierpinska, A. (1992). On understanding the notion of function, en Ed Dubinsky y Harel, G. (eds.), The concept of Function: Aspects of Epistemology and Pedagogy USA, MAA Notes 25, pp. 23-58.

IIII Varela, F. et al. (1997). De cuerpo presente. Barcelona: Gedisa. 


\section{Recursos semióticos en la enseñanza de las matemáticas}

La enseñanza de las matemáticas, en cualquiera de sus ramas, se enfrenta a la animadversión de muchos estudiantes por lo difícil que les es aprender y dominar sus herramientas básicas, cuanto más, que es una de las disciplinas inevitable de toda ciencia, incluyendo la psicología. Una manera de superar estas dificultades y mejorar la disposición psicológica del estudiante para aprender las matemáticas, es utilizar todos los recursos semióticos no formales (los que nada tienen que ver con signos y algoritmos matemáticos, empezando por el lenguaje cotidiano, imágenes, gráficas, objetos, colores, metáforas, analogías, etc.) disponibles por el profesor, para enseñar los recursos formales (signos, fórmulas, etc., matemáticas). Nuestro proyecto de investigación "El uso didáctico del lenguaje natural en la enseñanza del lenguaje formal de la estadística en la FES Zaragoza" PAPIME-UNAM 302915, analizó empíricamente qué recursos semióticos usaban los profesores de estadística en la Carrera de Psicología de la FES Zaragoza, y aterrizó sus hallazgos en este texto, y en una propuesta pedagógica que será publicada en otro libro y en recursos multimedia que estarán disponibles para cualquier persona. Nuestra investigación expuesta en este libro tuvo como marco de referencia un modelo de lenguaje y una aproximación semiótica (capítulos 1 y 3); un análisis bibliométrico (capítulo 2); la aplicación empírica de diversos recursos semióticos (capítulos 4 y 5); y la aceptación de que el conocimiento matemático es una construcción social, que ha sido teorizado por la teoría socioepistemológica, y llevado a la práctica de la matemática educativa (capítulo 6) desde hace muchos años en México.
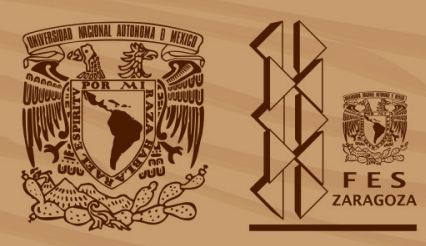

Facultad de Estudios Superiores Zaragoza,

Campus I. Av. Guelatao No. 66 Col. Ejército de Oriente,

Campus II. Batalla 5 de Mayo s/n Esq. Fuerte de Loreto.

Col. Ejército de Oriente.

Iztapalapa, C.P. 09230 México D.F.

http://www.zaragoza.unam.mx

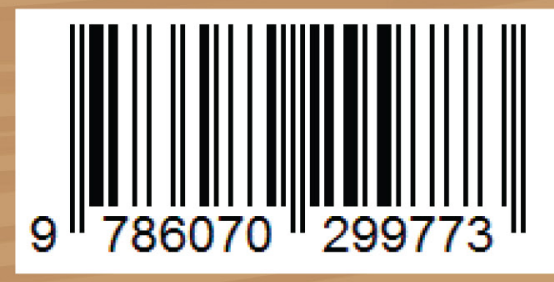

